\title{
Early metabolic risk in COPD
}

Citation for published version (APA):

van den Borst, B. (2013). Early metabolic risk in COPD. [Doctoral Thesis, Maastricht University]. Uitgeverij BOXPress. https://doi.org/10.26481/dis.20130517bb

Document status and date:

Published: 01/01/2013

DOI:

10.26481/dis.20130517bb

Document Version:

Publisher's PDF, also known as Version of record

\section{Please check the document version of this publication:}

- A submitted manuscript is the version of the article upon submission and before peer-review. There can be important differences between the submitted version and the official published version of record.

People interested in the research are advised to contact the author for the final version of the publication, or visit the DOI to the publisher's website.

- The final author version and the galley proof are versions of the publication after peer review.

- The final published version features the final layout of the paper including the volume, issue and page numbers.

Link to publication

\footnotetext{
General rights rights.

- You may freely distribute the URL identifying the publication in the public portal. please follow below link for the End User Agreement:

www.umlib.nl/taverne-license

Take down policy

If you believe that this document breaches copyright please contact us at:

repository@maastrichtuniversity.nl

providing details and we will investigate your claim.
}

Copyright and moral rights for the publications made accessible in the public portal are retained by the authors and/or other copyright owners and it is a condition of accessing publications that users recognise and abide by the legal requirements associated with these

- Users may download and print one copy of any publication from the public portal for the purpose of private study or research.

- You may not further distribute the material or use it for any profit-making activity or commercial gain

If the publication is distributed under the terms of Article $25 \mathrm{fa}$ of the Dutch Copyright Act, indicated by the "Taverne" license above, 
Early metabolic risk in COPD 
Copyright (C) 2013 Bram van den Borst, Maastricht

Cover design Tijs van den Borst

Layout Bram van den Borst

Production Proefschriftmaken.nl

Publisher Uitgeverij BOXPress

ISBN 978-90-8891-604-5

The research described in this thesis was performed at the Department of Respiratory Medicine, NUTRIM School for Nutrition, Toxicology, and Metabolism, at Maastricht University Medical Center+, Maastricht, The Netherlands; and at the Laboratory of Epidemiology, Demography and Biometry, National Institute on Aging, Bethesda, MD, USA.

The work described in this thesis was performed within the framework of the Dutch Top Institute Pharma, project 'Transition of systemic inflammation into multiorgan pathology, T1-201.' Partners in this project are Maastricht University Medical Center+, University Medical Center Groningen, University Medical Center Utrecht, GlaxoSmithKline, AstraZeneca Nederland B.V., Danone Research, and Nycomed (now Takeda).

The publication of this thesis was financially supported by GlaxoSmithKline B.V., Nutricia Advanced Medical Nutrition, Danone Research - Centre for Specialised Nutrition, and Chiesi Pharmaceuticals B.V. 


\title{
Early metabolic risk in COPD
}

\author{
Proefschrift
}

Ter verkrijging van de graad van doctor

aan de Universiteit Maastricht, op gezag van de Rector Magnificus, Prof. dr. L.L.G. Soete, volgens het besluit van het College van Decanen, in het openbaar te verdedigen op vrijdag 17 mei 2013 om 12:00 uur

door

Bram van den Borst

Geboren op 18 juli 1983 te Eindhoven 


\section{$\underline{\text { Promotor }}$}

Prof. dr. ir. A.M.W.J. Schols

\section{Co-promotor}

Dr. H.R. Gosker

\section{Beoordelingscommissie}

Prof. dr. M.K. Hesselink (voorzitter)

Prof. dr. M. Laville (Université de Lyon, France)

Prof. dr. D.S. Postma (Universitair Medisch Centrum Groningen)

Prof. dr. C.D.A. Stehouwer

Prof. dr. E.E. Blaak 


\section{CONTENTS}

Chapter 1 General introduction

7

Published in part as: Chronic obstructive pulmonary disease; co-morbidities and systemic consequences. Book Chapter. 2011 Humana Press. Pp 171-92

Chapter 2 Is age-related decline in lean mass and physical function accelerated by obstructive lung disease or smoking?

Thorax 2011;66(11):961-9

Chapter 3 Loss of quadriceps muscle oxidative phenotype and decreased endurance in patients with mild-to-moderate COPD Journal of Applied Physiology 2012 Jul 19 [Epub ahead of print]

Chapter 4 Low-grade adipose tissue inflammation in patients with mildto-moderate COPD American Journal of Clinical Nutrition 2011;94(6):1504-12

Chapter 5 The influence of abdominal visceral fat on inflammatory 89 pathways and mortality risk in obstructive lung disease American Journal of Clinical Nutrition 2012;96(3):516-26

Chapter 6 Characterization of the inflammatory and metabolic profile of adipose tissue in a mouse model of chronic hypoxia Journal of Applied Physiology 2013 Mar 28 [Epub ahead of print]

Chapter 7 Dietary fiber and fatty acids in COPD risk and progression: 129 a systematic review Submitted

Chapter 8 Discussion

Central fat and peripheral muscle: partners in crime in COPD American Journal of Respiratory and Critical Care Medicine 2013;187(1):8-13

Summary 157

Samenvatting 161

Dankwoord 167

Curriculum Vitae 171

List of publications 



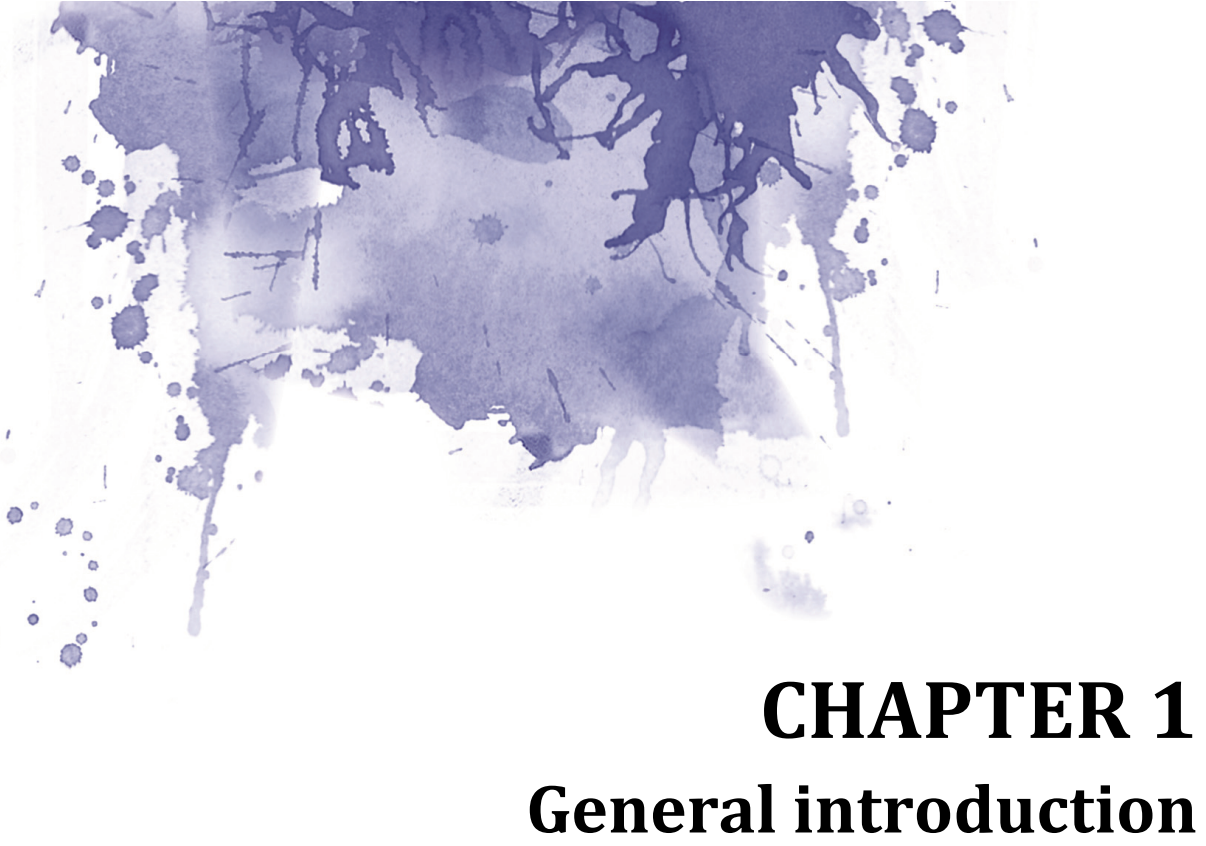

Bram van den Borst, Harry R. Gosker, Annemie M.W.J. Schols

In part published as:

Body composition abnormalities in COPD. Book Chapter in: Chronic obstructive pulmonary disease; co-morbidities and systemic consequences. 2011 Humana Press. Pp 171-92 


\section{An introduction to COPD}

Chronic obstructive pulmonary disease (COPD) is a common disease and is associated with high burden. Symptoms include shortness of breath, exercise limitation and cough. Sixty-four million people suffer from COPD worldwide, being the fourth leading cause of mortality [1]. In the Netherlands, more than 320.000 people suffer from COPD, causing 4\% of all deaths [2].

Cigarette smoke is the primary cause of COPD, but other risk factors have been identified including occupational exposure to toxic gases, air pollution and genetic predisposition [3]. COPD patients display an enhanced and persistent inflammatory response to inhaled particles which is believed to underlie local pulmonary pathology [4]. Chronic bronchitis and emphysema are the two major pathological features of COPD. Briefly, chronic bronchitis is characterized by thickening of the airway walls and increased mucus production, whereas emphysema denotes the destruction of alveolar walls. These disruptions of the pulmonary architecture ultimately lead to the obstruction of airflow during exhalation, which is usually progressive in time. As the degree of airflow limitation can be measured relatively easily and with good reproducibility through spirometry, it is commonly used as the single measure of COPD severity. However, clinical observations and advancing research have clearly shown that the degree of airflow limitation is poorly correlated with actual disease burden.

\section{Clinical heterogeneity and body composition}

Clinical heterogeneity is an important characteristic of COPD that complicates treatment. Different body composition phenotypes contribute to this heterogeneity and reflect important extrapulmonary disease features in COPD, as illustrated by the following cases.

\section{Case 1: the cachectic COPD patient}

Patient A, 63 years old, has a forced expiratory volume in 1 sec $\left(\mathrm{FEV}_{1}\right)$ and diffusion capacity for carbon monoxide (DLCO) of $52 \%$ and $37 \%$ of predicted, respectively. Since diagnosis she has lost $18 \mathrm{~kg}$ of body mass and now she weighs only $40 \mathrm{~kg}$ resulting in a current body mass index (BMI) of $15.2 \mathrm{~kg} / \mathrm{m}^{2}$. Body composition measures reveal a fat-free mass index (FFMI) and fat mass index (FMI) of 12.1 and $3.1 \mathrm{~kg} / \mathrm{m}^{2}$, respectively. Both the FFMI and FMI are below the $5^{\text {th }}$ percentile of reference values, indicative of severe depletion. After having smoked 60 pack years she remains unmotivated to quit. Last year, she had been admitted to the hospital twice for an acute exacerbation and has also been diagnosed with osteoporosis. Due to her weakness she is homebound and spends most of the day sedentary. She has an arterial oxygen tension of $6.9 \mathrm{kPa}$, with a 
carbon dioxide pressure of $5.6 \mathrm{kPa}$, consistent with arterial hypoxaemia without respiratory insufficiency.

\section{Case 2: the sarcopenic COPD patient}

Although patient B, 72 years old, was diagnosed with COPD many years ago, he remains a smoker with 45 pack years. The $\mathrm{FEV}_{1}$ has been stable around $49 \%$ of predicted. His BMI has remained stable for years at $27 \mathrm{~kg} / \mathrm{m}^{2}$, yet his weight has recently started to decrease slowly. The FFMI and FMI measure $17.8\left(10-25^{\text {th }}\right.$ percentile) and 9.2 (90-95 th percentile) $\mathrm{kg} / \mathrm{m}^{2}$, respectively. His daily $20-\mathrm{min}$ walk becomes increasingly difficult due to a feeling of whole body weakness. He questions whether this is due to aging or if this is caused by the COPD.

\section{Case 3: the obese COPD patient}

Patient $\mathrm{C}$ is 58 years old and was diagnosed with COPD four years ago. She has a part-time job and although she experiences mild shortness of breath upon exertion, she is an active member of a walking club. The $\mathrm{FEV}_{1}$ and DLCO measure $56 \%$ and $81 \%$ of predicted, respectively. Her BMI is $33 \mathrm{~kg} / \mathrm{m}^{2}$ which is classified as obese. FFMI and FMI measure $18.2\left(75-90^{\text {th }}\right.$ percentile) and $12.7\left(90-95^{\text {th }}\right.$ percentile) $\mathrm{kg} / \mathrm{m}^{2}$, respectively. Her weight has been stable for decades. Peak oxygen uptake during an incremental cycling test is $89 \%$ of predicted during which no arterial desaturation is observed. The COPD is controlled by her general practitioner and after having smoked 45 pack years she succeeded quitting, after which she gained some more weight. She has also been diagnosed with hypertension.

Notwithstanding that the lung is the major organ of pathology in COPD, these cases illustrate three patients with comparable degrees of airflow limitation but with widely varying clinical presentations. Skeletal muscle wasting and weakness, osteoporosis, but also obesity are common in COPD patients, and differentially contribute to disease burden throughout the disease course. Only very recently, however, it has been officially recognized in the definition of COPD that "...comorbidities contribute to the overall severity in individual patients" [4]. In fact, it has been shown that COPD patients have on average two to three other chronic conditions, of which skeletal muscle dysfunction and cardiovascular comorbidities are particularly common [5].

\section{Skeletal muscle dysfunction in COPD}

Skeletal muscle dysfunction is probably the most investigated extrapulmonary manifestation in COPD. Muscle wasting, along with general weight loss, is particularly outspoken in but not restricted to advanced COPD, and has been 
identified as a poor prognostic factor independently of the degree of airflow limitation [6]. Importantly, weight gain can reverse this prognosis [7].

With aging, particularly in the eighth decade of life, a change in body composition occurs which has been termed sarcopenia [8]. Sarcopenia is the process of a decreasing muscle mass during which fat mass increases or remains stable, and during which body weight can remain stable. This hidden loss of muscle mass has been identified in a significant proportion of COPD patients in cross-sectional studies (up to 25\% [9-11]), but whether sarcopenia occurs in an accelerated fashion in COPD needs to be investigated in longitudinal studies with appropriate control groups.

In addition to muscle wasting, intrinsic alterations in the skeletal muscle of COPD patients have been identified. These are characterized by a shift from less oxidative towards more glycolytic fibers, decreased oxidative enzyme capacity and mitochondrial dysfunction leading to early fatigued muscles and decreased exercise capacity $[12,13]$. Although the intrinsic alterations underlying muscle dysfunction have been well-documented in patients with advanced COPD, few studies have explored the mechanisms of skeletal muscle dysfunction in earlier stages of COPD.

\section{Cardiovascular comorbidity in COPD}

Throughout all severity stages COPD patients have an approximate 2 to 3 -fold increased risk of cardiovascular disease (CVD), which goes beyond cigarette smoke exposure [14]. Various factors have been suggested to increase CVD risk in COPD patients, including generic risk factors (unhealthy lifestyle) as well as COPD-related factors such as low-grade systemic inflammation, hypoxaemia, oxidative stress, and systemic elastin abnormalities. The observation that CVD is even the leading cause of mortality in COPD patients with mild-to-moderate airflow limitation [15], stresses the need to identify underlying mechanisms that drive cardiovascular risk particularly in this subgroup of COPD patients.

The metabolic syndrome and diabetes appear to be more common in COPD patients compared to control populations, with mild-to-moderate COPD patients being more affected than severe COPD patients [16]. Likely, these co-morbid conditions also contribute to CVD risk. Peripheral skeletal muscle mitochondrial dysfunction has been associated with insulin resistance in diabetes and obesity [17], and excessive abdominal visceral fat accumulation has been suggested to play an upstream role in low-grade systemic inflammation, hypertension and atherosclerotic disease in epidemiological population studies [18]. It is unknown whether these metabolic alterations already exist in patients with mild-tomoderate COPD. 


\section{Low-grade systemic inflammation in COPD: a role for adipose tissue?}

Pathophysiological mechanisms linking COPD and extrapulmonary manifestations remain incompletely understood. As several studies have suggested that smoking does not fully account for these associations, it appears that other factors are implicated [19]. It has been suggested that increased levels of circulating inflammatory mediators, also referred to as low-grade systemic inflammation, are implicated in the risk of extrapulmonary manifestations [5]. Indeed, many studies have reported systemic inflammation in COPD [20], and inflammatory cytokines have been proposed to play a pivotal role in the development of e.g. skeletal muscle dysfunction [21, 22], atherosclerosis [23] and osteoporosis [24]. Knowing the source of low-grade systemic inflammation is important as it may guide targeted future therapeutic strategies. Classically it is thought that enhanced levels of plasma cytokines in COPD originate from leakage from the pulmonary compartment [5]. However, to date no convincing evidence for this in stable disease has been published, suggesting that other sources of inflammation exist.

Whereas the adipose organ was always considered a passive storage compartment for energy, it is now widely recognized as a highly potent production site of inflammation. Adipose tissue produces and secretes inflammatory mediators, which have been termed adipokines or adipocytokines. Interleukin-6, TNF- $\alpha$, leptin and adiponectin are some examples [25]. Adipocytokines act both locally (paracrine) as well as systemically (endocrine) and influence inflammation and metabolism. Obesity, also in the absence of any other chronic condition, is associated with low-grade systemic inflammation. In the field of obesity research, major advances have been made in understanding the relation between excessive fat mass and low-grade systemic inflammation. Adipose tissue hypoxia resulting from hypertrophying adipocytes and impaired neovascularisation has been suggested to trigger adipose tissue inflammation in obesity. Therefore, it can be speculated that adipose tissue hypoxia, as a consequence of hypoxaemia (chronic or intermittent resulting from desaturations), also triggers adipose tissue inflammation in COPD. Moreover, overweight and obesity are common in COPD [26], particularly in those with mild-to-moderate airflow limitation [27]. Although several recent studies have suggested a positive relation between BMI and low-grade systemic inflammation $[28,29]$, the relations between (changes in) fat mass, body fat distribution, adipose tissue inflammation, and systemic inflammation remain poorly understood in COPD. 


\section{Lifestyle factors}

Exposure to cigarette smoke is not only the major risk factor for COPD development; it has also been associated with low-grade systemic inflammation in the absence of COPD, suggesting that smoking accounts for at least part of the systemic manifestations in COPD. Also, smokers in the general population are usually leaner [30] and score worse on physical performance tests compared to never-smokers [31]. It remains unclear, however, to what extent smoking accounts for the changes in body composition and physical functioning in COPD.

COPD patients experience major difficulties in performing physical activity. Dyspnea upon exertion partially contributes to physical inactivity. Being physically inactive is known to have deconditioning effects on peripheral skeletal muscles which, in turn, further accelerate this downward spiral. Although it has been well-described that COPD patients perform less total daily physical activity, the quality of the activity has been scarcely investigated. In fact, regular moderate-to-vigorous physical exercise lasting at least 30 minutes per day has been recommended in order to gain health benefits [32]. It is unknown how the quality of physical activity in COPD relates to these recommendations, and to what extent this is associated with muscular deconditioning or adverse body fat distribution.

Western society is characterized by an 'obesogenic' environment in which poor dietary quality contributes to low health status. In fact, the European Respiratory Society has recently called for more research on whether diet influences the severity of respiratory diseases [33]. A 'Western diet' rich in refined grains, red meat, desserts and French fries has been associated with increased risk of COPD development, independent of smoking [34], and, conversely, a dietary pattern rich in fruit, vegetables, oily fish and wholemeal cereals may protect against impaired lung function and COPD [35]. To improve nutritional recommendations in COPD, there is a need to examine the specific relations between dietary components and outcomes in COPD. In this context, dietary fiber and fatty acids are of particular interest given their potential to influence inflammatory processes. 


\section{Aim of this thesis}

The general aim of this thesis is to study the reciprocal relation between body composition and low-grade systemic inflammation in mild-to-moderate COPD, and to explore the potential involvement of an unhealthy lifestyle in this relation (Figure 1).

Figure 1. Schematic representation of the general aim of this thesis.

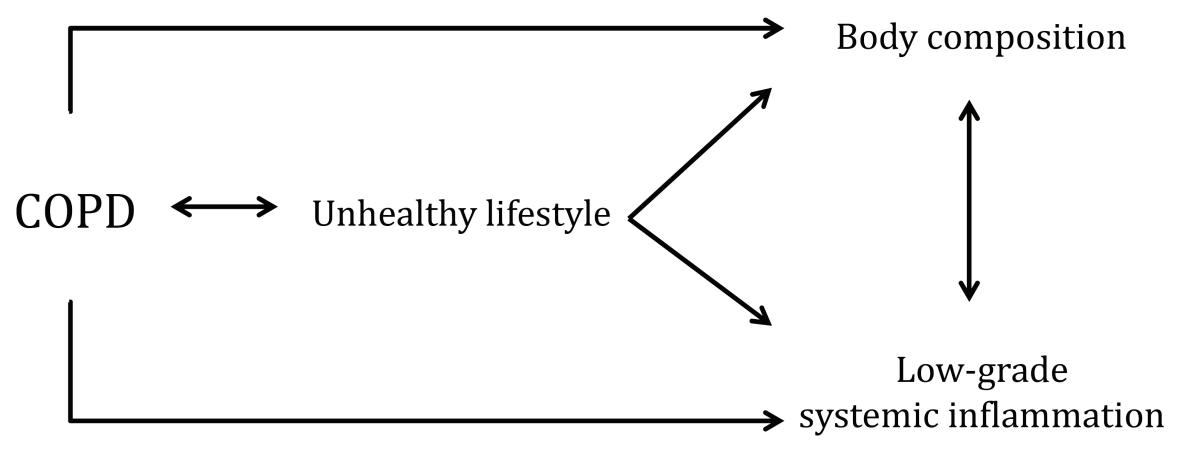

The research questions that are addressed in this thesis are:

1. Are changes in body composition in COPD different from the aging-related natural course of a changing body composition?

2. Are mild-to-moderate COPD patients at an early metabolic risk as reflected in:

a. impaired skeletal muscle phenotype and metabolism;

b. adipose tissue inflammation contributing to low-grade systemic inflammation;

c. excessive abdominal visceral fat mass?

3. What is the influence of smoking, diet and physical activity on early metabolic risk in COPD and on COPD outcomes?

\section{Outline of this thesis}

Chapter 2 presents a combined cross-sectional and 7-year longitudinal analysis of body composition, muscle strength and physical functioning of COPD patients and control persons with normal lung function stratified by smoking status (research questions 1 and 3).

Chapter 3 presents a cross-sectional comparison of quadriceps muscle oxidative phenotype, quadriceps fatigue and daily physical activity level between patients with mild-to-moderate COPD and matched healthy subjects (research questions 2a and 3). 
Chapter 4 presents a cross-sectional analysis of abdominal subcutaneous adipose tissue inflammatory status and its relation with circulating adipocytokine levels in patients with mild-to-moderate COPD and matched healthy subjects (research question $2 \mathrm{~b}$ ).

Chapter 5 presents a comprehensive analysis of differences in abdominal fat distribution between COPD patients and matched controls, and assesses the associations between visceral fat mass and systemic inflammation and their predictive value for 9-year mortality. This chapter also investigates differences in dietary composition and physical activity between these COPD patients and matched controls (research questions $2 \mathrm{~b}, 2 \mathrm{c}$ and 3 ).

Chapter 6 presents an experimental study in mice in which the inflammatory and metabolic changes in abdominal subcutaneous and visceral adipose tissue are characterized after exposure to chronic hypoxia (research question $2 \mathrm{~b}$ ).

Chapter 7 presents a systematic literature review on the associations between dietary intake of fiber and specific fatty acids and COPD etiology and progression (research question 3).

In Chapter 8 the metabolic abnormalities and adverse lifestyle components in COPD patients identified in this thesis are discussed. 


\section{CHAPTER 1}

\section{References}

1. World Health Organization. The global burden of disease: 2004 update. 2008; Available from http://www.who.int/healthinfo/global_burden_disease/GBD_report_2004update_full.pdf.

2. Boezen HM, Postma DS, Smit HA. COPD samengevat. In: Volksgezondheid Toekomst Verkenning, Nationaal Kompas Volksgezondheid. Bilthoven: RIVM. 2008.

3. Soriano JB, Rodriguez-Roisin R. Chronic obstructive pulmonary disease overview: epidemiology, risk factors, and clinical presentation. Proc Am Thorac Soc. 2011;8(4):363-7.

4. Global Initiative for Chronic Obstructive Lung Disease. Global strategy for the diagnosis, management, and prevention of chronic obstructive pulmonary disease. Revised 2011. Available from http://www.goldcopd.org/uploads/users/files/GOLD_Report_2011_Feb21.pdf.

5. Barnes PJ, Celli BR. Systemic manifestations and comorbidities of COPD. Eur Respir J. 2009;33(5):1165-85.

6. Schols AM, Wouters EF. Nutritional considerations in the treatment of chronic obstructive pulmonary disease. Clin Nutr. 1995;14(2):64-73.

7. Schols AM, Slangen J, Volovics L, Wouters EF. Weight loss is a reversible factor in the prognosis of chronic obstructive pulmonary disease. Am J Respir Crit Care Med. 1998;157(6 Pt 1):1791-7.

8. Fielding RA, Vellas B, Evans WJ, Bhasin S, Morley JE, Newman AB, Abellan van Kan G, Andrieu S, Bauer J, Breuille D, et al. Sarcopenia: an undiagnosed condition in older adults. Current consensus definition: prevalence, etiology, and consequences. International working group on sarcopenia. J Am Med Dir Assoc. 2011;12(4):249-56.

9. Schols AM, Soeters PB, Dingemans AM, Mostert R, Frantzen PJ, Wouters EF. Prevalence and characteristics of nutritional depletion in patients with stable COPD eligible for pulmonary rehabilitation. Am Rev Respir Dis. 1993;147(5):1151-6.

10. Schols AM, Broekhuizen R, Weling-Scheepers CA, Wouters EF. Body composition and mortality in chronic obstructive pulmonary disease. Am J Clin Nutr. 2005;82(1):53-9.

11. Vestbo J, Prescott E, Almdal T, Dahl M, Nordestgaard BG, Andersen T, Sorensen TI, Lange P. Body mass, fat-free body mass, and prognosis in patients with chronic obstructive pulmonary disease from a random population sample: findings from the Copenhagen City Heart Study. Am J Respir Crit Care Med. 2006;173(1):79-83.

12. Allaire J, Maltais F, Doyon JF, Noel M, LeBlanc P, Carrier G, Simard C, Jobin J. Peripheral muscle endurance and the oxidative profile of the quadriceps in patients with COPD. Thorax. 2004;59(8):673-8.

13. Gosker HR, Zeegers MP, Wouters EF, Schols AM. Muscle fibre type shifting in the vastus lateralis of patients with COPD is associated with disease severity: a systematic review and meta-analysis. Thorax. 2007;62(11):944-9.

14. Sin DD, Man SF. Why are patients with chronic obstructive pulmonary disease at increased risk of cardiovascular diseases? The potential role of systemic inflammation in chronic obstructive pulmonary disease. Circulation. 2003;107(11):1514-9.

15. McGarvey LP, John M, Anderson JA, Zvarich M, Wise RA. Ascertainment of cause-specific mortality in COPD: operations of the TORCH Clinical Endpoint Committee. Thorax. 2007;62(5):411-5.

16. Watz H, Waschki B, Kirsten A, Muller KC, Kretschmar G, Meyer T, Holz O, Magnussen H. The metabolic syndrome in patients with chronic bronchitis and COPD: frequency and associated consequences for systemic inflammation and physical inactivity. Chest. 2009;136(4):1039-46.

17. Kelley DE, He J, Menshikova EV, Ritov VB. Dysfunction of mitochondria in human skeletal muscle in type 2 diabetes. Diabetes. 2002;51(10):2944-50.

18. Kishida K, Funahashi T, Matsuzawa Y, Shimomura I. Visceral adiposity as a target for the management of the metabolic syndrome. Ann Med. 2012;44(3):233-41.

19. Patel AR, Hurst JR. Extrapulmonary comorbidities in chronic obstructive pulmonary disease: state of the art. Expert Rev Respir Med. 2011;5(5):647-62.

20. Gan WQ, Man SF, Senthilselvan A, Sin DD. Association between chronic obstructive pulmonary disease and systemic inflammation: a systematic review and a meta-analysis. Thorax. 2004;59(7):574-80.

21. Remels AH, Gosker HR, Schrauwen P, Hommelberg PP, Sliwinski P, Polkey M, Galdiz J, Wouters EF, Langen RC, Schols AM. TNF-alpha impairs regulation of muscle oxidative phenotype: implications for cachexia? FASEB J. 2010;24(12):5052-62.

22. Langen RC, Schols AM, Kelders MC, van der Velden JL, Wouters EF, Janssen-Heininger YM. Muscle wasting and impaired muscle regeneration in a murine model of chronic pulmonary inflammation. Am J Respir Cell Mol Biol. 2006;35(6):689-96.

23. Paoletti R, Gotto AM, Jr., Hajjar DP. Inflammation in atherosclerosis and implications for therapy. Circulation. 2004;109(23 Suppl 1):III20-6.

24. McLean RR. Proinflammatory cytokines and osteoporosis. Curr Osteoporos Rep. 2009;7(4):134-9.

25. Trayhurn P, Wood IS. Adipokines: inflammation and the pleiotropic role of white adipose tissue. Br J Nutr. 2004;92(3):347-55.

26. Vozoris N, O'Donnell DE. Prevalence, risk factors, activity limitation and health care utilization of an obese, population-based sample with chronic obstructive pulmonary disease. Can Respir J. 2012;19(3):e18-24.

27. Agusti A, Calverley PM, Celli B, Coxson HO, Edwards LD, Lomas DA, MacNee W, Miller BE, Rennard S, Silverman EK, et al. Characterisation of COPD heterogeneity in the ECLIPSE cohort. Respir Res. 2010;11:122.

28. Eagan TM, Ueland T, Wagner PD, Hardie JA, Mollnes TE, Damas JK, Aukrust P, Bakke PS. Systemic inflammatory markers in COPD: results from the Bergen COPD Cohort Study. Eur Respir J. 2010;35(3):540-8. 


\section{GENERALINTRODUCTION}

29. Agusti A, Edwards LD, Rennard SI, Macnee W, Tal-Singer R, Miller BE, Vestbo J, Lomas DA, Calverley PM, Wouters E, et al. Persistent Systemic Inflammation is Associated with Poor Clinical Outcomes in COPD: A Novel Phenotype. PLoS One. 2012;7(5):e37483.

30. Akbartabartoori M, Lean ME, Hankey CR. Relationships between cigarette smoking, body size and body shape. Int J Obes (Lond). 2005;29(2):236-43.

31. Strand BH, Mishra G, Kuh D, Guralnik JM, Patel KV. Smoking history and physical performance in midlife: results from the British 1946 birth cohort. J Gerontol A Biol Sci Med Sci. 2011;66(1):142-9.

32. Pate RR, Pratt M, Blair SN, Haskell WL, Macera CA, Bouchard C, Buchner D, Ettinger W, Heath GW, King AC, et al. Physical activity and public health. A recommendation from the Centers for Disease Control and Prevention and the American College of Sports Medicine. JAMA. 1995;273(5):402-7.

33. European Respiratory roadmap- recommendations for the future of respiratory medicine. 2012; Available from: http://www.ersroadmap.org.

34. Varraso R, Fung TT, Hu FB, Willett W, Camargo CA. Prospective study of dietary patterns and chronic obstructive pulmonary disease among US men. Thorax. 2007;62(9):786-91.

35. Shaheen SO, Jameson KA, Syddall HE, Sayer AA, Dennison EM, Cooper C, Robinson SM. The relation of dietary patterns with adult lung function and COPD. Eur Respir J. 2010;36(2):277-84. 


\section{CHAPTER 2}

\section{Is age-related decline in lean mass and physical function accelerated by obstructive lung disease or smoking?}

Bram van den Borst, Annemarie Koster, Binbing Yu, Harry R. Gosker, Bernd Meibohm, Douglas C. Bauer, Stephen B. Kritchevsky, Yongmei Liu, Anne B. Newman, Tamara B. Harris, Annemie M.W.J. Schols

For the Health, Aging and Body Composition (Health ABC) Study

Thorax 2011;66(11):961-9 


\section{Abstract}

Background and aims: Cross-sectional studies suggest that obstructive lung disease (OLD) and smoking affect lean mass and mobility. We aimed to investigate whether OLD and smoking accelerate aging-related decline in lean mass and physical functioning.

Methods: 260 persons with OLD ( $\mathrm{FEV}_{1} 63 \pm 18 \%$ of predicted), 157 smoking controls $\left(\mathrm{FEV}_{1} 95 \pm 16 \%\right.$ of predicted), 866 formerly smoking controls $\left(\mathrm{FEV}_{1}\right.$ $100 \pm 16 \%$ of predicted) and 891 never-smoking controls (FEV $104 \pm 17 \%$ of predicted) participating in the Health, Aging and Body Composition (ABC) Study were studied. At baseline, the mean age was $74 \pm 3$ y and participants reported no functional limitations. Baseline and seven-year longitudinal data were investigated of body composition (by dual-energy X-ray absorptiometry), muscle strength (by hand and leg dynamometry) and short physical performance battery (SPPB).

Results: Compared to never-smoking controls, OLD persons and smoking controls had a significantly lower weight, fat mass, lean mass and bone mineral content (BMC) at baseline $(P<.05)$. While the loss of weight, fat mass, lean mass and strength was comparable between OLD persons and never-smoking controls, the SPPB declined 0.12 points/yr faster in OLD men $(P=.01)$ and BMC 4 $\mathrm{g} / \mathrm{yr}$ faster in OLD women $(P=.02)$. In smoking controls, only lean mass declined $0.1 \mathrm{~kg} / \mathrm{yr}$ faster in women $(P=.03)$ and BMC $8 \mathrm{~g} / \mathrm{yr}$ faster in men $(P=.02)$ compared to never-smoking controls.

Conclusions: Initially well-functioning older adults with mild-to-moderate OLD and smokers without OLD have a comparable compromised baseline profile of body composition and physical functioning, while seven-year longitudinal trajectories are to a large extent comparable to those observed in never-smokers without OLD. This suggests a common insult earlier in life related to smoking. 


\section{Introduction}

Chronic obstructive pulmonary disease (COPD) affects approximately 14\% of older adults and is related to increased immobility, hospitalizations and resulting health care costs [1]. COPD is characterized by irreversible airflow limitation and is associated with an abnormal inflammatory response of the lungs mainly to cigarette smoke [2]. It has been increasingly recognized as a disease with marked extrapulmonary manifestations such as muscle wasting and weakness, osteoporosis and cardiovascular disease [3], in which systemic inflammation is thought to play an important role [4, 5]. It remains unclear, however, if these systemic manifestations are co-morbid conditions related to a common noxious exposure or if these are systemic consequences of the disease itself.

So far skeletal muscle weakness and wasting are the most studied and established extra-pulmonary determinants of impaired mobility and increased mortality in COPD [6]. Putative pathophysiological mechanisms of altered body composition and physical functioning in COPD have originated from crosssectional studies [7-10] and from longitudinal case studies without appropriate control groups [11-14]. However, since body composition changes and dysregulation of inflammation are also common with aging $[15,16]$ and since studied COPD populations often consist of older adults $(60+)$, inclusion of matched non-COPD control groups is crucial to unravel the effect of airflow obstruction on the pattern and progression of changes in body composition and physical function, as well as the potential modulating role of systemic inflammatory markers. To our best knowledge, such studies are currently lacking. Cross-sectional studies in healthy smokers have suggested detrimental effects of smoking on skeletal muscle function $[17,18]$. Increased systemic levels of pro-inflammatory markers were observed in healthy smokers [19], but also in former smokers [20]. Collectively, these data suggest that also in the absence of chronic airflow limitation, smoking may enhance skeletal muscle wasting and accelerate the decline in physical functioning, and that systemic inflammation could be a modulator.

We hypothesized that older adults with obstructive lung disease (OLD) and smokers with normal lung function have accelerated loss of lean mass and physical functioning compared to a never-smoking population. Systemic inflammatory markers could contribute to the association with body composition and physical functioning. We therefore examined seven-year longitudinal changes in body composition and physical functioning in older persons with OLD and in a non-OLD population stratified by smoking status. 


\section{Methods}

\section{Study population}

This study was performed in persons participating in the Health, Aging and Body Composition (Health ABC) study. This is a longitudinal study of 3075 wellfunctioning black and white men and women between the ages of 70-79 years residing in and near Pittsburgh, Pennsylvania and Memphis, Tennessee. Baseline data was obtained in 1997/1998 through in-person interview and clinic based examination. Inclusion criteria were no reported difficulty walking a quarter mile, climbing 10 steps without resting, or performing mobility-related activities of daily living. Exclusion criteria were any life-threatening condition, participation in any research study involving medications or modification of eating or exercise habits, plans to move from the geographic area within 3 years, and difficulty in communicating with the study personnel or cognitive impairment. The Health ABC study protocol was approved by the Institutional Review Boards of the clinical sites. Written informed consent was obtained for all participants. The current study presents an analysis of the Health $\mathrm{ABC}$ dataset using 7-year follow-up data from participants who met the criteria for obstructive lung disease (OLD) $(n=260)$ and control participants with normal lung function $(\mathrm{n}=1914)$. Participants with missing body composition measures at baseline and those with no measures of systemic inflammatory markers were excluded (Figure 1).

\section{Measures}

\section{Lung function, smoking status and smoking history}

Lung function was assessed according to international standards as previously reported [10]. OLD was defined at baseline as reduced (i.e. < lower limit of normal, LLN) forced expiratory volume in $1 \mathrm{~s}\left(\mathrm{FEV}_{1}\right) /$ forced vital capacity (FVC) as determined by age, sex, and race-normalized values [10, 21, 22]. Cigarette smoking status (smoker, former smoker, never-smoker) was recorded based on self-report. At baseline, smokers, former smokers and never-smokers without OLD (i.e. $\mathrm{FEV}_{1} / \mathrm{FVC} \geq \mathrm{LLN}$ ) were designated as the smoking controls, formerly smoking controls and never-smoking controls, respectively. Participants with restrictive lung disease $\left(\mathrm{FEV}_{1} / \mathrm{FVC} \geq \mathrm{LLN}\right.$ but $\left.\mathrm{FVC}<\mathrm{LLN}\right)$ were excluded. At baseline, the number of pack years smoked ( 1 pack year $=20$ cigarettes $/$ day for 1 year) was obtained based on self-report.

Lung function was repeated in years 5 and 8. Participants with valid lung function measures both at baseline and in year 5 and/or 8 were included in the analysis of lung function decline. Consequently, lung function decline could be analyzed in $\mathrm{n}=1658$ participants over a mean (SD) period of 6.2 (1.3) years including 2.6 (0.5) valid measurements per participant. 
Figure 1. Flow chart of participant selection at baseline.

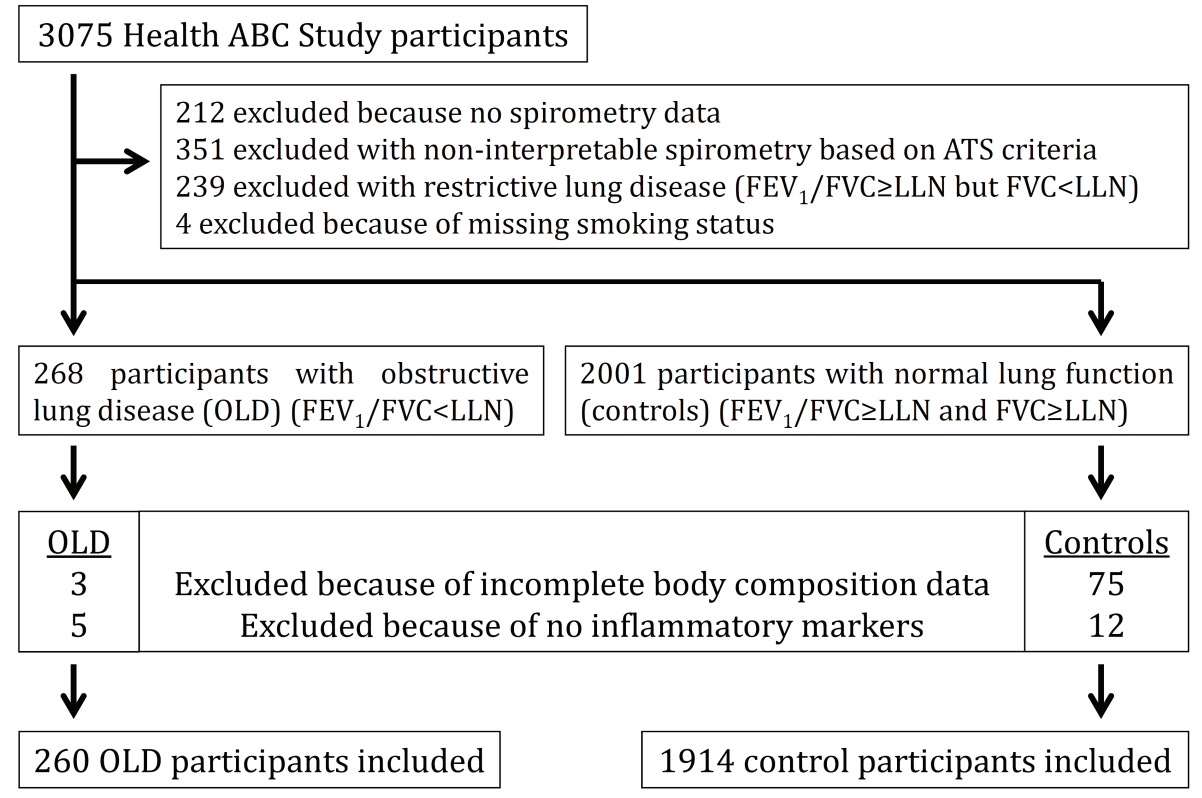

Abbreviations: ATS, American Thoracic Society; FEV1, forced expiratory volume in 1 ; FVC, forced vital capacity; LLN, lower limit of normal; OLD, obstructive lung disease.

\section{Body composition}

Height was measured using a wall mounted stadiometer. Body weight was assessed to the nearest $0.1 \mathrm{~kg}$ using a standard balance beam scale and body mass index (BMI) was calculated as weight/height ${ }^{2}\left(\mathrm{~kg} / \mathrm{m}^{2}\right)$. Weight was measured in years 1 to 6 and 8. Whole body dual energy X-ray absorptiometry (DXA, Hologic 4500A software version 8.21, Waltham, MA) was applied to retrieve whole body fat mass, lean mass, leg lean mass (left and right leg were summed) and bone mineral content (BMC). DXA measurements were performed in years 1 to 6 and 8 .

\section{Muscle function and mobility}

In years 1, 2, 4, 6 and 8, maximal isokinetic strength of the quadriceps muscle was assessed by a Kin-Com 125 AP Dynamometer (Chattanooga, TN, USA) at $60^{\circ} \mathrm{s}$. The right leg was tested unless there was a contraindication. The maximum torque was taken from three reproducible and acceptable trials. Participants with a systolic blood pressure $\geq 200 \mathrm{mmHg}$ or a diastolic blood pressure $\geq 110 \mathrm{mmHg}$ or who reported a history of cerebral aneurysm, cerebral bleeding, bilateral total knee replacement, or severe bilateral knee pain were 
excluded from testing (12.7\% of original cohort) [15]. As a consequence, baseline measures for quadriceps strength were available for $n=228$ OLD participants and $\mathrm{n}=1730$ controls. Hand grip strength was measured using a Jamar Hydraulic Hand Dynamometer at baseline and in years 2, 4, 6 and 8. The maximum values of the right and the left hand were summed from two trials. In years 1, 4 and 6, lower extremity function was assessed using the SPPB (Short Physical Performance Battery) [23, 24]. The battery consists of a test of gait speed, standing balance, and time to rise from a chair five times. Each item was scored using a five-point scale $(0=$ inability to complete test, $4=$ highest level of performance) leading to a combined 0-12-point summary scale.

\section{Inflammatory markers}

At baseline, measures of the cytokines interleukin (IL)-6, tumor necrosis factor (TNF)- $\alpha$ and C-reactive protein (CRP) were obtained from frozen stored plasma or serum (see for further details [25]).

\section{Covariates}

At baseline, clinic site, age, race (black/white), oral steroid use, calcium supplementation and vitamin D supplementation were based on self-report. Prevalent health conditions (diabetes, cardiovascular disease and depression) were assessed based on self-report and medication inventory. Physical activity in the preceding seven days was assessed at baseline by questionnaire [26, 27].

\section{$\underline{\text { Statistical analyses }}$}

Differences in descriptive characteristics at baseline between OLD persons, smoking controls, formerly smoking controls and never-smoking controls were tested using ANOVA for continuous variables, $\chi^{2}$ for categorical variables and Kruskal-Wallis test for continuous variables with skewed distributions. Post-hoc comparisons were performed applying Bonferroni correction for multiple testing. Change in lung function could be calculated from a maximum of three time points only, hence per participant simple linear regression was applied to examine the yearly change (slope) in lung function. Subsequently, the mean slopes were tested between the study groups using ANOVA. The longitudinal data on body composition and physical functioning were analyzed using multilevel regression models, allowing for the intercepts and slopes to vary between the four groups. This type of analysis takes into account the intraindividual correlation between repeated measurements and allows the inclusion of participants with incomplete data at follow-up. Therefore, no imputation of missing data was applied. The primary model included group (OLD, smoking controls, formerly smoking controls, never-smoking controls), age, race, clinic 
site, examination year (time), oral steroid use (yes/no), calcium supplementation (yes/no), vitamin D supplementation (yes/no), cardiovascular disease (yes/no), diabetes (yes/no), depression (yes/no), physical activity, and an interaction term with time for all of these variables. The reported slopes are the coefficients of the interaction term group*time in which the never-smoking controls served as the reference group. In the second model further adjustment was made for IL-6, TNF- $\alpha$ and CRP and their interactions with time. There were no significant interaction effects between race and clinic site with the group variable on changes in body composition or physical functioning ( $P>.05)$. Sample size considerations precluded examination of the effect of smoking status within the OLD group. The current analyses were performed for men and women separately because the gender distribution across the study groups was significantly different $(P<.001)$, which was most pronounced in the formerly smoking controls and never-smoking controls.

A small proportion of participants did not have measurements of body composition and physical functioning due to missing clinic visits while being alive. To examine the sensitivity of the results from the multilevel regression analyses to these missing observations, we used a joint model for the primary outcomes and missing probabilities [28]. Statistical analyses were performed using PASW Statistics 17.0 (SPSS inc. Chicago, IL). Differences were declared to be statistically significant at $P<.05$.

\section{Results}

Baseline characteristics are presented in Tables 1 (men) and 2 (women). The degree of airflow limitation in OLD persons was mild ( $\mathrm{FEV}_{1}>70 \%$ of predicted), moderate $\left(\mathrm{FEV}_{1} 50-70 \%\right.$ of predicted) and severe $\left(\mathrm{FEV}_{1}<50 \%\right.$ of predicted) in $32 \%, 38 \%$ and $30 \%$ of cases in men and in $36 \%, 41 \%$ and $23 \%$ of cases in women, respectively. The proportion of smokers, former smokers and neversmokers in the OLD persons was $63 \%, 28 \%$ and $9 \%$ in men and $46 \%, 27 \%$ and $27 \%$ in women, respectively. Compared to never-smoking controls, the decline in $\mathrm{FEV}_{1}$ was lower in OLD men $(-38 \pm 6 v s .-57 \pm 3 \mathrm{~mL} / \mathrm{yr}, P=.038)$ but not in OLD women $(-33 \pm 5$ vs. $-40 \pm 2 \mathrm{~mL} / \mathrm{yr}, P=.45)$ (Supplemental Table 1$)$. The formerly smoking controls had abstained from smoking for 25 (14) years. The prevalence of co-morbid conditions was not different across the groups $(P>.05)$. Persons with OLD and smoking controls had comparable levels of physical activity as the never-smoking controls $(P>.05)$. In men, OLD persons had increased CRP and IL6, and smoking controls had increased IL-6 compared with never-smoking controls $(P<.05)$. In women, smoking controls had increased IL-6 compared to never-smoking controls $(P<.05)$.

In both sexes, persons with OLD and smoking controls showed striking similarities regarding lower measures of body composition and physical functioning as compared to the never-smoking controls (Figure 2). In general, 
Table 1. Baseline characteristics of men in the Health ABC Study according to obstructive lung disease (OLD) status and smoking status.

\begin{tabular}{|c|c|c|c|c|c|c|}
\hline & OLD $(n=150)$ & $\begin{array}{c}\text { Smoking } \\
\text { controls } \\
(n=74)\end{array}$ & $\begin{array}{l}\text { Formerly } \\
\text { smoking } \\
\text { controls } \\
(n=534)\end{array}$ & $\begin{array}{l}\text { Never- } \\
\text { smoking } \\
\text { controls } \\
(\mathrm{n}=\mathbf{3 0 1})\end{array}$ & $P$ & $\begin{array}{c}\text { Significant } \\
\text { post-hoc } \\
\text { comparisons }^{\mathrm{a}}\end{array}$ \\
\hline & $\mathbf{A}$ & B & $\mathrm{C}$ & D & & \\
\hline \multicolumn{7}{|l|}{ Demographics } \\
\hline Age, $y$ & $73.4(2.9)$ & $73.0(2.5)$ & 73.7 (2.9) & $74.0(2.8)$ & .06 & - \\
\hline Race, \% white & 52 & 35 & 70 & 65 & $<.001$ & $\mathrm{AC}, \mathrm{BC}, \mathrm{BD}$ \\
\hline Site, \% Memphis & 60 & 50 & 47 & 51 & .013 & $\mathrm{AC}, \mathrm{AD}$ \\
\hline $\begin{array}{l}\text { Physical activity, } \\
\mathrm{kcal} / \mathrm{kg} / \mathrm{wk}^{\mathrm{b}}\end{array}$ & $68(37-105)$ & $59(35-125)$ & $67(40-114)$ & $72(39-114)$ & .68 & - \\
\hline \multicolumn{7}{|c|}{ Co-morbidity, steroid use, calcium and vitamin D supplementation } \\
\hline Depression, \% & 7 & 1 & 8 & 5 & .22 & - \\
\hline $\begin{array}{l}\text { Cardiovascular } \\
\text { disease, } \%\end{array}$ & 25 & 24 & 30 & 23 & .10 & - \\
\hline Diabetes, \% & 13 & 15 & 16 & 15 & .91 & - \\
\hline Oral steroid use, $\%$ & 1 & 1 & 2 & 0 & .49 & - \\
\hline $\begin{array}{l}\text { Calcium } \\
\text { supplementation, \% }\end{array}$ & 5 & 7 & 7 & 9 & .35 & - \\
\hline $\begin{array}{l}\text { Vitamin D } \\
\text { supplementation, \% }\end{array}$ & 3 & 1 & 3 & 4 & .63 & - \\
\hline \multicolumn{7}{|c|}{ Lung function and smoking } \\
\hline $\mathrm{FEV}_{1}, \%$ pred $^{\mathrm{c}}$ & $61(17)$ & $93(12)$ & $100(14)$ & $102(15)$ & $<.001$ & $\begin{array}{c}\mathrm{AB}, \mathrm{AC}, \mathrm{AD}, \mathrm{BC}, \mathrm{BD}, \\
\mathrm{CD}\end{array}$ \\
\hline $\mathrm{FEV}_{1}, \mathrm{~L}$ & $1.68(0.50)$ & $2.47(0.41)$ & $2.77(0.50)$ & $2.78(0.49)$ & $<.001$ & $\mathrm{AB}, \mathrm{AC}, \mathrm{AD}, \mathrm{BC}, \mathrm{BD}$ \\
\hline $\mathrm{FEV}_{1} / \mathrm{FVC}$, ratio & $56(7)$ & $73(5)$ & $75(5)$ & $77(5)$ & $<.001$ & $\begin{array}{c}\mathrm{AB}, \mathrm{AC}, \mathrm{AD}, \mathrm{BC}, \mathrm{BD}, \\
\mathrm{CD}\end{array}$ \\
\hline Pack years ${ }^{b}$ & $48(26-64)$ & $48(27-60)$ & $25(10-41)$ & $0(0)$ & $<.001$ & $\mathrm{AC}, \mathrm{AD}, \mathrm{BC}, \mathrm{BD}, \mathrm{CD}$ \\
\hline \multicolumn{7}{|c|}{ Systemic inflammatory markers } \\
\hline IL-6, pg/mlb & $2.2(1.6-3.6)$ & $2.5(1.6-3.9)$ & $1.7(1.2-2.7)$ & $1.7(1.2-2.3)$ & $<.001$ & $\mathrm{AC}, \mathrm{AD}, \mathrm{BD}$ \\
\hline $\mathrm{CRP}, \mu \mathrm{g} / \mathrm{ml}^{\mathrm{b}}$ & $2.0(1.2-3.5)$ & $1.5(0.9-3.3)$ & $1.3(0.9-2.4)$ & $1.3(0.9-2.2)$ & $<.001$ & $\mathrm{AC}, \mathrm{AD}$ \\
\hline $\mathrm{TNF}-\alpha, \mathrm{pg} / \mathrm{ml}^{\mathrm{b}}$ & $3.1(2.4-4.3)$ & $3.2(2.3-4.4)$ & $3.3(2.6-4.3)$ & $3.1(2.4-4.0)$ & .23 & - \\
\hline
\end{tabular}

Abbreviations: CRP, C-reactive protein; IL, interleukin; $F E V_{1}$, forced expiratory volume in $1 \mathrm{~s}$; $F V C$, forced vital capacity; SPPB, short physical performance battery; TNF- $\alpha$, tumor necrosis factor- $\alpha$. Data are mean (SD) unless specified otherwise. ${ }^{a}$ Corrected for multiple testing. ${ }^{b}$ Median (IQR). ${ }^{c}$ From reference equations [21].

the adjusted intercepts from the multilevel models (Figures 3 and 4 and the corresponding Supplemental Tables 2 and 3) showed similar findings to the baseline comparisons in Figure 2. While at baseline large differences were observed in body composition and physical functioning, the rates of longitudinal change of weight, fat mass, lean mass and strength were comparable between OLD persons and never-smoking controls (all $P>.05$ ), except for the change in SPPB in OLD men $(P=.01)$ and BMC in OLD women $(P=.02)$. In smoking controls, only lean mass declined faster in women $(P=.03)$ and BMC faster in men $(P=.02)$ 
Table 2. Baseline characteristics of women in the Health ABC Study according to obstructive lung disease (OLD) status and smoking status.

\begin{tabular}{|c|c|c|c|c|c|c|}
\hline & OLD $(n=110)$ & $\begin{array}{c}\text { Smoking } \\
\text { controls } \\
(n=83)\end{array}$ & $\begin{array}{l}\text { Formerly } \\
\text { smoking } \\
\text { controls } \\
(n=332) \\
\end{array}$ & $\begin{array}{l}\text { Never- } \\
\text { smoking } \\
\text { controls } \\
(\mathrm{n}=590) \\
\end{array}$ & $P$ & $\begin{array}{c}\text { Significant } \\
\text { post-hoc } \\
\text { comparisons }^{\mathrm{a}}\end{array}$ \\
\hline & A & B & $\mathrm{C}$ & D & & \\
\hline \multicolumn{7}{|l|}{ Demographics } \\
\hline Age, $y$ & $72.8(2.8)$ & $73.7(3.0)$ & $73.3(2.8)$ & $73.5(2.9)$ & .06 & - \\
\hline Race, $\%$ white & 62 & 37 & 56 & 59 & .001 & $\mathrm{AB}, \mathrm{BC}, \mathrm{BD}$ \\
\hline Site, \% Memphis & 42 & 43 & 46 & 51 & .11 & - \\
\hline $\begin{array}{l}\text { Physical activity, } \\
\mathrm{kcal} / \mathrm{kg} / \mathrm{wk}^{\mathrm{b}}\end{array}$ & $67(36-91)$ & $66(36-107)$ & $65(40-97)$ & $74(45-113)$ & .006 & $\mathrm{CD}$ \\
\hline \multicolumn{7}{|c|}{ Co-morbidity, steroid use, calcium and vitamin D supplementation } \\
\hline Depression, \% & 12 & 16 & 11 & 11 & .70 & - \\
\hline $\begin{array}{l}\text { Cardiovascular } \\
\text { disease, } \%\end{array}$ & 18 & 27 & 22 & 17 & .42 & - \\
\hline Diabetes, \% & 10 & 15 & 11 & 13 & .63 & - \\
\hline Oral steroid use, \% & 9 & 2 & 3 & 2 & .001 & $\mathrm{AD}$ \\
\hline $\begin{array}{l}\text { Calcium } \\
\text { supplementation, \% }\end{array}$ & 27 & 24 & 29 & 32 & .35 & - \\
\hline $\begin{array}{l}\text { Vitamin D } \\
\text { supplementation, \% }\end{array}$ & 9 & 7 & 13 & 15 & .10 & - \\
\hline \multicolumn{7}{|c|}{ Lung function and smoking } \\
\hline $\mathrm{FEV}_{1}, \%$ pred $^{\mathrm{c}}$ & $65(19)$ & 97 (19) & $101(18)$ & $104(18)$ & \multicolumn{2}{|c|}{$<.001 \mathrm{AB}, \mathrm{AC}, \mathrm{AD}, \mathrm{BD}, \mathrm{CD}$} \\
\hline $\mathrm{FEV}_{1}, \mathrm{~L}$ & $1.24(0.38)$ & $1.66(0.33)$ & $1.87(0.38)$ & $1.95(0.36)$ & \multicolumn{2}{|c|}{$\begin{array}{c}<.001 \mathrm{AB}, \mathrm{AC}, \mathrm{AD}, \mathrm{BC}, \mathrm{BD}, \\
\mathrm{CD}\end{array}$} \\
\hline $\mathrm{FEV}_{1} / \mathrm{FVC}$, ratio & $58(7)$ & $75(6)$ & $76(5)$ & $77(5)$ & \multicolumn{2}{|c|}{$<.001 \mathrm{AB}, \mathrm{AC}, \mathrm{AD}, \mathrm{BD}, \mathrm{CD}$} \\
\hline Pack years ${ }^{\mathrm{b}}$ & $20(0-51)$ & $29(19-50)$ & $15(5-38)$ & $0(0)$ & \multicolumn{2}{|c|}{$<.001 \mathrm{AB}, \mathrm{AD}, \mathrm{BC}, \mathrm{BD}, \mathrm{CD}$} \\
\hline \multicolumn{7}{|c|}{ Systemic inflammatory markers } \\
\hline IL-6, pg/mlb & $1.9(1.3-2.9)$ & $1.9(1.3-2.8)$ & $1.7(1.2-2.5)$ & $1.6(1.1-2.5)$ & .021 & $\mathrm{BC}$ \\
\hline $\mathrm{CRP}, \mu \mathrm{g} / \mathrm{ml}^{\mathrm{b}}$ & $2.1(1.1-3.7)$ & $2.0(1.2-4.0)$ & $2.2(1.3-3.8)$ & $1.6(1.0-3.1)$ & $<.001$ & $\mathrm{CD}$ \\
\hline $\mathrm{TNF}-\alpha, \mathrm{pg} / \mathrm{ml}^{\mathrm{b}}$ & $2.9(2.2-3.8)$ & $3.1(2.2-4.0)$ & $3.0(2.4-3.9)$ & $3.1(2.3-4.0)$ & .63 & - \\
\hline
\end{tabular}

Abbreviations: CRP, C-reactive protein; IL, interleukin; $F E V_{1}$, forced expiratory volume in $1 \mathrm{~s} ; F V C$, forced vital capacity; $S P P B$, short physical performance battery; TNF- $\alpha$, tumor necrosis factor- $\alpha$. Data are mean (SD) unless specified otherwise. ${ }^{a}$ Corrected for multiple testing. ${ }^{b}$ Median (IQR). ${ }^{c}$ From reference equations [21].

compared to never-smoking controls, while the declines in weight and fat mass were comparable $(P>.05)$.

Further adjustment for baseline systemic cytokines resulted in a modest attenuation of several outcome measures (Supplemental Tables 2 and 3). In particular, the lower baseline and faster decline of BMC in smoking control men (and to a lesser extent in women) was explained by the cytokines for $26 \%$ and $25 \%$, respectively. The lower quadriceps strength in men and women with OLD was explained for $12 \%$ and $18 \%$ by the cytokines, respectively. 
Figure 2. Baseline characteristics of body composition and physical functioning in men and women.
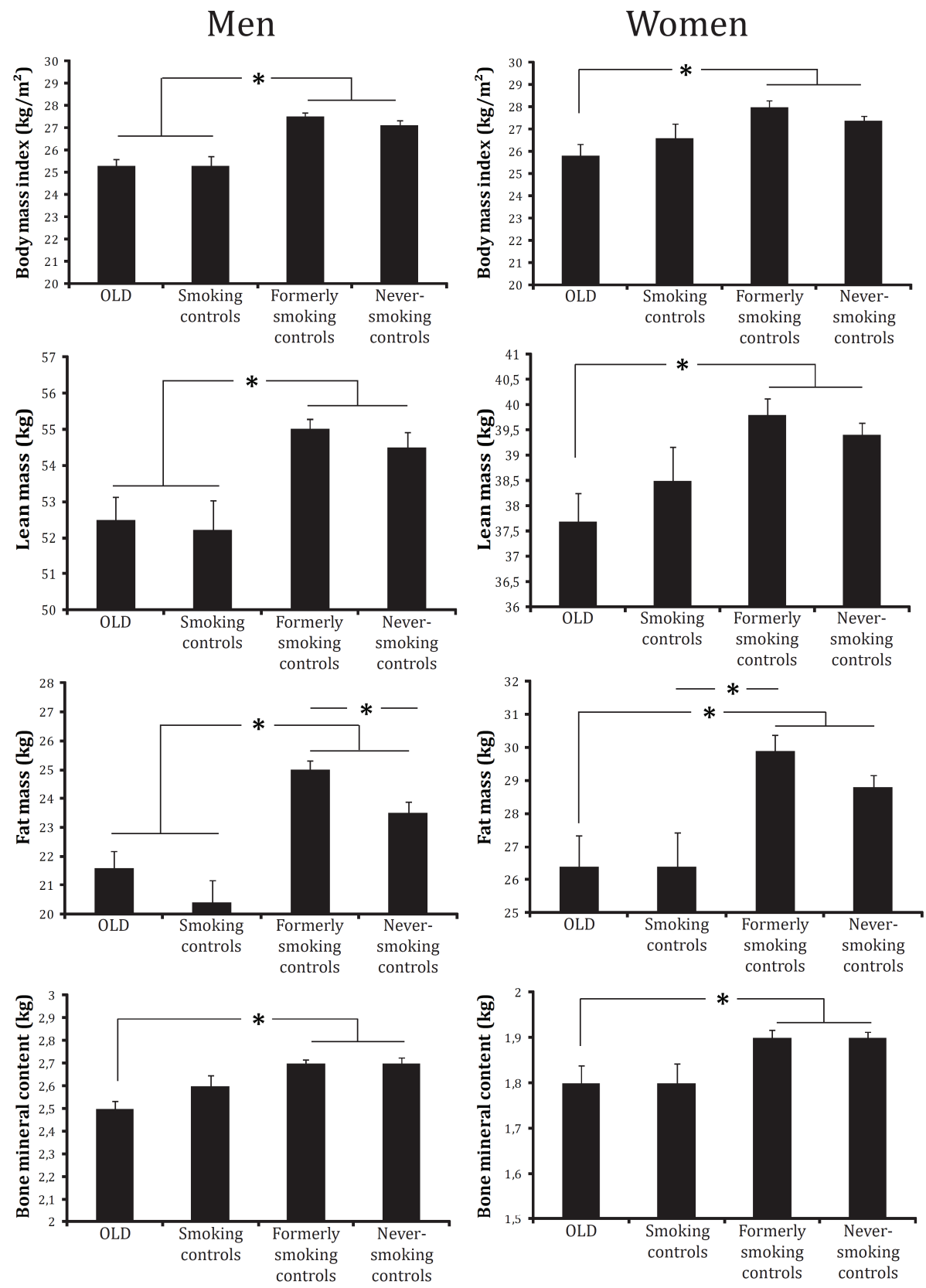
Figure 2. continued.
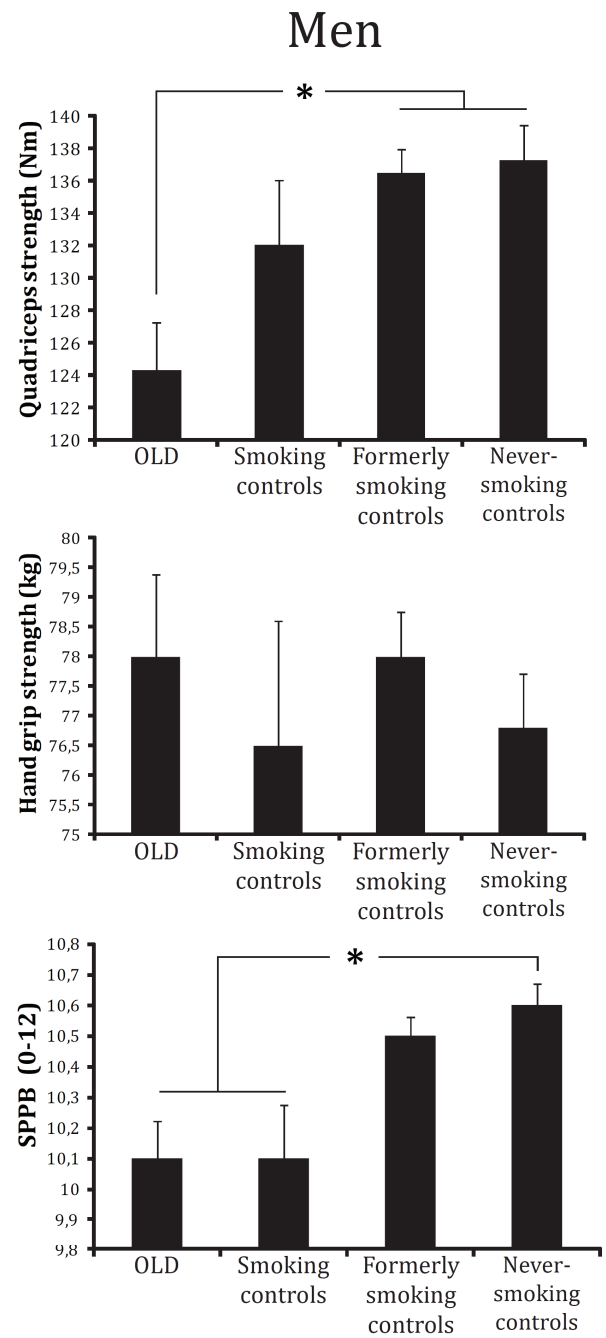

\section{Women}
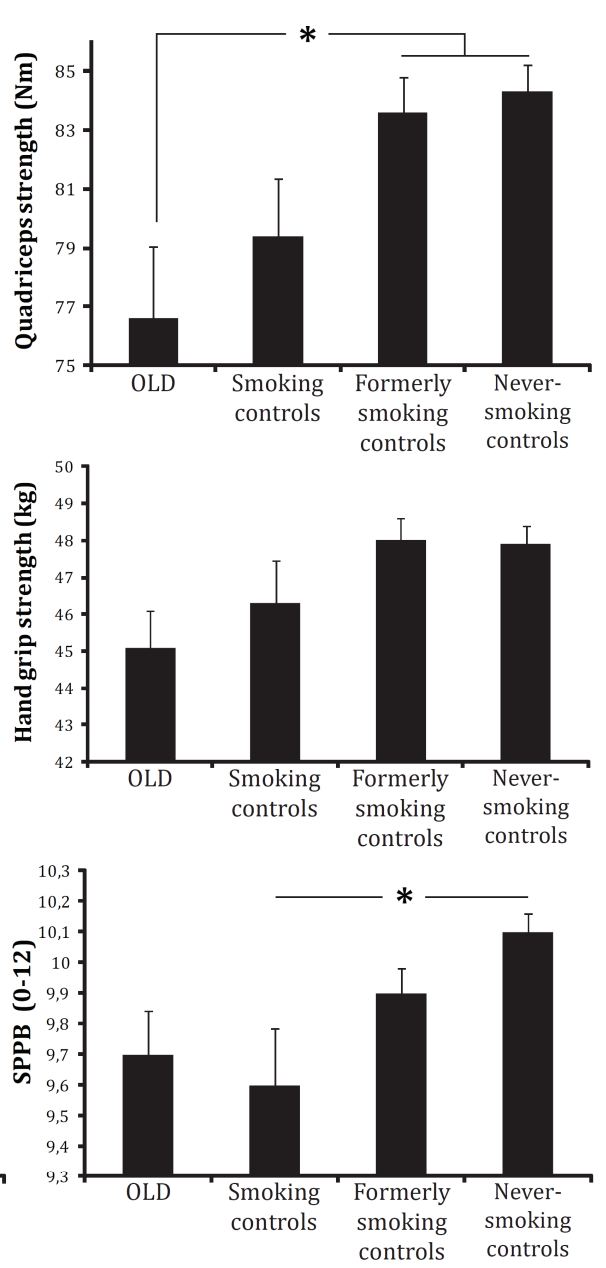

Abbreviations: OLD, obstructive lung disease; SPPB, short physical performance battery. Bars represent the means and error bars represent the $S E .{ }^{*} P<.05$.

In additional analyses, pack years were added to model 1 , which did not result in any major differences. Compared to the never-smoking controls, the formerly-smoking controls, smoking controls, and OLD persons had slightly higher probabilities of being missing along the seven years of follow-up. However, the trajectories of the outcomes essentially remained the same when we adjusted for missingness (not tabulated). The percentages of participants being alive at the year- 8 visit were $62 \%, 66 \%, 77 \%$ and $85 \%$ for the OLD 
Figure 3. Longitudinal course of body composition and physical functioning according to obstructive lung disease and smoking status in men. ${ }^{\mathrm{a}}$
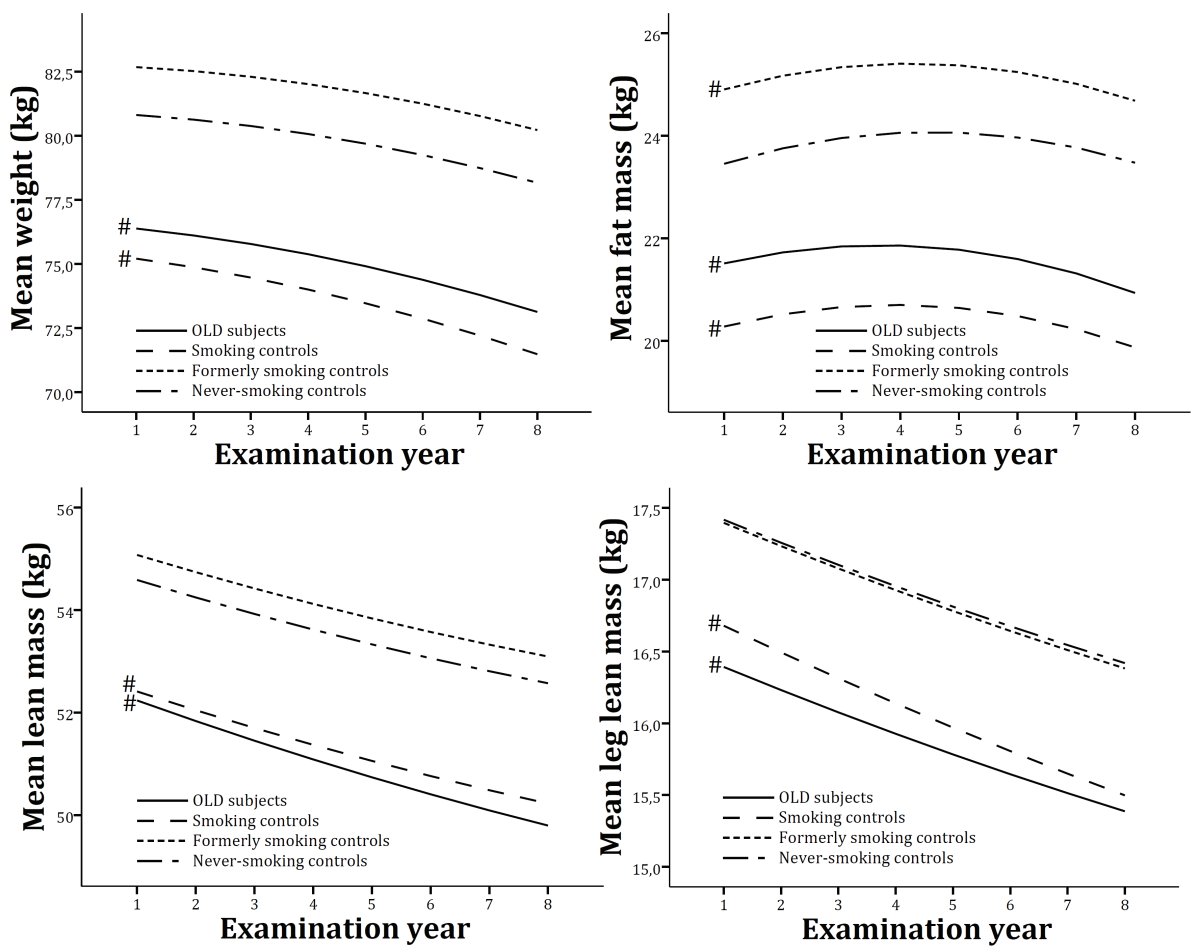

persons, smoking controls, formerly smoking controls and never-smoking controls, respectively.

\section{Discussion}

In the current study, we have shown striking similarities in body composition and physical functioning between older adult men and women with mild-tomoderate OLD and smokers with normal lung function. These were characterized by a markedly lower body weight, lean mass, fat mass, BMC and quadriceps strength compared to never-smoking controls. Interestingly, because longitudinal trajectories in the $8^{\text {th }}$ decade of life were to a large extent comparable to those of their never-smoking controls, the large baseline differences persisted over a period of 7 years follow up. This suggests that a common insult related to smoking induced a divergent pattern earlier in life, which may not uniformly persist into old-age. 
Figure 3. continued. ${ }^{\mathrm{a}}$
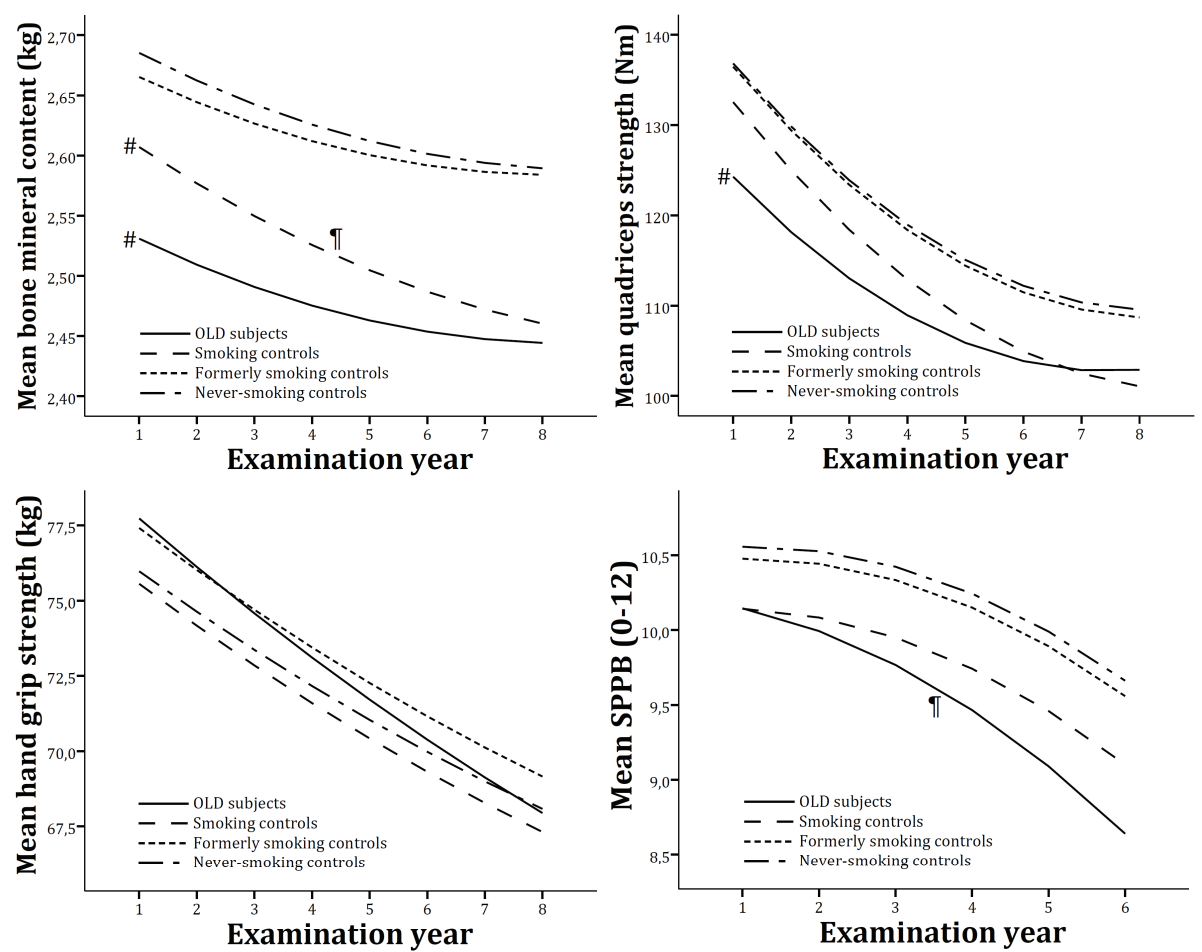

Abbreviations: OLD, obstructive lung disease; SPPB, short physical performance battery. ${ }^{a}$ Lines represent the mean predicted values adjusted for time, age, site, race, diabetes, cardiovascular disease, depression, physical activity, oral steroid use, calcium supplementation, vitamin $D$ supplementation, time $^{2}$, age $\times$ time, race $\times$ time, site $\times$ time, diabetes $\times$ time, cardiovascular disease $\times$ time, depression $\times$ time and physical activity $\times$ time, oral steroid use $\times$ time, calcium supplementation $\times$ time and vitamin $D$ supplementation $\times$ time. \#Intercept significantly different from never-smoking controls, P<.05. "Slope significantly different from never-smoking controls, $P<.05$.

The unique design of the Health $\mathrm{ABC}$ Study enabled us to investigate for the first time the longitudinal pattern and progression of body composition changes and the decline in physical functioning simultaneously in persons with OLD and smokers without OLD in comparison to aging effects in a never-smoking control group without OLD. Furthermore, by design of the Health ABC Study, none of the participants had functional limitations at baseline, and likely as a result of this selection, physical activity and prevalence of co-morbidity were comparable between the study groups. The Health ABC Study was therefore particularly of interest to examine the effects of smoking and OLD on body composition and physical functioning with aging. Our results may, however, not be generalized to all older adults nor to clinical COPD patients since study participants were 70-79 years old and well-functioning at baseline, and the OLD group was defined by lung function rather than a clinical COPD diagnosis. Therefore, it cannot be ruled 
Figure 4. Longitudinal course of body composition and physical functioning according to obstructive lung disease and smoking status in women. ${ }^{\mathrm{a}}$
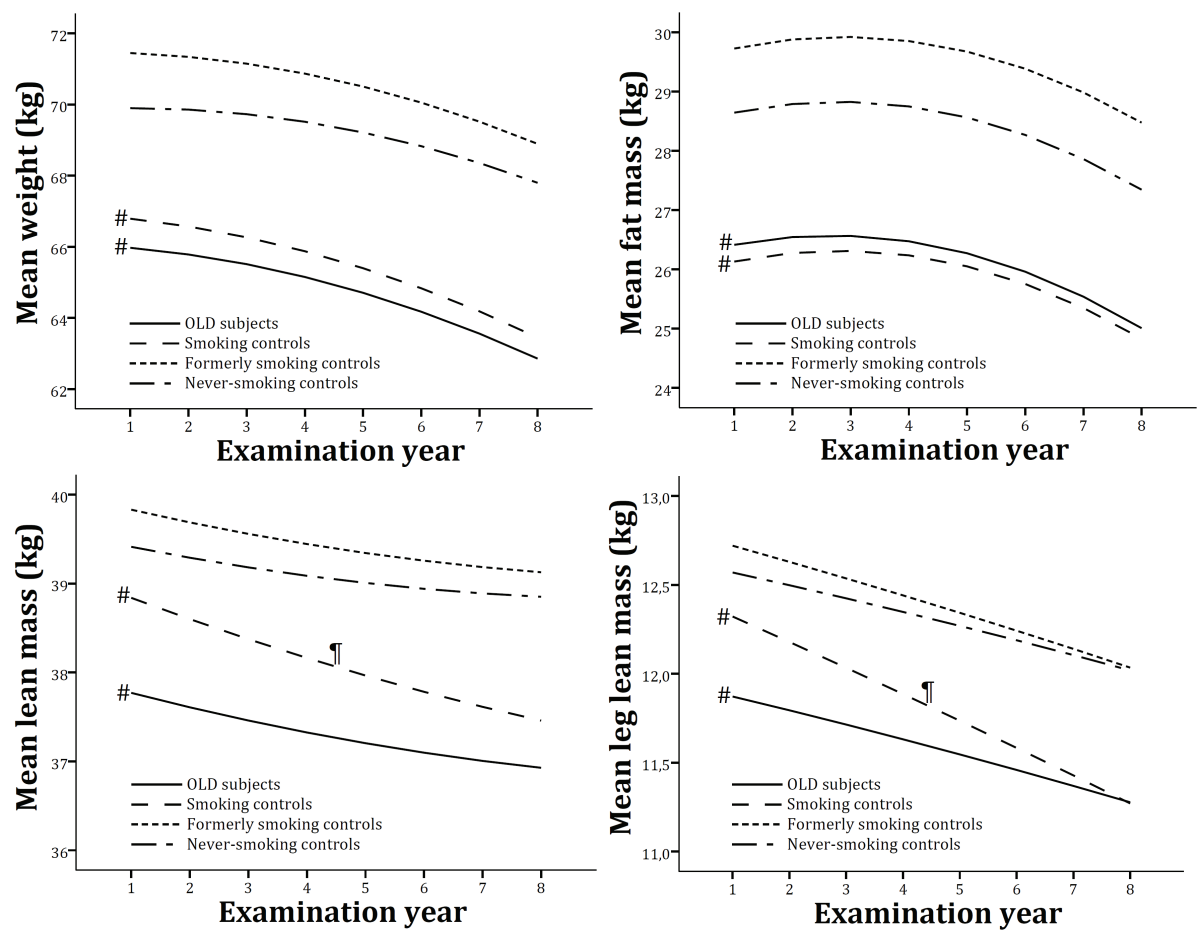

out that our data might underestimate "real" changes. Another strength of our study is that we carried out a sensitivity analysis to estimate the potential effect of missing observations on the observed trajectories. This effect was estimated to be small which, however, does not rule out that survival bias may have obscured our results. While we were unable to examine the effect of smoking status with the OLD persons due to sample size considerations, results between groups remained similar after further adjustment for pack years, suggesting that the observed differences are independent of the quantity of smoking.

We found that the decline in $\mathrm{FEV}_{1}$ was lower in OLD men compared to their never-smoking controls. Because this data was generated from a relatively low number of follow-up lung function measures we are careful in its interpretation, but it suggests that longitudinal body composition and physical functioning trajectories in OLD persons in our study are not related to a faster decline in $\mathrm{FEV}_{1}$.

In OLD men, but not in OLD women, we found an accelerated decline in SPPB. This gender difference may be explained by a greater relative difference in leg lean mass and quadriceps strength between OLD persons and neversmoking controls in men than in women. This is in line with a previous report 
Figure 4. continued. ${ }^{\mathrm{a}}$
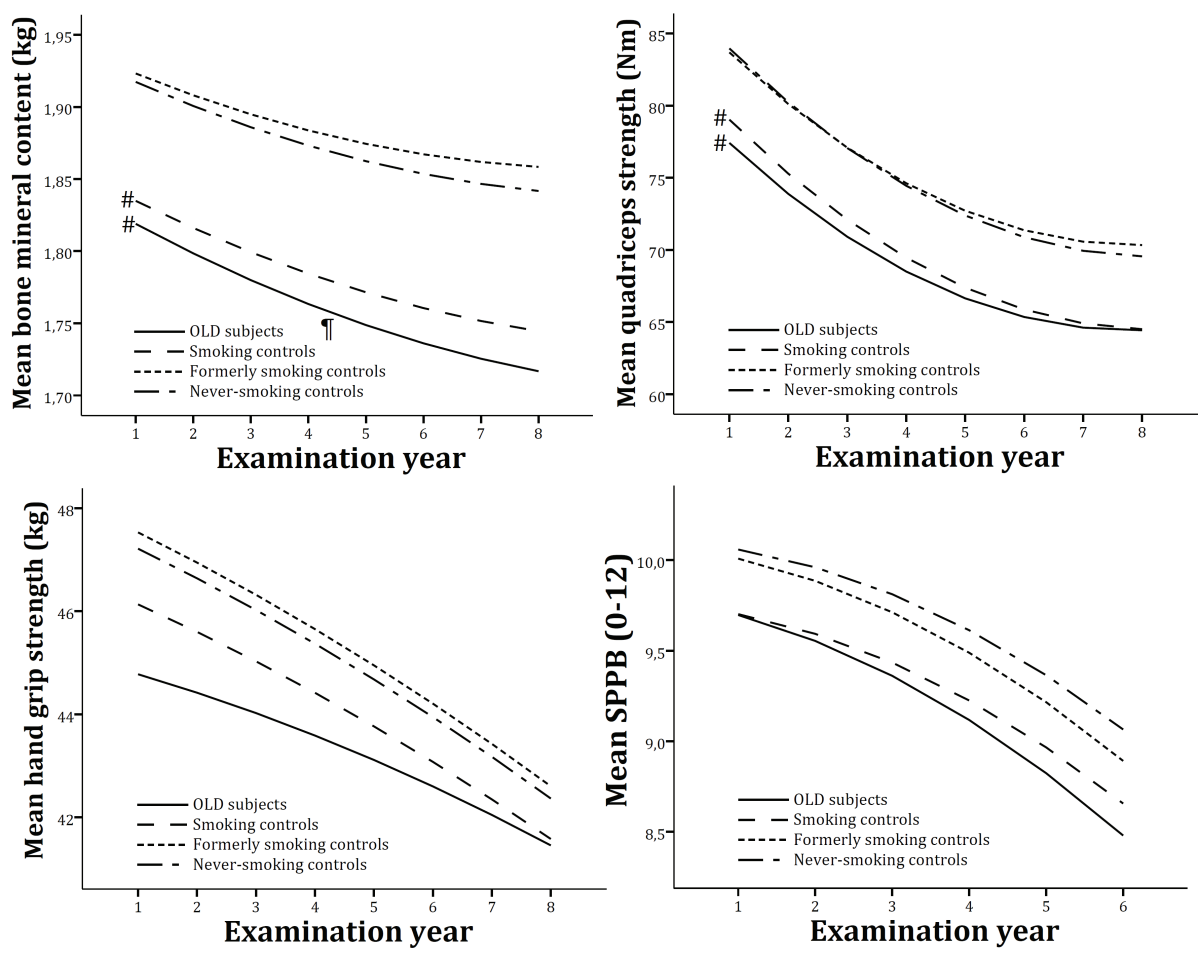

Abbreviations: OLD, obstructive lung disease; SPPB, short physical performance battery. "aLines represent the mean predicted values adjusted for time, age, site, race, diabetes, cardiovascular disease, depression, physical activity, oral steroid use, calcium supplementation, vitamin D supplementation, time $^{2}$, age $\times$ time, race $\times$ time, site $\times$ time, diabetes $\times$ time, cardiovascular disease $\times$ time, depression $\times$ time and physical activity $\times$ time, oral steroid use $\times$ time, calcium supplementation $\times$ time and vitamin $D$ supplementation $\times$ time. \#Intercept significantly different from never-smoking controls, $P<.05$. "Slope significantly different from never-smoking controls, $P<.05$.

showing that the relation between a lower fat-free mass and physical disability was more pronounced in men with COPD [29]. A lower SPPB has been strongly related to subsequent disability and mortality [24,30], and may thus be of clinical importance in particularly in men with OLD. Notably, despite a similar pattern of daily physical activity, quadriceps strength was much better able to discriminate between OLD persons, smoking controls and never-smoking controls than hand grip strength. Smoking control women had an accelerated decline in lean mass compared to never-smoking controls, which confirms previous cross-sectional data of a sarcopenic phenotype in older smoking women [31].

Systemic inflammation has been considered a key player in the extrapulmonary manifestations of COPD [5], and has been linked to muscle atrophy [32] and bone demineralization [33]. In the present study we indeed 
confirmed the presence of mildly elevated circulating cytokines in particularly OLD men but also in smoking controls. After further adjustment for systemic inflammatory markers we found little attenuation for the majority of outcome measures, but systemic inflammatory markers did explain 11-26\% of the observed baseline differences in BMC, and explained $25 \%$ of the accelerated BMC decline in smoking control men.

The observation that smoking cessation is associated with weight gain is well-known [34]. While this effect is mainly considered a relatively short-term effect (months) [35], former smokers in our study -who abstained from smoking for $\sim 25$ years- still showed a trend towards higher baseline weight, which was mainly due to higher fat mass. Apart from fat mass, body composition and physical functioning in former smokers were comparable to that of neversmokers, suggesting a high recovery potential from smoking-induced losses. As higher body weight and lean mass have been associated with better survival in COPD [36], it needs to be determined whether this recovery potential is as functional in the state of COPD. We found higher CRP in formerly smoking women, and borderline significantly higher TNF- $\alpha$ in formerly smoking men, which may be related to metabolic effects associated with fat abundance or altered fat distribution in obesity.

Although it was not part of our analyses, our data raise the possibility that low body and muscle mass may increase the risk of COPD development. In support of this, recent data from a large group of never-smokers from the Burden of Obstructive Lung Disease Study showed that the risk of COPD was significantly increased in those with a $\mathrm{BMI}<20 \mathrm{~kg} / \mathrm{m}^{2}$, especially in women [37]. In the case of smoking-induced COPD, however, it remains to be investigated whether a compromised body composition related to smoking contributes to the risk of COPD development. Our observation that while our smoking controls had comparable pack years smoked as OLD persons and had a similarly compromised body composition but no airflow obstruction, indicates that it is not solely low body weight that would increases the risk of COPD development, but suggests that other factors such as genetic susceptibility to for example emphysema and associated wasting are important.

In conclusion, our study shows that smoking is not only an important risk factor in OLD etiology, but also adversely affects body composition and physical functioning. The individual contributions of impaired weight gain and accelerated weight loss and a potential role for cytokinaemic stress associated with smoking remain to be studied in comparable future longitudinal studies in middle-aged persons. 


\section{References}

1. Gooneratne NS, Patel NP, Corcoran A. Chronic Obstructive Pulmonary Disease diagnosis and management in older adults. J Am Geriatr Soc. 2010;58:1153-62.

2. Celli BR, MacNee W. Standards for the diagnosis and treatment of patients with COPD: a summary of the ATS/ERS position paper. Eur Respir J. 2004;23(6):932-46.

3. Chatila WM, Thomashow BM, Minai OA, Criner GJ, Make BJ. Comorbidities in chronic obstructive pulmonary disease. Proc Am Thorac Soc. 2008;5(4):549-55.

4. Gan WQ, Man SF, Senthilselvan A, Sin DD. Association between chronic obstructive pulmonary disease and systemic inflammation: a systematic review and a meta-analysis. Thorax. 2004;59(7):574-80.

5. Wouters EF, Reynaert NL, Dentener MA, Vernooy JH. Systemic and local inflammation in asthma and chronic obstructive pulmonary disease: is there a connection? Proc Am Thorac Soc. 2009;6(8):638-47.

6. Vestbo J, Prescott E, Almdal T, Dahl M, Nordestgaard BG, Andersen T, Sorensen TI, Lange P. Body mass, fat-free body mass, and prognosis in patients with chronic obstructive pulmonary disease from a random population sample: findings from the Copenhagen City Heart Study. Am J Respir Crit Care Med. 2006;173(1):79-83.

7. Eisner MD, Iribarren C, Yelin EH, Sidney S, Katz PP, Ackerson L, Lathon P, Tolstykh I, Omachi T, Byl N, et al. Pulmonary function and the risk of functional limitation in chronic obstructive pulmonary disease. Am J Epidemiol. 2008;167(9):1090-101.

8. Gosker HR, Zeegers MP, Wouters EF, Schols AM. Muscle fibre type shifting in the vastus lateralis of patients with COPD is associated with disease severity: a systematic review and meta-analysis. Thorax. 2007;62(11):944-9.

9. Graat-Verboom L, Wouters EF, Smeenk FW, van den Borne BE, Lunde R, Spruit MA. Current status of research on osteoporosis in COPD: a systematic review. Eur Respir J. 2009;34(1):209-18.

10. Yende S, Waterer GW, Tolley EA, Newman AB, Bauer DC, Taaffe DR, Jensen R, Crapo R, Rubin S, Nevitt M, et al. Inflammatory markers are associated with ventilatory limitation and muscle dysfunction in obstructive lung disease in well functioning elderly subjects. Thorax. 2006;61(1):10-6.

11. Scanlon PD, Connett JE, Wise RA, Tashkin DP, Madhok T, Skeans M, Carpenter PC, Bailey WC, Buist AS, Eichenhorn M, et al. Loss of bone density with inhaled triamcinolone in Lung Health Study II. Am J Respir Crit Care Med. 2004;170(12):1302-9.

12. Oga T, Nishimura K, Tsukino M, Sato S, Hajiro T, Mishima M. Exercise capacity deterioration in patients with COPD: longitudinal evaluation over 5 years. Chest. 2005;128(1):62-9.

13. Oga T, Nishimura K, Tsukino M, Sato S, Hajiro T, Mishima M. Longitudinal deteriorations in patient reported outcomes in patients with COPD. Respir Med. 2007;101(1):146-53.

14. Habraken JM, van der Wal WM, Ter Riet G, Weersink EJ, Toben F, Bindels PJ. Health-related quality of life and functional status in end-stage COPD: a longitudinal study. Eur Respir J. 2011;37(2):280-8.

15. Koster A, Visser M, Simonsick EM, Yu B, Allison DB, Newman AB, van Eijk JT, Schwartz AV, Satterfield S, Harris TB. Association between fitness and changes in body composition and muscle strength. J Am Geriatr Soc. 2010;58(2):219-26.

16. Fulop T, Larbi A, Witkowski JM, McElhaney J, Loeb M, Mitnitski A, Pawelec G. Aging, frailty and age-related diseases. Biogerontology. 2010;11(5):547-63.

17. Montes de Oca M, Loeb E, Torres SH, De Sanctis J, Hernandez N, Talamo C. Peripheral muscle alterations in non-COPD smokers. Chest. 2008;133(1):13-8.

18. Wust RC, Morse CI, de Haan A, Rittweger J, Jones DA, Degens H. Skeletal muscle properties and fatigue resistance in relation to smoking history. Eur J Appl Physiol. 2008;104(1):103-10.

19. Tanni SE, Pelegrino NR, Angeleli AY, Correa C, Godoy I. Smoking status and tumor necrosis factor-alpha mediated systemic inflammation in COPD patients. J Inflamm (Lond). 2010;7:29.

20. Levitzky YS, Guo CY, Rong J, Larson MG, Walter RE, Keaney JF, Jr., Sutherland PA, Vasan A, Lipinska I, Evans JC, et al. Relation of smoking status to a panel of inflammatory markers: the framingham offspring. Atherosclerosis. 2008;201(1):217-24.

21. Hankinson JL, Odencrantz JR, Fedan KB. Spirometric reference values from a sample of the general U.S. population. Am J Respir Crit Care Med. 1999;159(1):179-87.

22. Mehrotra N, Freire AX, Bauer DC, Harris TB, Newman AB, Kritchevsky SB, Meibohm B. Predictors of mortality in elderly subjects with obstructive airway disease: the PILE score. Ann Epidemiol. 2010;20(3):223-32.

23. Guralnik JM, Simonsick EM, Ferrucci L, Glynn RJ, Berkman LF, Blazer DG, Scher PA, Wallace RB. A short physical performance battery assessing lower extremity function: association with self-reported disability and prediction of mortality and nursing home admission. J Gerontol. 1994;49(2):M85-94.

24. Guralnik JM, Ferrucci L, Simonsick EM, Salive ME, Wallace RB. Lower-extremity function in persons over the age of 70 years as a predictor of subsequent disability. N Engl J Med. 1995;332(9):556-61.

25. Koster A, Stenholm S, Alley DE, Kim LJ, Simonsick EM, Kanaya AM, Visser M, Houston DK, Nicklas BJ, Tylavsky FA, et al. Body Fat Distribution and Inflammation Among Obese Older Adults With and Without Metabolic Syndrome. Obesity (Silver Spring). 2010;18(12):2354-61.

26. Koster A, Patel KV, Visser M, van Eijk JT, Kanaya AM, de Rekeneire N, Newman AB, Tylavsky FA, Kritchevsky SB, Harris TB. Joint effects of adiposity and physical activity on incident mobility limitation in older adults. J Am Geriatr Soc. 2008;56(4):636-43.

27. Ainsworth BE, Haskell WL, Whitt MC, Irwin ML, Swartz AM, Strath SJ, O'Brien WL, Bassett DR, Jr., Schmitz KH, Emplaincourt PO, et al. Compendium of physical activities: an update of activity codes and MET intensities. Med Sci Sports Exerc. 2000;32(9 Suppl):S498-504. 


\section{SMOKING, SARCOPENIA AND COPD}

28. Ghosh P, Tu W. Assessing Sexual Attitudes and Behaviors of Young Women: A Joint Model with Nonlinear Time Effects, Time Varying Covariates, and Dropouts. J Am Stat Assoc. 2008;103(484):1496-507.

29. Schols AM, Broekhuizen R, Weling-Scheepers CA, Wouters EF. Body composition and mortality in chronic obstructive pulmonary disease. Am J Clin Nutr. 2005;82(1):53-9.

30. Melzer D, Lan TY, Guralnik JM. The predictive validity for mortality of the index of mobility-related limitation-results from the EPESE study. Age Ageing. 2003;32(6):619-25.

31. Castillo EM, Goodman-Gruen D, Kritz-Silverstein D, Morton DJ, Wingard DL, Barrett-Connor E. Sarcopenia in elderly men and women: the Rancho Bernardo study. Am J Prev Med. 2003;25(3):226-31.

32. Langen RC, Schols AM, Kelders MC, van der Velden JL, Wouters EF, Janssen-Heininger YM. Muscle wasting and impaired muscle regeneration in a murine model of chronic pulmonary inflammation. Am J Respir Cell Mol Biol. 2006;35(6):689-96.

33. McLean RR. Proinflammatory cytokines and osteoporosis. Curr Osteoporos Rep. 2009;7(4):134-9.

34. Filozof C, Fernandez Pinilla MC, Fernandez-Cruz A. Smoking cessation and weight gain. Obes Rev. 2004;5(2):95-103.

35. Cropsey KL, McClure LA, Jackson DO, Villalobos GC, Weaver MF, Stitzer ML. The Impact of Quitting Smoking on Weight Among Women Prisoners Participating in a Smoking Cessation Intervention. Am J Public Health. 2010;100(8):1442-8.

36. Schols AM, Slangen J, Volovics L, Wouters EF. Weight loss is a reversible factor in the prognosis of chronic obstructive pulmonary disease. Am J Respir Crit Care Med. 1998;157(6 Pt 1):1791-7.

37. Lamprecht B, McBurnie MA, Vollmer WM, Gudmundsson G, Welte T, Nizankowska-Mogilnicka E, Studnicka M, Bateman E, Anto JM, Burney P, et al. COPD in Never Smokers: Results From the Population-Based Burden of Obstructive Lung Disease Study. Chest. 2011;139(4):752-63. 


\section{Supplemental material}

Supplemental Table 1. Decline in lung function in $n=1658$ participants with at least two valid lung function measurements in time (mean [SD] follow-up period of 6.2 [1.3] years including 2.6 [0.5] valid measurements per participant).

\begin{tabular}{|c|c|c|c|c|c|c|}
\hline & OLD & $\begin{array}{l}\text { Smoking } \\
\text { controls }\end{array}$ & $\begin{array}{c}\text { Formerly } \\
\text { smoking } \\
\text { controls }\end{array}$ & $\begin{array}{l}\text { Never- } \\
\text { smoking } \\
\text { controls }\end{array}$ & $P$ & $\begin{array}{c}\text { Significant } \\
\text { post-hoc } \\
\text { comparisons }^{\mathrm{a}}\end{array}$ \\
\hline & A & B & C & D & & \\
\hline \multicolumn{7}{|l|}{ Men } \\
\hline $\mathrm{n}$ & 91 & 48 & 406 & 240 & & \\
\hline $\mathrm{FEV}_{1}(\mathrm{~mL} / \mathrm{yr})$ & $-38(6)$ & $-54(7)$ & $-55(3)$ & $-57(3)$ & .039 & $\mathrm{AD}$ \\
\hline \multicolumn{7}{|l|}{ Women } \\
\hline $\mathrm{n}$ & 75 & 50 & 262 & 486 & & \\
\hline $\mathrm{FEV}_{1}(\mathrm{~mL} / \mathrm{yr})$ & $-33(5)$ & $-39(5)$ & $-40(2)$ & $-40(2)$ & .45 & - \\
\hline
\end{tabular}


Supplemental Table 2. Intercepts and slopes of body composition and physical functioning in men.

\begin{tabular}{|c|c|c|c|c|c|c|c|c|}
\hline & \multicolumn{4}{|c|}{ Model 1} & \multicolumn{4}{|c|}{ Model 2} \\
\hline & Intercept & $P$ & Slope & $P$ & Intercept & $P$ & Slope & $P$ \\
\hline \multicolumn{9}{|l|}{ Weight (kg) } \\
\hline Never-smoking controls & Ref & & Ref & & Ref & & Ref & \\
\hline Formerly smoking controls & 1.66 & .08 & 0.01 & .88 & 1.19 & .23 & 0.001 & .92 \\
\hline Smoking controls & -6.53 & $<.001$ & -0.14 & .37 & -6.34 & .001 & -0.18 & .26 \\
\hline OLD & -5.08 & $<.001$ & -0.07 & .54 & -5.31 & $<.001$ & -0.01 & .94 \\
\hline \multicolumn{9}{|l|}{ Fat mass (kg) } \\
\hline Never-smoking controls & Ref & & Ref & & Ref & & Ref & \\
\hline Formerly smoking controls & 1.34 & .011 & -0.05 & .36 & 1.12 & .040 & -0.06 & .29 \\
\hline Smoking controls & -3.11 & .001 & -0.08 & .41 & -3.05 & .003 & -0.11 & .30 \\
\hline OLD & -2.02 & .006 & -0.10 & .19 & -2.21 & .005 & -0.06 & .43 \\
\hline \multicolumn{9}{|l|}{ Lean mass (kg) } \\
\hline Never-smoking controls & Ref & & Ref & & Ref & & Ref & \\
\hline Formerly smoking controls & 0.45 & .37 & -0.01 & .88 & 0.22 & .68 & -0.00 & .91 \\
\hline Smoking controls & -3.15 & .001 & -0.01 & .86 & -3.01 & .002 & -0.03 & .69 \\
\hline OLD & -2.83 & $<.001$ & -0.07 & .20 & -2.85 & $<.001$ & -0.04 & .46 \\
\hline \multicolumn{9}{|l|}{ Leg lean mass (kg) } \\
\hline Never-smoking controls & Ref & & Ref & & Ref & & Ref & \\
\hline Formerly smoking controls & 0.02 & .92 & -0.01 & .71 & -0.04 & .82 & -0.00 & .88 \\
\hline Smoking controls & -1.27 & $<.001$ & -0.02 & .56 & -1.17 & .001 & -0.03 & .36 \\
\hline OLD & -1.30 & $<.001$ & 0.00 & .88 & -1.26 & $<.001$ & 0.01 & .59 \\
\hline \multicolumn{9}{|l|}{ Bone mineral content $(\mathrm{kg})$} \\
\hline Never-smoking controls & Ref & & Ref & & Ref & & Ref & \\
\hline Formerly smoking controls & -0.007 & .83 & 0.001 & .27 & -0.012 & .70 & 0.002 & .20 \\
\hline Smoking controls & -0.143 & .010 & -0.008 & .017 & -0.106 & .07 & -0.006 & .08 \\
\hline OLD & -0.176 & $<.001$ & 0.002 & .82 & -0.170 & $<.001$ & 0.003 & .32 \\
\hline \multicolumn{9}{|l|}{ Quadriceps strength (Nm) } \\
\hline Never-smoking controls & Ref & & Ref & & Ref & & Ref & \\
\hline Formerly smoking controls & 0.08 & .98 & -0.12 & .74 & 0.33 & .90 & -0.04 & .92 \\
\hline Smoking controls & -7.18 & .13 & -0.42 & .56 & -4.43 & .38 & -0.77 & .30 \\
\hline OLD & -14.21 & $<.001$ & 0.90 & .12 & -12.55 & .001 & 0.76 & .21 \\
\hline
\end{tabular}

Abbreviations: OLD, obstructive lung disease; Ref, reference. The intercepts denote the adjusted baseline differences with the never-smoking controls. The slopes denote the adjusted differences in yearly change with the never-smoking controls. Model 1: adjusted for time, age, site, race, diabetes, cardiovascular disease, depression, physical activity, oral steroid use, calcium supplementation, vitamin $D$ supplementation, time ${ }^{2}$, age $\times$ time, race $\times$ time, site $\times$ time, diabetes $\times$ time, cardiovascular disease $\times$ time, depression $\times$ time, physical activity $\times$ time, oral steroid use $\times$ time, calcium supplementation $\times$ time, vitamin $D$ supplementation $\times$ time. Model 2: further adjustment for IL-6, TNF- $\alpha, C R P, I L-6 \times t i m e, T N F-$ $\alpha \times$ time and CRP $\times$ time. 
CHAPTER 2

Supplemental Table 2. continued.

\begin{tabular}{|c|c|c|c|c|c|c|c|c|}
\hline & \multicolumn{4}{|c|}{ Model 1} & \multicolumn{4}{|c|}{ Model 2} \\
\hline & Intercept & $\boldsymbol{P}$ & Slope & $\boldsymbol{P}$ & Intercept & $\boldsymbol{P}$ & Slope & $\boldsymbol{P}$ \\
\hline \multicolumn{9}{|l|}{ Hand grip strength (kg) } \\
\hline Never-smoking controls & Ref & & Ref & & Ref & & Ref & \\
\hline Formerly smoking controls & 1.68 & .13 & -0.07 & .61 & 1.51 & .19 & -0.03 & .82 \\
\hline Smoking controls & -3.65 & .07 & 0.09 & .71 & -3.42 & .11 & 0.16 & .54 \\
\hline OLD & -0.57 & .71 & -0.13 & .71 & 0.01 & .99 & -0.14 & .51 \\
\hline \multicolumn{9}{|l|}{ SPPB (0-12) } \\
\hline Never-smoking controls & Ref & & Ref & & Ref & & Ref & \\
\hline Formerly smoking controls & -0.09 & .43 & -0.00 & .94 & -0.11 & .33 & 0.01 & .71 \\
\hline Smoking controls & -0.26 & .21 & -0.04 & .53 & -0.27 & .22 & -0.01 & .87 \\
\hline OLD & -0.22 & .16 & -0.12 & .01 & -0.14 & .40 & -0.14 & .01 \\
\hline
\end{tabular}

Abbreviations: OLD, obstructive lung disease; Ref, reference; SPPB, short physical performance battery. The intercepts denote the adjusted baseline differences with the never-smoking controls. The slopes denote the adjusted differences in yearly change with the never-smoking controls. Model 1: adjusted for time, age, site, race, diabetes, cardiovascular disease, depression, physical activity, oral steroid use, calcium supplementation, vitamin $D$ supplementation, time ${ }^{2}$, age $\times$ time, race $\times$ time, site $\times$ time, diabetes $\times$ time, cardiovascular disease $\times$ time, depression $\times$ time, physical activity $\times$ time, oral steroid use $\times$ time, calcium supplementation $\times$ time, vitamin $D$ supplementation $\times$ time. Model 2: further adjustment for IL-6, TNF- $\alpha, C R P, I L-6 \times$ time, TNF- $\alpha \times$ time and CRP $\times$ time. 
Supplemental Table 3. Intercepts and slopes of body composition and physical functioning in women.

\begin{tabular}{|c|c|c|c|c|c|c|c|c|}
\hline & \multicolumn{4}{|c|}{ Model 1} & \multicolumn{4}{|c|}{ Model 2} \\
\hline & Intercept & $P$ & Slope & $P$ & Intercept & $P$ & Slope & $P$ \\
\hline \multicolumn{9}{|l|}{ Weight (kg) } \\
\hline Never-smoking controls & Ref & & Ref & & Ref & & Ref & \\
\hline Formerly smoking controls & 1.29 & .17 & -0.08 & .25 & 1.55 & .11 & -0.04 & .58 \\
\hline Smoking controls & -4.93 & .003 & -0.14 & .29 & -5.56 & .001 & -0.07 & .61 \\
\hline OLD & -4.29 & .003 & -0.19 & .09 & -3.51 & .019 & -0.17 & .15 \\
\hline \multicolumn{9}{|l|}{ Fat mass (kg) } \\
\hline Never-smoking controls & Ref & & Ref & & Ref & & Ref & \\
\hline Formerly smoking controls & 0.86 & .17 & -0.00 & .99 & 0.89 & .16 & 0.03 & .51 \\
\hline Smoking controls & -3.55 & .001 & 0.03 & .72 & -4.13 & $<.001$ & 0.09 & .32 \\
\hline OLD & -2.62 & .006 & -0.04 & .57 & -2.23 & .023 & -0.02 & .81 \\
\hline \multicolumn{9}{|l|}{ Lean mass (kg) } \\
\hline Never-smoking controls & Ref & & Ref & & Ref & & Ref & \\
\hline Formerly smoking controls & 0.33 & .39 & -0.01 & .55 & 0.55 & .17 & -0.01 & .59 \\
\hline Smoking controls & -1.38 & .039 & -0.10 & .028 & -1.43 & .039 & -0.10 & .049 \\
\hline OLD & -1.72 & .003 & -0.03 & .40 & -1.34 & .030 & -0.02 & .56 \\
\hline \multicolumn{9}{|l|}{ Leg lean mass (kg) } \\
\hline Never-smoking controls & Ref & & Ref & & Ref & & Ref & \\
\hline Formerly smoking controls & 0.12 & .42 & -0.02 & .07 & 0.21 & .19 & -0.02 & .09 \\
\hline Smoking controls & -0.62 & .018 & -0.07 & .001 & -0.66 & .016 & -0.06 & .002 \\
\hline OLD & -0.71 & .002 & -0.01 & .72 & -0.58 & .017 & -0.00 & .94 \\
\hline \multicolumn{9}{|l|}{ Bone mineral content $(\mathrm{kg})$} \\
\hline Never-smoking controls & Ref & & Ref & & Ref & & Ref & \\
\hline Formerly smoking controls & 0.002 & .93 & 0.002 & .19 & 0.006 & .79 & 0.001 & .48 \\
\hline Smoking controls & -0.121 & .003 & -0.001 & .68 & -0.108 & .010 & -0.002 & .32 \\
\hline OLD & -0.093 & .008 & -0.004 & .024 & -0.083 & .027 & -0.005 & .017 \\
\hline \multicolumn{9}{|l|}{ Quadriceps strength (Nm) } \\
\hline Never-smoking controls & Ref & & Ref & & Ref & & Ref & \\
\hline Formerly smoking controls & -0.66 & 69 & 0.13 & .70 & -0.42 & .82 & 0.11 & .77 \\
\hline Smoking controls & -6.05 & .048 & 0.09 & .87 & -5.27 & .10 & -0.09 & .89 \\
\hline OLD & -7.57 & .003 & 0.12 & .82 & -6.21 & .025 & 0.06 & .92 \\
\hline
\end{tabular}

Abbreviations: OLD, obstructive lung disease; Ref, reference. The intercepts denote the adjusted baseline differences with the never-smoking controls. The slopes denote the adjusted differences in yearly change with the never-smoking controls. Model 1: adjusted for time, age, site, race, diabetes, cardiovascular disease, depression, physical activity, oral steroid use, calcium supplementation, vitamin $D$ supplementation, time ${ }^{2}$, age $\times$ time, race $\times$ time, site $\times$ time, diabetes $\times$ time, cardiovascular disease $\times$ time, depression $\times$ time, physical activity $\times$ time, oral steroid use $\times$ time, calcium supplementation $\times$ time, vitamin $D$ supplementation $\times$ time. Model 2: further adjustment for $I L-6, T N F-\alpha, C R P, I L-6 \times$ time, TNF$\alpha \times$ time and CRP $\times$ time. 
CHAPTER 2

Supplemental Table 3. continued.

\begin{tabular}{|c|c|c|c|c|c|c|c|c|}
\hline & \multicolumn{4}{|c|}{ Model 1} & \multicolumn{4}{|c|}{ Model 2} \\
\hline & Intercept & $P$ & Slope & $P$ & Intercept & $P$ & Slope & $P$ \\
\hline \multicolumn{9}{|l|}{ Hand grip strength (kg) } \\
\hline Never-smoking controls & Ref & & Ref & & Ref & & Ref & \\
\hline Formerly smoking controls & 0.77 & .29 & -0.06 & .55 & 0.42 & .58 & -0.04 & .71 \\
\hline Smoking controls & -1.53 & .24 & 0.02 & .93 & -1.35 & .31 & 0.06 & .78 \\
\hline OLD & -1.64 & .14 & 0.12 & .44 & -1.57 & .19 & 0.14 & .42 \\
\hline \multicolumn{9}{|l|}{ SPPB (0-12) } \\
\hline Never-smoking controls & Ref & & Ref & & Ref & & Ref & \\
\hline Formerly smoking controls & 0.00 & .99 & -0.02 & 61 & -0.01 & .96 & -0.04 & .29 \\
\hline Smoking controls & -0.20 & .33 & 0.03 & .61 & -0.24 & .26 & 0.03 & .65 \\
\hline OLD & -0.33 & .06 & -0.04 & .40 & -0.34 & .07 & -0.09 & .10 \\
\hline
\end{tabular}

Abbreviations: OLD, obstructive lung disease; Ref, reference; SPPB, short physical performance battery. The intercepts denote the adjusted baseline differences with the never-smoking controls. The slopes denote the adjusted differences in yearly change with the never-smoking controls. Model 1: adjusted for time, age, site, race, diabetes, cardiovascular disease, depression, physical activity, oral steroid use, calcium supplementation, vitamin $D$ supplementation, time ${ }^{2}$, age $\times$ time, race $\times$ time, site $\times$ time, diabetes $\times$ time, cardiovascular disease $\times$ time, depression $\times$ time, physical activity $\times$ time, oral steroid use $\times$ time, calcium supplementation $\times$ time, vitamin $D$ supplementation $\times$ time. Model 2: further adjustment for IL-6, TNF- $\alpha, C R P, I L-6 \times$ time, TNF- $\alpha \times$ time and CRP $\times$ time. 



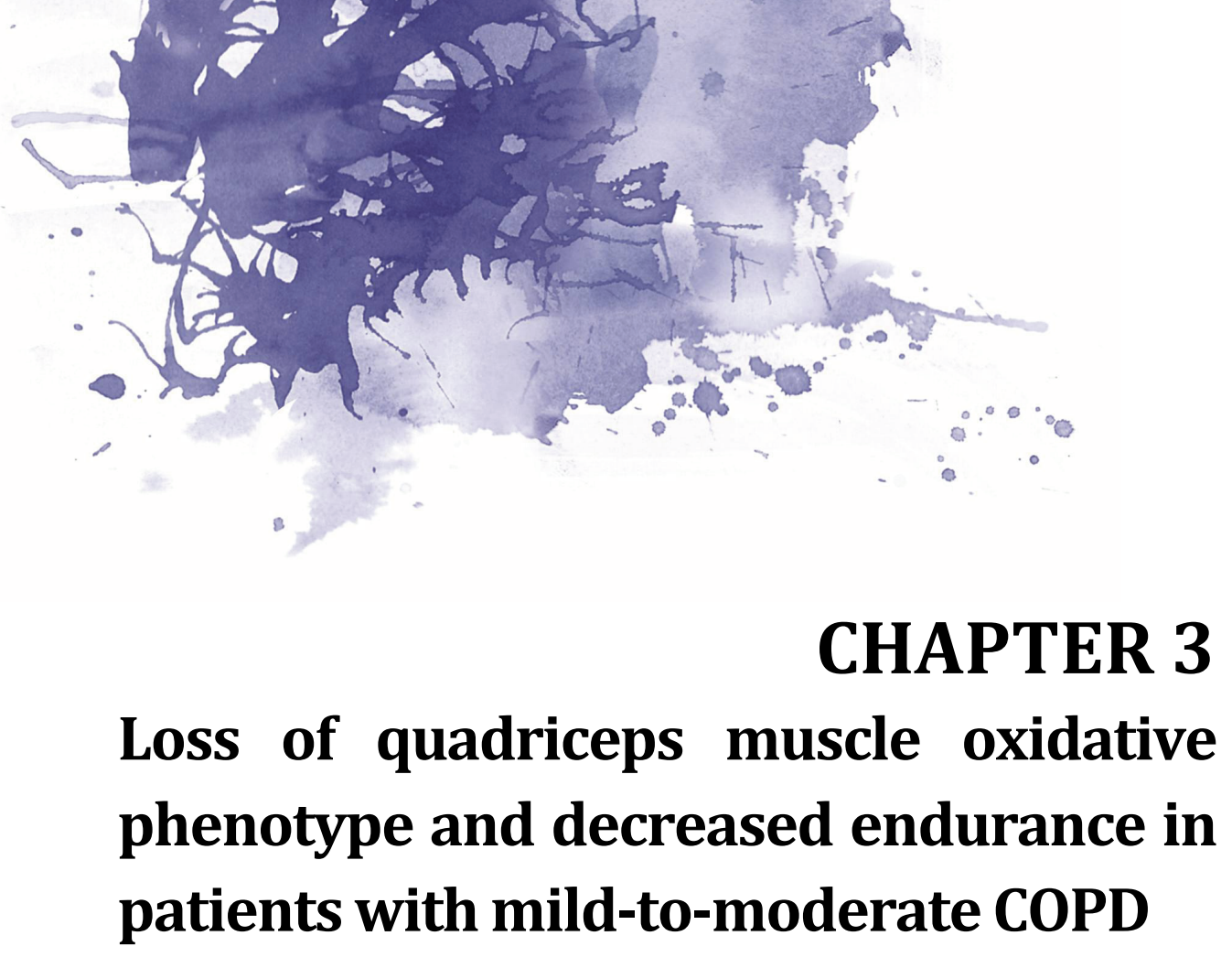

Bram van den Borst, Ilse G.M. Slot, Valéry A.C.V. Hellwig, Bettine A.H. Vosse, Marco C.J.M. Kelders, Esther Barreiro, Annemie M.W.J. Schols, Harry R. Gosker

Journal of Applied Physiology 2012 Jul 19 (Epub ahead of print) 


\section{Abstract}

Background: Being well-established in advanced chronic obstructive pulmonary disease (COPD), skeletal muscle dysfunction and its underlying pathology have been scarcely investigated in patients with mild-to-moderate airflow obstruction. We hypothesized that a loss of oxidative phenotype (oxphen), associated with decreased endurance, is already present in skeletal muscle of mild-to-moderate COPD patients.

Methods: In quadriceps muscle biopsies from $n=29$ COPD patients (forced expiratory volume in $1 \mathrm{~s}\left[\mathrm{FEV}_{1}\right] 58 \pm 16 \%$ pred, body mass index [BMI] $26 \pm 4$ $\mathrm{kg} / \mathrm{m}^{2}$ ) and $\mathrm{n}=15$ controls (BMI $25 \pm 3 \mathrm{~kg} / \mathrm{m}^{2}$ ) we assessed fiber type distribution, fiber cross-sectional areas (CSA), oxidative and glycolytic gene expression, OXPHOS protein levels, metabolic enzyme activity, and levels of oxidative stress markers. Quadriceps function was assessed by isokinetic dynamometry, body composition by dual-energy X-ray absorptiometry, exercise capacity by an incremental load test, and physical activity level by accelerometry.

Results: Compared to controls, patients had comparable fat-free mass index (FFMI), quadriceps strength and fiber CSA, but quadriceps endurance was decreased by $29 \%(P=.002)$. Patients had a clear loss of muscle oxphen: a fiber type I-to-II shift, decreased levels of OXPHOS complexes IV and V subunits (47\% and $31 \%$ respectively, $P<.05)$, a decreased ratio of 3-hydroxyacyl-CoA dehydrogenase/ phosphofructokinase (PFK) enzyme activities $(38 \%, P<.05)$, and decreased peroxisome proliferator-activated receptor- $\gamma$ coactivator- $1 \alpha(40 \%$; $P<.001)$ versus increased PFK $(67 \% ; P<.001)$ gene expression levels. Within the patients, markers of oxphen were significantly positively correlated with quadriceps endurance and inversely with the increase in plasma lactate relative to work rate during the incremental test. Levels of protein carbonylation, tyrosine nitration and malondialdehyde protein adducts were comparable between patients and controls. However, among patients oxidative stress levels significantly correlated inversely with markers of oxphen and quadriceps endurance.

Conclusion: Reduced muscle endurance associated with underlying loss of muscle oxphen is already present in patients with mild-to-moderate COPD without muscle wasting. 


\section{Introduction}

Skeletal muscle dysfunction is a hallmark of advanced chronic obstructive pulmonary disease (COPD) and significantly contributes to decreased exercise capacity and poor quality of life $[1,2]$. Peripheral skeletal muscle wasting and a loss of oxidative phenotype (oxphen) are the two major myopathological findings recognized in advanced COPD patients, being associated with decreased muscle strength [3] and endurance [4], respectively. Important to note is that studies investigating skeletal muscle dysfunction and its underlying pathology in COPD have been performed almost exclusively in patients with GOLD stages 3-4 with significant muscle wasting. In the Interdisciplinary Community-based COPD management trial, Van Wetering et al. [5] have recently shown that patients with on average mild-to-moderate COPD (mean forced expiratory volume in $1 \mathrm{~s}\left[\mathrm{FEV}_{1}\right]$ $60 \%$ of predicted) responded well to a lifestyle intervention program in terms of improvement in cycle endurance capacity and health status. Muscle strength and muscle mass of that study group were within the normal range, but no information was available regarding peripheral muscle endurance and markers of skeletal muscle oxphen.

Loss of peripheral muscle oxphen in advanced COPD includes a fiber type Ito-II shift and reduced activities of enzymes involved in oxidative energy metabolism [4, 6, 7]. In addition, Remels et al. [8] previously showed that key oxphen regulators (peroxisome proliferator-activated receptors [PPARs], PPAR$\gamma$ coactivator- $1 \alpha$ [PGC- $1 \alpha]$, mitochondrial transcription factor A [TFAM]) were reduced in muscles of patients with advanced COPD. Moreover, loss of muscle oxphen may render the muscle more susceptible to oxidative stress [9-11]. Oxidative stress is thought to be an important player in skeletal muscle wasting and dysfunction in COPD $[12,13]$. However, data on muscle oxphen and oxidative stress in COPD patients with milder degrees of airflow obstruction are scarce.

In the current study we compared markers of oxphen measured in quadriceps muscle biopsies from patients with on average mild-to-moderate COPD and age-, sex-, and body mass index (BMI)-matched healthy controls. In addition, we explored associations between muscle metabolic profile and quadriceps function, exercise capacity, physical activity level and skeletal muscle oxidative stress. We hypothesized that a loss of oxphen, associated with decreased endurance, is already present in skeletal muscle of mild-to-moderate COPD patients. 


\section{Methods}

\section{$\underline{\text { Subjects and study design }}$}

The study population comprised $n=29$ clinically stable mild-to-moderate COPD patients and $n=15$ healthy controls. Patients were recruited from the outpatient clinic of the Maastricht University Medical Center+ (MUMC+, Maastricht, The Netherlands) and via advertisements in local newspapers. Patients were excluded in case of long-term oxygen therapy, oral prednisolone use, acute exacerbation with hospital admission in the past eight weeks and rehabilitation in the past six months. Patients with known co-morbidity potentially interfering with study outcome parameters were carefully excluded. These included diabetes, recent cardiovascular events, inflammatory bowel disease, obstructive sleep apnea, thyroid disease, and cancer. Healthy controls were recruited via advertising in local newspapers. The absence of these diseases in the healthy subjects was verified through history-taking by a physician, and pulmonary function tests verified absence of airflow limitation in these subjects. Care was taken to select a group of healthy controls with similar age, BMI and sex distribution as the COPD patients, regardless of their daily physical activity level. Written informed consent was obtained from all subjects and the ethical review board of the MUMC+ approved the study (08-2-059). The trial was registered at www.trialregister.nl as NTR1402.

On day 1 , body composition and quadriceps function were assessed as described below, and subjects started wearing an accelerometer for 6 days in order to objectively quantify physical activity level. On day 7, the accelerometry data was retrieved, quadriceps tissue samples were obtained, pulmonary function was assessed, and an incremental load test was performed.

\section{Pulmonary function, smoking status and exercise capacity}

Pulmonary function testing included forced spirometry and single breath diffusion capacity measurement (Masterlab, Jaeger, Würzburg, Germany). Instruments were calibrated twice a day. All values obtained were expressed as a percentage of reference values [14]. Smoking status was based on self-report and those who had smoked or were current smokers were designated as eversmokers. All subjects performed an incremental load cycling test to determine peak oxygen uptake $\left(\mathrm{VO}_{2}\right.$ peak) and peak load (W peak) as previously described [15]. Arterial punctures of the radial artery at rest and at $\mathrm{VO}_{2}$ peak were available from $n=19$ COPD patients and $n=11$ healthy subjects. Arterial blood gas analyses and lactate concentrations were determined (Blood gas analyzer 865, Chiron Diagnostics, Emeryville, CA). 
Anthropometry and body composition

Height in meters and weight in kilograms were assessed on a standard scale. BMI was calculated as weight/height ${ }^{2}$. Whole-body dual-energy X-ray absorptiometry was performed to assess body composition as described [16]. Fat-free mass index (FFMI) was calculated as fat-free mass/height ${ }^{2}$. The prevalence of muscle depletion was explored by applying the criteria from Schols et al. [17] (FFMI<16 $\mathrm{kg} / \mathrm{m}^{2}$ for men and FFMI $<15 \mathrm{~kg} / \mathrm{m}^{2}$ for women).

\section{Quadriceps endurance and strength}

Isokinetic muscle endurance and strength of the dominant knee extensor (quadriceps muscle) were measured using a dynamometer (Biodex System, Biodex Corporation, Shirley, New York, USA). Subjects were seated upright on the chair of the dynamometer with support of the back. At the level of the chest, pelvis and thigh, subjects were secured with straps. The hip joint was at an angle between $90-100^{\circ}$ of flexion during testing. The test consisted of thirty sequential volitional maximal contractions at an angular velocity of $90^{\circ} / \mathrm{s}$, during which the subject was strongly encouraged. Maximal isokinetic strength was defined as the highest peak torque (in $\mathrm{N} \cdot \mathrm{m}$ ) in this series of thirty. To determine isokinetic quadriceps endurance, the proportional decline in peak torques (relative to the highest peak torque) per repetition $(\% \mathrm{~N} \cdot \mathrm{m} / \mathrm{rep})$ was used as determined by linear regression, as described previously [18]. We used this slope as a measure of quadriceps endurance (i.e., a slope closer to zero indicates a better endurance). Valid quadriceps endurance measures were available for $n=24$ COPD patients and $n=13$ healthy controls.

\section{Daily physical activity}

Physical activity (PA) was measured using a dual-axis GT1M accelerometer (ActiGraph $^{\text {TM }}$, LLC, Fort Walton Beach, FL, USA) for six consecutive days (4 week days and 2 weekend days). Subjects were instructed to wear the accelerometer during the time they were not asleep, except when showering or bathing [19]. The accelerometer was firmly attached to an elastic belt worn at the waist. The accelerometer registers PA in 'counts', which are the summation of the accelerations measured during a specified time interval (epoch), which was set at one minute. Counts represent the intensity of activity in that epoch. Non-wear time was defined as 60 consecutive counts of 0 , in which up to two epochs $<100$ counts were allowed [20]. Only days with $\geq 10$ hours of wear time were accepted as valid days [20]. The total amount of PA was expressed as the total counts divided by the total wear time (counts/min). Cut-off points for sedentary, lifestyle and combined moderate-to-vigorous PA (MVPA) intensity levels were defined as $<100,100-759, \geq 760$ counts/min, respectively [20, 21]. The time 
spent in each category of intensity was presented as a percentage of total wear time. Furthermore, we analyzed the number, duration and intensity of MVPA bouts ( $\geq 10$ consecutive minutes spent in MVPA) [22]. The classification of MVPA bouts was motivated by the PA recommendations of the Centers for Disease Control and Prevention and the American College of Sports Medicine [23] and the British Association of Sport and Exercise Sciences [24], which call for MVPA to be accumulated in bouts of $\geq 10 \mathrm{~min}$ to achieve health benefits. Moreover, these recommendations call for at least $150 \mathrm{~min} /$ week of bouted MVPA. We investigated whether the participants in our study complied with these recommendations, accounting for the number of valid accelerometry days.

\section{$\underline{\text { Skeletal muscle biopsy }}$}

Biopsies of the quadriceps muscle (vastus lateralis) from the dominant leg were obtained using the needle biopsy technique [25]. Muscle tissue was frozen in melting isopentane precooled in liquid nitrogen and stored at $-80^{\circ} \mathrm{C}$ for histological purposes. Another specimen was snap-frozen in liquid nitrogen and stored at $-80^{\circ} \mathrm{C}$ for gene and protein expression analyses and for enzyme activity assays.

\section{Fiber size and composition analysis}

$5 \mu \mathrm{m}$ serial cryosections with fibers in transverse orientation were cut from OCT-embedded muscle biopsies on a cryostat microtome (Leica CM 1900, Meyer Instruments, USA) at $-20^{\circ} \mathrm{C}$ and mounted on SuperFrost microscope slides (Menzel-Gläser, Braunschweig, Germany) to be stored at $-80^{\circ} \mathrm{C}$ until further analyses. For immunohistochemistry, sections were incubated with primary anti-myosin heavy chain (MyHC) I (Developmental Studies Hybridoma Bank [DSHB], University of Iowa, USA), anti-MyHC IIa (DSHB, University of Iowa, USA) and anti-laminin (Sigma, Zwijndrecht, the Netherlands) followed by secondary antibodies labeled with Alexa Fluor 555, Alexa Fluor 488 and Alexa Fluor 350 (Invitrogen, Breda, the Netherlands). Fiber typing was aided by means of myosin ATPase-activity staining with acidic pre-incubation at $\mathrm{pH} 4.40$ [26]. Immunofluorescence-stained and ATPase-stained sections were microscopically photographed at $10 \times$ magnification. In a blinded fashion, fibers were classified primarily based on immunofluorescence, with ATPase-stained sections used to confirm type I/IIa and type IIa/IIx hybrid fiber types. Fiber cross-sectional area was measured with Lucia 4.82 software (Laboratory Imaging, Czech Republic) based on laminin staining of the basement membrane [27]. 


\section{$\underline{\text { RNA extraction and RT-qPCR analysis }}$}

10-30 mg muscle tissue was homogenized in Denaturation Solution (ToTALLY RNA $^{\text {TM }}$ Kit; Ambion Ltd., Foster City, CA, USA) using a Polytron PT 1600 E (Kinematica AG, Littau/Luzern, Germany) and RNA extracted according to the supplier's protocol, followed by genomic DNA removal and clean-up with the RNeasy Mini Kit with RNase-free DNase (Qiagen, Venlo, The Netherlands). After elution, RNA concentration was determined using a spectrophotometer (NanoDrop ND-1000, Isogen Lifescience, IJsselstein, The Netherlands) and integrity verified for a selection of samples by gel electrophoresis and on a Bioanalyzer (Agilent Technologies, Amstelveen, The Netherlands). 400 ng RNA was reverse transcribed to cDNA with anchored oligo(dT) primers according to the supplier's protocol (Transcriptor First Strand cDNA Synthesis kit, Roche Diagnostics, Woerden, The Netherlands). RT-qPCR primers were designed based on Ensembl transcript sequences or selected from literature [28, 29] and ordered from Sigma Genosys (Zwijndrecht, the Netherlands). The genes encoding PGC- $1 \alpha$, PGC-1 $\beta$, PGC related coactivator (PRC), PPAR- $\alpha$, Tfam, Nuclear Respiratory Factor (NRF)-1, NRF-2 $\alpha$, Myosin Heavy Chain (MHC) I, muscle phosphofructokinase (PFKM), MHCIIa and MYHCIIx were the target genes. RTqPCR reactions contained SensiMix SYBR Hi-ROX Kit (Quantace-Bioline, London, UK) with $300 \mathrm{nM}$ primers and were run in 384-well MicroAmp Optical 384-Well Reaction Plate (Applied Biosystems, Nieuwerkerk a/d IJssel, The Netherlands) on a 7900HT Fast Real-Time PCR System (Applied Biosystems). Standard curves, prepared from pooled cDNA, and melt curves were analyzed to verify efficiency and specificity of amplification. Twelve reference genes (ALAS1, ACTB, B2M, PPIA, GAPDH, GUSB, HMBS, HPRT1, RPL13A, RPLPO, UBC, YWHAZ) were measured and stability of expression was assessed by visual inspection of expression differences between the study groups and a stability assessment by geNorm [29]. Eventually, nine reference genes (all except $A C T B, G A P D H$ and $U B C$ ) were used to calculate a geNorm factor, which was used to normalize expression levels of the target genes.

\section{Immunoblotting of OXPHOS subunits and oxidative stress markers}

10-20 mg tissue was crushed in liquid nitrogen and homogenized in $400 \mu \mathrm{IP}$ lysis buffer (50 mM Tris, $150 \mathrm{mM} \mathrm{NaCl}, 10 \%$ glycerol, $0.5 \%$ Nonidet P40, $1 \mathrm{mM}$ EDTA, $1 \mathrm{mM} \mathrm{Na}_{3} \mathrm{VO}_{4}, 5 \mathrm{mM} \mathrm{NaF}, 10 \mathrm{mM} \beta$-glycerophosphate, $1 \mathrm{mM} \mathrm{Na} \mathrm{O}_{7} \mathrm{P}_{2}, 1$ $\mathrm{mM}$ dithiothreitol, $10 \mu \mathrm{g} / \mathrm{ml}$ leupeptin, $1 \%$ aprotenin, $1 \mathrm{mM}$ PMSF, pH 7.4) with a Polytron PT 1600 E (Kinematica). After homogenization, samples were incubated for 15 minutes on a rotating wheel at $4^{\circ} \mathrm{C}$ and spun for 30 minutes at maximum speed $(20817 \times g)$ in a centrifuge cooled to $4^{\circ} \mathrm{C}$. Supernatant was aliquoted, snap-frozen and stored without sample buffer at $-80^{\circ} \mathrm{C}$ until analysis. 
Protein concentration in lysates was determined using the bicinchoninic acid assay (Pierce, Thermo Fisher Scientific, Breda, The Netherlands). For western blot analysis, aliquots were supplemented with $4 \times$ sample buffer $(250 \mathrm{mM}$ Tris$\mathrm{HCl} \mathrm{pH} \mathrm{6.8,8 \% (w/v)} \mathrm{sodium} \mathrm{dodecyl} \mathrm{sulfate,} \mathrm{40 \%} \mathrm{(v/v)} \mathrm{glycerol,} 0.4 \mathrm{M}$ dithiothreitol, $0.02 \%(\mathrm{w} / \mathrm{v}$ ) bromophenol blue) and kept on ice. Per sample, $5 \mu \mathrm{g}$ unboiled protein was separated on gel (4-12\% Bis-Tris XT gel, Criterion, BioRad) with XT MOPS running buffer (Bio-Rad). One sample was loaded on all gels to facilitate gel-gel comparisons. Proteins were transferred to a $0.45 \mu \mathrm{m}$ nitrocellulose membrane (Protran, Schleicher and Schuell, 's-Hertogenbosch, The Netherlands) in transfer buffer (25 mM Tris, $192 \mathrm{mM}$ glycine, 20\% (v/v) methanol) by electrophoresis. After transfer, membranes were blocked from nonspecific protein binding with blocking solution, which contains $5 \%(\mathrm{w} / \mathrm{v})$ non-fat dry milk (Campina, Eindhoven, The Netherlands) in Tris-buffered saline with Tween20 (TBST; $25 \mathrm{mM}$ Tris, $137 \mathrm{mM} \mathrm{NaCl}, 2.7 \mathrm{mM} \mathrm{KCl}, 0.05 \%$ (v/v) Tween20, pH 7.4), for one hour at room temperature, followed by incubation in primary antibody solution overnight at $4{ }^{\circ} \mathrm{C}$ (mouse anti-Total OXPHOS Rodent WB Antibody Cocktail (MS604-300, Abcam, Cambridge, UK) diluted 1:1000 in blocking solution or rabbit anti-GAPDH (\#2118, Cell Signaling Technology, Leiden, The Netherlands) diluted 1:5000 in TBST). Membranes were incubated in secondary antibody solution (peroxidase-labeled horse anti-mouse IgG or goat anti-rabbit IgG (PI-2000 and PI-1000, respectively; Vector Laboratories, Burlingame, CA, USA) diluted 1:5000 in blocking solution) for one hour at room temperature before incubation with enhanced chemiluminescence substrate (Pierce SuperSignal West PICO Chemiluminescent Substrate; Thermo Fisher Scientific). Protein bands were detected using Super RX films (Fujifilm, Düsseldorf, Germany) and scanned on a GS-800 densitometer (Bio-Rad). Bands were quantified using Quantity One software (v4.6.2, Bio-Rad), with GAPDH as loading control (GAPDH levels were not different between COPD patients and controls).

Protein content of oxidative stress markers were identified using specific primary antibodies for protein carbonylation (anti-2,4-dinitrophenylhydrazone [DNP] moiety antibody, Oxyblot kit, Chemicon International Inc., Temecula, CA), total protein nitration (anti-3-nitrotyrosine antibody, Invitrogen, Eugene, Oregon), and total malondialdehyde (MDA)-protein adducts (anti-MDA antibody, AcademyBio- Medical Company, Inc. Houston). For protein carbonylation, carbonyl groups in the protein side chains were first derivatized to 2,4-DNP using the Oxyblot kit (Chemicon International Inc., Temecula, CA, USA) according to the manufacturer's instructions. Briefly, $15 \mu \mathrm{g}$ of protein were used per derivatization reaction. Proteins were then denatured by addition of $12 \%$ SDS. The samples were subsequently derivatized by adding $10 \mu \mathrm{l}$ of $1 \mathrm{X}$ 2,4-DNP solution and incubated for 20 minutes. Finally, $7.5 \mu \mathrm{l}$ of neutralization solution and 2-mercaptoethanol were added to the sample mixture. Immunoblotting was similar as described above with some minor differences: polyvinylidene 
difluoride (PVDF) membranes were used, which were scanned with the Molecular Imager Chemidoc XRS System (Bio-Rad Laboratories, Hercules, CA, USA) and bands were quantified using the software Image Lab version 2.0.1 (BioRad Laboratories). Values of total reactive carbonyl groups, total protein tyrosine nitration, and total MDA-protein adducts in a given sample were calculated by addition of optical densities (arbitrary units) of individual protein bands in each case. Final optical densities obtained in each specific group of subjects corresponded to the mean values of the different samples (lanes) of each of the antigens studied. Actin (anti-alpha-sarcomeric actin antibody, clone 5C5, Sigma-Aldrich, St. Louis, MO, USA) was used as the loading control for all the oxidative stress markers $[12,30]$.

\section{Enzyme activity assays}

15-30 mg tissue was crushed in liquid nitrogen and homogenized in $350 \mu$ l SET buffer (250 mM sucrose, $2 \mathrm{mM}$ EDTA, $10 \mathrm{mM}$ Tris, pH 7.4) with a Polytron PT $1600 \mathrm{E}$ (Kinematica). After homogenization, samples were incubated for 10 minutes on a rotating wheel at $4^{\circ} \mathrm{C}$ and spun for 5 minutes at maximum speed $(20817 \times g)$ in a centrifuge cooled to $4^{\circ} \mathrm{C}$. An aliquot of supernatant was stored for protein determination. To the remaining supernatant, $5 \times$ aqueous BSA solution was added to a final BSA concentration of $1 \%(\mathrm{v} / \mathrm{v})$ and samples were aliquoted, snap-frozen and stored at $-80^{\circ} \mathrm{C}$ until analysis. Protein concentration in SET lysate aliquots without BSA was determined using the bicinchoninic acid assay (Pierce). Citrate synthase (CS, EC 2.3.3.1), 3-hydroxyacyl-CoA dehydrogenase (HADH, EC 1.1.1.35) and phosphofructokinase (PFK, EC 2.7.1.11) activities were assayed spectrophotometrically (Multiskan Spectrum; Thermo Labsystems, Breda, The Netherlands) as previously described [31-33]. Absolute CS, HADH and PFK activities were normalized to total protein.

\section{Statistical analysis}

Differences between COPD patients and controls were tested using Student's $t$ test, Mann-Whitney-U tests or $\chi^{2}$ tests as appropriate. Correlations were tested using Pearson's correlation coefficient or Spearman's $\rho$ in case of non-normally distributed data. Analyses were performed using PASW Statistics 17.0 (SPSS inc. Chicago, IL, USA). A $P$-value $<.05$ was declared to be statistically significant.

\section{Results}

The control subjects were matched to the COPD patients based on age, sex and BMI (Table 1). $\mathrm{FEV}_{1}$ was between $30-50 \%$ of predicted in $\mathrm{n}=13$ patients $(45 \%)$, between $50-70 \%$ of predicted in $n=11$ patients $(38 \%)$ and $>70 \%$ of predicted in $\mathrm{n}=5$ patients $(17 \%) . \mathrm{VO}_{2}$ peak and $\mathrm{W}$ peak were significantly decreased in the 
COPD patients (Table 1 ). $\mathrm{FEV}_{1}$ (\% of predicted) was strongly correlated with $\mathrm{VO}_{2}$ peak ( $\%$ of predicted) in the total population $(\mathrm{r}=0.83, P<.001)$, within the COPD patients $(\mathrm{r}=0.78, P<.001)$, and within the controls $(\mathrm{r}=0.53, P=.044)$.

Table 1. Main characteristics of healthy controls and COPD patients.

\begin{tabular}{|c|c|c|}
\hline & Controls $(n=15)$ & COPD $(n=29)$ \\
\hline \multicolumn{3}{|l|}{ Demographics } \\
\hline Age, $y$ & $65(6)$ & $65(6)$ \\
\hline Sex, \%men & 60 & 55 \\
\hline Ever smoker, \% & 53 & $100^{\mathrm{a}}$ \\
\hline BMI, kg/m² & $24.9(3.3)$ & $25.5(3.6)$ \\
\hline \multicolumn{3}{|l|}{ Pulmonary function } \\
\hline $\mathrm{FEV}_{1}, \%$ pred & $113(15)$ & $58(16)^{\mathrm{a}}$ \\
\hline FVC, \%pred & $120(17)$ & $104(22)^{b}$ \\
\hline $\mathrm{FEV}_{1} / \mathrm{FVC}, \%$ & $74(5)$ & $45(11)^{\mathrm{a}}$ \\
\hline DLCO, \%pred & 95 (19) & $53(18)^{\mathrm{a}}$ \\
\hline \multicolumn{3}{|l|}{ Incremental load test } \\
\hline Peak $\mathrm{VO}_{2}, \%$ pred & $123(8)$ & $72(4)^{\mathrm{a}}$ \\
\hline Peak WR, \%pred & $133(7)$ & $61(4)^{\mathrm{a}}$ \\
\hline$\Delta$ Borg dyspnea score & $3.4(0.8)$ & $3.6(0.4)$ \\
\hline$\Delta$ Borg leg fatigue score & $2.7(0.6)$ & $2.3(0.4)$ \\
\hline$\Delta \mathrm{PaO}_{2}, \mathrm{kPa}$ & $1.04(0.53)$ & $-0.38(0.31)^{b}$ \\
\hline$\Delta$ Lactate $/ \mathrm{WR}(\mathrm{mmol} / \mathrm{L} / \mathrm{W})$ & $0.039(0.003)$ & $0.035(0.003)$ \\
\hline
\end{tabular}

Abbreviations: BMI, body mass index; DLCO, diffusion capacity of the lungs for carbon monoxide; FEV forced expiratory volume in $1 s ; F V C$, forced vital capacity; WR, work rate. ${ }^{a} P<.001,{ }^{b} P<.05$.

Quadriceps muscle endurance and markers of oxidative phenotype

Quadriceps muscle endurance was significantly lower in the COPD patients (Figure 1A). The mean decline in peak torque per repetition was $-1.67 \pm 0.09$ $\% \mathrm{~N} \cdot \mathrm{m} / \mathrm{rep}$ in the COPD patients versus $-1.18 \pm 0.10 \% \mathrm{~N} \cdot \mathrm{m} / \mathrm{rep}$ in the controls $(P=.002)$. Patients had a lower proportion of type I fibers and a higher proportion of type IIa, type IIa/IIx and IIx fibers compared to controls, indicative of a fiber type I-to-II shift (Figures 1B-D, and Figure 2). The mean mRNA expression levels of the key regulator of oxidative metabolism PGC- $1 \alpha$ and of the structural marker of oxidative fibers MyHCI were significantly decreased in the COPD patients compared to controls, and reached borderline significance for Tfam (Figure 1E). Other (co-) transcription factors implicated in 
Figure 1. Quadriceps muscle endurance, fiber type distribution, gene expression, OXPHOS protein expression and enzyme activity.

A

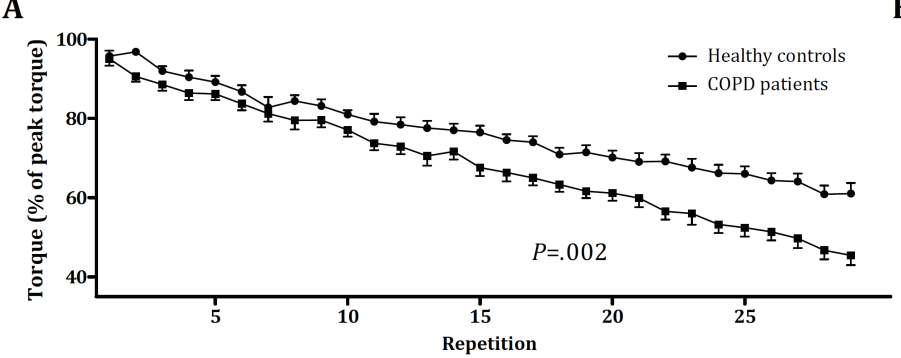

C

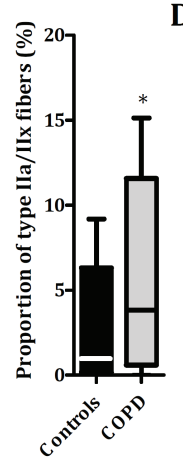

$\mathbf{F}$

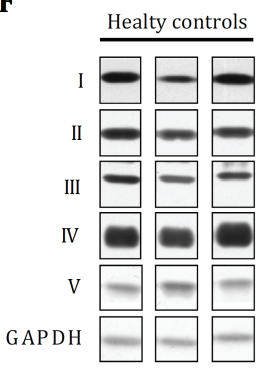

H

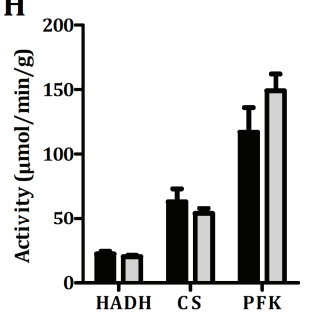

E

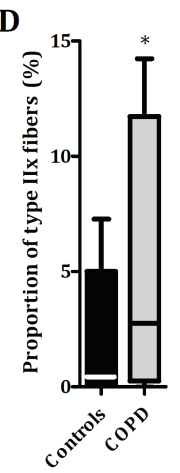

COPD patients

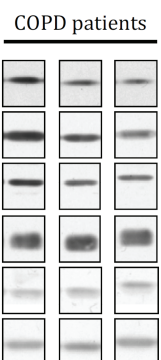

G

I

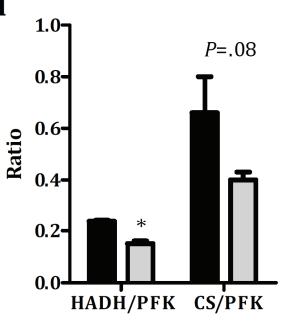

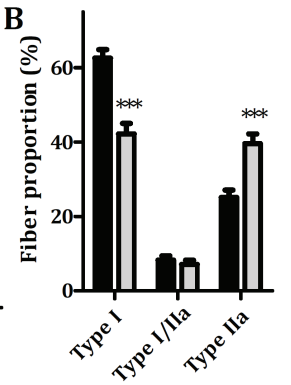
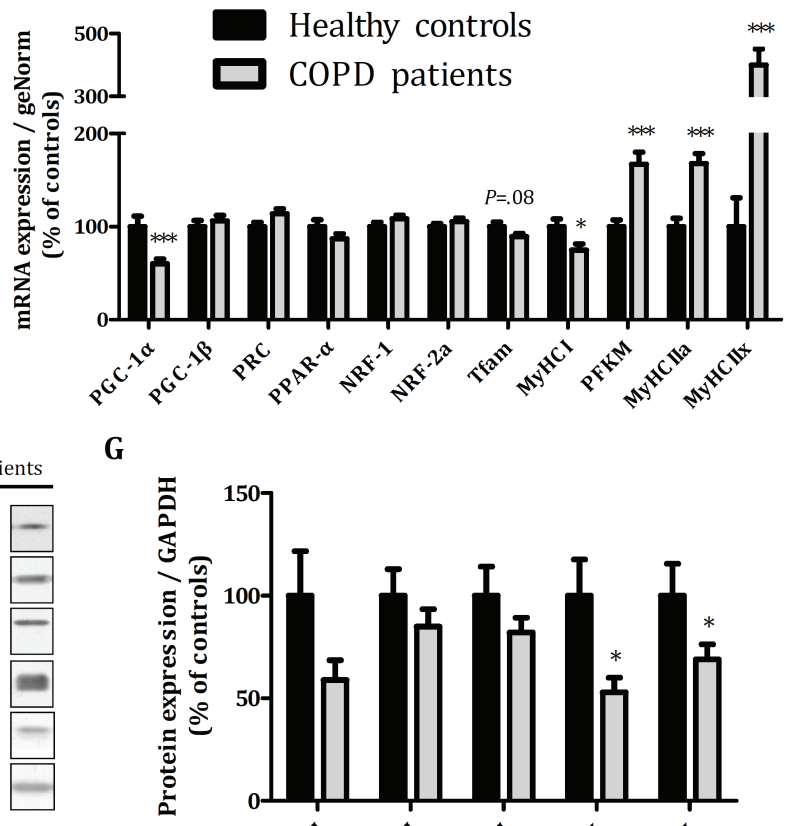

A) Quadriceps endurance as assessed by isokinetic dynamometry. The P value denotes the statistical significance of the difference in slopes between COPD patients and healthy controls. B) Quadriceps muscle fiber type distribution as determined by fluorescent immunohistochemistry and ATPase staining. C) Boxplot of fiber type IIa/IIx proportion. Boxes represent $25^{\text {th }}$ and $75^{\text {th }}$ percentiles, and whiskers represent $10^{\text {th }}$ and $90^{\text {th }}$ percentiles. D) Boxplot of fiber type IIx proportion. Boxes represent $25^{\text {th }}$ and $75^{\text {th }}$ percentiles, and whiskers represent $10^{\text {th }}$ and $90^{\text {th }}$ percentiles. E) Quadriceps muscle $m R N A$ expression of peroxisome proliferator-activated receptor (PPAR)- $\gamma$ coactivator-1 $\alpha(P G C-1 \alpha)$, myosin heavy chain 
(MyHC) I, IIa and IIx, mitochondrial transcription factor (Tfam), PPAR- $\alpha, P G C-1 \beta$, nuclear respiratory factor (NRF)-1, NRF-2 $\alpha, P G C$ related coactivator (PRC), and phosphofructokinase muscle (PFKM) as determined by RT-qPCR. F) Representative Western Blot of the five OXPHOS protein subunits and GAPDH from three healthy controls and three COPD patients. All bands are from the same blot and were reorganized for illustrative purposes as patients and controls were randomized over the blot and to respect the ascending order of the five subunits. G) Levels of the five OXPHOS protein subunits as determined by Western Blot. H) 3-hydroxyacyl-CoA dehydrogenase (HADH), citrate synthase (CS) and phosphofructokinase (PFK) enzyme activities. I) Ratios between $H A D H / P F K$ and $C S / P F K .{ }^{*} P<.05$. ${ }^{* *} P<.01$. ${ }^{* * *} P<.001$.

driving oxidative gene expression (PPAR- $\alpha$, PGC-1 $\beta$, PRC, NRF-1, NRF-2 $\alpha$ ) were not differentially expressed between patients and controls. Gene expression levels of the key glycolytic enzyme PFKM and of the structural markers of glycolytic fibers, i.e. MyHCIIa and MyHCIIx, were significantly higher in the COPD patients (Figure 1F). Congruently, mean OXPHOS subunit protein levels were all lower in the COPD patients compared to controls, reaching statistical significance for those of complexes IV and V (Figures 1F-G). The mean differences in HADH, CS and PFK enzyme activity were not statistically significant (Figure $1 \mathrm{H}$ ), yet the ratio $\mathrm{HADH} / \mathrm{PFK}$ was significantly lower in the COPD patients. The ratio CS/PFK reached borderline significance (Figure 1I).

Figure 2. Peripheral muscle fiber type I-to-II shift, as an example of loss of oxidative phenotype in COPD.

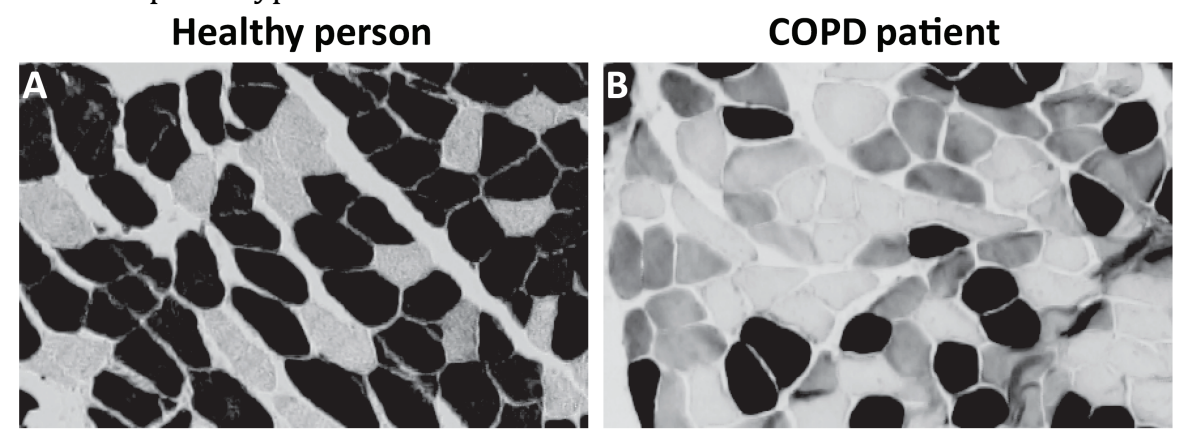

Representative myosin heavy chain ATPase stainings of quadriceps muscle biopsies from a healthy person (A) and a COPD patient (FEV $167 \%$ of predicted) (B) matched for age, sex and body mass index $\left(25 \mathrm{~kg} / \mathrm{m}^{2}\right)$. Black fibers indicate type I fibers and dark and light grey fibers correspond with type IIX and type IIA fibers, respectively.

\section{Quadriceps strength, muscle mass and fiber cross-sectional area}

FFMI nor quadriceps peak torque were significantly different between the COPD patients and the controls (Figures 3A-B). In line, the prevalence of muscle wasting was not different between the COPD patients and the controls $(20.7 \%$ versus $13.3 \%$, respectively, $P=.70$ ). Congruently, there were no differences in muscle fiber CSA (Figure 3C). 
Figure 3. Fat-free mass index, quadriceps strength and fiber cross-sectional area.
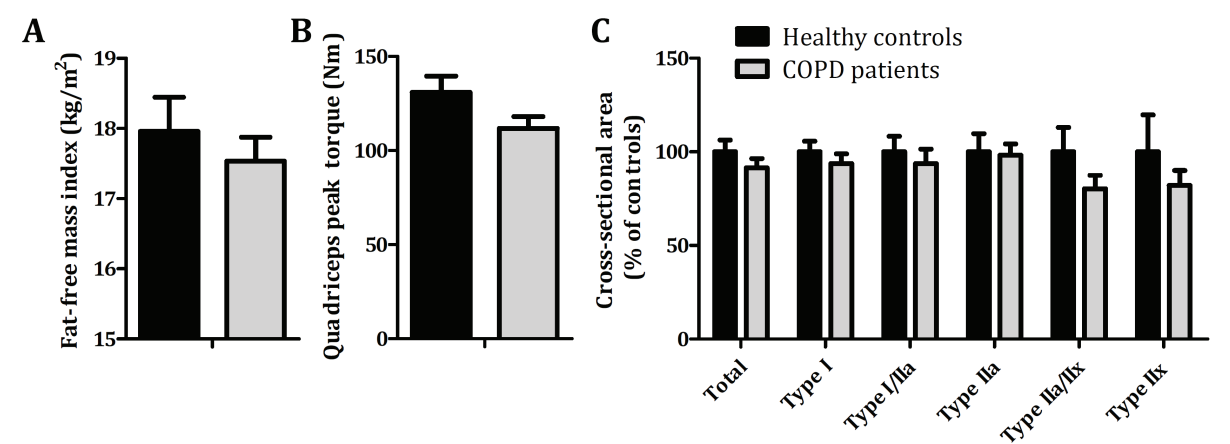

A) Fat-free mass index as determined by whole-body dual-energy X-ray absorptiometry, P>.05. B) Quadriceps peak torque as determined by isokinetic dynamometry, P>.05. C) Quadriceps muscle fiber cross-sectional areas presented for total fibers and per fiber type, all $P>.05$.

\section{Daily living physical activity level}

From all the subjects, $5.5 \pm 0.9$ valid accelerometry days were available with a mean of $14 \pm 1$ hours of wear time per day. Total PA was significantly lower in COPD patients compared with controls, and patients spent more time in sedentary behavior and less time in MVPA (Table 2). Also, patients had fewer MVPA bouts, which were shorter and less intense compared with the MVPA bouts of controls (Table 2). Total PA (counts/min) was positively correlated with $\mathrm{FEV}_{1}$ (\% of predicted) in the entire study population $(\mathrm{r}=0.58, P<.001)$ and also within the COPD patients $(\mathrm{r}=0.55, P=.002)$ but not in the controls $(\mathrm{r}=-0.06$, $P=$.82). Within the COPD patients, $\mathrm{FEV}_{1}(\%$ of predicted) was negatively correlated with time spent in sedentary PA ( $\mathrm{r}=-0.54, P=.002)$ and positively with time spent in MVPA $(\mathrm{r}=0.61, P<.001)$, number of MVPA bouts per day $(\mathrm{r}=0.46$, $P=.013)$, and with time spent in MVPA bouts ( $\mathrm{r}=0.41, P=.039)$. Only $31 \%$ of the patients fulfilled the criteria of $150 \mathrm{~min} / \mathrm{wk}$ of bouted MVPA time versus $80 \%$ of the controls $(P=.004)$. Within the patients, those who fulfilled these criteria had a significantly higher $\mathrm{FEV}_{1}$ compared to the patients who did not $(67 \pm 5$ versus $54 \pm 3 \%$ of predicted, $P=.049$ ).

\section{Associations with quadriceps oxphen in COPD patients}

In the COPD patients, quadriceps endurance was significantly positively correlated with myosin heavy chain I gene expression and PGC- $1 \alpha$ gene expression, and showed a trend towards a positive correlation with type I fiber proportion (Figures 4A-C). In line, type IIx fiber proportion was negatively correlated with quadriceps endurance $(\rho=-0.43, P=.038)$. Moreover, type I fiber 
Table 2. Accelerometry data from COPD patients and controls.

\begin{tabular}{lcc}
\hline & Controls (n=15) & COPD (n=29) \\
\hline Total activity, counts/min & $360(134)$ & $220(101)^{\mathrm{a}}$ \\
Time spent in sedentary PA, \% of wear time & $60.5(6.6)$ & $67.4(9.4)^{\mathrm{b}}$ \\
Time spent in lifestyle PA, \% of wear time & $25.5(4.6)$ & $24.3(6.5)$ \\
Time spent in MVPA, \% of wear time & $13.8(5.3)$ & $8.6(5.3)^{\mathrm{b}}$ \\
Total number of MVPA bouts $^{\mathrm{d}}$ & $12(8-18)$ & $5(3-11)^{\mathrm{b}}$ \\
Number of MVPA bouts per day $^{\mathrm{d}}$ & $2.0(1.3-2.0)$ & $1.0(0.6-2.2)^{\mathrm{c}}$ \\
Time spent in MVPA bouts, min $^{\mathrm{d}}$ & $267(108-494)$ & $68(38-204)^{\mathrm{b}}$ \\
Mean MVPA bout duration, min $^{\mathrm{b}}$ & $22.1(9.4)$ & $14.7(3.7)^{\mathrm{b}}$ \\
Mean intensity of MVPA bouts, counts $^{\mathrm{e}}$ & $2700(605)$ & $1913(498)^{\mathrm{a}}$ \\
Compliance with MVPA recommendation, \% $^{\mathrm{f}}$ & 80 & $3^{\mathrm{b}}$ \\
\hline
\end{tabular}

Abbreviations: MVPA, moderate-to-vigorous physical activity; $P A$, physical activity. ${ }^{a} P<.001 .{ }^{b} P<.01$. ${ }^{c} P<.05$. ${ }^{d}$ Median (IQR). ${ }^{e}$ Weighted for individual MVPA bout duration. ${ }^{\text {fAt }}$ least $150 \mathrm{~min} / \mathrm{wk}$ of bouted MVPA time.

proportion was negatively correlated with the increase in lactate relative to work rate (Figure 4D).

No significant correlations were found between markers of oxphen and quadriceps peak torque, pulmonary function, exercise capacity, total PA, time spent in sedentary PA or MVPA, or any of the MVPA bout-related variables (data not shown).

\section{$\underline{\text { Skeletal muscle oxidative stress }}$}

The levels of protein carbonylation, tyrosine nitration and MDA-protein adducts were not different between patients and controls (Figure 5). Among the patients, we found inverse correlations between protein carbonylation and type I fiber proportion, myosin heavy chain I gene expression and quadriceps endurance, and a positive correlation between protein carbonylation level and myosin heavy chain IIa expression (Figure 6). In line, protein carbonylation was positively correlated with type IIx fiber proportion $(\rho=0.43, P=.023)$. Additionally, tyrosine nitration was inversely correlated with quadriceps endurance $(\mathrm{r}=-0.42, P=.040)$, and MDA-protein adducts were inversely associated with myosin heavy chain I gene expression $(\mathrm{r}=-0.38, P=.044)$. Markers of oxidative stress were not correlated with FFMI or fiber CSA among patients, and no correlations were found between oxidative stress markers and markers of oxphen in the healthy subjects (data not shown). 
Figure 4. Correlations among COPD patients between markers of skeletal muscle oxidative phenotype and quadriceps endurance and the rise in blood lactate relative to work rate during an incremental cycling test.
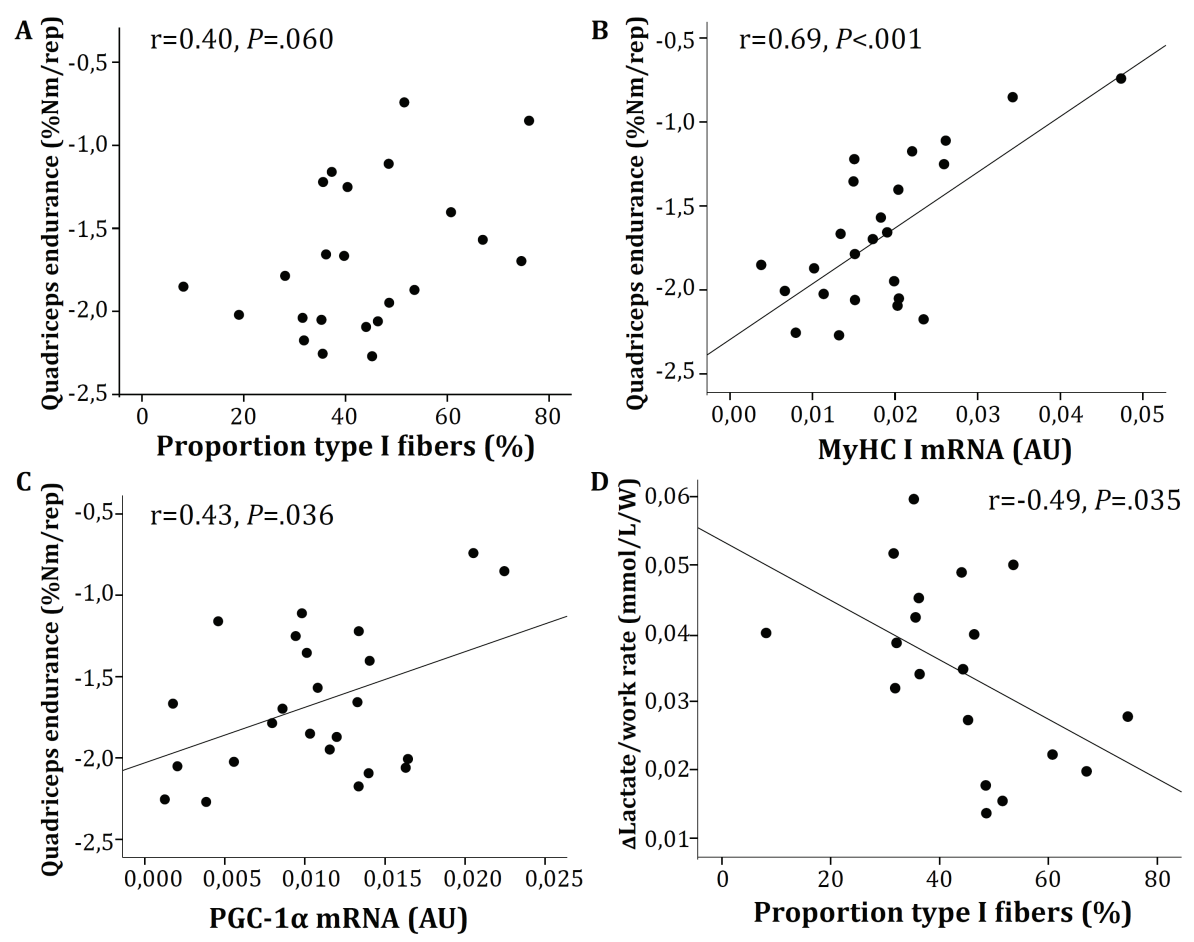

A) Correlation between the proportion type I fibers and quadriceps endurance. B) Correlation between myosin heavy chain I mRNA expression and quadriceps endurance. C) Correlation between PGC-1 $\alpha$ $m R N A$ expression and quadriceps endurance. D) Correlation between the proportion type I fibers and the rise in blood lactate relative to work rate during an incremental cycling test.

\section{Discussion}

Whereas previous studies have clearly shown skeletal muscle dysfunction in advanced COPD, the main novelty of the current study is that we identified a loss of quadriceps oxphen and decreased quadriceps endurance in patients with mild-to-moderate COPD. Interestingly, these abnormalities existed even in the absence of significant muscle wasting. Also we found consistent inverse correlations between markers of oxphen and oxidative stress among the patients. It should be pointed out that our study is of cross-sectional nature, and does not allow for longitudinal inferences. However, linking the various cross- 
Figure 5. Levels of skeletal muscle oxidative stress.

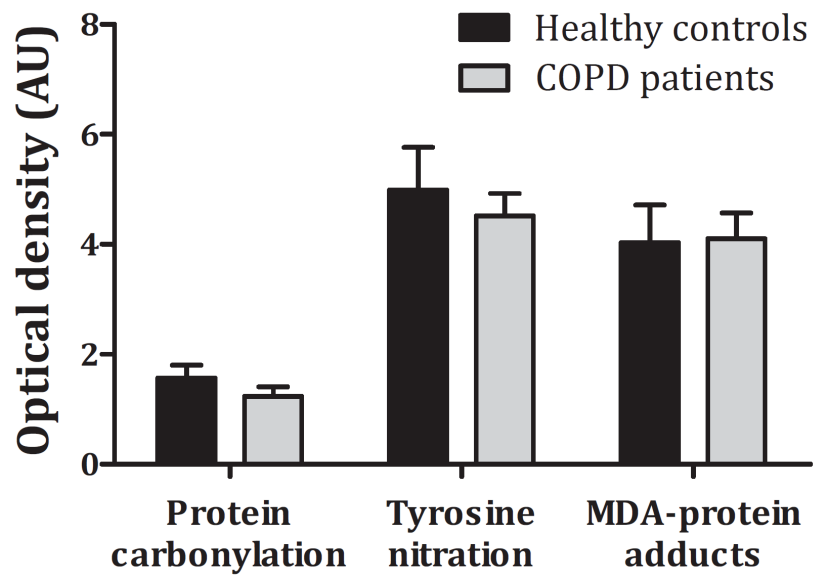

The levels of protein carbonylation, tyrosine nitration and MDA-protein adducts were not different between COPD patients and controls, all $P>05$.

sectional studies across COPD severity stages, the available data suggest that the loss of skeletal muscle endurance and skeletal muscle oxphen occur already in patients with mild-to-moderate COPD and progress with declining lung function, and suggest potential involvement of oxidative stress.

We assessed a large panel of markers of skeletal muscle oxphen, and found that many were significantly decreased in our mild-to-moderate COPD patients compared to well-matched controls. More specifically, the loss of oxphen in our COPD patients was characterized by a decreased proportion of type I fibers, decreased gene expression of PGC- $1 \alpha$ and MyHCI, decreased protein expression of subunits of OXPHOS complexes IV and V, and decreased HADH/PFK enzyme activity. The mean differences in proportions of type I, IIa and IIx fibers between our mild-to-moderate COPD patients and matched healthy controls were $20 \%$, $15 \%$ and $4 \%$, respectively. For comparison, pooled analyses from a metaanalysis in advanced COPD patients showed these differences to be $22 \%, 7 \%$ and $13 \%$, respectively [7]. These combined data suggest that a decrease in slowoxidative type I fiber proportion occurs already in early COPD, and that a further shift from fast-oxidative type IIa to fast-glycolytic type IIx fibers continues in advanced COPD towards even more dependence on glycolytic metabolism. It should be acknowledged that decreased expression of subunits of the key respiratory chain complexes does not necessarily indicate decreased cytochrome c oxidase (COX) activity or overall lower mitochondrial respiration. Several other studies have assessed COX activity in muscle biopsies of COPD patients, and showed contrasting results. For example, reduced skeletal muscle COX activity has been reported in moderate COPD patients by some authors [34- 
Figure 6. Correlations among COPD patients between markers of skeletal muscle oxidative phenotype, quadriceps endurance and the level of protein carbonylation.
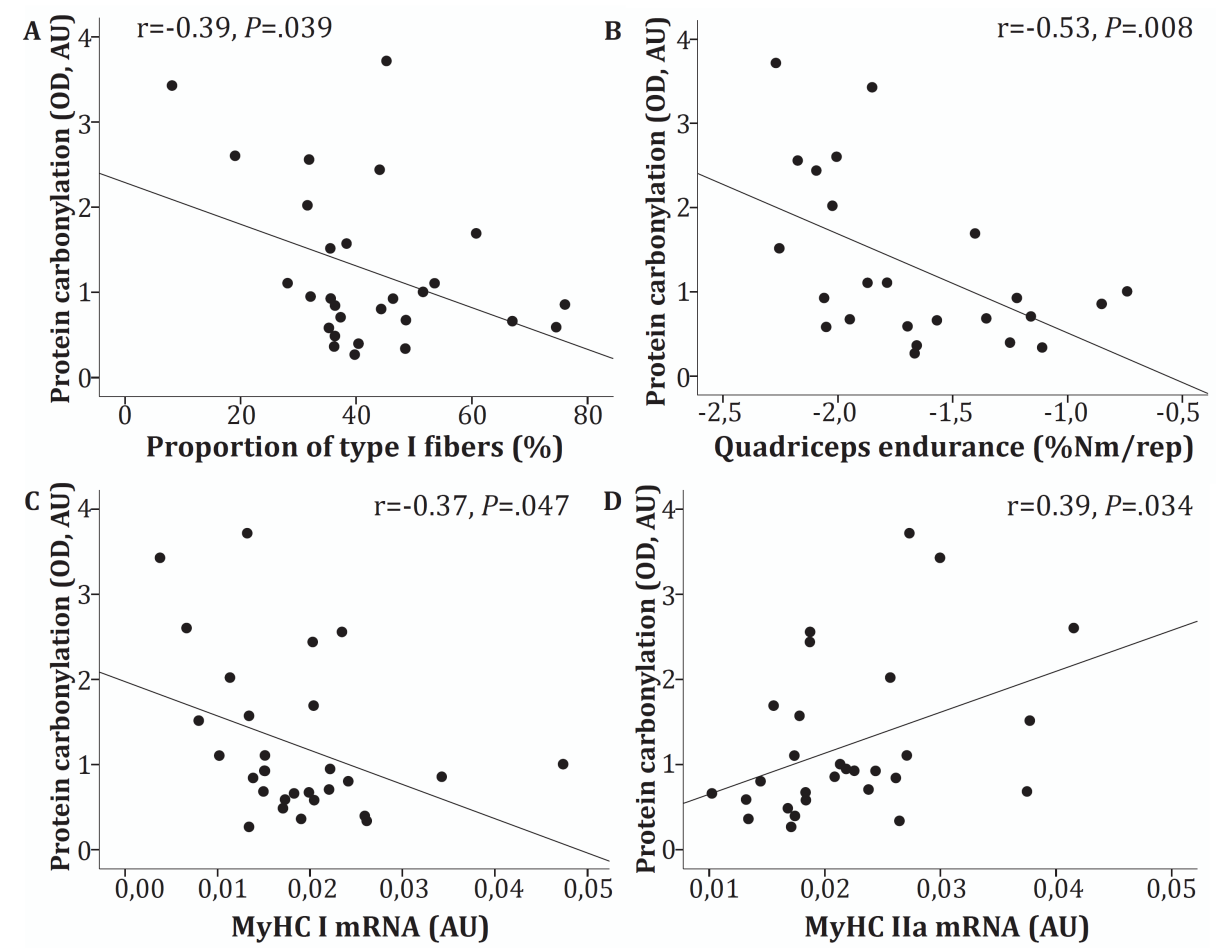

Correlations between the level of protein carbonylation and proportion type I fibers (A), quadriceps endurance (B), myosin heavy chain $m R N A$ expression (C), and myosin heavy chain IIa mRNA expression (D).

36], whereas others reported even higher COX activity in moderate-to-severe COPD patients [37, 38]. Between-study differences remain unexplained. Therefore, these data provide further indication for studying mitochondrial respiration in more detail in different COPD disease stages, including the early stages.

We found that markers of oxidative phenotype were significantly correlated with quadriceps endurance, implying that the magnitude of loss of oxidative phenotype reached the level of clinical importance in terms of quadriceps endurance. Similar findings were previously reported in a population of advanced COPD patients with significant muscle wasting [4]. Our data show that these abnormalities are already present in early COPD even in the absence of muscle wasting. In a recent study by Saey et al. [39] $\Delta$ lactate/WR during a constant work rate test was significantly higher in muscle-wasted COPD patients (mean $\mathrm{FEV}_{1} 45 \%$ of predicted) compared with controls. This coincided with a decreased proportion of type I fibers and increased type Ila fibers and a wide 
array of increased glycolytic markers. The authors argued that increased glycolysis underlies the increased $\Delta$ lactate/WR. Although this seems plausible, no correlations between $\Delta$ lactate/WR and metabolic markers were presented by Saey et al. [39]. We however did find that the proportion of type I fibers was associated with increased $\Delta$ lactate/WR during an incremental load test in nonmuscle wasted COPD patients.

PGC- $1 \alpha$ is considered the major regulator of skeletal muscle oxidative metabolism. Indeed, its expression is known to be significantly induced upon aerobic exercise, which subsequently orchestrates oxidative gene expression in order to prepare the muscle for a next bout of exercise [40]. Puente-Maestu et al. [41] have recently shown that moderate-intensity exercise increased skeletal muscle PGC- $1 \alpha$ gene expression in COPD patients $\left(\mathrm{FEV}_{1} 50 \%\right.$ of predicted) with normal FFMI. As we found that PGC- $1 \alpha$ gene expression was decreased by $40 \%$ in our patients, this would suggest that the muscle oxidative machinery fails, at least in part, at the regulatory level. PGC- $1 \alpha^{\prime}$ 's downstream target Tfam tended to be decreased expressed as well. Expression levels of other (co-) transcription factors implicated in the regulation of Tfam expression (PGC- $1 \beta$, PRC, NRF-1, and NRF-2 $\alpha$ ) were not differentially expressed between patients and controls.

Physical inactivity, or deconditioning, has been proposed to contribute to skeletal muscle dysfunction in COPD [42]. We used accelerometry to assess both quantitative and qualitative daily living physical activity, and studied the relations with muscle oxphen. We did not specifically select the healthy subjects based on sedentary behavior, so the finding that our COPD patients were on average 39\% less physically active compared with the controls was not surprising. In addition, we found that our patients engaged in less MVPA bouts and these bouts were shorter and less intense compared to those of our controls. The level and intensity of physical activity was positively correlated with $\mathrm{FEV}_{1}$ within the COPD patients, which is consistent with previous reports [43-45]. Interestingly, however, we could not identify any relation between markers of oxphen and total physical activity level nor its intensity in our patients. Although we did not select our healthy controls on sedentary behavior, our data do not support the presumption that physical inactivity is the principle determinant of impaired skeletal muscle oxphen in mild-to-moderate COPD. Still, the fact that no association between loss of oxphen and physical inactivity was found does not exclude the possibility that physical activity plays a role in the multifactorial pathways involved in loss of oxphen.

Whereas basal levels of skeletal muscle oxidative stress were comparable between our patients and controls, we found that markers of muscle oxidative stress were significantly associated with the loss in muscle oxphen among COPD patients, but were not related to muscle mass. Oxidative stress has been suggested to render the muscle susceptible to atrophy as damaged (oxidized) proteins are prone to be degraded. However, this concept has recently been challenged as no differences in basal skeletal muscle oxidative stress levels were 
found between advanced COPD patients with and without muscle wasting [12]. Enhanced mitochondrial production of reactive oxygen species (ROS) has been observed in patients which moderate-to-severe COPD, which has been proposed to be linked to the proportional increase in type II fibers [46]. Recently, it has also been demonstrated that OXPHOS complex III is the main site of ROS production within peripheral muscles of COPD patients, who exhibited similar clinical features as those recruited in the current investigation [9]. Furthermore, compared to type I fiber mitochondria, type II fiber mitochondria exhibit enhanced ROS production, as was shown in rats [47]. Taken together, the associations encountered between protein oxidation levels and the slow-to-fast phenotype shift among mild-to-moderate COPD patients may be partly explained by mitochondrial dysfunction and enhanced ROS production.

In peripheral skeletal muscle of emphysematous hamsters, decreased citrate synthase activity and increased lipid peroxidation have been reported, which were not related to decreased body weight, muscle mass or physical activity level [10, 11]. In line, in a rat model of emphysema, Zhang et al. [48] reported no change in muscle mass but showed increased skeletal muscle lipofuscin inclusions (a marker of oxidative stress) which were correlated with decreased muscle endurance. Collectively, the available data suggest a relation between oxidative stress and the loss of oxidative capacity in COPD-related muscle dysfunction and it can be speculated that loss of oxphen, through enhanced oxidative stress, may eventually augment muscle wasting as well.

In conclusion, this study shows evidence for a loss of muscle oxphen and decreased quadriceps endurance in patients with mild-to-moderate COPD without overt loss of muscle mass. Our results indicate that timely intervention strategies aimed at improving muscle oxphen in early COPD may improve or prevent a further loss in quadriceps endurance. 


\section{SKELETAL MUSCLE FATIGUE IN EARLY COPD}

\section{References}

1. Barnes PJ, Celli BR. Systemic manifestations and comorbidities of COPD. Eur Respir J. 2009;33(5):1165-85.

2. Skeletal muscle dysfunction in chronic obstructive pulmonary disease. A statement of the American Thoracic Society and European Respiratory Society. Am J Respir Crit Care Med. 1999;159(4 Pt 2):S1-40.

3. Bernard S, LeBlanc P, Whittom F, Carrier G, Jobin J, Belleau R, Maltais F. Peripheral muscle weakness in patients with chronic obstructive pulmonary disease. Am J Respir Crit Care Med. 1998;158(2):629-34.

4. Allaire J, Maltais F, Doyon JF, Noel M, LeBlanc P, Carrier G, Simard C, Jobin J. Peripheral muscle endurance and the oxidative profile of the quadriceps in patients with COPD. Thorax. 2004;59(8):673-8.

5. van Wetering CR, Hoogendoorn M, Mol SJ, Rutten-van Molken MP, Schols AM. Short- and long-term efficacy of a community-based COPD management programme in less advanced COPD: a randomised controlled trial. Thorax. 2010;65(1):7-13.

6. Schols AM, Gosker HR. The pathophysiology of cachexia in chronic obstructive pulmonary disease. Curr Opin Support Palliat Care. 2009;3(4):282-7.

7. Gosker HR, Zeegers MP, Wouters EF, Schols AM. Muscle fibre type shifting in the vastus lateralis of patients with COPD is associated with disease severity: a systematic review and meta-analysis. Thorax. 2007;62(11):944-9.

8. Remels AH, Schrauwen P, Broekhuizen R, Willems J, Kersten S, Gosker HR, Schols AM. Peroxisome proliferator-activated receptor expression is reduced in skeletal muscle in COPD. Eur Respir J. 2007;30(2):245-52.

9. Puente-Maestu L, Tejedor A, Lazaro A, de Miguel J, Alvarez-Sala L, Gonzalez-Aragoneses F, Simon C, Agusti A. Site of Mitochondrial ROS Production in Skeletal Muscle of COPD and its Relationship with Exercise Oxidative Stress. Am J Respir Cell Mol Biol. 2012;47(3):358-62.

10. Mattson JP, Poole DC. Pulmonary emphysema decreases hamster skeletal muscle oxidative enzyme capacity. J Appl Physiol. 1998;85(1):210-4.

11. Mattson JP, Sun J, Murray DM, Poole DC. Lipid peroxidation in the skeletal muscle of hamsters with emphysema. Pathophysiology. 2002;8(3):215-21.

12. Fermoselle C, Rabinovich R, Ausin P, Puig-Vilanova E, Coronell C, Sanchez F, Roca J, Gea J, Barreiro E. Does oxidative stress modulate limb muscle atrophy in severe copd patients? Eur Respir J. 2012 Mar 9 [Epub ahead of print].

13. Barreiro E, Gea J, Corominas JM, Hussain SN. Nitric oxide synthases and protein oxidation in the quadriceps femoris of patients with chronic obstructive pulmonary disease. Am J Respir Cell Mol Biol. 2003;29(6):771-8.

14. Quanjer PH, Tammeling GJ, Cotes JE, Pedersen OF, Peslin R, Yernault JC. Lung volumes and forced ventilatory flows. Report Working Party Standardization of Lung Function Tests, European Community for Steel and Coal. Official Statement of the European Respiratory Society. Eur Respir J Suppl. 1993;16:5-40.

15. Franssen FM, Sauerwein HP, Ackermans MT, Rutten EP, Wouters EF, Schols AM. Increased postabsorptive and exercise-induced whole-body glucose production in patients with chronic obstructive pulmonary disease. Metabolism. 2011;60(7):957-64.

16. van den Borst B, Gosker HR, Wesseling G, de Jager W, Hellwig VA, Snepvangers FJ, Schols AM. Low-grade adipose tissue inflammation in patients with mild-to-moderate chronic obstructive pulmonary disease. Am J Clin Nutr. 2011;94(6):1504-12.

17. Schols AM, Soeters PB, Dingemans AM, Mostert R, Frantzen PJ, Wouters EF. Prevalence and characteristics of nutritional depletion in patients with stable COPD eligible for pulmonary rehabilitation. Am Rev Respir Dis. 1993;147(5):1151-6.

18. Franssen FM, Broekhuizen R, Janssen PP, Wouters EF, Schols AM. Limb muscle dysfunction in COPD: effects of muscle wasting and exercise training. Med Sci Sports Exerc. 2005;37(1):2-9.

19. Wagenmakers R, van den Akker-Scheek I, Groothoff JW, Zijlstra W, Bulstra SK, Kootstra JW, Wendel-Vos GC, van Raaij JJ, Stevens M. Reliability and validity of the short questionnaire to assess health-enhancing physical activity (SQUASH) in patients after total hip arthroplasty. BMC Musculoskelet Disord. 2008;9:141.

20. Troiano RP, Berrigan D, Dodd KW, Masse LC, Tilert T, McDowell M. Physical activity in the United States measured by accelerometer. Med Sci Sports Exerc. 2008;40(1):181-8.

21. Matthew CE. Calibration of accelerometer output for adults. Med Sci Sports Exerc. 2005;37(11 Suppl):S512-22.

22. Masse LC, Fuemmeler BF, Anderson CB, Matthews CE, Trost SG, Catellier DJ, Treuth M. Accelerometer data reduction: a comparison of four reduction algorithms on select outcome variables. Med Sci Sports Exerc. 2005;37(11 Suppl):S544-54.

23. Pate RR, Pratt M, Blair SN, Haskell WL, Macera CA, Bouchard C, Buchner D, Ettinger W, Heath GW, King AC, et al. Physical activity and public health. A recommendation from the Centers for Disease Control and Prevention and the American College of Sports Medicine. JAMA. 1995;273(5):402-7.

24. O'Donovan G, Blazevich AJ, Boreham C, Cooper AR, Crank H, Ekelund U, Fox KR, Gately P, Giles-Corti B, Gill JM, et al. The $\mathrm{ABC}$ of Physical Activity for Health: a consensus statement from the British Association of Sport and Exercise Sciences. J Sports Sci. 2010;28(6):573-91.

25. Bergstrom L. Muscle electrolytes in man. Determination by neutron activation analysis on needle biopsy specimens. A study on normal subjects, kidney patients, and patients with chronic diarrhea. Scand J Clin Lab Invest. 1962;68:1-110.

26. Ogilvie RW, Feeback DL. A metachromatic dye-ATPase method for the simultaneous identification of skeletal muscle fiber types I, IIA, IIB and IIC. Stain Technol. 1990;65(5):231-41. 
27. Verdijk LB, Koopman R, Schaart G, Meijer K, Savelberg HH, van Loon LJ. Satellite cell content is specifically reduced in type II skeletal muscle fibers in the elderly. Am J Physiol Endocrinol Metab. 2007;292(1):E151-7.

28. Allen D, Winters E, Kenna PF, Humphries P, Farrar GJ. Reference gene selection for real-time rtPCR in human epidermal keratinocytes. J Dermatol Sci. 2008;49(3):217-25.

29. Vandesompele J, De Preter K, Pattyn F, Poppe B, Van Roy N, De Paepe A, Speleman F. Accurate normalization of real-time quantitative RT-PCR data by geometric averaging of multiple internal control genes. Genome Biol. 2002;3(7):RESEARCH0034.

30. Rodriguez DA, Kalko S, Puig-Vilanova E, Perez-Olabarria M, Falciani F, Gea J, Cascante M, Barreiro E, Roca J. Muscle and blood redox status after exercise training in severe COPD patients. Free Radic Biol Med. 2012;52(1):88-94.

31. Bergmeyer HU, Gawehn K, Grassl M. 3-Hydroxyacyl-CoA dehydrogenase. In: Bergmeyer HU, editor. Methods of enzymatic analysis. Weinheim; Germany: Verlag Chemie GmbH; 1974. p. 474.

32. Ling KH, Paetkau V, Marcus F, Lardy HA. Phosphofructokinase: I. Skeletal Muscle. Methods in Enzymology: Academic Press; 1966. p. 425-9.

33. Shepherd D, Garland PB. Citrate synthase from rat liver. Methods in Enzymology: Academic Press; 1969.p. 11-6.

34. Gosker HR, van Mameren H, van Dijk PJ, Engelen MPKJ, van der Vusse GJ, Wouters EFM, Schols AMWJ. Skeletal muscle fibre type shifting and metabolic profile in patients with COPD. Eur Respir J. 2002;19:617-26.

35. Naimi AI, Bourbeau J, Perrault H, Baril J, Wright-Paradis C, Rossi A, Taivassalo T, Sheel AW, Rabol R, Dela F, et al. Altered mitochondrial regulation in quadriceps muscles of patients with COPD. Clin Physiol Funct Imaging. 2011;31(2):124-31.

36. Green HJ, Bombardier E, Burnett M, Iqbal S, D'Arsigny CL, O'Donnell DE, Ouyang J, Webb KA. Organization of metabolic pathways in vastus lateralis of patients with chronic obstructive pulmonary disease. Am J Physiol Regul Integr Comp Physiol. 2008;295(3):R935-41.

37. Sauleda J, Garcia-Palmer F, Wiesner RJ, Tarraga S, Harting I, Tomas P, Gomez C, Saus C, Palou A, Agusti AG. Cytochrome oxidase activity and mitochondrial gene expression in skeletal muscle of patients with chronic obstructive pulmonary disease. Am J Respir Crit Care Med. 1998;157(5 Pt 1):1413-7.

38. Puente-Maestu L, Perez-Parra J, Godoy R, Moreno N, Tejedor A, Gonzalez-Aragoneses F, Bravo JL, Alvarez FV, Camano S, Agusti A. Abnormal mitochondrial function in locomotor and respiratory muscles of COPD patients. Eur Respir J. 2009;33(5):1045-52.

39. Saey D, Lemire BB, Gagnon P, Bombardier E, Tupling AR, Debigare R, Cote CH, Maltais F. Quadriceps metabolism during constant workrate cycling exercise in chronic obstructive pulmonary disease. J Appl Physiol. 2011;110(1):116-24.

40. Pilegaard H, Saltin B, Neufer PD. Exercise induces transient transcriptional activation of the PGC-1alpha gene in human skeletal muscle. J Physiol. 2003;546(Pt 3):851-8.

41. Puente-Maestu L, Lazaro A, Tejedor A, Camano S, Fuentes M, Cuervo M, Navarro BO, Agusti A. Effects of exercise on mitochondrial DNA content in skeletal muscle of patients with COPD. Thorax. 2011;66(2):121-7.

42. Wagner PD. Skeletal muscles in chronic obstructive pulmonary disease: deconditioning, or myopathy? Respirology. 2006;11(6):681-6.

43. Steele BG, Holt L, Belza B, Ferris S, Lakshminaryan S, Buchner DM. Quantitating physical activity in COPD using a triaxial accelerometer. Chest. 2000;117(5):1359-67.

44. Jehn M, Schmidt-Trucksass A, Meyer A, Schindler C, Tamm M, Stolz D. Association of daily physical activity volume and intensity with COPD severity. Respir Med. 2011;105(12):1846-52.

45. Garcia-Rio F, Lores V, Mediano O, Rojo B, Hernanz A, Lopez-Collazo E, Alvarez-Sala R. Daily physical activity in patients with chronic obstructive pulmonary disease is mainly associated with dynamic hyperinflation. Am J Respir Crit Care Med. 2009;180(6):506-12.

46. Picard M, Godin R, Sinnreich M, Baril J, Bourbeau J, Perrault H, Taivassalo T, Burelle Y. The mitochondrial phenotype of peripheral muscle in chronic obstructive pulmonary disease: disuse or dysfunction? Am J Respir Crit Care Med. 2008;178(10):1040-7.

47. Anderson EJ, Neufer PD. Type II skeletal myofibers possess unique properties that potentiate mitochondrial H(2)O(2) generation. Am J Physiol Cell Physiol. 2006;290(3):C844-51.

48. Zhang XL, Pang BS, Hou XL, Wang J, Wang C. Oxidative stress and peripheral skeletal muscle dysfunction in rats with emphysema. Chin Med J (Engl). 2010;123(1):40-4. 



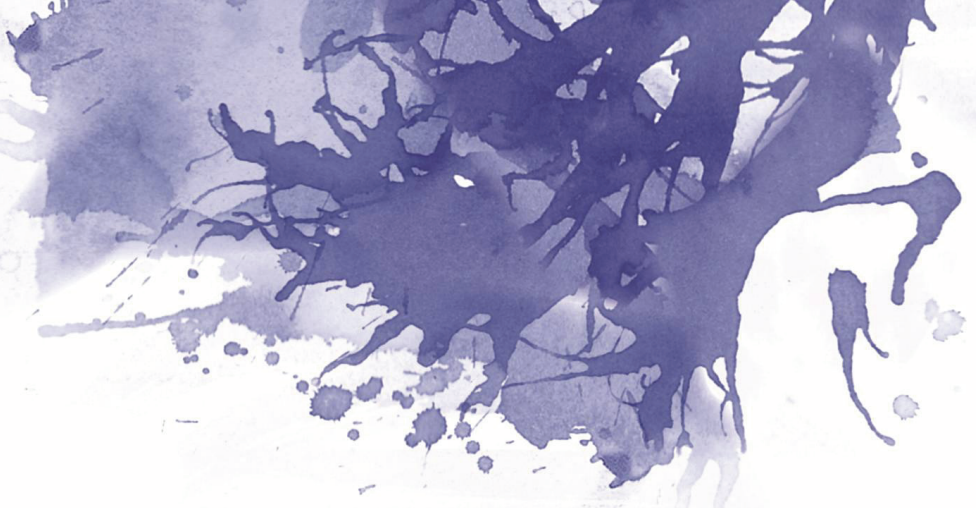

\section{CHAPTER 4 Low-grade adipose tissue inflammation in patients with mild-to-moderate COPD}

Bram van den Borst, Harry R. Gosker, Geertjan Wesseling, Wilco de Jager, Valéry A.C.V. Hellwig, Frank J. Snepvangers, Annemie M.W.J. Schols

American Journal of Clinical Nutrition 2011;94(6):1504-12 


\section{Abstract}

Background: Low-grade systemic inflammation is common in chronic obstructive pulmonary disease (COPD), but its source remains unclear. Adipose tissue is a potent producer of inflammatory mediators and may contribute to systemic inflammation in COPD, possibly via hypoxia.

Objective: To study the influence of COPD and exercise-induced oxygen desaturation on adipose tissue inflammation (ATI) and its contribution to systemic inflammation.

Design: Subcutaneous adipose tissue biopsies were investigated of 28 clinically stable COPD patients $\left(\mathrm{FEV}_{1} 58 \pm 16 \%\right.$ of predicted, body mass index [BMI] $24.9 \pm 2.9 \mathrm{~kg} / \mathrm{m}^{2}$ ) and 15 matched healthy controls. Fat mass was measured with dual-energy X-ray absorptiometry. Patients were pre-stratified by oxygen desaturation assessed by incremental cycle ergometry. Adipocyte size and adipose tissue expression of 19 inflammatory and hypoxia-related genes were measured and adipose tissue macrophages (ATMs) were histologically quantified. Systemic inflammatory markers included CRP and a panel of 20 adipokines.

Results: COPD patients had comparable fat mass but higher CRP and HOMA-IR index compared to controls. COPD patients and controls had comparable adipose tissue gene expression, adipocyte size, ATM infiltration and systemic adipokine levels. Desaturating COPD patients had no different ATI status compared to nondesaturating patients. COPD patients with high CRP had significantly greater ATM infiltration compared to patients with low CRP, which was independent of BMI and fat mass.

Conclusions: We identified a possible role of ATMs in the low-grade systemic inflammation in COPD. ATI and systemic adipokine levels were comparable to controls and partly related to fat mass. Oxygen desaturation was not associated with ATI. 


\section{Introduction}

Chronic obstructive pulmonary disease (COPD) is characterized by low-grade systemic inflammation which has been associated with insulin resistance (IR) [1]. Classically, systemically elevated cytokine levels are hypothesized to result from a 'spill-over' of the pulmonary compartment. However, there is no convincing evidence to support this theory in clinically stable disease. Alternatively, adipose tissue has been proposed to contribute to systemic inflammation in obese COPD patients [2]. In addition to storing energy, adipose tissue is an active producer of mediators involved in inflammation; the so-called adipokines of which leptin and adiponectin are examples [2].

Several mechanisms have been proposed to induce or relate to adipose tissue inflammation (ATI), that we hypothesized could be involved in COPD and result in enhanced systemic inflammation. First, large adipocytes produce more pro-inflammatory adipokines than small adipocytes [3], indicative of adipocyte size as a marker of ATI. Most patients with COPD receive chronic $\beta 2$-agonists that could contribute to the blunted $\beta$-adrenoreceptor mediated lipolysis and thermogenesis resulting in maintenance or relative expansion of fat tissue in COPD [4]. Second, a major reduction of oxygen supply may lead to ATI and may potentially be aggravated via a disbalance between adipocyte size and (neo-) vascularisation leading to local hypoxic areas and/or intra-adipocytic hypoxia [5]. It is unknown, however, whether mild hypoxaemia as present in early stages of COPD or intermittent desaturations in some COPD phenotypes could also trigger ATI in COPD. Chronic hypoxaemia can occur during advanced disease but recurrent desaturations also occur in moderate disease during daily physical activities [6]. Third, IR has been linked to both systemic inflammation [7] and ATI [8]. Finally, although adipose tissue macrophages (ATMs) have been put forward as the orchestrators of ATI [9] they have never been quantified in COPD.

Recently, Tkacova et al. [10] showed higher pro-inflammatory gene expression in adipose tissue of underweight GOLD IV patients compared to overweight GOLD I-III patients. Interestingly, groups were also different in $\mathrm{PaO}_{2}$ (7.7 vs $9.4 \mathrm{kPa}$, respectively) suggesting that hypoxaemia may play a role in ATI. Moreover, this study suggests that ATI may not be restricted to the obese state. Subsequently, the same authors showed that with increasing body mass index (BMI) (range 18-36 kg/m²), a higher prevalence of IR was present in COPD patients which was associated with higher adipose tissue expression of proinflammatory genes [11]. BMI and fat mass are, however, known correlates of ATI $[8,12,13]$. Thus, to answer the question if COPD per se is characterized by ATI and to study its relation with systemic inflammation, we studied COPD patients and BMI- and fat mass-matched healthy controls. Additionally, we investigated a potential role of exercise-induced desaturation in COPD on ATI and systemic inflammation. 


\section{Methods}

A detailed methodology can be found in the supplemental material.

\section{Subjects, pulmonary function and incremental exercise test}

This study included 28 clinically stable COPD patients without overt comorbidity and 15 healthy controls. Pulmonary medication is listed in Supplemental Table 1. Pulmonary function testing included forced spirometry and single breath diffusion capacity measurement (Masterlab, Jaeger, Würzburg, Germany). All subjects performed an incremental cycle ergometry test according to international standards to determine exercise-induced desaturation defined as a fall in oxygen saturation $\left(\mathrm{SaO}_{2}\right.$, by pulse oximetry) of $\geq 4 \%$ [14]. Twelve COPD patients desaturated $\left(\mathrm{COPD}_{\mathrm{D}}\right.$, mean $\left.\pm \mathrm{SD} \Delta \mathrm{SaO}_{2}-8.5 \pm 2.2 \%\right)$ and 16 did not $\left(\mathrm{COPD}_{\mathrm{ND}}, \Delta \mathrm{SaO}_{2}-2.1 \pm 1.7 \%\right)$. Arterial blood gas analysis (Blood gas analyzer 865 , Chiron Diagnostics, Emeryville, $\mathrm{CA}$ ) was performed at rest and at $\mathrm{VO}_{2}$ max from a radial artery puncture. Written informed consent was obtained from all subjects and the ethical review board of the Maastricht UMC+ approved the study (MEC 08-2-059). This study is registered on www.trialregister.nl (NTR1402).

\section{Anthropometrics and body composition}

Height was measured using a wall-mounted stadiometer. Body weight was assessed to the nearest $0.1 \mathrm{~kg}$ using a standard balance beam scale. BMI was calculated as weight/height ${ }^{2}\left(\mathrm{~kg} / \mathrm{m}^{2}\right)$. Whole-body dual energy X-ray absorptiometry (DXA, Hologic Discovery, Hologic, or Lunar Prodigy, GE Healthcare) was applied to retrieve whole body fat mass (FM) and fat-free mass (FFM). Comparison of Lunar and Hologic retrieved measures was enabled through applying cross-calibration equations (kindly provided by Dr. Shepherd at the University of California, San Francisco, CA, USA, unpublished). Fat-free mass index (FFMI) and fat mass index (FMI) were calculated as FFM/height ${ }^{2}$ and FM/height ${ }^{2}$, respectively.

\section{Adipose tissue biopsy}

Subcutaneous adipose tissue (SAT) was obtained para-umbilically after an overnight fast through needle biopsy. One specimen was snap-frozen in liquid nitrogen and stored at $-80^{\circ} \mathrm{C}$ until further analysis and another specimen was processed in $4 \%$ formalin for paraffin embedding. 
$\underline{\text { Real-time quantitative polymerase chain reaction (RT-qPCR) }}$

Total RNA from SAT was extracted with the RNeasy ${ }^{\circledR}$ Lipid Tissue Mini Kit (Qiagen, Venlo, The Netherlands) and reverse-transcribed into cDNA using the Transcriptor cDNA synthesis kit (Roche Applied Sciences, Mannheim, Germany). cDNA was amplified using SYBR Green Fluorescein Mix (Westburg, Leusden, The Netherlands) on a quantitative PCR machine (Bio-Rad laboratories B.V., Veenendaal, The Netherlands). We measured a panel of genes consisting of adipokines (leptin, adiponectin, plasminogen activator inhibitor-1 [PAI-1], chemerin, osteoprotegerin, adrenomedullin and visfatin), markers of hypoxia and (neo)vascularisation (glucose transporter-1 [GLUT1], hypoxia inducible factor-1 $\alpha$ [HIF-1 $\alpha]$, vascular endothelial growth factor-A [VEGF-A] and CD34), markers of macrophages (CD68, CD163, CD206, CD11b and monocyte chemotactic protein-1 [MCP-1]), markers of inflammation (IL-8 and IL-10) and peroxisome proliferator-activated receptor- $\gamma$ (PPAR- $\gamma$ ) as a marker of adipocyte differentiation. GeNorm software (Primerdesign, Southampton, USA) was applied to calculate a normalization factor based on the expression levels of three housekeeping genes [15]. Primer sequences are provided in Supplemental Table 2. Gene expression was quantified and expressed as arbitrary units (AU).

\section{Adipocyte size}

Adipocyte size was determined on haematoxylin-eosin stained paraffin sections by quantifying the actual area of $\geq 400$ unique adipocytes per individual through computer image analysis software (Lucia GF, Version 4.81).

\section{Quantification of adipose tissue macrophages (ATMs)}

ATMs were quantified on adipose tissue paraffin sections that were incubated with anti-CD68, visualized by the EnVision $^{\text {TM }}$ FLEX/FLEX+ System (DakoCytomation, Glostrup, Denmark) and counter-stained with haematoxylin. Through direct microscopy at 400x magnification, two blinded raters systematically quantified the number of solitary ATMs and crown-like structures (CLS) (Figure 1) and their densities were expressed as number of solitary ATMs and CLS per $\mathrm{mm}^{2}$ of analyzed tissue.

\section{Cardiometabolic and systemic inflammatory profile}

Fasting plasma concentrations of 19 adipocytokines were analyzed with a multiplex immunoassay as described in detail elsewhere [16]. The lower limits of detection (LLOD) are presented in Table E3. Further measurements included Creactive protein (CRP), N-terminal pro-Brain Natriuretic Peptide (NT-proBNP), glucose and insulin. See online supplement for more details. Homeostatic model 
assessment (HOMA) was applied to estimate IR by HOMA-IR=(Insulin * Glucose)/22,5 [17].

Figure 1. CD68-staining of adipose tissue macrophages (ATMs).
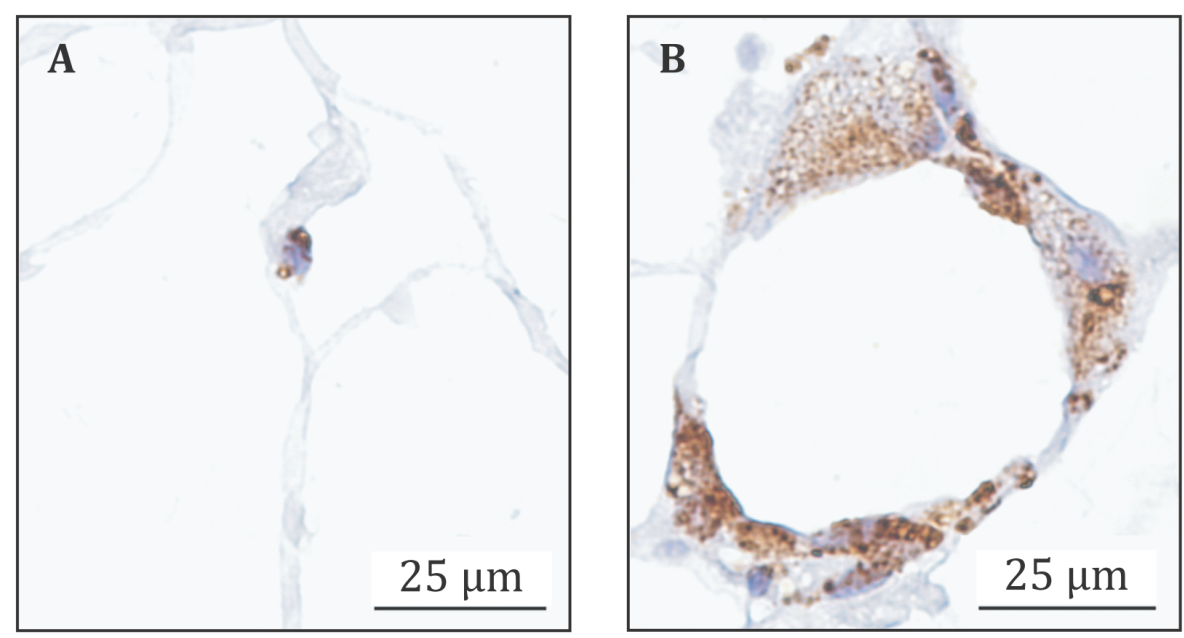

A) Solitary ATM, B) Crown-like structure (CLS): a well-organized collection of macrophages surrounding an adipocyte, which is a marker of adipocyte death [34]. CD68 is a lysosomal glycoprotein that is implicated in endocytosis and lysosomal migration of macrophages. Note the difference in macrophage size and granulomatous aspect between a solitary ATM and ATMs forming a CLS.

\section{$\underline{\text { Statistical analyses }}$}

Differences in descriptive characteristics between COPD patients and healthy controls were tested using independent-samples $t$-test for continuous variables and $\chi^{2}$ for categorical variables. In case of a significantly skewed distribution according to the Shapiro-Wilk test, natural logarithmic transformation was applied and for these variables the geometrical mean and 95\% confidence intervals (CI) are presented. Analyses of adipose tissue mRNA expression and systemic adipocytokines were corrected for multiple comparisons by using false discovery rate method [18]. Correlations were tested using Pearson's $r$ and Spearman's $\rho$. Analyses were performed in PASW Statistics 17.0 (SPSS inc., Chicago, IL). Differences were declared to be statistically significant at $P<.05$.

\section{Results}

COPD patient had mild-to-moderate airflow obstruction (Table 1). FFMI and FMI were not different between COPD patients and healthy controls. COPD patients had slightly higher fasting plasma glucose, insulin and HOMA-IR scores 
Table 1. Main characteristics of the study population.

\begin{tabular}{|c|c|c|c|c|}
\hline & $\begin{array}{c}\text { Healthy } \\
\text { controls } \\
(n=15)\end{array}$ & $\begin{array}{c}\text { Total COPD } \\
\text { group } \\
(n=28)\end{array}$ & $\begin{array}{l}\text { Desaturating } \\
\text { COPD patients } \\
(n=12)\end{array}$ & $\begin{array}{c}\text { Non- } \\
\text { s desaturating } \\
\text { COPD patients } \\
(\mathrm{n}=16)\end{array}$ \\
\hline \multicolumn{5}{|l|}{ Demographics } \\
\hline Sex, $m / f$ & $9 / 6$ & $17 / 11$ & $7 / 5$ & $10 / 6$ \\
\hline Age, y & $65(6)$ & $65(7)$ & $65(6)$ & $66(7)$ \\
\hline \multicolumn{5}{|l|}{ Smoking status } \\
\hline Current, n (\%) & $1(6.7)$ & $10(36)$ & $2(20)$ & $8(50)$ \\
\hline Former, n (\%) & $7(46.7)$ & $18(64)^{\mathrm{a}}$ & $10(80)$ & $8(50)$ \\
\hline Never, n (\%) & $7(46.7)$ & $0(0)$ & $0(0)$ & $0(0)$ \\
\hline \multicolumn{5}{|c|}{ Pulmonary function } \\
\hline $\mathrm{FEV}_{1}, \%$ pred & $113(15)$ & $58(16)^{a}$ & 57 (19) & $59(15)$ \\
\hline FVC, \%pred & $120(17)$ & $105(22)^{c}$ & $114(21)$ & $98(17)$ \\
\hline $\mathrm{FEV}_{1} / \mathrm{FVC}, \%$ & $74(5)$ & $45(12)^{\mathrm{a}}$ & $39(9)^{f}$ & $49(12)$ \\
\hline DLCO, \%pred & 95 (19) & $51(16)^{a}$ & $48(16)$ & $54(17)$ \\
\hline $\mathrm{SaO}_{2}$ at rest, $\%$ & $99(1)$ & $96(2)^{\mathrm{a}}$ & $96(2)$ & $97(1)$ \\
\hline $\mathrm{SaO}_{2}$ at $\mathrm{VO}_{2, \max } \%$ & $98(1)$ & $91(4)^{\mathrm{a}}$ & $87(3)^{d}$ & $94(2)$ \\
\hline $\mathrm{PaO}_{2}$ at rest, $\mathrm{kPa}$ & $12.1(1.1)$ & $9.4(1.0)^{\mathrm{a}}$ & $9.2(1.2)$ & $9.6(0.8)$ \\
\hline $\mathrm{PaO}_{2}$ at $\mathrm{VO}_{2, \text { max }}, \mathrm{kPag}$ & $13.1(1.3)$ & $9.1(1.4)^{\mathrm{a}}$ & $7.9(1.2)^{\mathrm{d}}$ & $9.8(1.0)$ \\
\hline \multicolumn{5}{|l|}{ Body composition } \\
\hline BMI, $\mathrm{kg} / \mathrm{m}^{2}$ & $24.9(3.3)$ & $24.9(2.9)$ & $23.2(2.2)^{\mathrm{e}}$ & $26.1(2.7)$ \\
\hline FFMI, $\mathrm{kg} / \mathrm{m}^{2}$ & $18.0(1.9)$ & $17.6(1.7)$ & $17.1(1.4)$ & $17.9(1.9)$ \\
\hline FMI, $\mathrm{kg} / \mathrm{m}^{2}$ & $7.0(3.3)$ & $7.2(2.6)$ & $6.0(2.1)^{\mathrm{f}}$ & $8.1(2.7)$ \\
\hline Total body fat, $\%$ & $28.1(10.3)$ & $29.2(8.2)$ & $26.5(7.6)$ & $31.3(8.1)$ \\
\hline \multicolumn{5}{|c|}{ Cardiometabolic profile ${ }^{\mathrm{h}, \mathrm{i}}$} \\
\hline Glucose, mmol/L & $5.3(5.1-5.6)$ & $5.9(5.6-6.1)^{\mathrm{b}}$ & $5.7(5.3-6.1)$ & $6.0(5.7-6.3)$ \\
\hline Insulin, pmol/L & $29(23-37)$ & $48(36-64)^{c}$ & $30(23-37)^{\mathrm{d}}$ & $70(46-106)$ \\
\hline HOMA-IR & $0.8(0.5-1.1)$ & $1.5(1.0-2.3)^{c}$ & $0.8(0.5-1.3)^{\mathrm{d}}$ & $2.6(1.6-4.2)$ \\
\hline NT-proBNP, pmol/L & $6.6(4.4-9.8)$ & $9.6(6.8-13.5)$ & $15.2(10.4-22.2)^{\mathrm{f}}$ & )$^{f} 6.6(4.1-10.8)$ \\
\hline \multicolumn{5}{|c|}{ Systemic inflammation ${ }^{\mathrm{h}, \mathrm{i}}$} \\
\hline $\mathrm{CRP}, \mathrm{mg} / \mathrm{L}$ & $0.95(0.57-1.59)$ & $2.05(1.31-3.21)^{c}$ & $1.62(0.95-2.76)$ & $2.48(1.19-5.15)$ \\
\hline \multicolumn{5}{|c|}{ 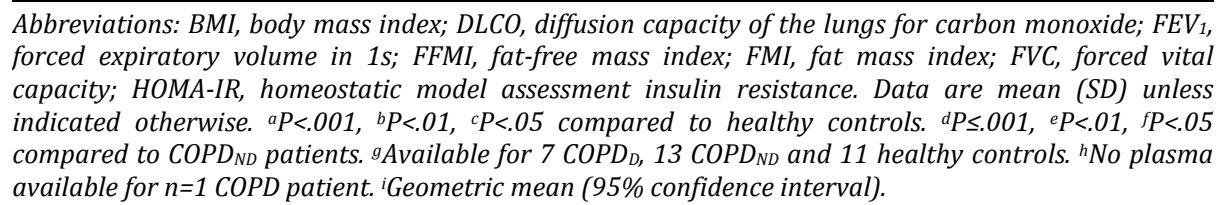 } \\
\hline
\end{tabular}


than healthy controls $(P \leq .021)$ and CRP was also modestly but significantly higher in COPD patients $(P=.031)$ reflecting a low-grade systemic inflammatory state. CRP and HOMA-IR were positively correlated (Figure 2).

Figure 2. Correlation between CRP and HOMA-IR.

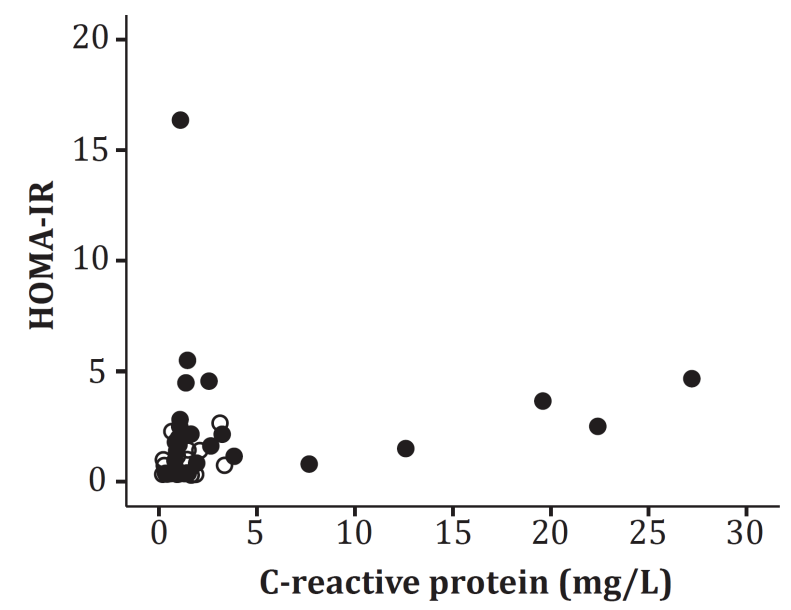

Closed circles represent COPD patients, open circles represent healthy controls (Spearman's $\rho=0.36, P=.018, n=44$ ).

Comparisons between healthy controls and the total COPD group

Adipocyte size and the correlation between fat mass and adipocyte size were not different between the two groups (Figure 3). None of the measured gene expression levels were significantly different between COPD patients and healthy controls after adjustment for multiple testing (Table 2). The solitary ATM density in COPD patients was not different from healthy controls (30.4 [23.9-38.6] vs. 23.7 [18.0-31.3] ATMs $/ \mathrm{mm}^{2}, P=.19$ ). CLS were found in $\mathrm{n}=12$ COPD patients $(43 \%)$ and $n=5$ healthy controls $(33 \%)(P=.75)$. In this subset, the CLS density was not different between COPD patients and healthy controls $(0.15$ [0.08-0.28] vs. 0.09 [0.04-0.19] CLS $\left./ \mathrm{mm}^{2}, P=.27\right)$. CLS density was positively correlated with CD68 gene expression ( $\mathrm{r}=0.66, P=.003)$, while ATM density was not (Supplemental Figure 1).

None of the measured systemic adipokine levels were significantly different between COPD patients and healthy controls (Table 3). Systemic IL-6 levels were near detection limit in both COPD patients and healthy controls and no differences were found between these two groups. Measures above the LLOD of systemic IL-1 $\beta$, IL-8, IL-10, IFN- $\gamma$ and TNF- $\alpha$ were found in only $n=1, n=24, n=4$, $n=15$ and $n=2$ subjects, respectively, without clear differences between COPD 
Figure 3. Adipocyte size in COPD patients and healthy controls.

A

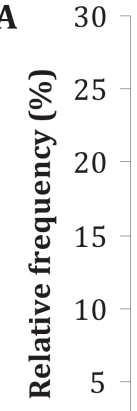

0

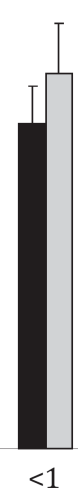

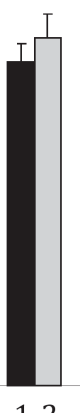
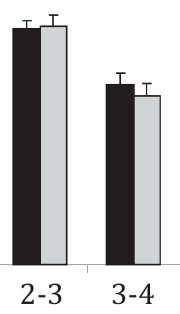

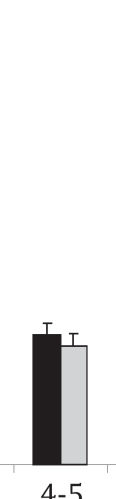

B กิ

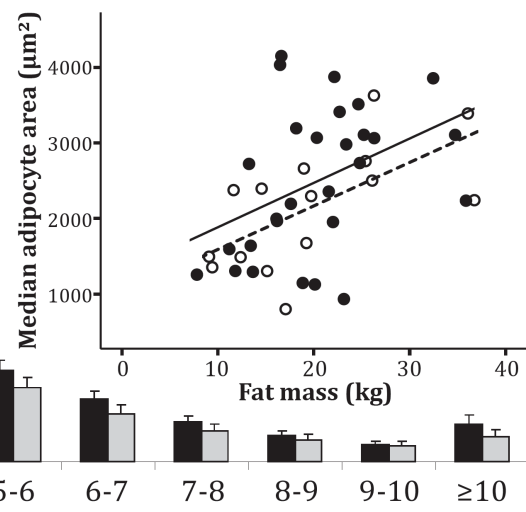

C
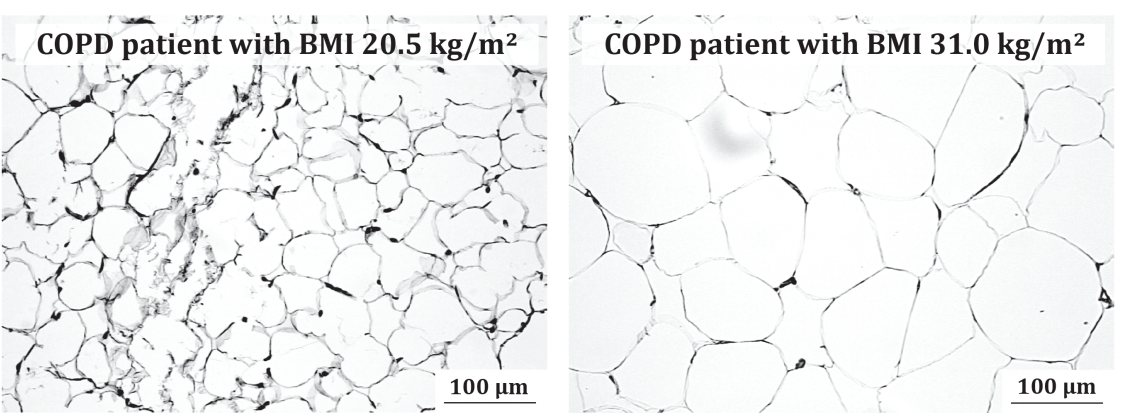

Healthy control with BMI $21.6 \mathrm{~kg} / \mathrm{m}^{2}$,
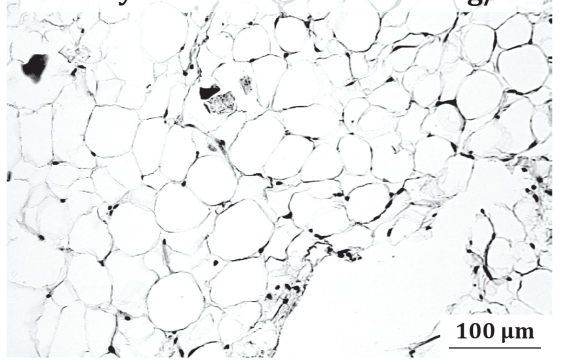

Healthy control with BMI $31.2 \mathrm{~kg} / \mathrm{m}^{2}$
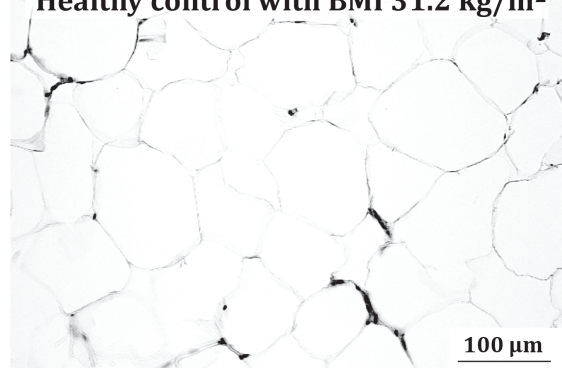

A) Comparison of adipocyte size between COPD patients $(n=28$, black bars) and healthy controls $(n=15$, gray bars). Data are means $\pm S E$. No differences were observed (all P>.05). B) Similar correlations between fat mass and median adipocyte size in COPD patients (closed circles, solid line, Pearson's $r=0.41, P=.031, n=28$ ) and healthy controls (open circles, dashed line, Pearson's $r=0.63, P=.012, n=15$ ). $C$ ) Haematoxylin-eosin stained adipose tissue sections at 200x magnification illustrating the similarity in adipocyte size between COPD patients and healthy controls.

patients and healthy controls. Because of these low numbers, we did not include these in our analyses. Fat mass, circulating leptin and adiponectin, and adipose tissue leptin and adiponectin gene expression correlated in a similar fashion in 
Table 2. Comparison of adipose tissue mRNA levels (arbitrary units) between COPD patients and healthy controls.

\begin{tabular}{|c|c|c|c|c|}
\hline & $\begin{array}{c}\text { Healthy } \\
\text { controls }(n=15)\end{array}$ & $\begin{array}{c}\text { Total COPD } \\
\text { group }(n=28)\end{array}$ & $\begin{array}{c}\text { Desaturating } \\
\text { COPD patients } \\
(\mathrm{n}=12)\end{array}$ & $\begin{array}{c}\text { Non- } \\
\text { desaturating } \\
\text { COPD patients } \\
(\mathrm{n}=16)\end{array}$ \\
\hline GLUT1 & $0.17(0.12-0.23)$ & $0.17(0.14-0.20)$ & $0.17(0.13-0.23)$ & $0.17(0.13-0.22)$ \\
\hline HIF1 $\alpha$ & $0.18(0.16-0.20)$ & $0.19(0.18-0.20)$ & $0.19(0.17-0.20)$ & $0.19(0.17-0.21)$ \\
\hline VEGF-A & $0.16(0.11-0.22)$ & $0.15(0.13-0.19)$ & $0.18(0.12-0.26)$ & $0.14(0.11-0.18)$ \\
\hline CD34 & $0.14(0.07-0.27)$ & $0.16(0.13-0.20)$ & $0.17(0.13-0.22)$ & $0.15(0.11-0.22)$ \\
\hline PAI-1 & $0.14(0.11-0.18)$ & $0.18(0.14-0.24)$ & $0.14(0.09-0.22)$ & $0.22(0.16-0.30)$ \\
\hline Adrenomedullin & $0.16(0.10-0.26)$ & $0.23(0.19-0.27)$ & $0.22(0.17-0.29)$ & $0.23(0.18-0.29)$ \\
\hline Visfatin & $0.19(0.09-0.37)$ & $0.22(0.17-0.28)$ & $0.21(0.14-0.30)$ & $0.23(0.16-0.32)$ \\
\hline Osteoprotegerin & $0.16(0.09-0.29)$ & $0.23(0.19-0.28)$ & $0.19(0.14-0.27)$ & $0.26(0.20-0.33)$ \\
\hline IL-8 & $0.14(0.08-0.26)$ & $0.15(0.11-0.22)$ & $0.11(0.06-0.21)$ & $0.19(0.12-0.31)$ \\
\hline MCP-1 & $0.11(0.08-0.14)$ & $0.16(0.13-0.20)$ & $0.16(0.12-0.22)$ & $0.16(0.11-0.22)$ \\
\hline CD68 & $0.15(0.11-0.19)$ & $0.18(0.15-0.22)$ & $0.16(0.12-0.22)$ & $0.20(0.16-0.25)$ \\
\hline CD163 & $0.11(0.05-0.21)$ & $0.17(0.12-0.23)$ & $0.14(0.08-0.26)$ & $0.20(0.14-0.28)$ \\
\hline CD206 & $0.13(0.09-0.21)$ & $0.21(0.16-0.27)$ & $0.17(0.10-0.28)$ & $0.24(0.19-0.31)$ \\
\hline $\mathrm{CD} 11 \mathrm{~b}$ & $0.16(0.10-0.26)$ & $0.18(0.12-0.27)$ & $0.20(0.13-0.30)$ & $0.16(0.08-0.34)$ \\
\hline Leptina & $0.16(0.11)$ & $0.17(0.08)$ & $0.16(0.10)$ & $0.19(0.05)$ \\
\hline Adiponectin ${ }^{a}$ & $0.19(0.08)$ & $0.18(0.07)$ & $0.19(0.09)$ & $0.17(0.05)$ \\
\hline PPAR- $\gamma^{\mathrm{a}}$ & $0.19(0.09)$ & $0.16(0.06)$ & $0.17(0.07)$ & $0.15(0.05)$ \\
\hline Chemerin $^{a}$ & $0.20(0.10)$ & $0.19(0.08)$ & $0.20(0.08)$ & $0.18(0.08)$ \\
\hline IL-10a & $0.30(0.11)$ & $0.28(0.08)$ & $0.29(0.07)$ & $0.28(0.08)$ \\
\hline
\end{tabular}

Abbreviations: GLUT1, glucose transporter 1; HIF1 $\alpha$, hypoxia inducible factor $1 \alpha$; IL, interleukin; MCP1, monocyte chemotactic protein-1; PAI-1, plasminogen activator inhibitor-1; PPAR- $\gamma$, peroxisome proliferator-activated receptor- $\gamma$; VEGF-A, vascular endothelial growth factor-A. Data are geometric means and $95 \%$ confidence intervals, except indicated otherwise. Independent-samples $t$-tests were used to analyze the data, and $P$ values were interpreted applying false discovery rate correction for multiple testing. None of the comparisons were statistically significant. a Mean (SD).

both COPD patients and healthy controls (Figure 4). Positive correlations between fat mass and ATM markers were also highly comparable between COPD patients and healthy controls (Figure 5). Neither in COPD patients nor in healthy controls any significant correlations were found between fat mass and the remaining systemic adipokines (all $P>.05$, data not shown). 
Comparisons between desaturating and non-desaturating COPD patients

BMI $(P=.007)$ and FMI $(P=.040)$ were significantly lower in desaturating COPD patients $\left(\mathrm{COPD}_{\mathrm{D}}\right)$. Non-desaturating $\mathrm{COPD}$ patients $\left(\mathrm{COPD}_{\mathrm{ND}}\right)$ had higher $\mathrm{FEV}_{1} / \mathrm{FVC}(P=.028)$, higher HOMA-IR $(P \leq .001)$ and lower NT-proBNP $(P=.010)$. No marked differences in adipocyte size were noted between $\mathrm{COPD}_{\mathrm{D}}$ and $\mathrm{COPD}_{\mathrm{ND}}$ patients (data not shown). We found no significant differences between $\operatorname{COPD}_{\mathrm{D}}$ and $\mathrm{COPD}_{\mathrm{ND}}$ patients for all of the measured SAT gene expressions (Table 2), systemic adipokine levels (Table 3), ATM density (30.6 [21.3-43.8] vs. 30.2 [21.243.2] ATMs $\left./ \mathrm{mm}^{2}, P=.96\right)$ and CLS density (0.10 [0.05-0.20] vs. 0.20 [0.07-0.56] $\mathrm{CLS} / \mathrm{mm}^{2}, P=.22$ ).

Based on the median CRP level in COPD patients, we performed a post-hoc comparison between patients with high CRP (n=14, CRP 4.38 [2.33-8.24] mg/L) and low CRP ( $\mathrm{n}=13$, CRP 0.90 [0.75-1.08] mg/L) (Supplemental Tables 3-5) showing that high CRP patients had higher ATM density $(P=.021$, Figure 6$)$. Linear regression analysis further revealed that ATM density (ln transformed) was significantly predicted by $\mathrm{CRP}$ status (low $\mathrm{CRP}=1$, high $\mathrm{CRP}=2, \beta=0.61$, $\mathrm{SE}=0.23, P=.013)$ independent of BMI $(\beta=-0.04, \mathrm{SE}=0.04, P=.29)$. In a separate model CRP status $(\beta=0.63, \mathrm{SE}=0.22, P=.008)$ also predicted ATM density independent of fat mass $(\beta=-0.03, \mathrm{SE}=0.02, P=.07)$.

\section{Discussion}

We investigated whether ATI is enhanced in stable mild-to-moderate COPD independent of age, sex, BMI and body composition. The second aim was to investigate whether ATI was more pronounced in COPD patients with a desaturation phenotype. Knowledge of potential adipose tissue dysfunction in COPD may increase our understanding of the origin of enhanced systemic inflammation in COPD and contribute to tailoring interventions. COPD patients were characterized by a slightly higher CRP and higher HOMA-IR that could be interrelated (as supported by a positive correlation). COPD patients tended to have higher adipose tissue gene expression of two macrophage markers (MCP-1 and CD206). We found that COPD patients with high CRP had greater ATM infiltration and tended to have higher CD206 expression compared to low-CRP patients. Other markers of ATI were, however, not different between COPD patients and healthy controls, and neither was the desaturation phenotype of influence on any of these markers.

As larger adipocytes have been shown to be more pro-inflammatory than smaller adipocytes [3], we explored whether COPD patients would have enlarged adipocytes, for which we did not find any evidence. In mild-to-moderate COPD patients, Skyba et al. reported a positive association between adipocyte size and BMI which was not associated with different gene expression of apoptosis markers, suggesting that fat wasting is not associated with 
Table 3. Comparison of systemic adipokine levels between COPD patients ${ }^{\mathrm{a}}$ and healthy controls.

\begin{tabular}{lccccc}
\hline & $\begin{array}{c}\text { Healthy } \\
\text { controls (n=15) }\end{array}$ & $\begin{array}{c}\text { Total COPD } \\
\text { group (n=28) }\end{array}$ & $\begin{array}{c}\text { Desaturating } \\
\text { COPD patients } \\
(\mathbf{n = 1 2})\end{array}$ & $\begin{array}{c}\text { Non- } \\
\text { desaturating } \\
\text { COPD patients } \\
(\mathbf{n = 1 6 )}\end{array}$ \\
\hline $\mathrm{IL}-6, \mathrm{pg} / \mathrm{ml}$ & $3.73(2.52-5.52)$ & $5.04(3.12-8.15)$ & & $5.63(1.86-17.1)$ & $4.62(3.38-6.30)$ \\
$\mathrm{Leptin}, \mathrm{ng} / \mathrm{ml}$ & $3.92(2.32-6.63)$ & $5.19(3.73-7.22)$ & & $4.03(2.40-6.77)$ & $6.36(4.05-9.99)$ \\
Adiponectin, $\mu \mathrm{g} / \mathrm{ml}$ & $25.6(19.9-32.9)$ & $19.7(15.5-25.1)$ & & $23.9(14.5-39.3)$ & $16.9(13.6-20.9)$ \\
$\mathrm{PAI}-1, \mu \mathrm{g} / \mathrm{ml}$ & $1.60(1.25-2.05)$ & $1.72(1.24-2.39)$ & & $2.36(1.17-4.73)$ & $1.34(1.05-1.71)$ \\
Chemerin, $\mu \mathrm{g} / \mathrm{ml}$ & $0.33(0.28-0.39)$ & $0.33(0.28-0.39)$ & & $0.38(0.28-0.53)$ & $0.29(0.25-0.34)$ \\
Adipsin, $\mu \mathrm{g} / \mathrm{ml}$ & $1.25(1.04-1.51)$ & $1.18(0.96-1.46)$ & & $1.23(0.87-1.74)$ & $1.14(0.84-1.54)$ \\
Resistin, $\mu \mathrm{g} / \mathrm{ml}$ & $3.16(2.54-3.93)$ & $2.86(2.40-3.41)$ & & $3.12(2.22-4.39)$ & $2.68(2.19-3.28)$ \\
$\mathrm{SAA}-1, \mu \mathrm{g} / \mathrm{ml}$ & $8.04(6.88-9.39)$ & $7.55(6.67-8.54)$ & & $8.06(6.27-10.4)$ & $7.17(6.31-8.14)$ \\
$\mathrm{CXCL} 10, \mathrm{ng} / \mathrm{ml}$ & $1.55(1.22-1.96)$ & $1.73(1.36-2.20)$ & & $2.06(1.32-3.23)$ & $1.51(1.15-1.98)$ \\
$\mathrm{MIF}, \mathrm{ng} / \mathrm{ml}$ & $2.51(1.92-3.28)$ & $2.30(1.71-3.09)$ & & $2.35(1.87-2.95)$ & $2.26(1.33-3.86)$ \\
$\mathrm{MIP}-1 \alpha, \mathrm{pg} / \mathrm{ml} \mathrm{b}$ & $37.5(20.3-69.1)$ & $55.4(41.2-74.4)$ & & $45.0(23.7-85.3)$ & $64.0(47.0-87.0)$ \\
$\mathrm{MCP}-1, \mathrm{ng} / \mathrm{ml} \mathrm{c}$ & $0.95(0.48)$ & $1.05(0.39)$ & & $1.03(0.41)$ & $1.06(0.38)$ \\
$\mathrm{OPG}, \mathrm{ng} / \mathrm{ml} \mathrm{c}$ & $1.18(0.45)$ & $1.10(0.27)$ & & $1.05(0.25)$ & $1.15(0.28)$ \\
\hline
\end{tabular}

Abbreviations: CXCL10, C-X-C motif chemokine 10; IL-1RA, interleukin-1 receptor antagonist; IL-6, interleukin-6; MCP-1, monocyte chemotactic protein-1; MIF, macrophage migration inhibiting factor; $M I P-1 \alpha$, macrophage inflammatory protein-1 $\alpha$; OPG, osteoprotegerin; PAI-1, plasminogen activator inhibitor-1; SAA-1, serum amyloid A1. Data are geometric means and 95\% confidence intervals, except indicated otherwise. ${ }^{a}$ No plasma available for $n=1$ COPD patient. ${ }^{b}$ Valid measures above the lower limit of detection available for $n=22$ COPD patients and $n=13$ healthy controls. ${ }^{c}$ Mean (SD). None of the comparisons were statistically significant.

adipocyte death but rather with adipocyte atrophy [11]. In line, we report a positive relation between fat mass and adipocyte size in COPD, which was similar in healthy controls. This suggests that the behavior of adipocyte atrophy and hypertrophy with changing fat mass follows a physiological pattern in COPD patients.

ATMs are believed to be mediators of ATI, so a quantification of ATMs would provide an indication of ATI. Whereas we found no differences in ATM infiltration between COPD patients and healthy controls, ATM infiltration was higher in high-CRP COPD patients compared to low-CRP patients, suggesting a relation between low-grade systemic inflammation and ATI. Interestingly, we found that CD68 mRNA levels were not correlated with the density of solitary ATMs but a correlation was found with the density of CLS. As CD68 is a lysosomal glycoprotein that is implicated in endocytosis and lysosomal migration of macrophages, our findings suggest that ATMs involved in a CLS express considerably more CD68 compared to residing/resting solitary ATMs (Figure 1). In line with previous publications $[11,19]$, we found that fat mass was positively 
Figure 4. Correlations between fat mass, adipose tissue mRNA and systemic concentrations of leptin and adiponectin in COPD patients (closed circles) and healthy controls (open circles).

A

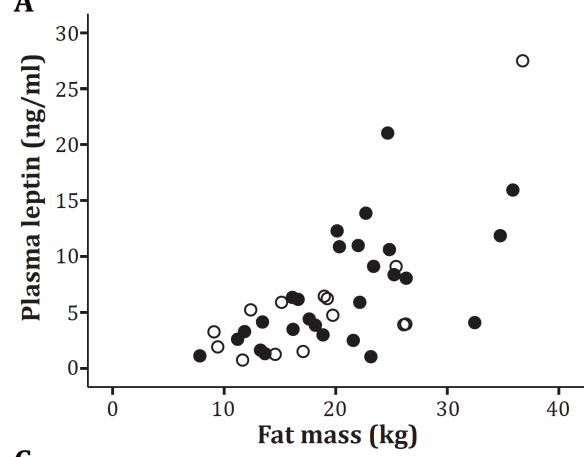

C

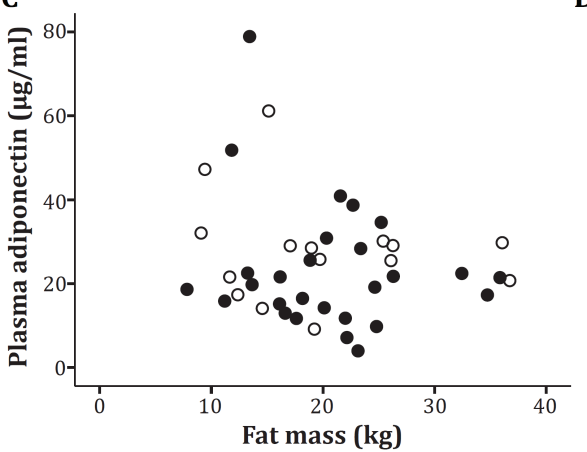

B
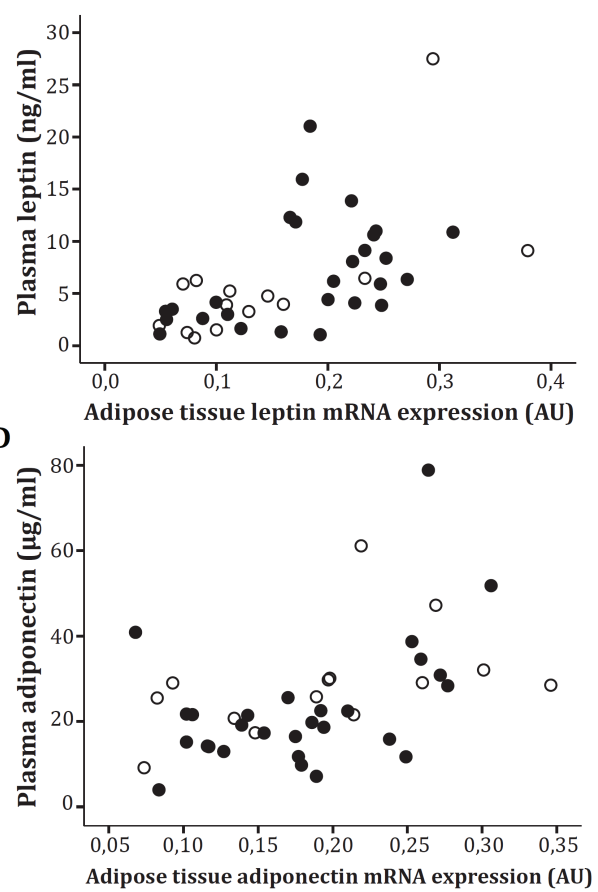

A) Correlation between fat mass and systemic leptin concentration, COPD patients: Spearman's $\rho=0.62$, $P=.001, n=27$, healthy controls: Spearman's $\rho=0.58, P=.029, n=14, B$ ) Correlation between adipose tissue leptin $m R N A$ expression and systemic leptin concentration, COPD patients: Spearman's $\rho=0.50, P=.009$, $n=27$, healthy controls: Spearman's $\rho=0.63, P=.016, n=14, C$ ) Correlation between fat mass and systemic adiponectin concentration, COPD patients: Spearman's $\rho=-0.05, P=.80, n=27$, healthy controls: Spearman's $\rho=-0.14, P=.63, n=15$, D) Correlation between adipose tissue adiponectin $m R N A$ expression and systemic adiponectin concentration, COPD patients: Spearman's $\rho=0.41, P=.033, n=27$, healthy controls: Spearman's $\rho=0.68, P=.005, n=15$.

correlated with markers of ATMs, which was highly comparable between COPD patients and healthy controls. This has been well-accepted to be a characteristic of obesity and has been linked to the development of IR via ATI [19].

Interestingly, despite the absence of greater ATM density, COPD patients were characterized by a higher HOMA-IR compared to the healthy controls, suggesting that IR in COPD patients is not necessarily associated with greater ATM infiltration. Likewise, $\mathrm{COPD}_{\mathrm{ND}}$ patients had considerably higher insulin and HOMA-IR compared to $\mathrm{COPD}_{\mathrm{D}}$ patients, but no differences in ATM infiltration were found. It must, however, be mentioned that we did not perform a hyperinsulinemic euglycemic clamp to verify IR. 
Figure 5. Correlations between fat mass and markers of adipose tissue macrophages in COPD patients (closed circles) and healthy controls (open circles).
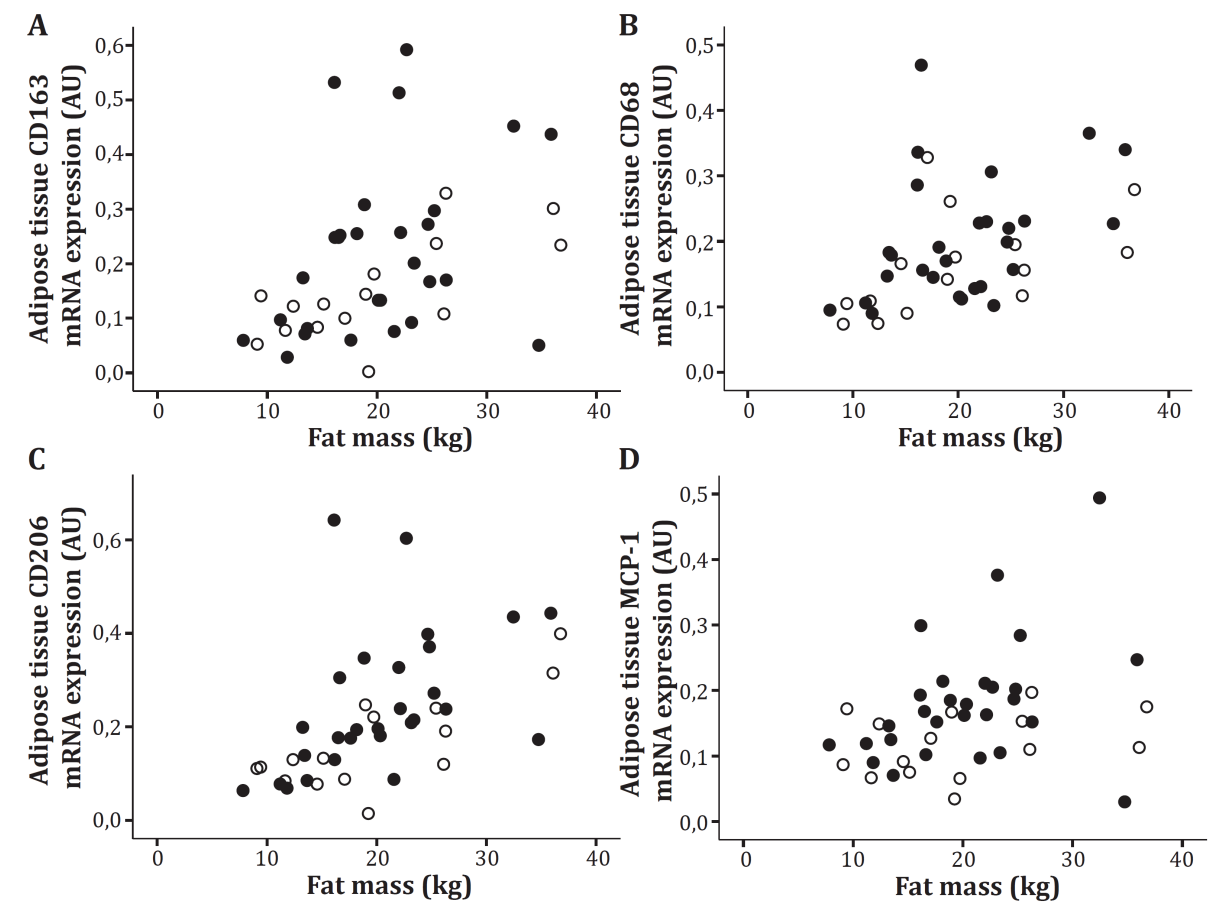

A) Correlation between fat mass and adipose tissue CD163 mRNA expression, COPD patients: Spearman's $\rho=0.36, P=.060, n=28$, healthy controls: Spearman's $\rho=0.66, P=.007, n=15$, B) Correlation between fat mass and adipose tissue CD68 mRNA expression, COPD patients: Spearman's $\rho=0.42, P=.025$, $n=28$, healthy controls: Spearman's $\rho=0.66, P=.007, n=15, C)$ Correlation between fat mass and adipose tissue CD206 mRNA expression, COPD patients: Spearman's $\rho=0.60, P=.001, n=28$, healthy controls: Spearman's $\rho=0.64, P=.010, n=15, D)$ Correlation between fat mass and adipose tissue MCP-1 mRNA expression, COPD patients: Spearman's $\rho=0.41, P=.033, n=28$, healthy controls: Spearman's $\rho=0.30$, $P=.28, n=15$.

Animal and in vitro studies indicate that hypoxia may lead to ATI. For example, hypoxia increased the activity of the pro-inflammatory transcription factor Nuclear Factor- $\mathrm{kB}$ and the TNF- $\alpha$ gene promoter in murine adipocytes [20], and it deregulates the production of adiponectin and PAI-1 [21]. In obesity, it has been postulated that adipocyte hypertrophy combined with impaired neovascularisation may ultimately lead to an unbridgeable diffusion distance for oxygen both on the tissue level as well as on the cellular level [5]. Indeed, obese mice had hypoxic patches in the adipose tissue which was associated with ATI $[20,22]$. However, human data on adipose tissue hypoxia as underlying ATI is scarce. Recently, Goossens et al. challenged the concept of adipose tissue hypoxia in humans by showing that obese insulin resistant men were characterized by 
adipose tissue hyperoxia rather than hypoxia [23]. We found that in the presence of a mild hypoxaemia in the COPD patients relative to the healthy controls (i.e., a mean difference in $\mathrm{PaO}_{2}$ of $2.7 \mathrm{kPa}$ ), no clear differences could be observed with regard to markers of adipose tissue hypoxia or ATI. Assuming that $\mathrm{COPD}_{\mathrm{D}}$ patients would also desaturate during daily living activities [6], we show that the desaturating COPD phenotype is not associated with either of these outcomes. Additionally, adipocyte size and (neo-) vascularisation markers were comparable across the current study groups. Collectively, our data suggest that neither mild hypoxaemia nor a desaturation phenotype is associated with ATI in COPD patients.

Figure 6. Adipose tissue macrophages in COPD patients with low versus high CRP.

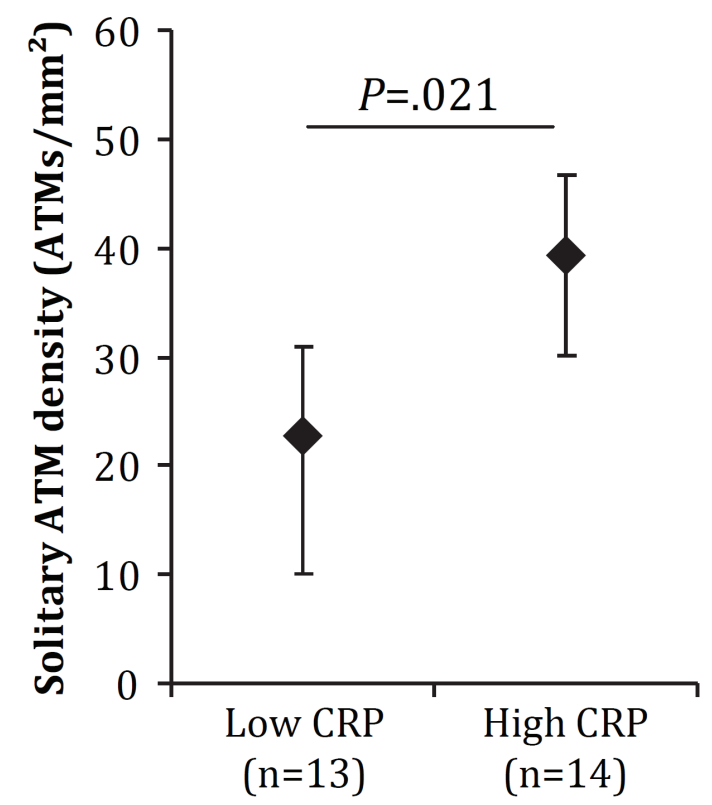

Data points are geometrical means, error bars represent the 95\% confidence interval. Data were tested using independent-samples $t$-test.

Several authors have claimed disturbances in systemic adipokine levels in COPD patients [24-29]. Takabatake et al. [28] showed lower systemic leptin levels in underweight COPD patients compared to normal-weight non-COPD controls and Eker et al. [30] found lower systemic leptin levels in COPD patients with decreased FFM compared to BMI- and sex-matched healthy controls. In our study, none of the measured systemic adipokines (including leptin and 
adiponectin) revealed different levels between COPD patients and matched healthy controls, indicating the importance of adjusting for fat mass. Indeed, we found a strong positive correlation between fat mass and circulating leptin levels, which was found to be similar in COPD patients and healthy controls. In addition, adipose tissue expression of leptin and adiponectin were positively correlated with systemic leptin and adiponectin levels, respectively, also in a similar fashion in COPD patients as in healthy controls.

Recently, important distinct functions and characteristics of SAT versus visceral adipose tissue (VAT) have been reported. For example, the relative contribution of SAT compared to VAT to systemic adipokine levels may be limited [31] and differences exist in neovascularisation with expanding fat mass which may exert different metabolic effects in SAT and VAT [32]. Also, expanding VAT is generally associated with increased cardiovascular risk whereas expanding SAT may even lower cardiovascular risk especially in women [33]. Therefore, it would be interesting to explore a potential VAT dysfunction in COPD patients in future studies and compare it to SAT function. In addition, studying potential adipose tissue dysfunction in more severe COPD patients and during acute exacerbations may add to optimizing nutritional and lifestyle interventions.

In conclusion, markers of ATI and systemic adipokine levels in clinically stable mild-to-moderate COPD patients who are characterized by low-grade systemic inflammation, higher HOMA-IR and mild relative hypoxaemia, were comparable to age-, sex-, BMI- and body composition-matched healthy controls. Our study provides a first indication for a possible role of ATMs in the systemic inflammatory response in COPD that warrants further investigation. 


\section{References}

1. Barnes PJ, Celli BR. Systemic manifestations and comorbidities of COPD. Eur Respir J. 2009;33(5):1165-85.

2. Mancuso P. Obesity and lung inflammation. J Appl Physiol. 2010;108(3):722-8.

3. Skurk T, Alberti-Huber C, Herder C, Hauner H. Relationship between adipocyte size and adipokine expression and secretion. J Clin Endocrinol Metab. 2007;92(3):1023-33.

4. Schiffelers SL, Blaak EE, Baarends EM, Van Baak MA, Saris WH, Wouters EF, Schols AM. beta-Adrenoceptormediated thermogenesis and lipolysis in patients with chronic obstructive pulmonary disease. Am J Physiol Endocrinol Metab. 2001;280(2):E357-64.

5. Trayhurn P, Wang B, Wood IS. Hypoxia in adipose tissue: a basis for the dysregulation of tissue function in obesity? Br J Nutr. 2008;100(2):227-35.

6. Soguel Schenkel N, Burdet L, de Muralt B, Fitting JW. Oxygen saturation during daily activities in chronic obstructive pulmonary disease. Eur Respir J. 1996;9(12):2584-9.

7. Bolton CE, Evans M, Ionescu AA, Edwards SM, Morris RH, Dunseath G, Luzio SD, Owens DR, Shale DJ. Insulin resistance and inflammation - A further systemic complication of COPD. Copd. 2007;4(2):121-6.

8. Torres-Leal FL, Fonseca-Alaniz MH, Rogero MM, Tirapegui J. The role of inflamed adipose tissue in the insulin resistance. Cell Biochem Funct. 2011;28(8):623-31.

9. Morris DL, Singer K, Lumeng CN. Adipose tissue macrophages: phenotypic plasticity and diversity in lean and obese states. Curr Opin Clin Nutr Metab Care. 2011;14(4):341-6.

10. Tkacova R, Ukropec J, Skyba P, Ukropcova B, Pobeha P, Kurdiova T, Joppa P, Klimes I, Tkac I, Gasperikova D. Increased adipose tissue expression of proinflammatory CD40, MKK4 and JNK in patients with very severe chronic obstructive pulmonary disease. Respiration. 2011;81(5):386-93.

11. Skyba P, Ukropec J, Pobeha P, Ukropcova B, Joppa P, Kurdiova T, Stroffekova K, Brusik M, Klimes I, Tkac I, et al. Metabolic phenotype and adipose tissue inflammation in patients with chronic obstructive pulmonary disease. Mediators Inflamm. 2010;2010:173498.

12. Fulda S, Linseisen J, Wolfram G, Himmerich S, Gedrich K, Pollmacher T, Himmerich H. Leptin plasma levels in the general population: influence of age, gender, body weight and medical history. Protein Pept Lett. 2010;17(11):1436-40.

13. Boyne MS, Bennett NR, Cooper RS, Royal-Thomas TY, Bennett FI, Luke A, Wilks RJ, Forrester TE. Sexdifferences in adiponectin levels and body fat distribution: longitudinal observations in Afro-Jamaicans. Diabetes Res Clin Pract. 2010;90(2):e33-6.

14. ATS/ACCP Statement on cardiopulmonary exercise testing. Am J Respir Crit Care Med. 2003;167(2):211-77.

15. Vandesompele J, De Preter K, Pattyn F, Poppe B, Van Roy N, De Paepe A, Speleman F. Accurate normalization of real-time quantitative RT-PCR data by geometric averaging of multiple internal control genes. Genome Biol. 2002;3(7):RESEARCH0034.

16. Schipper HS, de Jager W, van Dijk ME, Meerding J, Zelissen PM, Adan RA, Prakken BJ, Kalkhoven E. A multiplex immunoassay for human adipokine profiling. Clin Chem. 2010;56(8):1320-8.

17. Wallace TM, Levy JC, Matthews DR. Use and abuse of HOMA modeling. Diabetes Care. 2004;27(6):1487-95.

18. Benjamini $Y$, Hochberg Y. Controlling the false discovery rate: a practical and powerful approach to multiple testing. Journal of the Royal Statistical Society. 1995;57(1):289-300.

19. Red Eagle A, Chawla A. In obesity and weight loss, all roads lead to the mighty macrophage. J Clin Invest. 2010;120(10):3437-40.

20. Ye J, Gao Z, Yin J, He Q. Hypoxia is a potential risk factor for chronic inflammation and adiponectin reduction in adipose tissue of ob/ob and dietary obese mice. Am J Physiol Endocrinol Metab. 2007;293(4):E1118-28.

21. Chen B, Lam KS, Wang Y, Wu D, Lam MC, Shen J, Wong L, Hoo RL, Zhang J, Xu A. Hypoxia dysregulates the production of adiponectin and plasminogen activator inhibitor-1 independent of reactive oxygen species in adipocytes. Biochem Biophys Res Commun. 2006;341(2):549-56.

22. Hosogai N, Fukuhara A, Oshima K, Miyata Y, Tanaka S, Segawa K, Furukawa S, Tochino Y, Komuro R, Matsuda $\mathrm{M}$, et al. Adipose tissue hypoxia in obesity and its impact on adipocytokine dysregulation. Diabetes. 2007;56(4):901-11.

23. Goossens GH, Bizzarri A, Venteclef N, Essers Y, Cleutjens JP, Konings E, Jocken JW, Cajlakovic M, Ribitsch V, Clement $\mathrm{K}$, et al. Increased adipose tissue oxygen tension in obese compared with lean men is accompanied by insulin resistance, impaired adipose tissue capillarization, and inflammation. Circulation. 2011;124(1):67-76.

24. Breyer MK, Rutten EP, Vernooy JH, Spruit MA, Dentener MA, van der Kallen C, Vangreevenbroek MM, Wouters EF. Gender differences in the adipose secretome system in chronic obstructive pulmonary disease (COPD): A pivotal role of leptin. Respir Med. 2011;105(7):1046-53.

25. Wang QY, Zhang H, Yan X, Kang J, Yu RJ. [Serum resistin and leptin in patients with chronic obstructive pulmonary disease and their relationship to nutritional state]. Zhonghua Jie $\mathrm{He} \mathrm{He} \mathrm{Hu} \mathrm{Xi} \mathrm{Za} \mathrm{Zhi.}$ 2005;28(7):445-7.

26. Poulain M, Doucet M, Drapeau V, Fournier G, Tremblay A, Poirier P, Maltais F. Metabolic and inflammatory profile in obese patients with chronic obstructive pulmonary disease. Chron Respir Dis. 2008;5(1):35-41.

27. Tomoda K, Yoshikawa M, Itoh T, Tamaki S, Fukuoka A, Komeda K, Kimura H. Elevated circulating plasma adiponectin in underweight patients with COPD. Chest. 2007;132(1):135-40.

28. Takabatake N, Nakamura H, Abe S, Hino T, Saito H, Yuki H, Kato S, Tomoike H. Circulating leptin in patients with chronic obstructive pulmonary disease. Am J Respir Crit Care Med. 1999;159(4 Pt 1):1215-9.

29. Yuan Y, Wang Z, Liu C. [Preliminary investigation of effect of serum leptin on nutritional state of COPD patients]. Zhonghua Jie He He Hu Xi Za Zhi. 2000;23(5):292-5. 


\section{ADIPOSE TISSUE INFLAMMATION IN COPD}

30. Eker S, Ayaz L, Tamer L, Ulubas B. Leptin, visfatin, insulin resistance, and body composition change in chronic obstructive pulmonary disease. Scand J Clin Lab Invest. 2010;70(1):40-4.

31. Hocking SL, Wu LE, Guilhaus M, Chisholm DJ, James DE. Intrinsic depot-specific differences in the secretome of adipose tissue, preadipocytes, and adipose tissue-derived microvascular endothelial cells. Diabetes. 2010;59(12):3008-16.

32. Gealekman O, Guseva N, Hartigan C, Apotheker S, Gorgoglione M, Gurav K, Tran KV, Straubhaar J, Nicoloro S, Czech MP, et al. Depot-specific differences and insufficient subcutaneous adipose tissue angiogenesis in human obesity. Circulation. 2011;123(2):186-94.

33. Zafon C. Fat and aging: a tale of two tissues. Curr Aging Sci. 2009;2(2):83-94.

34. Cinti S, Mitchell G, Barbatelli G, Murano I, Ceresi E, Faloia E, Wang S, Fortier M, Greenberg AS, Obin MS. Adipocyte death defines macrophage localization and function in adipose tissue of obese mice and humans. J Lipid Res. 2005;46(11):2347-55.

35. Quanjer PH, Tammeling GJ, Cotes JE, Pedersen OF, Peslin R, Yernault JC. Lung volumes and forced ventilatory flows. Report Working Party Standardization of Lung Function Tests, European Community for Steel and Coal. Official Statement of the European Respiratory Society. Eur Respir J Suppl. 1993;16:5-40. 


\section{Supplemental material}

\section{Detailed methodology}

Clinically stable COPD patients were recruited from the outpatient clinic of the Maastricht University Medical Centre (MUMC+, Maastricht, The Netherlands) and using advertisements in local newspapers. Patients were excluded in case of long-term oxygen therapy, acute exacerbation with hospital admission in the past eight weeks, oral steroid use, rehabilitation in the past six months, scheduled rehabilitation and $\alpha 1$-antitrypsin deficiency. COPD patients with known chronic heart failure, cancer treatment in the past three years, sarcoidosis, pulmonary embolism, obstructive or central sleep apnea syndrome, diabetes mellitus, hepatic or renal failure, rheumatoid arthritis, M. Bechterew and inflammatory bowel disease were excluded from this study. Subjects performed an incremental exercise test (see below for methodology) to determine exercise-induced desaturation defined as a fall in oxygen saturation $\left(\mathrm{SaO}_{2}\right)$ of $\geq 4 \%$ [14]. This study included $28 \mathrm{COPD}$ patients of whom 12 desaturated $\left(\mathrm{COPD}_{\mathrm{D}}\right.$, mean $\left.\pm \mathrm{SD} \Delta \mathrm{SaO}_{2}-8.5 \pm 2.2 \%\right)$ and 16 did not $\left(\mathrm{COPD}_{\mathrm{ND}}, \Delta \mathrm{SaO}_{2}\right.$ $-2.1 \pm 1.7 \%$ ). Fifteen healthy controls were recruited via advertising in local newspapers. The absence of co-morbidities in the healthy controls (including asthma and COPD) was ascertained based on a physician's diagnosis, lung function, self-reported history and/or treatment. Written informed consent was obtained from all subjects and the ethical review board of the MUMC+ approved the study (MEC 08-2-059).

\section{Pulmonary function and incremental exercise test}

Pulmonary function testing included forced spirometry and single breath diffusion capacity measurement (Masterlab, Jaeger, Würzburg, Germany). Instruments were calibrated twice a day. All values obtained were expressed as a percentage of reference values [35]. All subjects performed an incremental cycle ergometry test according to international standards [14]. After three minutes of unloaded cycling, workload was increased by 10 Watt every minute in patients. In control subjects, the load was increased with 15-25 Watt $\cdot \mathrm{min}^{-1}$, depending on relative fitness of the subject, so as to lead to fatigue in 10-12 minutes. Subjects were encouraged to cycle at $60 \mathrm{rpm}$ until exhaustion. $\mathrm{SaO}_{2}$ during the test was monitored by pulse oximetery. Arterial blood gas analysis (Blood gas analyzer 865, Chiron Diagnostics, Emeryville, CA, USA) was performed at rest and at $\mathrm{VO}_{2}$ max from a radial artery puncture. 
Cardiometabolic and systemic inflammatory profile

After an overnight fast, venous blood was drawn in the morning and plasma and serum were stored at $-80^{\circ} \mathrm{C}$ until further analysis. Plasma concentrations of 19 adipo(cyto)kines were analyzed with a multiplex immunoassay as described in detail elsewhere [16]. The lower limits of detection (LLOD) are presented in Table E3. For IL-6, 28\% ( $n=7$ COPD patients and $n=5$ healthy controls) of the data set was below the last linear point of the standard curve $(3.6 \mathrm{pg} / \mathrm{ml})$ but above the LLOD and therefore extrapolated data was used. Serum C-reactive protein (CRP) was determined with the CardioPhase ${ }^{\circledR}$ high-sensitive CRP kit (Siemens Healthcare Diagnostics Inc., Newark, N) (LLOD $0.18 \mathrm{mg} / \mathrm{L}$ ). Glucose was measured on a SensoStar GL 30 (DiaSys Diagnostics Systems GmbH, Holzheim, Germany) and insulin was measured by the AutoDELFIA ${ }^{\circledR}$ timeresolved fluoroimmunoassay (PerkinElmer, Turku, Finland). Homeostatic model assessment (HOMA) was applied to estimate IR by HOMA-IR=(Fasting insulin * Fasting glucose)/22,5 [17]. Serum N-terminal pro-Brain Natriuretic Peptide (NTproBNP) was measured using an electrochemiluminescence immunoassay (Roche Diagnostics, Woerden, The Netherlands).

Supplemental Table 1. Pulmonary medication in COPD patients $(\mathrm{n}=28)$.

\begin{tabular}{lcc}
\hline Pulmonary medication & n & \% \\
\hline Long-acting $\beta 2$ agonist (LABA) & 4 & 14 \\
Short-acting $\beta 2$ agonist & 10 & 36 \\
Long-acting anticholinergic & 18 & 64 \\
Short-acting anticholinergic & 4 & 14 \\
Inhaled corticosteroids (ICS) & 4 & 14 \\
LABA+ICS & 13 & 46 \\
Any $\beta 2$ agonist & 20 & 71 \\
\hline
\end{tabular}


Supplemental Table 2. Primer sequences used for RT-qPCR.

\begin{tabular}{|c|c|c|}
\hline & Forward 5'-3' & Reverse 5'-3' \\
\hline \multicolumn{3}{|l|}{ Target genes } \\
\hline Leptin & CGGAGAGTACAGTGAGCCAAGA & CGGAATCTCGCTCTGTCATCA \\
\hline Adiponectin & CCCAAAGAGGAGAGAGGAAGCT & GCCAGAGCAATGAGATGCAA \\
\hline Chemerin & AAGTCAGGCCCAATGGGAGG & CCAACCGGCCCAGAACTTTGT \\
\hline PAI-1 & GAAAGTGAAGATCGAGGTGAACGAGA & CATGCGGGCTGAGACTATGACA \\
\hline Adrenomedullin & ACTTGGCAGATCACTCTCTTAGCA & TCAGGGCGACGGAAACC \\
\hline CD163 & AGACAGAGACAGCGGCTTGCA & GCAAGAATTCATCTCCCGGTATTG \\
\hline CD206 & TCTGGAATGTCTTCGAATGGGTTC & GGCTCAACCCGATATGACAGAAAA \\
\hline CD11b & ACACGGGATCGGCTAAGAGAAGGA & CGGGAATGTGGGCGGC \\
\hline Visfatin & GGAAACCCTCTTGACACTGTGTTAAAGG & AAGATAAGGTGGCAGCAACTTGTAACC \\
\hline Osteoprotegerin & TTGGAGTGGTGCAAGCTGGAA & ACCCATCTGGACATCTTTTGCAAA \\
\hline PPAR- $\gamma$ & CGGGCCCTGGCAAAAC & AAGATCGCCCTCGCCTTT \\
\hline IL-8 & CACTGCGCCAACACAGAAAT & GAGCTCTCTTCCATCAGAAAGC \\
\hline IL-10 & ATGGTGGCGCGCACCTG & CCTGGGTTCAAGCAATTCTCTTGC \\
\hline VEGF-A & CCAGGCCCTCGTCATTG & AAGGAGGAGGGCAGAATCAT \\
\hline CD34 & TAACGCCCTCCGCCTTTGG & GCGCCTCTCCTTGGCTGCTA \\
\hline MCP1 & AGCAGCAAGTGTCCCAAAGAAGCT & CCTTGGCCACAATGGTCTTGAA \\
\hline CD68 & GGACATTCTCGGCTCAGAAT & GCCTGGTAGGCGATGGGCG \\
\hline GLUT-1 & TCTGGGCTGCCGGGTTCTAG & TTTGCAGGCTCCCACAGGC \\
\hline HIF- $1 \alpha$ & TGAACATAAAGTCTGCAACATGGA & TGAGGTTGGTTACTGTTGGTATCATATA \\
\hline \multicolumn{3}{|c|}{ Housekeeping genes } \\
\hline GAPDH & GCACCACCAACTGCTTAGCA & TGGCAGTGATGGCATGGA \\
\hline$\beta 2$-microglobulin & TGACTTTGTCACAGCCCAAGATA & AATGCGGCATCTTCAAACCT \\
\hline RPL13A & CCTGGAGGAGAAGAGGAAAGAGA & TTGAGGACCTCTGTGTATTTGTCAA \\
\hline
\end{tabular}




\section{ADIPOSE TISSUE INFLAMMATION IN COPD}

Supplemental Table 3. Lower limits of detection (LLOD) of plasma adipo(cyto)kines.

\begin{tabular}{lc}
\hline Adipo(cyto)kines & LLOD (pg/ml) \\
\hline IL-1RA & 0.7 \\
IL-1 $\beta$ & 0.5 \\
IL-6 & 0.8 \\
IL-10 & 0.8 \\
TNF- $\alpha$ & 0.4 \\
IFN- $\gamma$ & 1.4 \\
MIF & 1.4 \\
CCL2 (MCP-1) & 0.4 \\
CCL3 (MIP1 $\alpha$ ) & 3.1 \\
CXCL8 (IL-8) & 1.8 \\
CXCL10 (IP10) & 0.3 \\
Leptin & 0.3 \\
OPG & 0.7 \\
Chemerin & 31.7 \\
Adipsin (Compl Factor D) & 0.4 \\
Resistin & 12.8 \\
SAA-I & 832 \\
PAI-I & 88.2 \\
Adiponectin & 36.4 \\
\hline Abbreviations: CCL, C-C motif ligand; CXCL, C-X-C motif ligand; IL, interleukin; MCP-1, monocyte \\
chemotactic protein-1; MIF, macrophage migration inhibiting factor; \\
inflammatory protein-1 $\alpha$; OPG, osteoprotegerin; PAI-1, plasminogen activator inhibitor-1; SAA-1, serum \\
amyloid A1. & \\
\hline
\end{tabular}


Supplemental Table 4. Comparison between COPD patients with low CRP (i.e. $\mathrm{CRP}<$ median) versus high CRP (i.e. CRP $\geq$ median).

\begin{tabular}{|c|c|c|}
\hline & $\begin{array}{l}\text { Low CRP COPD } \\
\text { patients }(n=13)\end{array}$ & $\begin{array}{l}\text { High CRP COPD patients } \\
\qquad(n=14)\end{array}$ \\
\hline \multicolumn{3}{|l|}{ Demographics } \\
\hline Sex, $m / f$ & $8 / 5$ & $8 / 6$ \\
\hline Age, y & $66(7)$ & $65(7)$ \\
\hline \multicolumn{3}{|l|}{ Smoking status } \\
\hline Current, n (\%) & $6(46)$ & $3(21)$ \\
\hline Former, n (\%) & $7(54)$ & $11(79)$ \\
\hline Never, n (\%) & $0(0)$ & $0(0)$ \\
\hline \multicolumn{3}{|l|}{ Pulmonary function } \\
\hline $\mathrm{FEV}_{1}, \%$ pred & $57(18)$ & $60(16)$ \\
\hline FVC, \%pred & $110(19)$ & $100(24)$ \\
\hline $\mathrm{FEV}_{1} / \mathrm{FVC}, \%$ & $42(13)$ & $47(11)$ \\
\hline DLCO, \%pred & $48(15)$ & $54(18)$ \\
\hline $\mathrm{SaO}_{2}$ at rest, $\%$ & $97(2)$ & $96(1)$ \\
\hline $\mathrm{SaO}_{2}$ at $\mathrm{VO}_{2, \max } \%$ & $92(5)$ & $91(4)$ \\
\hline $\mathrm{PaO}_{2}$ at rest, $\mathrm{kPa}$ & $9.6(1.1)$ & $9.4(1.0)$ \\
\hline $\mathrm{PaO}_{2}$ at $\mathrm{VO}_{2, \max }, \mathrm{kPa}^{\mathrm{a}}$ & $9.4(1.9)$ & $8.9(1.1)$ \\
\hline \multicolumn{3}{|l|}{ Body composition } \\
\hline $\mathrm{BMI}, \mathrm{kg} / \mathrm{m}^{2}$ & $24.0(2.7)$ & $25.5(3.1)$ \\
\hline FFMI, $\mathrm{kg} / \mathrm{m}^{2}$ & $17.1(1.6)$ & $17.9(1.9)$ \\
\hline FMI, $\mathrm{kg} / \mathrm{m}^{2}$ & $6.8(3.0)$ & $7.7(2.4)$ \\
\hline Total body fat, $\%$ & $28(10)$ & $31(7)$ \\
\hline \multicolumn{3}{|c|}{ Cardiometabolic profile ${ }^{b, c}$} \\
\hline Glucose, mmol/L & $5.7(5.4-6.0)$ & $6.0(5.7-6.4)$ \\
\hline Insulin, pmol/L & $47(28-78)$ & $48(33-71)$ \\
\hline HOMA-IR & $1.38(0.68-2.78)$ & $1.68(1.02-2.77)$ \\
\hline NT-proBNP, pmol/L & $9.0(5.9-13.8)$ & $10.2(5.7-18.2)$ \\
\hline \multicolumn{3}{|c|}{ Systemic inflammation ${ }^{b, c}$} \\
\hline $\mathrm{CRP}, \mathrm{mg} / \mathrm{L}$ & $0.90(0.75-1.08)$ & $4.38(2.33-8.24)^{d}$ \\
\hline
\end{tabular}


Supplemental Table 5. Comparison of adipose tissue mRNA levels (arbitrary units) between low and high CRP COPD patients.

\begin{tabular}{|c|c|c|}
\hline & $\begin{array}{c}\text { Low CRP COPD patients } \\
(n=13)\end{array}$ & $\begin{array}{l}\text { High CRP COPD patients } \\
\qquad(n=14)\end{array}$ \\
\hline GLUT1 & $0.17(0.13-0.23)$ & $0.16(0.12-0.21)$ \\
\hline HIF $1 \alpha$ & $0.19(0.17-0.20)$ & $0.19(0.17-0.21)$ \\
\hline VEGF-A & $0.18(0.14-0.24)$ & $0.14(0.11-0.19)$ \\
\hline CD34 & $0.19(0.12-0.28)$ & $0.14(0.11-0.17)$ \\
\hline PAI-1 & $0.16(0.10-0.25)$ & $0.20(0.14-0.30)$ \\
\hline Adrenomedullin & $0.22(0.17-0.28)$ & $0.24(0.18-0.31)$ \\
\hline Visfatin & $0.19(0.13-0.28)$ & $0.23(0.16-0.33)$ \\
\hline Osteoprotegerin & $0.19(0.14-0.26)$ & $0.26(0.20-0.35)$ \\
\hline IL-8 & $0.14(0.07-0.26)$ & $0.16(0.10-0.25)$ \\
\hline MCP-1 & $0.14(0.09-0.20)$ & $0.18(0.14-0.23)$ \\
\hline CD68 & $0.16(0.12-0.20)$ & $0.20(0.16-0.25)$ \\
\hline CD163 & $0.15(0.09-0.25)$ & $0.19(0.12-0.30)$ \\
\hline CD206 & $0.16(0.11-0.24)$ & $0.26(0.19-0.37)$ \\
\hline CD11b & $0.13(0.05-0.30)$ & $0.23(0.16-0.32)$ \\
\hline Leptin $^{\mathrm{a}}$ & $0.17(0.09)$ & $0.19(0.06)$ \\
\hline Adiponectin $^{\mathrm{a}}$ & $0.20(0.06)$ & $0.16(0.07)$ \\
\hline PPAR- $\gamma^{\mathrm{a}}$ & $0.18(0.05)$ & $0.15(0.06)$ \\
\hline Chemerin $^{\mathrm{a}}$ & $0.21(0.07)$ & $0.17(0.08)$ \\
\hline IL-10a & $0.29(0.08)$ & $0.28(0.07)$ \\
\hline
\end{tabular}

Abbreviations: GLUT1, glucose transporter 1; HIF1 $\alpha$, hypoxia inducible factor $1 \alpha$; VEGF-A, vascular endothelial growth factor-A; PAI-1, plasminogen activator inhibitor-1; MCP-1, monocyte chemotactic protein-1, PPAR- $\gamma$, peroxisome proliferator-activated receptor- $\gamma$. Data are geometric means and 95\% confidence intervals, except indicated otherwise. Independent-samples t-tests were used to analyze the data, and P values were interpreted applying false discovery rate correction for multiple testing. ${ }^{a}$ Mean (SD). 
Supplemental Table 6. Comparison of systemic adipokine levels between low and high CRP COPD patients.

\begin{tabular}{lcc}
\hline & $\begin{array}{c}\text { Low CRP COPD patients } \\
\text { (n=13) }\end{array}$ & $\begin{array}{c}\text { High CRP COPD patients } \\
\text { (n=14) }\end{array}$ \\
\hline IL-6, pg/ml & $4.34(3.03-6.22)$ & $5.79(2.29-14.6)$ \\
Leptin, ng/ml & $4.98(2.89-8.59)$ & $5.39(3.40-8.55)$ \\
Adiponectin, $\mu \mathrm{g} / \mathrm{ml}$ & $22.2(17.6-28.2)$ & $17.6(11.3-27.2)$ \\
PAI-1, $\mu \mathrm{g} / \mathrm{ml}$ & $1.90(0.95-3.77)$ & $1.57(1.22-2.01)$ \\
Chemerin, $\mu \mathrm{g} / \mathrm{ml}$ & $0.35(0.26-0.47)$ & $0.31(0.26-0.37)$ \\
Adipsin, $\mu \mathrm{g} / \mathrm{ml}$ & $1.17(0.79-1.74)$ & $1.19(0.93-1.51)$ \\
Resistin, $\mu \mathrm{g} / \mathrm{ml}$ & $2.59(1.95-3.44)$ & $3.10(2.43-3.96)$ \\
SAA-1, $\mu \mathrm{g} / \mathrm{ml}$ & $7.73(6.27-9.53)$ & $7.39(6.26-8.72)$ \\
CXCL10, ng/ml & $1.89(1.40-2.56)$ & $1.60(1.07-2.39)$ \\
IL-1RA, ng/ml & $1.66(1.19-2.32)$ & $1.40(1.30-1.50)$ \\
$\mathrm{MIF}, \mathrm{ng} / \mathrm{ml}$ & $2.60(1.70-3.98)$ & $2.05(1.30-3.23)$ \\
$\mathrm{MIP}-1 \alpha, \mathrm{pg} / \mathrm{ml})$ & $59(25)$ \\
$\mathrm{MCP}-1, \mathrm{ng} / \mathrm{ml}{ }^{\mathrm{a}} \mathrm{b}$ & $73(50)$ & $0.93(0.36)$ \\
OPG, ng/mlb & $1.17(0.38)$ & $1.10(0.27)$ \\
\hline
\end{tabular}

Abbreviations: IL-6, interleukin-6; PAI-1, plasminogen activator inhibitor-1; OPG, osteoprotegerin; MCP1, monocyte chemotactic protein-1; MIF, macrophage migration inhibiting factor; MIP-1 $\alpha$, macrophage inflammatory protein-1 $\alpha$, IL-1RA, interleukin-1 receptor antagonist; SAA-1, serum amyloid A1; CXCL10, $C-X-C$ motif chemokine 10; OPG, osteoprotegerin. Data are geometric means and $95 \%$ confidence intervals, except indicated otherwise. Independent-samples $t$-tests were used to analyze the data, and $P$ values were interpreted applying false discovery rate correction for multiple testing. ${ }^{a}$ Valid measures above the lower limit of detection available for $n=22$ patients. ${ }^{b}$ Mean (SD). None of the comparisons were statistically significant. 
Supplemental Figure 1. Correlation between adipose tissue macrophages quantified from CD68-stained paraffin sections and adipose tissue CD68 mRNA expression.
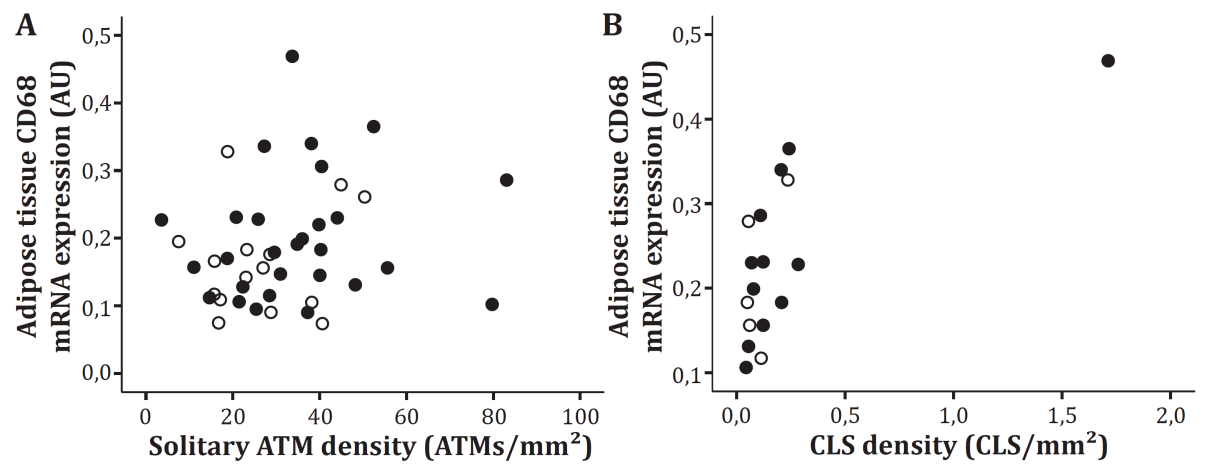

Abbreviations: ATM, adipose tissue macrophage; CLS, crown-like structure. A) Correlation between solitary ATMs and adipose tissue CD68 mRNA expression in COPD patients (black circles) and healthy controls (open circles). These correlations were not statistically significant (P>.05). B) Correlation between CLS density and adipose tissue CD68 mRNA expression in subjects in whom we encountered $\geq 1$ CLS. The CLS density was significantly correlated with adipose tissue CD68 mRNA expression (correlation for entire group because of the small sample size: Spearman's $\rho=0.53, P=.024, n=17)$. This positive correlation remained significant after excluding the outlier at CLS density=1.7 (Spearman's $\rho=0.50, P=.047, n=16$ ). 


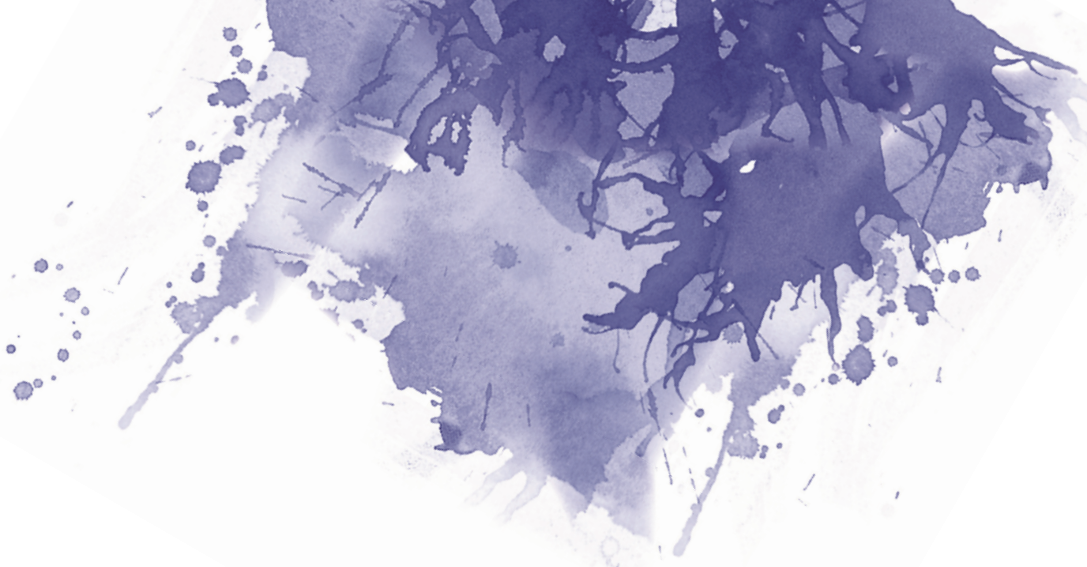

\section{CHAPTER 5}

\section{The influence of abdominal visceral fat on inflammatory pathways and mortality risk in obstructive lung disease}

Bram van den Borst, Harry R. Gosker, Annemarie Koster, Binbing Yu, Stephen B. Kritchevsky, Yongmei Liu, Bernd Meibohm, Thomas B. Rice, Michael Shlipak, Sachin Yende, Tamara B. Harris, Annemie M.W.J. Schols

For the Health, Aging and Body Composition (Health ABC) Study

American Journal of Clinical Nutrition 2012;96(3):516-26 


\section{Abstract}

Background: Low-grade systemic inflammation, particularly elevated IL-6, predicts mortality in chronic obstructive pulmonary disease (COPD). Although altered body composition, especially increased visceral fat (VF) mass, could be a significant contributor to low-grade systemic inflammation, this remains unexplored in COPD.

Objective: To investigate COPD-specific effects on VF, plasma adipocytokines and their predictive value for mortality.

Design: Within the Health, Aging and Body Composition Study, an observational study of community-dwelling older persons, we used propensity scores to match $\mathrm{n}=729$ persons with normal lung function to $\mathrm{n}=243$ persons with obstructive lung disease ( $\mathrm{OLD}$, defined as $\left.\mathrm{FEV}_{1} / \mathrm{FVC}<\mathrm{LLN}\right)$. Matching was based on age, gender, race, clinic site, body mass index and smoking. Within this well-balanced match, we compared CT-acquired VF area (VFA) and plasma adipocytokines, analyzed independent associations of VFA and OLD status on plasma adipocytokines, and studied their predictive value for 9.4-year mortality.

Results: Whereas whole-body fat mass was comparable between the groups, OLD persons had increased VFA and higher plasma IL-6, adiponectin and plasminogen activator inhibitor (PAI)-1. Both OLD status and VFA were independently positively associated with IL-6. Adiponectin was positively associated with OLD status, but negatively with VFA. PAI-1 was no longer associated with OLD status after accounting for VFA. OLD persons had increased risk of all-cause, respiratory and cardiovascular mortality, of which IL-6 was identified as an independent predictor.

Conclusions: Our data suggest that excessive abdominal visceral fat contributes to increased plasma IL-6 which, in turn, is strongly associated with all-cause and cause-specific mortality of older persons with OLD. 


\section{Introduction}

In older adults, the prevalence of chronic obstructive pulmonary disease (COPD) is $14 \%$ and as a consequence of general aging in the population and improved medical intervention, this prevalence is projected to increase even further [1]. COPD is characterized by altered body composition towards a relative or absolute increase in fat mass, low-grade systemic inflammation and high mortality [2]. Classically, low-grade systemic inflammation in these patients has been considered to be the result of a 'spill-over' of inflammatory mediators from the inflamed pulmonary compartment. For this, however, there has been no convincing evidence during clinically stable disease. The possibility of extrapulmonary tissues contributing to low-grade systemic inflammation in COPD has been relatively unexplored.

Adipose tissue has emerged as a potent producer of mediators of inflammation and energy homeostasis, termed adipocytokines [3], including interleukin (IL)-6, plasminogen activator inhibitor (PAI)-1, leptin and adiponectin. Notably, in diseases associated with excessive fat mass, such as obesity and type 2 diabetes, adipose tissue has been suggested to be the source of low-grade systemic inflammation [4]. In a recent clinical study, we examined adipocytokine gene expression and macrophage markers in biopsies from the abdominal subcutaneous fat (SF) compartment from COPD patients and fat mass-matched healthy subjects [5]. We found positive associations between fat mass and adipose tissue inflammation, which were highly comparable between COPD patients and controls. These data suggested that the SF compartment may not be the primary fat compartment contributing to low-grade systemic inflammation in COPD. Importantly, studies consistently indicate that the inflammatory capacity of abdominal visceral fat (VF) is considerably greater in comparison with other fat depots including SF $[6,7]$. Thus, VF may be a more plausible source of systemic inflammation than SF. Interestingly, a recent study in normal-weight mild-to-moderate COPD patients and healthy subjects used abdominal CT-scanning and found increased VF area (VFA) in COPD patients [8]. However, these patients also had increased whole-body fat mass, and it is unclear whether the increased VF was a reflection of the higher whole-body fat mass. Also, associations between VF and circulating adipocytokines were not assessed.

Whole-body fat mass increases with aging, and consistent data has shown that in this process, the expansion rate of VF exceeds that of SF $[9,10]$. Recently, in a review of inflammatory markers in population studies of aging, it has been proposed that aging-related mortality is associated with VF accumulation and 'inflammaging' [11]. Collectively, these studies stress the need for investigating the role of VF in low-grade systemic inflammation and mortality in COPD, accounting for important confounders including age and body mass index (BMI). The current study provides a comprehensive comparison of VF mass, plasma 
adipocytokines and their relation with 9.4-year mortality of COPD patients and propensity-score matched persons with normal lung function who participated in the Health, Aging and Body Composition (ABC) Study. Additionally, we explored dietary intake and physical activity as important lifestyle determinants in these subjects.

\section{Methods}

\section{Study population}

The observational Health ABC Study included 3075 community-dwelling black and white men and women between the ages of 70-79 years residing in and near Pittsburgh, Pennsylvania and Memphis, Tennessee. Baseline data were obtained in 1997/1998 through in-person interview and clinic based examination. Inclusion criteria were no self-reported difficulty walking a quarter mile, climbing 10 steps without resting, or performing mobility-related activities of daily living. Exclusion criteria were any life-threatening condition, participation in any research study involving medications or modification of eating or exercise habits, plans to move from the geographic area within 3 years, and difficulty in communicating with the study personnel or cognitive impairment. The study was approved by the Institutional Review Boards of the participating centers University of Tennessee Health Science Center, Memphis (\#95-05531-FB) and the University of Pittsburgh (\#960212), and of the coordinating center at the University of California, San Francisco (\#10-03322). Written informed consent was obtained for all participants. Clinic site, age and race (black/white) were based on self-report. In the current study we retrospectively analyzed baseline phenotypical data and 9.4-year mortality data.

\section{Lung function and smoking history}

Pre-bronchodilator lung function was assessed according to international standards as previously reported [12]. Since post-bronchodilator lung function was lacking, participants with a ratio between forced expiratory volume in $1 \mathrm{~s}$ $\left(\mathrm{FEV}_{1}\right)$ and forced vital capacity (FVC) below the age, sex, and race-normalized lower limit of normal (LLN) [12-14] were regarded as having obstructive lung disease (OLD). This method is exactly the same as applied in previous publications from the Health $\mathrm{ABC}$ Study $[12,15]$. Participants with restrictive lung disease $\left(\mathrm{FEV}_{1} / \mathrm{FVC} \geq \mathrm{LLN}\right.$ but $\left.\mathrm{FVC}<\mathrm{LLN}\right)$ were excluded (Figure 1). Normal lung function was defined as $\mathrm{FEV}_{1} / \mathrm{FVC} \geq \mathrm{LLN}$ and $\mathrm{FVC} \geq \mathrm{LLN}$. Participants with missing lung function and those with non-interpretable lung function measurements according to international criteria were excluded. Cigarette smoking status (current/former/never) and the number of pack years smoked ( 1 pack year $=20$ cigarettes $/$ day for 1 year ) were obtained based on self-report. 
Figure 1. Flow diagram of selection of study participants.

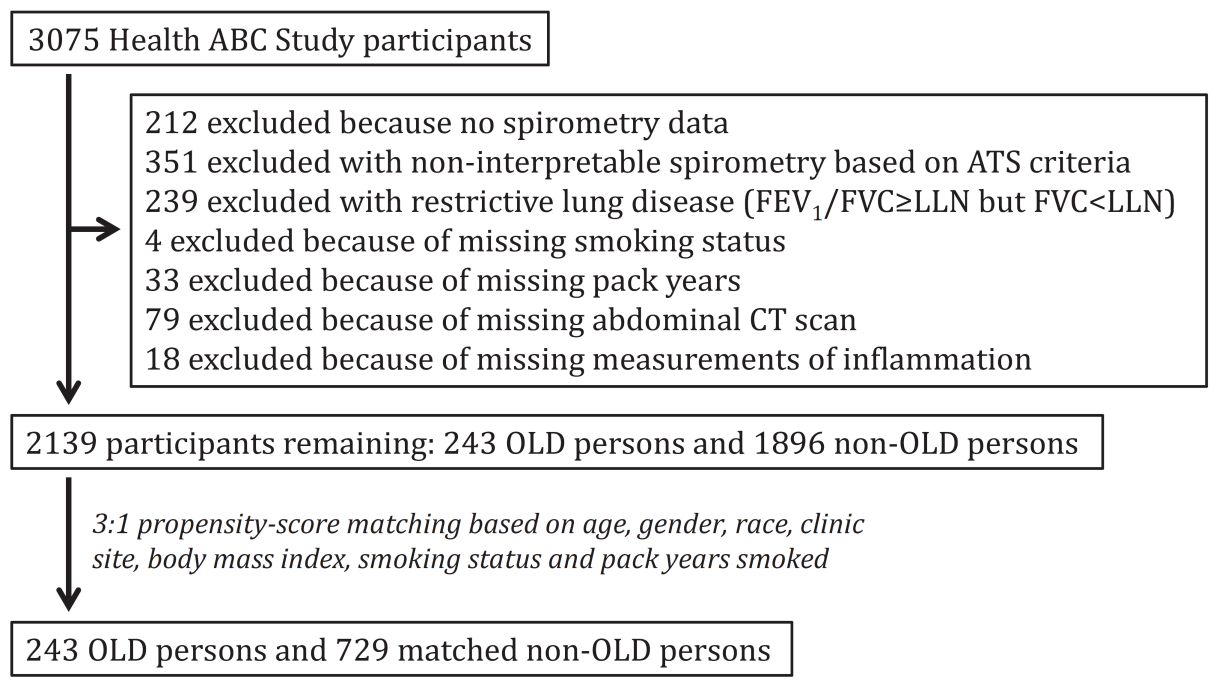

Abbreviations: ATS, American Thoracic Society; FEV 1 , forced expiratory volume in 1s; FVC, forced vital capacity; LLN, lower limit of normal; OLD, obstructive lung disease.

\section{Anthropometry and body composition}

Height was measured using a wall mounted stadiometer. Body weight was assessed to the nearest $0.1 \mathrm{~kg}$ using a standard balance beam scale and BMI was calculated as weight/height ${ }^{2}\left(\mathrm{~kg} / \mathrm{m}^{2}\right)$. Whole body DXA (Hologic $4500 \mathrm{~A}$ software version 8.21, Waltham, MA, USA) was used to assess total fat and fat free masses.

\section{Abdominal computerized tomography (CT)}

At $120 \mathrm{kVp}$ and $200-250 \mathrm{~mA}$ a $10 \mathrm{~mm}$ CT-scan of the abdomen was acquired at the L4-L5 level. Subjects were placed in the supine position with their arms above their head and legs elevated with a cushion to reduce the curve in the back. In Memphis the scan was acquired using a Somatom Plus 4 (Siemens, Erlangen, Germany) or a Picker PQ 2000S (Marconi Medical Systems, Cleveland, Oh, USA), and in Pittsburgh using a 9800 Advantage (General Electric, Milwaukee, WI, USA). Visceral Fat Area (VFA) was manually distinguished from subcutaneous fat area (SFA) by tracing along the fascial plane defining the internal abdominal wall. Areas were calculated by multiplying the number of pixels of a given tissue by the pixel area (see for further details [16]). 


\section{Circulating adipocytokines}

Interleukin (IL)-6, plasminogen activator inhibitor (PAI)-1, tumor necrosis factor (TNF)- $\alpha$, C-reactive protein (CRP), leptin and adiponectin were obtained from frozen stored plasma or serum obtained from a venipuncture after an overnight fast (a detailed description on measurement techniques was previously published [17]).

\section{$\underline{\text { Insulin resistance }}$}

The Homeostatic Model Assessment was used to estimate insulin resistance (HOMA-IR) from (fasting plasma glucose * fasting plasma insulin)/22,5 [18].

\section{Prevalent diseases}

The metabolic syndrome was defined according to international guidelines [19] as meeting at least three of the following criteria: 1) waist circumference $\geq 102$ $\mathrm{cm}$ in men and $\geq 88 \mathrm{~cm}$ in women, 2) diastolic blood pressure $\geq 85 \mathrm{mmHg}$ and/or systolic blood pressure $\geq 130 \mathrm{mmHg}$ or using antihypertensive medications, 3) fasting glucose level $\geq 100 \mathrm{mg} / \mathrm{dl}$ or using antidiabetic medication, 4) highdensity lipoprotein cholesterol (HDL) level $<40 \mathrm{mg} / \mathrm{dl}$ in men and $<50 \mathrm{mg} / \mathrm{dl}$ in women or currently on treatment for low HDL cholesterol, and 5) serum triglyceride level $\geq 150 \mathrm{mg} / \mathrm{dl}$ or currently on drug treatment for high triglycerides. Diabetes was defined by self-report or use of diabetes medication. Cardiovascular disease was defined by self-report or by medical records of coronary heart disease and/or stroke. Two seated resting blood pressures were taken and were averaged. Physiological hypertension was defined by systolic blood pressure $>140 \mathrm{mmHg}$ and/or diastolic blood pressure $>90 \mathrm{mmHg}$ or use of hypertension medication.

\section{$\underline{\text { Survival time and cause of death }}$}

Surveillance for survival was conducted by in-person visit alternating with telephone interview every 6 months. The date of death was determined on the basis of hospital records, death certificates or informant interviews. Thirty-eight persons (3\%) were lost during follow-up, and their survival time was censored on the basis of their date of last contact. Deaths were adjudicated by a central committee for immediate and underlying causes of death using established criteria, including review of death certificate, all recent hospital records, and interview with the next of kin. Respiratory mortality was defined as mortality from COPD, pneumonia and respiratory failure. We defined cardiovascular mortality as mortality from atherosclerotic cardiovascular disease (definite fatal myocardial infarction or definite or possible fatal coronary heart disease), 
stroke, atherosclerotic disease other than coronary or cardiovascular, and other cardiovascular disease.

\section{Dietary intake and physical activity level}

Usual nutrient and food group intake was estimated by administering a modified Block food frequency questionnaire by a trained dietary interviewer at the first annual follow-up examination (details published in [20]). A Healthy Eating Index (HEI) was calculated to measure the amount of variety in the diet and compliance with specific dietary guidelines [20]. HEI scores ranged from 0 to 100 with higher scores indicating better compliance with recommended intake range or amount. Physical activity level was assessed at baseline by means of a validated questionnaire [20].

\section{$\underline{\text { Statistical analyses }}$}

\section{Propensity score matching}

After applying exclusion criteria, $n=2139$ participants ( $n=243$ OLD persons and $\mathrm{n}=1896$ non-OLD persons) were identified (Figure 1). By means of independent t-tests, Mann-Whitney-U tests and $\chi^{2}$-tests as appropriate, sex, age, body mass index (BMI), pack years and smoking status were significantly different between OLD persons and non-OLD persons (Table 1). To enable balanced comparisons between OLD persons and non-OLD persons accounting for these confounders, we performed propensity score matching [21]. For this, propensity scores for OLD status were calculated for the entire population $(n=2139)$ using logistic linear regression based on sex, age, race, clinic site, BMI, smoking status and pack years. Subsequently, three non-OLD participants were matched to each OLD person with the closest propensity score. In this procedure we allowed for replacement of non-OLD persons, which has been shown to increase balance [22].

Four methods were employed to assess the success of the matching. First, we confirmed that none of the variables included in the propensity score calculation were statistically different anymore between OLD persons and non-OLD persons after matching (Table 1), indicating that a balanced match was reached. Also, comparisons of the mean propensity scores between OLD persons and non-OLD persons before $(0.211 \pm 0.149$ vs $0.101 \pm 0.093, P<.001)$ and after matching $(0.211 \pm 0.149$ vs $0.211 \pm 0.149, P=.99)$ showed a perfect match. Additionally, the standardized differences between the OLD persons and non-OLD persons of the variables included in the propensity score calculation were compared before and after matching (Table 1). The standardized differences were calculated as the absolute difference in sample means divided by the standard deviation of the total population, expressed as a percentage [23]. The standardized differences 
were considerably improved by the matching, reaching acceptable levels. Finally, empirical-QQ plots were created before and after matching for the continuous variables included in the propensity score calculation (i.e., age, BMI and pack years). These plots allow for a visual inspection of the data distribution in OLD persons and non-OLD persons and show that the equality of data distribution was markedly improved by the matching procedure (Figure 2).

Table 1. Sociodemographic data before and after propensity score matching.

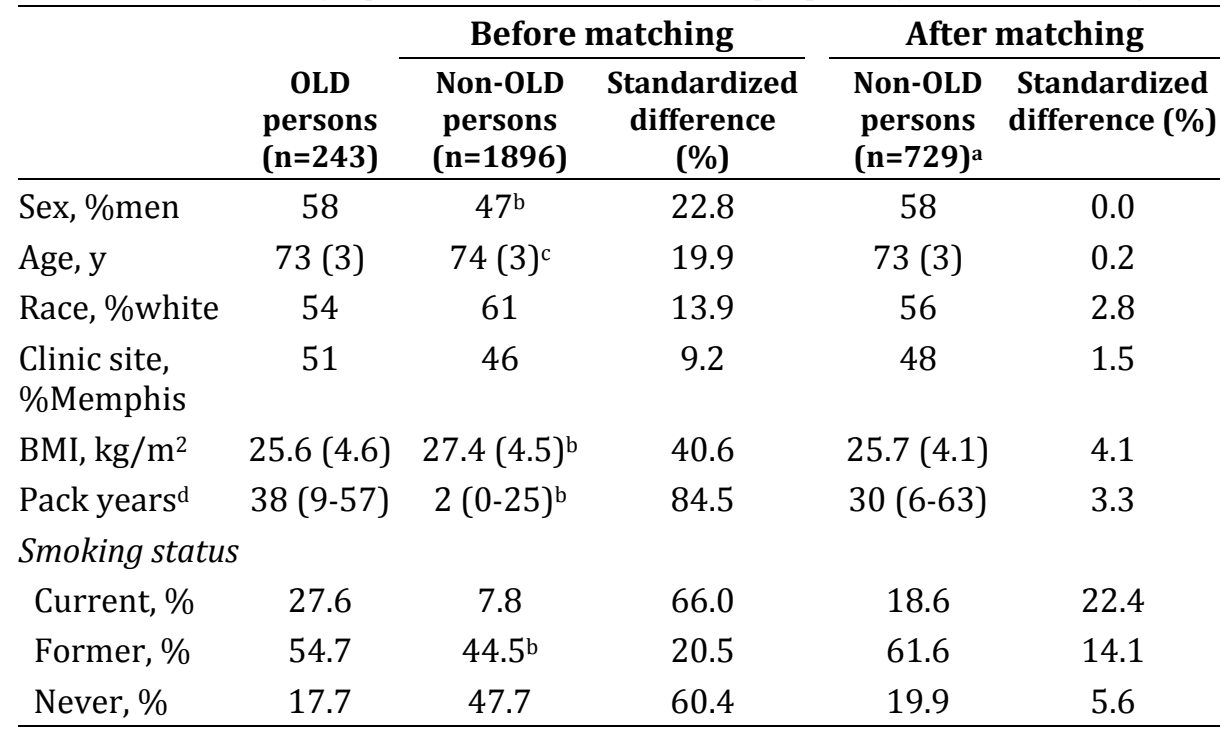

Abbreviations: BMI, body mass index; OLD, obstructive lung disease. Data are mean (SD) unless indicated otherwise. ${ }^{a}$ None of these variables were statistically different compared to OLD persons as tested with random-effects analysis of variance. ${ }^{b} P<.001,{ }^{c} P<.01$ compared to OLD persons as tested by independent $t$-tests, Mann-Whitney-U tests and $X^{2}$-tests as appropriate. dMedian (IQR).

\section{Analyses within the established match}

It is crucial that comparisons done after propensity score matching account for the lack of independence between matched sets [23]. We used random-effects analysis of variance to test phenotypical differences between OLD persons and matched non-OLD persons. Association analyses were performed using linear mixed models in which matched sets were treated as random factors. Cox proportional hazard models accounting for correlated data [24] were performed to investigate the hazard ratio (HR) of all-cause, respiratory and cardiovascular mortality of OLD persons relative to matched non-OLD persons. These models were first performed unadjusted and adjusted for the variables included in the propensity score calculation. Subsequently, the phenotypical variables that were significantly different between OLD persons and matched non-OLD persons 
Figure 2. Empirical-QQ plots for age (A), body mass index (B), and pack years (C) before and after matching.
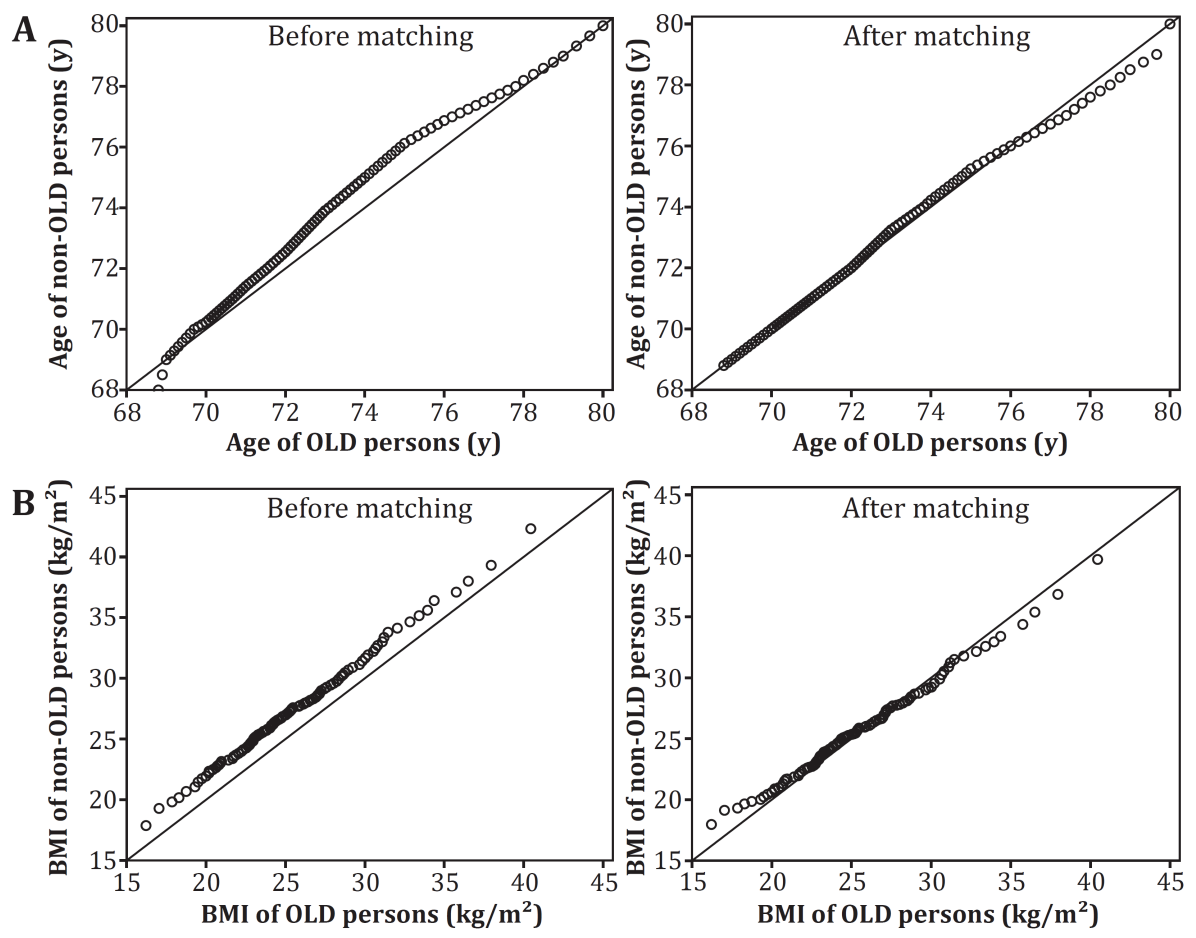

C
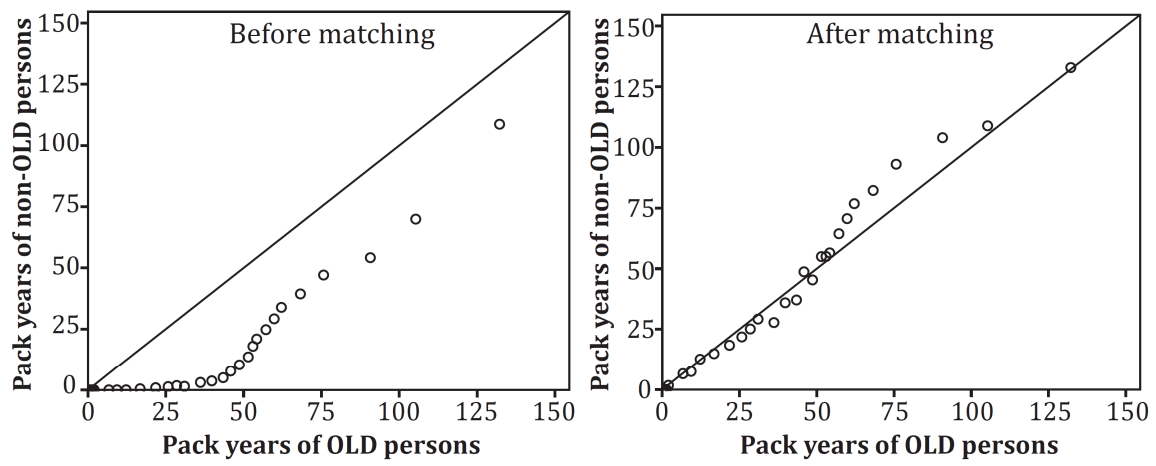

Quantiles of age, body mass index (BMI) and pack years of obstructive lung disease (OLD) persons and non-OLD persons were plotted against each other before and after matching. The solid line indicates $y=x$, which represents the situation in which the two distributions being compared are equal. It can be observed that the matching improved balance considerably. The "before matching" figures describe data from $n=243$ OLD persons and n=1896 non-OLD persons, and the "after matching" figures describe data from $n=243$ OLD persons and $n=729$ non-OLD persons.

were added to the model to test whether these predicted mortality and modified mortality by OLD status. 
$\mathrm{R}$ version 2.11.1 was used to establish the match (Matching package), to perform the linear mixed models (nlme package), and to perform the proportional hazard models (Survival package). Random-effects analysis of variance tests were performed in PASW Statistics 17.0 (SPSS inc. Chicago, IL, USA). Differences were declared to be statistically significant at $P<.05$.

\section{Results}

Phenotypical differences between OLD persons and matched non-OLD persons

Table 2 summarizes the main phenotypical characteristics of OLD persons and matched non-OLD persons. On the whole-body level, fat and fat-free masses were not different. Yet, OLD persons had significantly greater VFA $(P<.001)$ but no different SFA (Figure 3). Circulating levels of IL-6, adiponectin and PAI-1 were significantly higher in OLD persons whereas levels of CRP, TNF- $\alpha$ and leptin were not different. Apart from a higher prevalence of hypertension in OLD persons, no differences were found for HOMA-IR, diabetes, cardiovascular disease and metabolic syndrome criteria.

\section{Association analyses}

Our findings of concomitantly increased VFA, IL-6, adiponectin and PAI-1 raise the suggestion that VF may be a significant contributor to these elevated circulating adipocytokines. Table 3 summarizes the data from the linear mixed effects models studying the independent associations of VFA and OLD status on these plasma adipocytokine concentrations. VFA and OLD status were both significantly and independently associated with IL-6. OLD status was positively associated with adiponectin, independent of VFA, and VFA associated negative with adiponectin. OLD status was no longer associated with PAI-1 after accounting for VFA which was significantly associated with PAI-1. The data from these models did not change after further adjustment for BMI, suggesting specific VF effects.

\section{Mortality analyses}

During a median follow-up period of 9.4 years (7728 person years), 104 OLD persons (43\%) and 201 non-OLD persons (28\%) died from all causes. Unadjusted Cox proportional hazards models revealed a significantly worse survival in OLD persons compared to matched non-OLD persons for all-cause mortality (HR 1.70 [95\% CI 1.29, 2.34], P<.001) (Figure 4A). As expected, respiratory mortality risk was significantly higher in OLD persons (HR 4.03 [95\% CI 2.12, 7.64], $P<.001$ ) (Figure 4B). Also cardiovascular mortality risk was 
Table 2. Phenotypical characteristics of OLD persons and matched non-OLD persons.

\begin{tabular}{|c|c|c|c|}
\hline & OLD persons $(n=243)$ & Non-OLD persons $(n=729)$ & $\boldsymbol{P}$ \\
\hline \multicolumn{4}{|l|}{ Pulmonary function } \\
\hline $\mathrm{FEV}_{1}, \%$ pred $^{\mathrm{a}}$ & $63(18)$ & $99(16)$ & $<.001$ \\
\hline FVC, \%preda & $81(18)$ & $98(14)$ & $<.001$ \\
\hline $\mathrm{FEV}_{1} / \mathrm{FVC}, \%$ & $57(7)$ & $75(5)$ & $<.001$ \\
\hline \multicolumn{4}{|l|}{ Body composition } \\
\hline Weight, kg & $72.6(14.9)$ & $72.3(14.4)$ & .76 \\
\hline Fat mass, kg & $23.9(8.4)$ & $23.4(7.2)$ & .33 \\
\hline Fat free mass, kg & $48.7(10.5)$ & $49.0(10.7)$ & .72 \\
\hline Subcutaneous fat area, $\mathrm{cm}^{2}$ & $246(118)$ & $238(101)$ & .31 \\
\hline Visceral fat area, $\mathrm{cm}^{2}$ & $143(77)$ & $123(59)$ & $<.001$ \\
\hline \multicolumn{4}{|l|}{ Systemic adipocytokines } \\
\hline IL-6, pg/mlb & $2.16(1.52-3.34)$ & $1.75(1.20-2.69)$ & $<.001$ \\
\hline $\mathrm{CRP}, \mu \mathrm{g} / \mathrm{ml}^{\mathrm{b}}$ & $2.0(1.2-3.7)$ & $1.4(0.9-2.6)$ & .12 \\
\hline TNF- $\alpha, p g / \mathrm{ml}^{\mathrm{b}}$ & $3.03(2.35-4.08)$ & $3.10(2.40-4.07)$ & .77 \\
\hline $\mathrm{PAI}-1, \mathrm{ng} / \mathrm{ml}^{\mathrm{b}}$ & $22(12-37)$ & $18(11-31)$ & .008 \\
\hline Adiponectin, $\mu \mathrm{g} / \mathrm{ml}$ & $12.3(7.4)$ & $11.3(6.7)$ & .037 \\
\hline Leptin, ng/mlb & $7.61(3.33-14.07)$ & $7.86(4.22-14.28)$ & .91 \\
\hline \multicolumn{4}{|l|}{ Insulin sensitivity } \\
\hline HOMA-IR ${ }^{b}$ & $1.5(1.1-2.3)$ & $1.5(1.0-2.2)$ & .33 \\
\hline \multicolumn{4}{|l|}{ Metabolic syndrome } \\
\hline Abdominal obesity, \% & 48 & 45 & .42 \\
\hline High blood pressure, $\%$ & 79 & 77 & .57 \\
\hline High glucose, \% & 21 & 20 & .86 \\
\hline Low HDL, \% & 24 & 26 & .36 \\
\hline High triglycerides, \% & 21 & 20 & .14 \\
\hline \multicolumn{4}{|l|}{ Prevalent diseases } \\
\hline Hypertension, \% & 66 & 56 & .010 \\
\hline Diabetes, \% & 12 & 13 & .71 \\
\hline Cardiovascular disease, $\%$ & 22 & 28 & .27 \\
\hline
\end{tabular}

Abbreviations: $F E V_{1}$, forced expiratory volume in $1 s$; FVC, forced vital capacity; CRP, C-reactive protein; TNF- $\alpha$, tumor necrosis factor- $\alpha$. HOMA-IR, homeostatic model assessment insulin resistance; $H D L$, high density lipoprotein. Data are mean (SD) unless indicated otherwise. ${ }^{a}$ From reference equations [13]. ${ }^{b}$ Median (IQR). Analyses were performed using random-effects ANOVA.

significantly higher in OLD persons (HR 1.76 [95\% CI 1.07, 2.89], $P=.026$ ) (Figure 4C).

Table 4 describes the analyses of predictors for mortality. Adjustment for the variables included in the propensity score matching had no major effect on these hazard ratios (Model 2). Because we found increased VFA, elevated IL-6, adiponectin and PAI-1, and higher hypertension prevalence in OLD persons compared to matched non-OLD persons, we studied whether these predicted 
Figure 3. Excessive visceral fat accumulation but normal subcutaneous fat content in OLD.

Non-OLD person
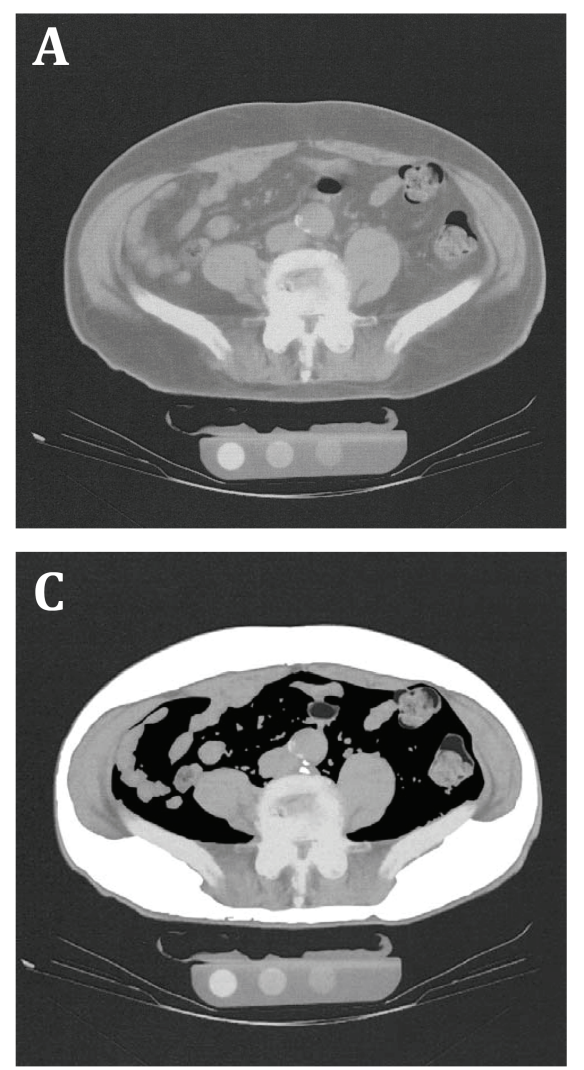

\section{OLD person}
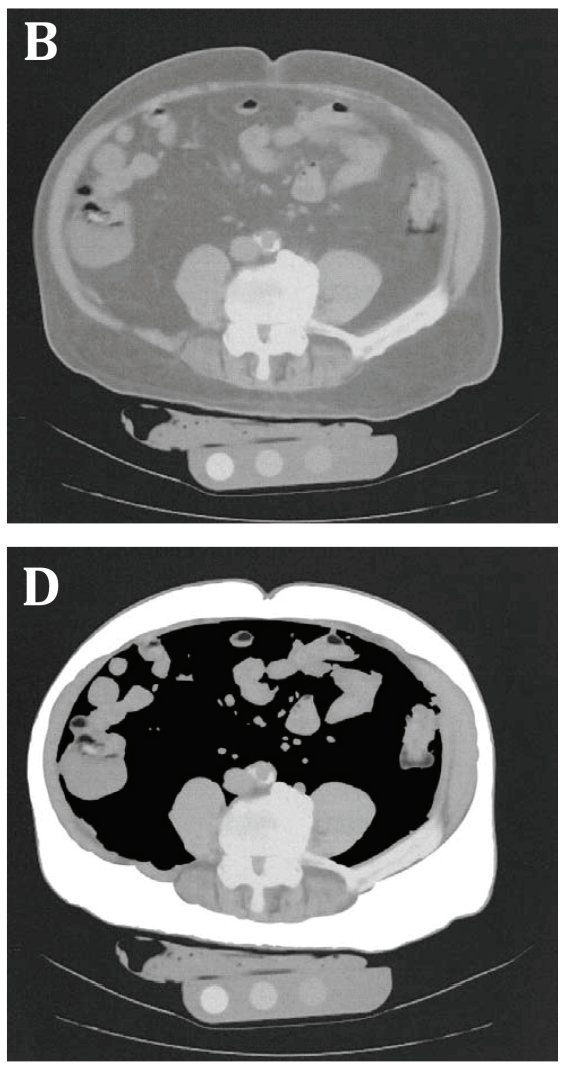

Abdominal CT-scans from a healthy person (A) and a COPD patient (FEV $153 \%$ of predicted) (B) matched for age, sex, and body mass index $\left(29 \mathrm{~kg} / \mathrm{m}^{2}\right)$. The black and white areas in $C$ and D denote the visceral and subcutaneous fat compartments, respectively.

mortality (Model 3). IL-6 and adiponectin independently predicted all-cause mortality. In the final model, only IL- 6 remained significant. IL- 6 was also found to be a strong and independent predictor of respiratory and cardiovascular mortality. PAI-1, VFA and hypertension were no predictors of mortality.

Table 5 summarizes the primary and underlying causes of mortality in OLD persons and matched non-OLD persons. Primary respiratory and cardiovascular causes were particularly common in OLD persons, whereas cardiovascular causes were most represented among non-OLD persons. Respiratory causes were reported as the underlying cause of mortality in 15\% of OLD persons and in only $3 \%$ in non-OLD persons, whereas cardiovascular causes underlying mortality were most common in non-OLD persons. 
Figure 4. All-cause (A), respiratory (B), and cardiovascular (C) mortality of OLD persons and matched non-OLD persons.
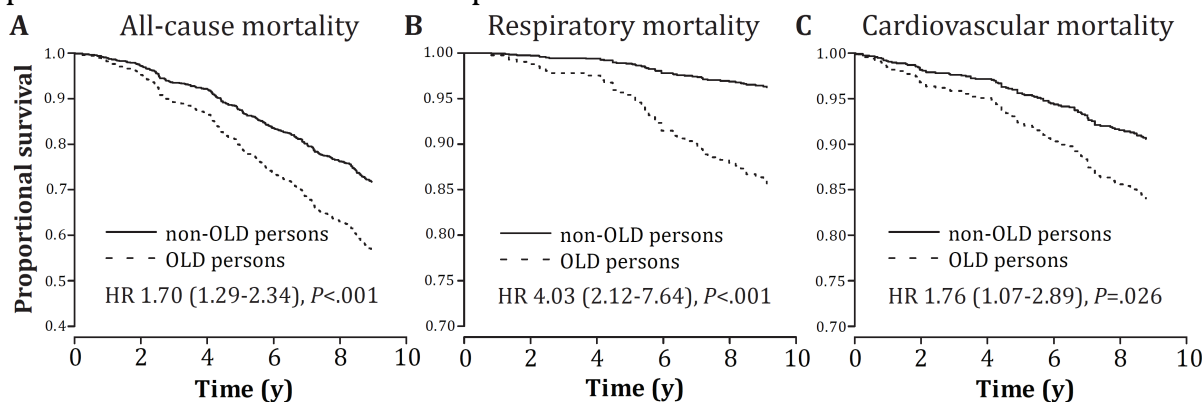

Abbreviations: OLD, obstructive lung disease. Plots are from unadjusted Cox proportional hazard models from $n=972$ persons.

\section{Dietary intake and physical activity level}

As explained, pack years smoked and smoking status were matched between the OLD persons and non-OLD persons. Consequently, the current study population consisted of mainly current/former smokers with a relatively high number of pack years.

Food Frequency Questionnaire data were available of $n=210$ OLD persons and $n=565$ non-OLD persons (Table 6). Whereas total calories, total protein and total carbohydrate intake were not different between the groups, OLD persons had significantly higher intakes of total fat, saturated fat, cholesterol and trans fat. Also, OLD persons had significantly lower intake of dietary fibers, which was attributable to a lower amount of fibers from fruits/vegetables (data not shown). Additionally, daily vitamin C intake was significantly lower in OLD persons. Whereas daily glycemic load was not different, daily glycemic index was significantly higher in OLD persons. On average, HEI scores were within the range that has been classified as 'needs improvement' in both OLD persons and non-OLD persons, but were even lower in OLD persons.

Total physical activity was significantly lower in OLD persons compared to non-OLD persons (Table 6). More specifically, fewer OLD persons walked briskly for $\geq 90 \mathrm{~min} / \mathrm{wk}$ and fewer OLD persons performed high-intensity exercise for $\geq 90 \mathrm{~min} /$ wk than non-OLD persons.

\section{Discussion}

We aimed to unravel OLD-specific effects from age-related effects on VF mass, to study the associations between VF and adipocytokines by OLD status and to investigate their relation with mortality. We found that OLD persons had significantly increased VF mass independent of age, BMI and whole-body fat 
Table 3. Mixed model analyses investigating the independent associations of OLD status and VFA on plasma concentrations of IL-6, adiponectin and PAI-1.

\begin{tabular}{lcccccc}
\hline \multicolumn{2}{c}{ Model 1 } & \multicolumn{2}{c}{ Model 2 } & \multicolumn{2}{c}{ Model 3 } \\
& $\boldsymbol{\beta}$ (SE) & $\boldsymbol{P}$ & $\boldsymbol{\beta}(\mathrm{SE})$ & $\boldsymbol{P}$ & $\boldsymbol{\beta}(\mathrm{SE})$ & $\boldsymbol{P}$ \\
\hline IL-6 (log transformed) & & & & & \\
OLD status & & & & & & \\
Non-OLD & $0[\mathrm{Ref}]$ & & $0[\mathrm{Ref}]$ & & $0[\mathrm{Ref}]$ & \\
OLD & $0.10(0.02)$ & $<.001$ & $0.08(0.02)$ & $<.001$ & $0.08(0.02)$ & $<.001$ \\
VFA, $\mathrm{dm}^{2}$ & & & $0.06(0.02)$ & $<.001$ & $0.07(0.02)$ & $<.001$ \\
\hline
\end{tabular}

Adiponectin $(\mu \mathrm{g} / \mathrm{ml})$

OLD status

\begin{tabular}{lcccccc} 
Non-OLD & $0[$ Ref $]$ & & $0[$ Ref $]$ & & $0[$ Ref $]$ & \\
OLD & $1.04(0.45)$ & $\mathbf{. 0 2 2}$ & $1.93(0.42)$ & $<.001$ & $1.69(0.43)$ & $<.001$ \\
VFA, $\mathrm{dm}^{2}$ & & & $-4.39(0.30)$ & $<.001$ & $-3.37(0.40)$ & $<.001$ \\
\hline
\end{tabular}

PAI-1 (log transformed)

OLD status

\begin{tabular}{lcccccc} 
Non-OLD & $0[$ Ref] & \multicolumn{3}{c}{0 [Ref] } & \multicolumn{2}{c}{0 Ref] } \\
OLD & $0.07(0.02)$ & $\mathbf{. 0 0 4}$ & $0.02(0.02)$ & .87 & $0.03(0.02)$ & .69 \\
VFA, $\mathrm{dm}^{2}$ & & & $0.22(0.02)$ & $<.001$ & $0.20(0.02)$ & $<.001$ \\
\hline
\end{tabular}

Abbreviations: IL-6, interleukin-6; OLD, obstructive lung disease; PAI-1, plasminogen activator inhibitor1; Ref, reference; VFA, visceral fat area. Analyses were performed using linear mixed models. Model 1: Adjusted for age, gender, race, clinic site, smoking status and pack years smoked. Model 2: Model 1 plus adjustment for VFA. Model 3: Model 2 plus adjustment for body mass index.

mass. Our data suggest that this excessive VF contributes to increased plasma IL6, which was subsequently shown to be a strong predictor of all-cause, respiratory and cardiovascular mortality. In addition, OLD persons engaged in an unhealthier lifestyle that was characterized by poorer dietary quality and lower daily physical activity level.

Making use of the wealth of data in the Health ABC Study, we were able to carefully match a non-OLD control group to OLD participants using propensity score matching for important confounders. This approach allowed us to disentangle OLD-specific effects from age-related effects for body fat distribution, inflammation and mortality. We found that a number of plasma adipocytokines were not different between OLD and matched non-OLD persons. It could be possible that whole-body fat mass rather than specific VF may be implicated, and as whole-body fat mass was matched, no differences in these markers were observed. 
Table 4. Hazard ratios (95\% confidence interval) of all-cause, respiratory, and cardiovascular mortality according to OLD status and factors accounting for the relationship (per $1 \mathrm{SD}$-increase for continuous variables).

\begin{tabular}{|c|c|c|c|c|}
\hline & Model 1 & Model 2 & Model 3 & Model 4 \\
\hline \multicolumn{5}{|c|}{ All-cause mortality } \\
\hline \multicolumn{5}{|l|}{ OLD status } \\
\hline Non-OLD & 1 [Ref] & 1 [Ref] & 1 [Ref] & 1 [Ref] \\
\hline OLD & $1.70(1.29-2.34)^{\mathrm{a}}$ & $1.72(1.30-2.26)^{\mathrm{a}}$ & $1.44(1.05-1.98)^{c}$ & $1.52(1.14-2.03)^{\mathrm{b}}$ \\
\hline IL-6 & & & $1.44(1.28-1.61)^{a}$ & $1.41(1.26-1.58)^{\mathrm{a}}$ \\
\hline Adiponectin & & & $1.23(1.02-1.48)^{c}$ & $1.18(0.98-1.41)^{\mathrm{d}}$ \\
\hline PAI-1 & & & $1.10(0.96-1.25)$ & \\
\hline VFA & & & $1.13(0.89-1.43)$ & \\
\hline \multicolumn{5}{|l|}{ Hypertension } \\
\hline No & & & 1 [Ref] & \\
\hline Yes & & & $1.20(0.86-1.67)$ & \\
\hline
\end{tabular}

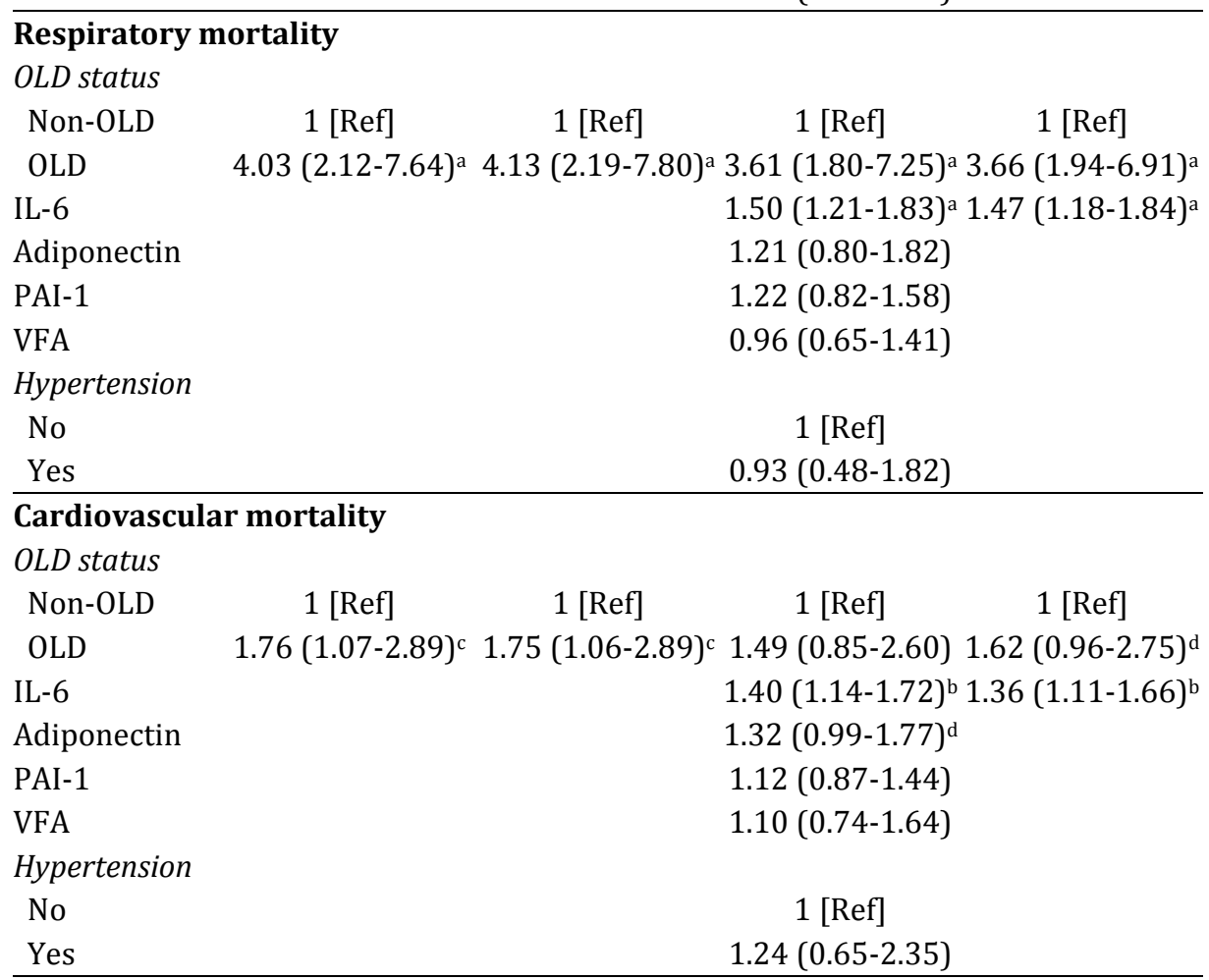

Abbreviations: IL-6, interleukin-6; OLD, obstructive lung disease; PAI-1, plasminogen activator-inhibitor1; Ref, reference; VFA, visceral fat area. Analyses were performed using Cox proportional hazard models. Model 1: unadjusted. Model 2: Adjusted for age, gender, race, clinic site, body mass index, smoking status and pack years. Model 3: Model 2 plus adjustment for IL-6, adiponectin, PAI-1, visceral fat area and hypertension. Model 4: Model 2 plus adjustment for significant predictors of Model 3. ${ }^{a} P<.001 .{ }^{b} P<.01$. ${ }^{c} P<.05 .{ }^{d} P \leq .08$. 
Table 5. Primary and underlying causes of OLD deaths and non-OLD deaths.

\begin{tabular}{|c|c|c|c|c|}
\hline & \multicolumn{2}{|c|}{ Primary cause of death } & \multicolumn{2}{|c|}{ Underlying cause of death } \\
\hline & $\begin{array}{l}\text { OLD deaths } \\
(n=104)\end{array}$ & $\begin{array}{c}\text { non-OLD } \\
\text { deaths } \\
(n=201)\end{array}$ & $\begin{array}{c}\text { OLD deaths } \\
(n=104)\end{array}$ & $\begin{array}{c}\text { non-OLD } \\
\text { deaths } \\
(n=201)\end{array}$ \\
\hline Cardiovascular, $\%^{\mathrm{a}}$ & 32 & 30 & 33 & 34 \\
\hline Respiratory, \% ${ }^{\mathrm{b}}$ & 26 & 11 & 15 & 3 \\
\hline Cancer, \% & 1 & 0 & 33 & 40 \\
\hline $\begin{array}{l}\text { Gastrointestinal bleed, } \\
\text { renal failure or sepsis, } \%\end{array}$ & 10 & 9 & 2 & 6 \\
\hline Other ${ }^{c}$ or unknown, $\%$ & 32 & 49 & 16 & 17 \\
\hline
\end{tabular}

${ }^{a}$ Cardiovascular causes included atherosclerotic cardiovascular disease (definite fatal myocardial infarction, definite fatal coronary heart disease, possible fatal coronary heart disease), cerebrovascular disease, atherosclerotic disease other than coronary or cerebrovascular, other cardiovascular disease (including valvular heart disease and other). ${ }^{b}$ Respiratory causes included chronic obstructive pulmonary disease, pneumonia and respiratory failure. ${ }^{c}$ Other causes included dementia, diabetes, and still other causes.

Our results cannot be generalized to all older persons, especially those with severe OLD, because participants in the Health ABC study were selected to be able to walk a quarter of a mile and to climb ten steps without resting. Our data apply to an older OLD population with on average mild airflow obstruction. A limitation in the Health ABC Study is that no post-bronchodilator pulmonary function is available, precluding the application of Global initiative of Obstructive Lung Disease criteria for defining COPD. However, instead of using the same cutoffs for all individuals, we used stringent criteria base on age-, sex- and raceadjusted LLN cut point to define OLD in this older and multi-ethnic population, as recommended by prior studies [25], and used in prior Health ABC Study publications $[12,14,15]$.

Elevated plasma IL-6 has been consistently reported in COPD patients [2630] and has recently been identified as an important biomarker with added predictive value for mortality in addition to clinical predictors [31]. It is estimated that about one-third of the plasma IL-6 originates from adipose tissues, and in obese subjects visceral adipocytes produce 3-fold more IL-6 than subcutaneous adipocytes [7]. Other potential sources may include a "spill-over" from the pulmonary compartment, but the liver, peripheral skeletal muscle, circulating immune cells and dietary factors have also been suggested to contribute to systemic inflammation. IL-6 was previously shown to be an independent predictor for mortality in various chronic aging-related diseases such as chronic kidney disease [32], peripheral artery disease [33], and also in OLD [14]. Importantly, IL-6 also has been identified as a predictor of mortality in older populations, after adjustment for chronic diseases [11,34]. Our data strengthen previous studies identifying IL-6 as an important biomarker of 
Table 6. Dietary intake and physical activity level of OLD and non-OLD participants.

\begin{tabular}{|c|c|c|c|}
\hline & OLD persons & $\begin{array}{c}\text { non-OLD } \\
\text { persons }\end{array}$ & $P$ \\
\hline \multicolumn{4}{|l|}{ Dietary intake ${ }^{a}$} \\
\hline Calories, kcal/d & $2021(824)$ & $1963(791)$ & .36 \\
\hline Protein, g/d & $70.8(29.4)$ & $69.1(30.4)$ & .49 \\
\hline Carbohydrate, g/d & $253(109)$ & $254(105)$ & .91 \\
\hline Total fat, g/d & $81.5(39.5)$ & $74.9(38.7)$ & .034 \\
\hline Saturated fat, g/d & $24.3(12.6)$ & $21.5(11.3)$ & .003 \\
\hline Cholesterol, mg/d & $250(154)$ & $216(141)$ & .003 \\
\hline Trans fat, g/d & $8.3(6.1)$ & $7.4(5.1)$ & .036 \\
\hline Total dietary fiber, g/d & $16.4(6.9)$ & $18.2(8.4)$ & .007 \\
\hline Vitamin $\mathrm{C}, \mathrm{mg} / \mathrm{d}$ & $129(71)$ & $144(79)$ & .014 \\
\hline Daily glycemic load, glucose scale & $135(62)$ & $133(58)$ & .64 \\
\hline Daily glycemic index, glucose scale & $56.7(4.3)$ & $56.0(4.7)$ & .037 \\
\hline Healthy eating index & $65.0(13.0)$ & $67.2(12.9)$ & .030 \\
\hline \multicolumn{4}{|l|}{ Physical activity level ${ }^{b}$} \\
\hline Total physical activity, kcal/kg/wk & $65(36-99)$ & $67(41-110)$ & .039 \\
\hline Walking briskly $\geq 90 \mathrm{~min} / \mathrm{wk}, \%$ & 6.6 & 17.3 & $<.001$ \\
\hline High-intensity exercise $\geq 90 \mathrm{~min} / \mathrm{wk}, \%$ & 8.2 & 17.6 & $<.001$ \\
\hline
\end{tabular}

mortality risk, and extend this by the finding that excessive VF is associated with increased IL-6 in OLD. Future studies are warranted to examine the inflammatory status in VF biopsies from COPD patients and BMI-matched control subjects to further elucidate the contribution of VF to low-grade systemic inflammation in COPD.

Adiponectin is almost exclusively produced by adipocytes and is typically described as an insulin sensitizer with anti-inflammatory properties [35]. Paradoxically, increased circulating adiponectin was found to be a strong independent predictor of mortality in a general older population [36], but also in various wasting-associated diseases such as chronic heart failure (CHF) [37, 38], chronic kidney disease [39], respiratory failure [40] and COPD [41]. It is noteworthy that adiponectin circulates in high, middle, and low-molecular weight isoforms. These isoforms have different affinities with the adiponectin receptors and therefore their mode of action may differ as well. We measured only total adiponectin in this study, but it might be relevant to explore adiponectin isoforms in future studies because SF and VF release different isoforms [42]. Interestingly, whereas we found that VF was strongly negatively 
associated with plasma adiponectin, OLD persons - who had increased VF - had elevated adiponectin levels. This suggests that other fat depots or even other organ systems are implicated in the elevated adiponectin levels in OLD. In a recent study it was found that adiponectin was highly expressed in pulmonary epithelium, and this pulmonary adiponectin expression was strongly increased in emphysematous COPD patients compared to control subjects [43]. Adiponectin may play a role in pulmonary inflammation after ozone exposure in mice [44], though its function in COPD-associated inflammation remains unclear. It has been proposed that elevated adiponectin levels increase energy expenditure and induce weight loss through a direct effect on the brain $[38,45]$, which would be unfavorable in chronic wasting-associated diseases, including COPD. Alternatively, elevated adiponectin levels in COPD and CHF [46] may be a sign of adiponectin resistance at the level of skeletal muscle. Lower expression levels of adiponectin receptors in skeletal muscle have been associated with insulin resistance [47] and, interestingly, Van Berendoncks et al. [48] recently showed lower adiponectin receptor expression in skeletal muscle biopsies of CHF patients. These data suggest an important cross-talk between adipose tissue and skeletal muscle that warrants further investigation in COPD patients.

Future studies are necessary to identify factors associated with increased VF accumulation in COPD. Poor dietary quality and decreased physical activity level deserve further attention with respect to body fat distribution in COPD but also point towards the need of more and integrated attention to diet and physical activity in addition to smoking as lifestyle determinants of COPD risk and progression. Also, hypogonadism has been associated with COPD [49] and with VF accumulation [50]. Interestingly, increased VF mass has also been observed in other diseases associated with chronic inflammation, including rheumatoid arthritis [51], Crohn's disease [52], and psoriasis [53], supporting a central role for VF in chronic inflammatory diseases.

In conclusion, our study demonstrates increased VF (independent of total fat mass) and a possible role of VF in inflammatory pathways associated with mortality in older persons with OLD. 


\section{CHAPTER 5}

\section{References}

1. Gooneratne NS, Patel NP, Corcoran A. Chronic obstructive pulmonary disease diagnosis and management in older adults. J Am Geriatr Soc. 2010;58(6):1153-62.

2. Patel AR, Hurst JR. Extrapulmonary comorbidities in chronic obstructive pulmonary disease: state of the art. Expert Rev Respir Med. 2011;5(5):647-62.

3. Trayhurn P, Wood IS. Adipokines: inflammation and the pleiotropic role of white adipose tissue. Br J Nutr. 2004;92(3):347-55.

4. Wood IS, de Heredia FP, Wang B, Trayhurn P. Cellular hypoxia and adipose tissue dysfunction in obesity. Proc Nutr Soc. 2009;68(4):370-7.

5. van den Borst B, Gosker HR, Wesseling G, de Jager W, Hellwig VA, Snepvangers FJ, Schols AM. Low-grade adipose tissue inflammation in patients with mild-to-moderate chronic obstructive pulmonary disease. Am J Clin Nutr. 2011;94(6):1504-12.

6. Koenen TB, Stienstra R, van Tits LJ, Joosten LA, van Velzen JF, Hijmans A, Pol JA, van der Vliet JA, Netea MG, Tack $\mathrm{CJ}$, et al. The inflammasome and caspase-1 activation: a new mechanism underlying increased inflammatory activity in human visceral adipose tissue. Endocrinology. 2011;152(10):3769-78.

7. Fried SK, Bunkin DA, Greenberg AS. Omental and subcutaneous adipose tissues of obese subjects release interleukin-6: depot difference and regulation by glucocorticoid. J Clin Endocrinol Metab. 1998;83(3):847-50.

8. Furutate R, Ishii T, Wakabayashi R, Motegi T, Yamada K, Gemma A, Kida K. Excessive visceral fat accumulation in advanced chronic obstructive pulmonary disease. Int J Chron Obstruct Pulmon Dis. 2011;6:423-30.

9. Kuk JL, Lee S, Heymsfield SB, Ross R. Waist circumference and abdominal adipose tissue distribution: influence of age and sex. Am J Clin Nutr. 2005;81(6):1330-4.

10. Sugihara M, Oka R, Sakurai M, Nakamura K, Moriuchi T, Miyamoto S, Takeda Y, Yagi K, Yamagishi M. Age-related changes in abdominal fat distribution in Japanese adults in the general population. Intern Med.2011;50(7):679-85.

11. Singh T, Newman AB. Inflammatory markers in population studies of aging. Ageing Res Rev. 2011;10(3):319-29.

12. Yende S, Waterer GW, Tolley EA, Newman AB, Bauer DC, Taaffe DR, Jensen R, Crapo R, Rubin S, Nevitt M, et al. Inflammatory markers are associated with ventilatory limitation and muscle dysfunction in obstructive lung disease in well functioning elderly subjects. Thorax. 2006;61(1):10-6.

13. Hankinson JL, Odencrantz JR, Fedan KB. Spirometric reference values from a sample of the general U.S. population. Am J Respir Crit Care Med. 1999;159(1):179-87.

14. Mehrotra N, Freire AX, Bauer DC, Harris TB, Newman AB, Kritchevsky SB, Meibohm B. Predictors of mortality in elderly subjects with obstructive airway disease: the PILE score. Ann Epidemiol. 2010;20(3):223-32.

15. van den Borst B, Koster A, Yu B, Gosker HR, Meibohm B, Bauer DC, Kritchevsky SB, Liu Y, Newman AB, Harris TB, et al. Is age-related decline in lean mass and physical function accelerated by obstructive lung disease or smoking? Thorax. 2011;66(11):961-9.

16. Snijder MB, Visser M, Dekker JM, Seidell JC, Fuerst T, Tylavsky F, Cauley J, Lang T, Nevitt M, Harris TB. The prediction of visceral fat by dual-energy X-ray absorptiometry in the elderly: a comparison with computed tomography and anthropometry. Int J Obes Relat Metab Disord. 2002;26(7):984-93.

17. Koster A, Stenholm S, Alley DE, Kim LJ, Simonsick EM, Kanaya AM, Visser M, Houston DK, Nicklas BJ, Tylavsky FA, et al. Body Fat Distribution and Inflammation Among Obese Older Adults With and Without Metabolic Syndrome. Obesity (Silver Spring). 2010;18(12):2354-61.

18. Matthews DR, Hosker JP, Rudenski AS, Naylor BA, Treacher DF, Turner RC. Homeostasis model assessment: insulin resistance and beta-cell function from fasting plasma glucose and insulin concentrations in man. Diabetologia. 1985;28(7):412-9.

19. Grundy SM, Cleeman JI, Daniels SR, Donato KA, Eckel RH, Franklin BA, Gordon DJ, Krauss RM, Savage PJ, Smith SC, Jr., et al. Diagnosis and management of the metabolic syndrome: an American Heart Association/National Heart, Lung, and Blood Institute Scientific Statement. Circulation. 2005;112(17):2735-52.

20. Lee JS, Kritchevsky SB, Tylavsky FA, Harris T, Everhart J, Simonsick EM, Rubin SM, Newman AB. Weight-loss intention in the well-functioning, community-dwelling elderly: associations with diet quality, physical activity, and weight change. Am J Clin Nutr. 2004;80(2):466-74.

21. Sekhon JS. Multivariate and propensity score matching software with automated balance optimization: the matching package for R. Journal of Statistical Software. 2011;42(7).

22. Ming K, Rosenbaum PR. Substantial gains in bias reduction from matching with a variable number of controls. Biometrics. 2000;56(1):118-24.

23. Austin PC. A critical appraisal of propensity-score matching in the medical literature between 1996 and 2003. Stat Med. 2008;27(12):2037-49.

24. Wei LJ, Lin DY, Weissfeld L. Regression analysis of multivariate incomplete failure time data by modeling marginal distributions. Journal of the American Statistical Association. 1989;84:1065-73.

25. Swanney MP, Ruppel G, Enright PL, Pedersen OF, Crapo RO, Miller MR, Jensen RL, Falaschetti E, Schouten JP, Hankinson JL, et al. Using the lower limit of normal for the $\mathrm{FEV}_{1} / \mathrm{FVC}$ ratio reduces the misclassification of airway obstruction. Thorax. 2008;63(12):1046-51.

26. Walter RE, Wilk JB, Larson MG, Vasan RS, Keaney JF, Jr., Lipinska I, O'Connor GT, Benjamin EJ. Systemic inflammation and COPD: the Framingham Heart Study. Chest. 2008;133(1):19-25.

27. Breyer MK, Rutten EP, Vernooy JH, Spruit MA, Dentener MA, van der Kallen C, Vangreevenbroek MM, Wouters EF. Gender differences in the adipose secretome system in chronic obstructive pulmonary disease (COPD): A pivotal role of leptin. Respir Med. 2011;105(7):1046-53. 


\section{EXCESSIVE ABDOMINAL VISCERALFAT IN COPD}

28. Attaran D, Lari SM, Towhidi M, Marallu HG, Ayatollahi H, Khajehdaluee M, Ghanei M, Basiri R. Interleukin-6 and airflow limitation in chemical warfare patients with chronic obstructive pulmonary disease. Int J Chron Obstruct Pulmon Dis. 2010;5:335-40.

29. He Z, Chen Y, Chen P, Wu G, Cai S. Local inflammation occurs before systemic inflammation in patients with COPD. Respirology. 2010;15(3):478-84.

30. Garcia-Rio F, Miravitlles M, Soriano JB, Munoz L, Duran-Tauleria E, Sanchez G, Sobradillo V, Ancochea J. Systemic inflammation in chronic obstructive pulmonary disease: a population-based study. Respir Res. 2010;11:63.

31. Celli BR, Locantore N, Yates J, Tal-Singer R, Miller BE, Bakke P, Calverley P, Coxson H, Crim C, Edwards LD, et al. Inflammatory biomarkers improve clinical prediction of mortality in chronic obstructive pulmonary disease. Am J Respir Crit Care Med. 2012;185(10):1065-72.

32. Barreto DV, Barreto FC, Liabeuf S, Temmar M, Lemke HD, Tribouilloy C, Choukroun G, Vanholder R, Massy ZA. Plasma interleukin-6 is independently associated with mortality in both hemodialysis and pre-dialysis patients with chronic kidney disease. Kidney Int. 2010;77(6):550-6.

33. Depalma RG, Hayes VW, Chow BK, Shamayeva G, May PE, Zacharski LR. Ferritin levels, inflammatory biomarkers, and mortality in peripheral arterial disease: a substudy of the Iron (Fe) and Atherosclerosis Study (FeAST) Trial. J Vasc Surg. 2010;51(6):1498-503.

34. Harris TB, Ferrucci L, Tracy RP, Corti MC, Wacholder S, Ettinger WH, Jr., Heimovitz H, Cohen HJ, Wallace R. Associations of elevated interleukin-6 and C-reactive protein levels with mortality in the elderly. Am J Med. 1999;106(5):506-12.

35. Ouchi N, Parker JL, Lugus JJ, Walsh K. Adipokines in inflammation and metabolic disease. Nat Rev Immunol. 2011;11(2):85-97.

36. Poehls J, Wassel CL, Harris TB, Havel PJ, Swarbrick MM, Cummings SR, Newman AB, Satterfield S, Kanaya AM. Association of adiponectin with mortality in older adults: the Health, Aging, and Body Composition Study. Diabetologia. 2009;52(4):591-5.

37. Tsutamoto T, Tanaka T, Sakai H, Ishikawa C, Fujii M, Yamamoto T, Horie M. Total and high molecular weight adiponectin, haemodynamics, and mortality in patients with chronic heart failure. Eur Heart J. 2007;28(14):172330.

38. Kistorp C, Faber J, Galatius S, Gustafsson F, Frystyk J, Flyvbjerg A, Hildebrandt P. Plasma adiponectin, body mass index, and mortality in patients with chronic heart failure. Circulation. 2005;112(12):1756-62.

39. Menon V, Li L, Wang X, Greene T, Balakrishnan V, Madero M, Pereira AA, Beck GJ, Kusek JW, Collins AJ, et al. Adiponectin and mortality in patients with chronic kidney disease. J Am Soc Nephrol. 2006;17(9):2599-606.

40. Walkey AJ, Rice TW, Konter J, Ouchi N, Shibata R, Walsh K, deBoisblanc BP, Summer R. Plasma adiponectin and mortality in critically ill subjects with acute respiratory failure. Crit Care Med. 2010;38(12):2329-34.

41. Waschki B, Kirsten A, Holz O, Muller KC, Meyer T, Watz H, Magnussen H. Physical activity is the strongest predictor of all-cause mortality in patients with chronic obstructive pulmonary disease: a prospective cohort study. Chest. 2011;140(2):331-42.

42. Kovacova Z, Tencerova M, Roussel B, Wedellova Z, Rossmeislova L, Langin D, Polak J, Stich V. The impact of obesity on secretion of adiponectin multimeric isoforms differs in visceral and subcutaneous adipose tissue. Int J Obes (Lond). 2011 Dec 6 [Epub ahead of print].

43. Miller M, Cho JY, Pham A, Ramsdell J, Broide DH. Adiponectin and functional adiponectin receptor 1 are expressed by airway epithelial cells in chronic obstructive pulmonary disease. J Immunol. 2009;182(1):684-91.

44. Zhu M, Hug C, Kasahara DI, Johnston RA, Williams AS, Verbout NG, Si H, Jastrab J, Srivastava A, Williams ES, et al. Impact of adiponectin deficiency on pulmonary responses to acute ozone exposure in mice. Am J Respir Cell Mol Biol. 2010;43(4):487-97.

45. Qi Y, Takahashi N, Hileman SM, Patel HR, Berg AH, Pajvani UB, Scherer PE, Ahima RS. Adiponectin acts in the brain to decrease body weight. Nat Med. 2004;10(5):524-9.

46. Van Berendoncks AM, Conraads VM. Functional adiponectin resistance and exercise intolerance in heart failure. Curr Heart Fail Rep. 2011;8(2):113-22.

47. Civitarese AE, Jenkinson CP, Richardson D, Bajaj M, Cusi K, Kashyap S, Berria R, Belfort R, DeFronzo RA, Mandarino LJ, et al. Adiponectin receptors gene expression and insulin sensitivity in non-diabetic Mexican Americans with or without a family history of Type 2 diabetes. Diabetologia. 2004;47(5):816-20.

48. Van Berendoncks AM, Garnier A, Beckers P, Hoymans VY, Possemiers N, Fortin D, Martinet W, Van Hoof V, Vrints CJ, Ventura-Clapier R, et al. Functional adiponectin resistance at the level of the skeletal muscle in mild to moderate chronic heart failure. Circ Heart Fail. 2010;3(2):185-94.

49. Van Vliet M, Spruit MA, Verleden G, Kasran A, Van Herck E, Pitta F, Bouillon R, Decramer M. Hypogonadism, quadriceps weakness, and exercise intolerance in chronic obstructive pulmonary disease. Am J Respir Crit Care Med. 2005;172(9):1105-11.

50. Zafon C. Fat and aging: a tale of two tissues. Curr Aging Sci. 2009;2(2):83-94.

51. Giles JT, Allison M, Blumenthal RS, Post W, Gelber AC, Petri M, Tracy R, Szklo M, Bathon JM. Abdominal adiposity in rheumatoid arthritis: association with cardiometabolic risk factors and disease characteristics. Arthritis Rheum. 2010;62(11):3173-82.

52. Katznelson L, Fairfield WP, Zeizafoun N, Sands BE, Peppercorn MA, Rosenthal DI, Klibanski A. Effects of growth hormone secretion on body composition in patients with Crohn's disease. J Clin Endocrinol Metab. 2003;88(11):5468-72.

53. Balci A, Balci DD, Yonden Z, Korkmaz I, Yenin JZ, Celik E, Okumus N, Egilmez E. Increased amount of visceral fat in patients with psoriasis contributes to metabolic syndrome. Dermatology. 2010;220(1):32-7. 


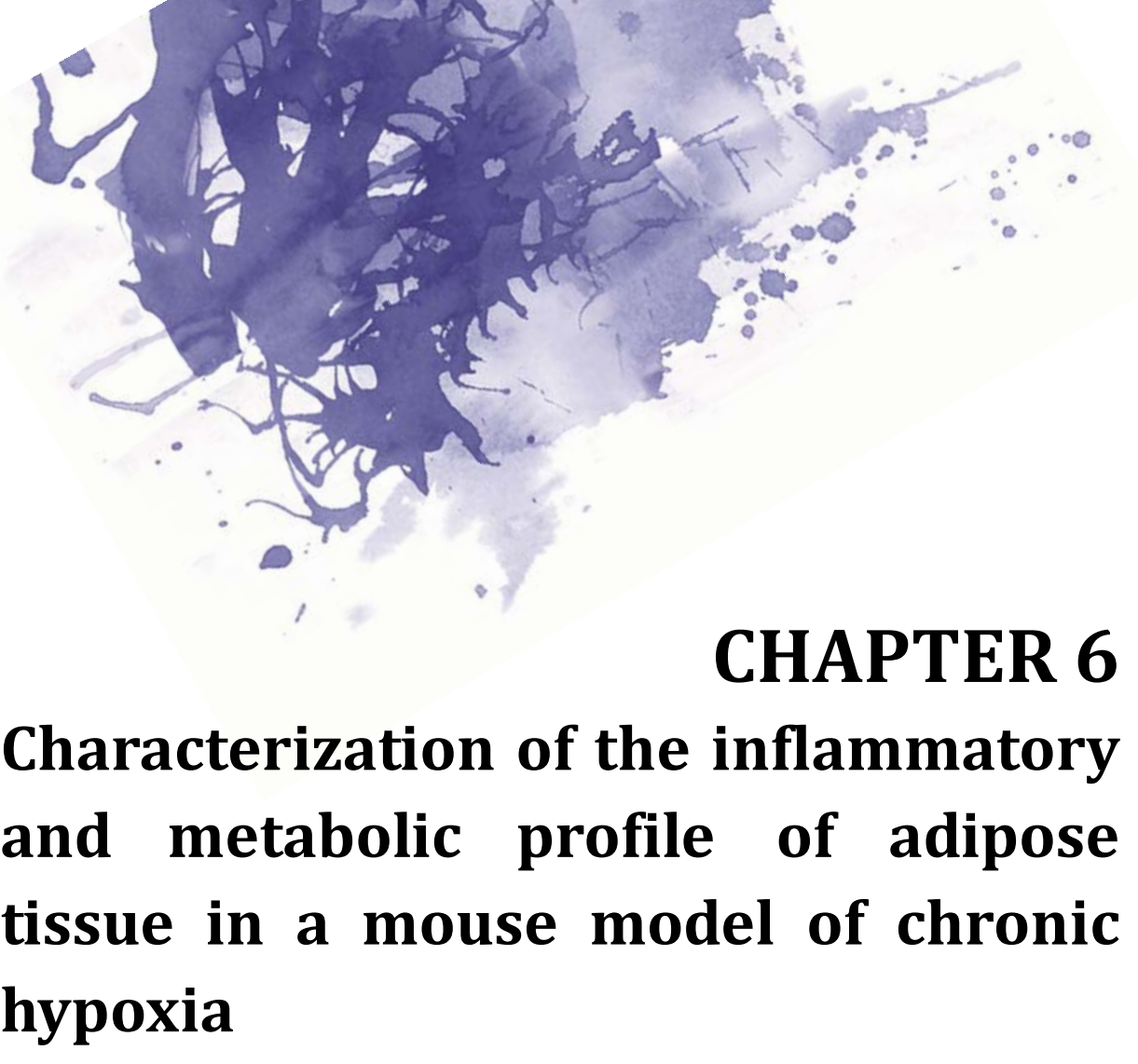

Bram van den Borst, Annemie M.W.J. Schols, Chiel de Theije, Agnes W. Boots, S. Eleonore Köhler, Gijs H. Goossens, Harry R. Gosker

Journal of Applied Physiology 2013 Mar 28 [Epub ahead of print] 


\begin{abstract}
Rationale: In both obesity and chronic obstructive pulmonary disease (COPD), altered oxygen tension in the adipose tissue (AT) has been suggested to evoke AT dysfunction, subsequently contributing to metabolic complications. Studying the effects of chronic hypoxia on AT function will add to our understanding of the complex pathophysiology of alterations in AT inflammation, metabolism and mass seen in both obesity and COPD. This study investigated the inflammatory and metabolic profile of AT after chronic hypoxia.
\end{abstract}

Methods: Fifty-two-week-old C57Bl/6J mice were exposed to chronic hypoxia $\left(8 \% \mathrm{O}_{2}\right)$ or normoxia for 21 days after which AT and plasma were collected. Adipocyte size, AT gene expression of inflammatory and metabolic genes, AT macrophage density and circulating adipokine concentrations were measured.

Results: Food intake and body weight decreased upon initiation of hypoxia. However, whereas food intake normalized after 10 days, lower body weight persisted. Chronic hypoxia markedly reduced AT mass and adipocyte size. AT macrophage density and expression of Emr1, Ccl2, Lep and Tnf were decreased, whereas Serpine1 and Adipoq expression levels were increased after chronic hypoxia. Concomitantly, chronic hypoxia increased AT expression of regulators of oxidative metabolism and markers of mitochondrial function and lipolysis. Circulating IL-6 and PAI-1 concentrations were increased and leptin concentration was decreased after chronic hypoxia.

Conclusion: Chronic hypoxia is associated with decreased rather than increased AT inflammation, and markedly decreased fat mass and adipocyte size. Furthermore, our data indicate that chronic hypoxia is accompanied by significant alterations in AT metabolic gene expression, pointing towards an enhanced AT metabolic rate. 


\section{Introduction}

Obesity and chronic obstructive pulmonary disease (COPD) are two major chronic conditions with high prevalence worldwide [1, 2], and are increasingly co-occurring $[3,4]$. In obesity, both decreased and increased oxygen tension within the adipose tissue (AT) have been suggested to contribute to AT dysfunction and inflammation, which may subsequently increase the risk of metabolic complications [5-8]. Chronic hypoxaemia in COPD, on the other hand, accelerates loss of body and fat masses, in part by increasing the resting metabolic rate [9-11]. However, the effects of chronic hypoxia on AT function remain incompletely understood. Studying the effects of chronic hypoxia on AT function is important as it may add to our understanding of the complex pathophysiology of alterations in AT inflammation, metabolism and mass seen in both obesity and COPD.

It is now well-established that AT is an inflammatory and metabolically active tissue [12]. Hypoxia may induce AT dysfunction and inflammation via direct effects of low $\mathrm{PaO}_{2}$, endoplasmic reticulum stress, oxidative stress or other mechanisms [8]. In obesity, the combination of hypertrophying adipocytes and insufficient neovascularisation may lead to local hypoxic tissue areas and to hypoxia within large adipocytes lying distant from capillaries [13]. Indeed, in various mouse models of obesity local areas of hypoxia were demonstrated in the AT [14-16]. This was accompanied by increased AT expression of hypoxiaresponsive markers (eg. glucose transporter [GLUT]-1 [15, 16], vascular endothelial growth factor [VEGF] [16]), altered adipokine mRNA expression ( $\mathrm{eg}$. increased leptin and plasminogen activator-inhibitor [PAI]-1, decreased adiponectin [14]), increased mRNA expression of pro-inflammatory markers $(\mathrm{eg}$. tumor necrosis factor [TNF]- $\alpha$, interleukin [IL]-6 [16]) and increased expression and presence of $\mathrm{F} 4 / 80+$ macrophages in the AT $[15,16]$. In order to further substantiate the potential direct role of hypoxia on adipocyte inflammation, many in vitro studies have been carried out in which either murine (mostly 3T3L1 cells) or human adipocytes were exposed to hypoxia. Although these studies used exposure to extreme, non-physiological $\mathrm{PaO}_{2}\left(1 \% \mathrm{O}_{2}\right)$, the majority of these studies have indeed reported gross hypoxia-induced changes rendering adipocytes more pro-inflammatory and altering their adipokine expression and secretion profiles $[14,16-19]$. Importantly, however, conflicting data have also been reported $[5,20]$. It has been demonstrated that chronic hypoxia substantially lowered the inflammatory response in primary human adipocytes [20], and $\mathrm{PaO}_{2}$ in abdominal subcutaneous AT was inversely associated with the expression of inflammatory markers in this fat depot [5].

The physiological cellular response to hypoxia includes switching from oxidative to anaerobic metabolism. In vitro studies have indeed shown increased expression of various glucose transporters and other markers of glycolytic metabolism and decreased expression of mitochondrial components and their 
major upstream regulator peroxisome proliferator-activated receptor (PPAR)- $\gamma$ coactivator-1 $\alpha$ (PGC-1 $\alpha$ ) [17]. This shift would imply increased lactate production from adipocytes which is indeed observed in obesity [21] and after hypoxia [22]. Studies investigating the effect of altered oxygen tension on lipolysis have yielded conflicting results. Both extreme hypoxia $\left(1 \% \mathrm{O}_{2}\right)[23]$ and hyperoxia $\left(95 \% \mathrm{O}_{2}\right)$ [24] enhanced lipolysis in 3T3-L1 adipocytes.

Chronic hypoxaemia as a consequence of COPD may also affect AT function. Recent studies have detected increased mRNA expression of the proinflammatory markers CD40, MAPK kinase 4, and c-Jun $\mathrm{NH}_{2}$-terminal kinase [25] and increased expression of nuclear factor- $\kappa \mathrm{B}$ inhibitors [26] in abdominal subcutaneous AT biopsies from hypoxaemic, underweight COPD patients when compared to normoxaemic, overweight COPD patients.

Although the data on the causal role of hypoxia on AT dysfunction and inflammation appear robust, there are several limitations that call for more research. Whereas AT hypoxia in obesity is chronic [8], the in vitro studies cited above investigated hypoxia exposures of $2-24 \mathrm{~h}$ which rather induced acute effects. In addition, the level of hypoxia applied in these studies was very extreme $\left(1 \% \mathrm{O}_{2}\right)$ which does not reflect physiological AT oxygen tension in obesity $\left(3-11 \% \mathrm{O}_{2}\right)[6]$. Third, given the fact that immune cells within the AT play an important role in (co-) driving AT dysfunction in obesity [27], an in vivo model is the preferred model to allow for the interaction of different cell types under hypoxic conditions. For these reasons we have designed a model in which we exposed mice to 21 days of hypoxia $\left(8 \% \mathrm{O}_{2}\right)$. This allowed us to investigate whether the acute inflammatory and metabolic alterations observed with acute, severe hypoxia also persist in a chronic model with more physiologically relevant levels of hypoxia.

\section{Methods}

\section{Experimental procedure}

Fifty-two-week-old male C57BL/6J mice (Charles River Laboratories) were exposed to ambient air (normoxia, $n=8$ ) or chronic hypoxia $(n=8)$ for 21 days. We studied 52-week-old mice, rather than the more commonly studied young adult but not fully-grown 12-week-old mice, to preclude increasing body weight (and expanding fat mass) as a confounder. 52-week-old mice remain weight stable under control conditions. All mice were housed in experimental chambers at $21^{\circ} \mathrm{C}$ with a 12 -hour dark/light cycle. Mice received standard chow (V1534000 ssniff R/M-H, ssniff Spezialdiäten $\mathrm{GmbH}$, Soest, Germany) and water ad libitum. Using the proOX P110 (BioSpherix, NY, USA) system, $\mathrm{O}_{2}$ was replaced by $\mathrm{N}_{2}$ in a stepwise manner to create normobaric oxygen levels of $12 \%$ (day 1), $10 \%$ (day 2), and finally $8 \%(60.8 \mathrm{mmHg}$ ) on day 3 . The latter oxygen concentration was maintained for the remainder of the experiment. Three to four mice were 
housed per cage. Daily food intake was determined per cage, and mice were weighed daily. On day 21, mice were anesthetized with isoflurane gas, the abdominal cavity was opened and aortic blood was collected into a heparincoated 1-mL syringe (Becton, Dickinson and Company, Breda, The Netherlands). Oxygen levels and pH were measured immediately using the ABL 510 Blood Gas Analyzer (Radiometer, Diamond Diagnostics, MA, USA) and blood cell count was determined with the Coulter Ac T Diff hematology Analyzer (Beckman Coulter, Woerden, The Netherlands). Plasma was stored at $-80^{\circ} \mathrm{C}$ until further analyses. Visceral adipose tissue (VAT, epididymal) and subcutaneous adipose tissue (SCAT, inguinal) pads were collected bilaterally and weighed. One specimen of each was fixed in $4 \%$ formaldehyde, transferred to $70 \%$ ethanol and subsequently embedded in paraffin. The other was snap-frozen in liquid nitrogen and stored at $-80^{\circ} \mathrm{C}$ for later mRNA analyses. Lower limb skeletal muscles (gastrocnemius, tibialis anterior, soleus, extensor digitorum longus and plantaris), liver and spleen were dissected and weighed. Two normoxic mice were excluded because of infection. The protocol was approved by the Committee for Animal Care and Use of Maastricht University (project no. 2009151).

\section{$\underline{\text { Plasma adipokine assays }}$}

Plasma adipokine profiles were determined using the Luminex xMAP-technology [28]. A Bio-Plex (Bio-Rad Laboratories, Veenendaal, the Netherlands) murine cytokine 6-plex panel was used to quantify the concentrations of interleukin (IL)-1 $\beta$, IL-6, keratinocyte-derived chemokine (KC), monocyte chemotactic protein (MCP)-1, tumor necrosis factor (TNF)- $\alpha$ and chemokine (C-C motif) ligand 5 (CCL5). Additionally, three independent single-plex panels were executed to assess the concentrations of leptin, adiponectin and plasminogen activator-inhibitor (PAI)-1. All assays were performed according to manufacturer's instructions. Data analysis was done with a Luminex 100 IS 2.3 system (Luminex, Austin, TX, USA) using the Bio-Plex Manager 4.1.1 software (Bio-Rad Laboratories, Veenendaal, The Netherlands). The lower limits of detection (LLOD) of the cytokines and adipokines measured were $0.74 \mathrm{pg} / \mathrm{ml}$ for IL-6, $3.4 \mathrm{pg} / \mathrm{ml}$ for TNF- $\alpha, 3.3 \mathrm{pg} / \mathrm{ml}$ for IL-1 $\beta, 1.9 \mathrm{pg} / \mathrm{ml}$ for $\mathrm{KC}, 23.7 \mathrm{pg} / \mathrm{ml}$ for CCL5, $2.4 \mathrm{pg} / \mathrm{ml}$ for MCP-1, $0.7 \mathrm{ng} / \mathrm{ml}$ for leptin, $6.5 \mathrm{pg} / \mathrm{ml}$ for PAI-1, and 6.5 $\mu \mathrm{g} / \mathrm{ml}$ for adiponectin. Cytokine concentrations for the measurements below the LLOD were imputed using a maximum-likelihood estimation procedure $[29,30]$, which was required for the IL- 6 and KC data. It is well-established that simpler methods such as assuming the value of one-half of the LLOD or omitting undetectable samples from analyses generate biased estimates of the measures [31]. Reproducibility statistics based on imputed data, on the other hand, are approximately unbiased when less than half of the measurements are below the LLOD [29] as was the case in our study. 


\section{Adipocyte size}

VAT and SCAT paraffin sections $(4 \mu \mathrm{m})$ were hematoxylin-eosin stained and nonoverlapping fields were photographed at 200× magnification (Nikon Eclipse E800, Nikon Instruments Europe BV, Amsterdam, The Netherlands). The areas of $\geq 400$ unique adipocytes per fat pad were measured using computerized software (Lucia GF, Version 4.81, Laboratory Imaging, Prague, Czech Republic).

\section{$\underline{\text { RT-qPCR analysis }}$}

Total RNA from VAT and SCAT was extracted with the Rneasy® Lipid Tissue Mini Kit (Qiagen, Venlo, The Netherlands) and reverse-transcribed into cDNA using the Transcriptor cDNA synthesis kit (Roche Applied Sciences, Mannheim, Germany). cDNA was amplified using Sensimix SYBR \& Fluorescein Kit (GC biotech B.V., Alphen a/d Rijn, The Netherlands) on a quantitative PCR machine (Bio-Rad laboratories B.V., Veenendaal, The Netherlands). Table 1 presents an overview of the target genes and primer sequences. Expression levels of target genes were normalized for the expression of three stable housekeeping genes (Ppia, Axin1 and Canx) using GeNorm software (Primerdesign, Southampton, NY, USA) [32].

\section{Immunohistochemistry}

Deparaffinized $4 \mu \mathrm{m}$ thick sections of VAT and SCAT were incubated with the antibody AIA31240 (SanBio, Uden, The Netherlands) directed against macrophages [33]. Macrophages were quantified on microscopic pictures at $200 \times$ magnification, and macrophage density was expressed as number of macrophages per 100 adipocytes. If crown-like structures (CLS; aggregations of single of fused macrophages around a single adipocyte) were encountered, their density was expressed as number of CLS per 100 adipocytes.

\section{$\underline{\text { Statistics }}$}

Differences between mice exposed to chronic hypoxia or to normoxia were tested using Student's $t$-test or Mann-Whitney-U tests as appropriate. Body weight changes during the experiment were tested using repeated measures ANOVA. Differences in the responses between VAT and SCAT were tested using linear regression analyses in which the interaction term of condition (normoxia vs hypoxia) and adipose depot (VAT vs SCAT) was evaluated for statistical significance. Correlations were tested using Pearson's correlation coefficient $r$. Data are presented as means \pm SEM. Analyses were performed using PASW Statistics 17.0 (SPSS inc. Chicago, IL, USA). A $P$-value $<.05$ was considered statistically significant. 


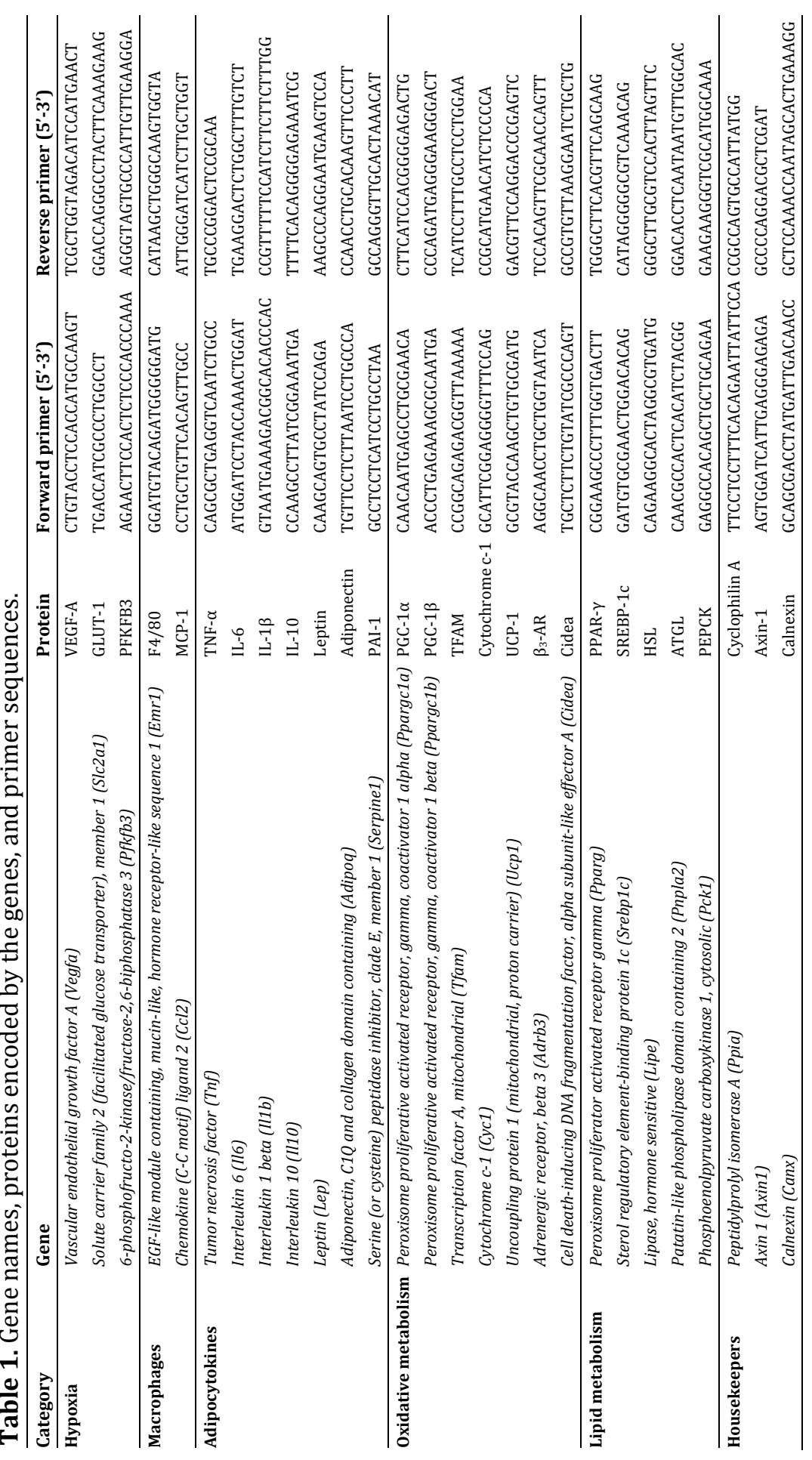




\section{Results}

Chronic hypoxia induces major hematological adaptations

Table 2 summarizes the blood gas analyses and hematological adaptations to chronic hypoxia. As expected, arterial $\mathrm{PaO}_{2}$ and $\mathrm{SaO}_{2}$ were markedly lower in mice exposed to chronic hypoxia. Furthermore, mice exposed to chronic hypoxia had lower $\mathrm{pH}$ and lower $\mathrm{HCO}_{3}$ - but normal $\mathrm{PaCO}_{2}$. Further differences included increased hematocrit, erythrocyte count, hemoglobin concentration, mean corpuscular volume, mean corpuscular hemoglobin, and a decreased mean corpuscular hemoglobin concentration in mice exposed to chronic hypoxia. In line with the acidosis, the significantly higher $p 50$ (a) (oxygen tension of blood at half saturation) in mice exposed to chronic hypoxia indicates a right-shift of the oxygen-hemoglobin dissociation curve, which means a lower affinity of hemoglobin for oxygen, suggesting improved delivery of oxygen to the tissues. Also, chronic hypoxia increased spleen weight by $263 \% \quad(P<.001$, data not shown).

Table 2. Arterial blood gas analysis and hematological adaptations.

\begin{tabular}{|c|c|c|c|}
\hline & $\begin{array}{l}\text { Mice exposed to } \\
\text { normoxia }(n=6)\end{array}$ & $\begin{array}{c}\text { Mice exposed to } \\
\text { chronic hypoxia }(n=6)\end{array}$ & $P$ \\
\hline \multicolumn{4}{|c|}{ Arterial blood gas analysis } \\
\hline $\mathrm{pH}$ & $7.28(0.01)$ & $7.11(0.02)$ & $<.001$ \\
\hline $\mathrm{PaO}_{2}, \mathrm{mmHg}$ & $129.8(3.7)$ & $34.3(1.6)$ & $<.001$ \\
\hline $\mathrm{PaCO}_{2}, \mathrm{mmHg}$ & $35.1(2.7)$ & $35.0(1.4)$ & .96 \\
\hline $\mathrm{HCO}_{3} ;, \mathrm{mmol} / \mathrm{L}$ & $15.9(1.1)$ & $10.7(0.7)$ & .002 \\
\hline $\mathrm{SaO}_{2}, \%$ & $100(0.4)$ & $24(2.4)$ & $<.001$ \\
\hline Base excess, mEq/L & $-9.7(0.9)$ & $-21.2(1.4)$ & $<.001$ \\
\hline \multicolumn{4}{|c|}{ Hematological adaptations } \\
\hline Hematocrit, \% & $45(1)$ & $76(1)$ & $<.001$ \\
\hline Hemoglobin, $\mathrm{mmol} / \mathrm{L}$ & $9.0(0.3)$ & $14.4(0.1)$ & $<.001$ \\
\hline Erythrocytes, x106 & $10.0(0.2)$ & $13.5(0.2)$ & $<.001$ \\
\hline MCV, fL & $45.6(0.3)$ & $56.1(0.8)$ & $<.001$ \\
\hline $\mathrm{MCH}, \mathrm{pg}$ & $0.91(0.01)$ & $1.07(0.02)$ & $<.001$ \\
\hline $\mathrm{MCHC}, \mathrm{g} / \mathrm{dL}$ & $19.8(0.2)$ & $19.0(0.3)$ & .026 \\
\hline$p 50(\mathrm{a})$ & $29.7(0.4)$ & $51.6(0.9)$ & $<.001$ \\
\hline
\end{tabular}

Data are means (SE). Abbreviations: $\mathrm{CH}$, chronic hypoxia; $\mathrm{MCV}$, mean corpuscular volume; $\mathrm{MCH}$, mean corpuscular hemoglobin, MCHC, mean corpuscular hemoglobin concentration. 
$\underline{\text { Recovery of food intake but lower body weight during chronic hypoxia }}$

Directly after initiation of normobaric hypoxia, a drop in food intake was observed, which reached its nadir at 58\% of starting food intake on day 3 (Figure 1A). During days 6 to 10, a complete recovery of food intake was seen, and thereafter it remained stable throughout the remaining 11 days of the experiment. Starting body weights were not different between the two groups (32.6 \pm 0.3 vs $33.1 \pm 0.6 \mathrm{~g}, P=.55$ ). During days 0 to 6 , body weight of mice exposed to chronic hypoxia gradually decreased with approximately $13 \%$ (Figure 1B). Even though their food intake reached normal values by day 10 , their body weights remained stably low throughout the rest of the experiment.

Figure 1. Hypoxia reduces food intake and body weight, but only food intake recovers.

A

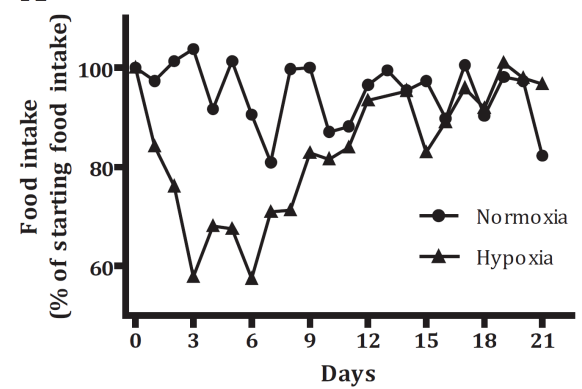

B

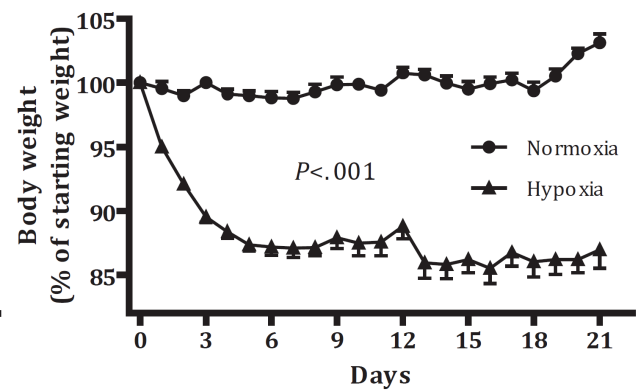

A) Food intake as percentage of starting food intake. Three to four mice were housed per cage and data represent the mean food intake per mouse, relative to day 0. B) Body weight as percentage of starting body weight.

\section{$\underline{\text { Circulating levels of cytokines and adipokines }}$}

Chronic hypoxia increased plasma IL-6 and PAI-1 concentrations, whereas it decreased leptin concentrations. Plasma concentrations of TNF- $\alpha$, IL-1 $\beta$, CCL5, MCP-1, KC, and adiponectin remained unaltered after chronic hypoxia (Table 3).

Loss of adipose tissue and skeletal muscle mass and decreased adipocyte size after chronic hypoxia

Whereas chronic hypoxia decreased lower limb muscle weights by $10.5 \pm 2.5 \%$ (Table 4), the loss of AT mass was much more pronounced (Figure 2A). The decrease in VAT was significantly greater than that of SCAT $(-65 \%$ vs $-55 \%$, $P<.001)$. In line, adipocytes in VAT shrunk significantly more compared to those in SCAT after chronic hypoxia $(-52 \%$ vs $-40 \%, P=.001)$ (Figure 2B). A strong correlation was found between AT mass and adipocyte size (VAT: $r=0.94$, $P<.001$; SCAT: $r=0.81, P<.001$ ). 
Table 3. Circulating levels of cytokines and adipokines.

\begin{tabular}{lccc}
\hline & $\begin{array}{c}\text { Mice exposed to } \\
\text { normoxia (n=6) }\end{array}$ & $\begin{array}{c}\text { Mice exposed to } \\
\text { chronic hypoxia (n=8) }\end{array}$ & $\boldsymbol{P}$ \\
\hline $\mathrm{IL}-6, \mathrm{pg} / \mathrm{ml}$ & $0.46(0.37-0.87)$ & $1.12(0.72-2.45)$ &. $\mathbf{0 4 4}$ \\
$\mathrm{TNF}-\alpha, \mathrm{pg} / \mathrm{ml}$ & $25.1(23.5-61.5)$ & $33.3(25.1-69.1)$ & .47 \\
$\mathrm{IL}-1 \beta, \mathrm{pg} / \mathrm{ml}$ & $27.1(15.9-36.4)$ & $25.7(15.9-35.7)$ & .90 \\
$\mathrm{KC}, \mathrm{pg} / \mathrm{ml}$ & $10.6(4.1-13.6)$ & $12.1(5.1-18.1)$ & .65 \\
$\mathrm{CCL} 5, \mathrm{pg} / \mathrm{ml}$ & $139(107-188)$ & $167(140-209)$ & .33 \\
$\mathrm{MCP}-1, \mathrm{pg} / \mathrm{ml}$ & $31.7(25.3-38.8)$ & $33.5(26.2-40.5)$ & .70 \\
Leptin, ng/ml & $8.9(6.1-11.9)$ & $4.6(4.2-5.1)$ &. $\mathbf{0 0 2}$ \\
Adiponectin, $\mu \mathrm{g} / \mathrm{ml}$ & $31.8(27.3-38.7)$ & $32.1(27.4-43.0)$ & .90 \\
PAI-1, ng/ml & $1.3(1.1-1.7)$ & $2.4(2.3-3.0)$ & $\mathbf{. 0 0 2}$ \\
\hline
\end{tabular}

Abbreviations: CCL5, chemokine (C-C motif) ligand 5; IL, interleukin; $K C$, keratinocyte-derived chemokine; MCP-1, monocyte chemotactic protein-1; PAI-1, plasminogen activator-inhibitor-1; TNF- $\alpha$, tumor necrosis factor- $\alpha$. Data are medians and $95 \%$ CIs.

Table 4. Peripheral skeletal muscle weights.

\begin{tabular}{lccc}
\hline & $\begin{array}{c}\text { Mice exposed to } \\
\text { normoxia (n=6) }\end{array}$ & $\begin{array}{c}\text { Mice exposed to } \\
\text { chronic hypoxia (n=8) }\end{array}$ & $P$ \\
\hline Gastrocnemius muscle, mg & $317(2.2)$ & $276(4.0)$ & $<.001$ \\
Tibialis muscle, mg & $117(1.3)$ & $106(1.6)$ & $<.001$ \\
Plantaris muscle, mg & $41.2(0.8)$ & $36.0(0.8)$ & $<.001$ \\
Extensor digitorum longus & $27.5(0.4)$ & $24.6(0.4)$ & $<.001$ \\
muscle, mg & & & \\
Soleus muscle, mg & $21.7(0.4)$ & $20.2(0.6)$ & .10 \\
\hline
\end{tabular}

Abbreviation: $\mathrm{CH}$, chronic hypoxia. Data are means (SE).

Figure 2. Chronic hypoxia reduces adipose tissue weight and adipocyte size in visceral (VAT) and subcutaneous adipose tissue (SCAT).
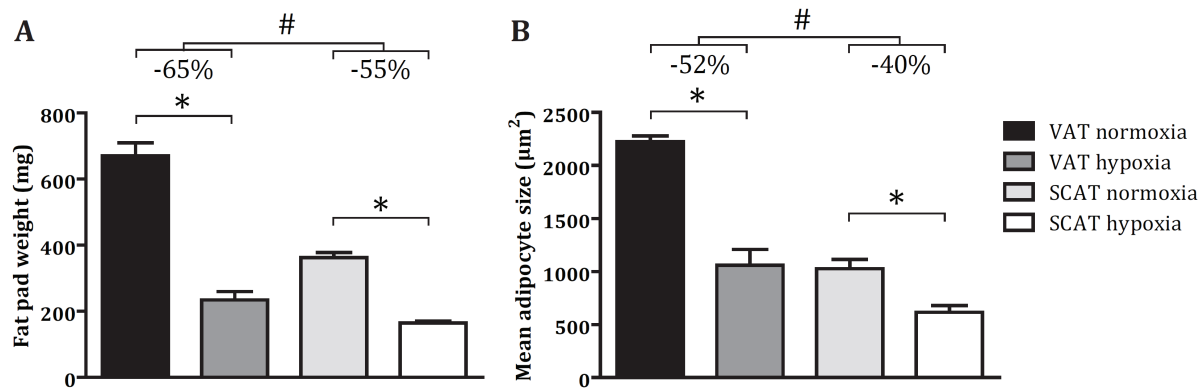

Mice were sacrificed after 21 days of normoxic ( $n=6)$ or hypoxic $(n=8)$ conditions and VAT and SCAT were isolated. A) Bilateral VAT and SCAT weights were significantly reduced during chronic hypoxia, being more pronounced in VAT. B) Decreased adipocyte size during chronic hypoxia, being more pronounced in VAT. ${ }^{*}<<.001$ for within-fat pad comparisons, ${ }^{*}<<.001$ for between-fat pad comparisons. 
Chronic hypoxia induces upregulation of hypoxia-sensitive genes in adipose tissue

Slc2a1, Vegfa and Pfkfb3 are hypoxia-inducible genes encoding glucose transporter-1 (GLUT-1), vascular endothelial growth factor-a (VEGF-A) and the glycolysis-promoting enzyme 6-phosphofructo-2-kinase/fructose-2,6-biphosphatase 3 (PFKFB3), respectively [34, 35]. Chronic hypoxia increased expression of Slc2a1 in SCAT and Vegfa and Pfkf3b in both SCAT and VAT (Figure 3), suggesting that despite the hematological adaptations described above, oxygen-delivery to AT was insufficient resulting in a reduced $\mathrm{AT} \mathrm{PaO}_{2}$. The degree of upregulation of these genes was similar in VAT and SCAT.

Figure 3. Expression of hypoxia-sensitive genes is increased in adipose tissue after chronic hypoxia exposure.

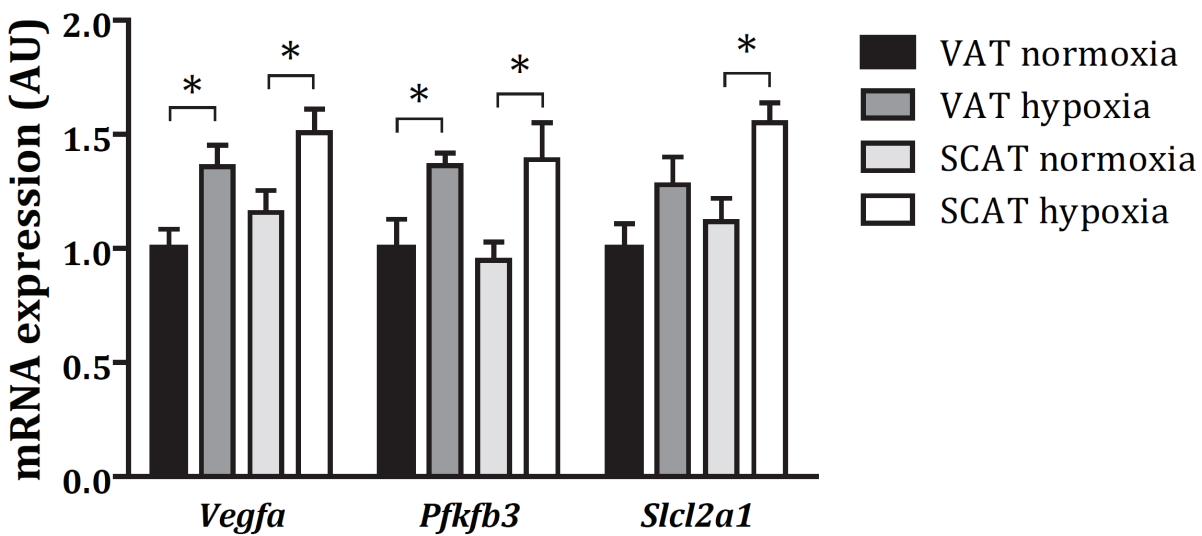

Mice were sacrificed after 21 days of normoxic $(n=6)$ or hypoxic $(n=8)$ conditions and VAT and SCAT were collected. $M R N A$ expression was corrected for a stable GeNorm factor and presented relative to the levels in VAT of normoxic mice. Expression levels of Vegfa (encoding Vascular endothelial growth factorA, VEGF-A), Pfkfb3 (encoding 6-phosphofructo-2-kinase/fructose-2,6-biphosphatase 3, PFKFB3), and Scl2a1 (encoding glucose transporter 1, GLUT-1) were measured. ${ }^{*} P<.05$.

Chronic hypoxia attenuates the inflammatory profile in VAT and SCAT

AT macrophages are considered to be pivotal players in adipose tissue inflammation [27]. In both VAT and SCAT of mice exposed to chronic hypoxia, we found significantly lower gene expression of key markers related to macrophage presence (Emr1) and macrophage recruitment (Ccl2) (Figure 4A). This was confirmed by lower macrophage density in both VAT and SCAT (Figures 4B-C). The decreases in macrophage markers and density were not different between VAT and SCAT. CLS counts were too low to draw a firm conclusion, but tended to be lower in mice exposed to chronic hypoxia, particularly in VAT (data not shown). 
Figure 4. Reduced adipose tissue macrophage infiltration after chronic hypoxia.

A

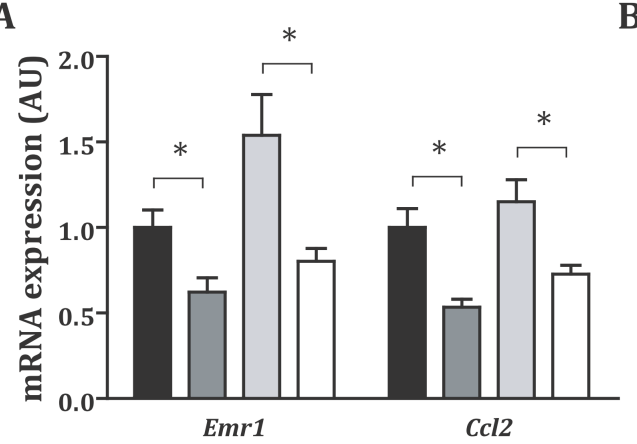

C

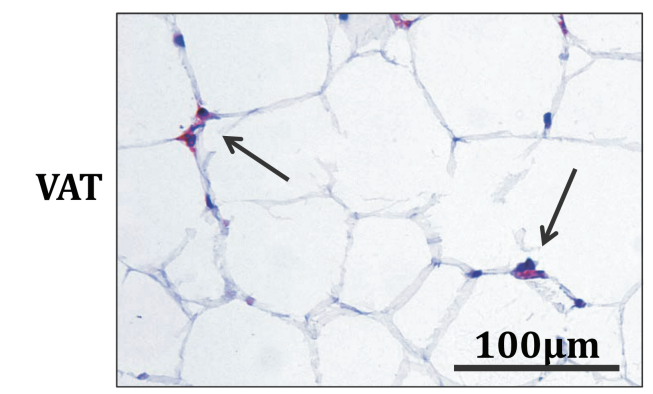

Normoxia

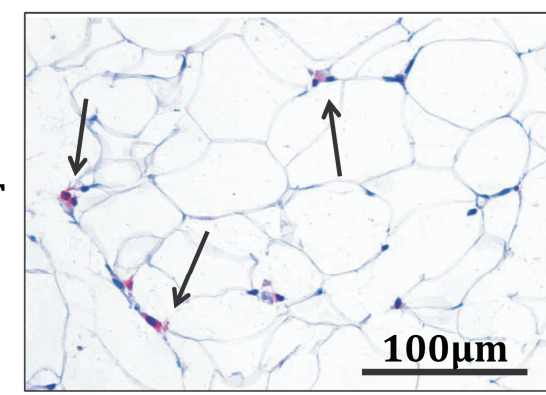

B

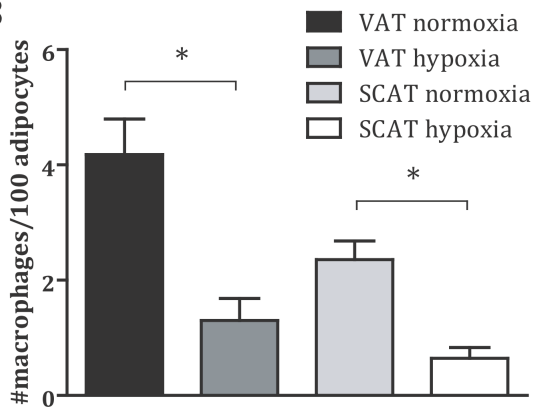

Hypoxia
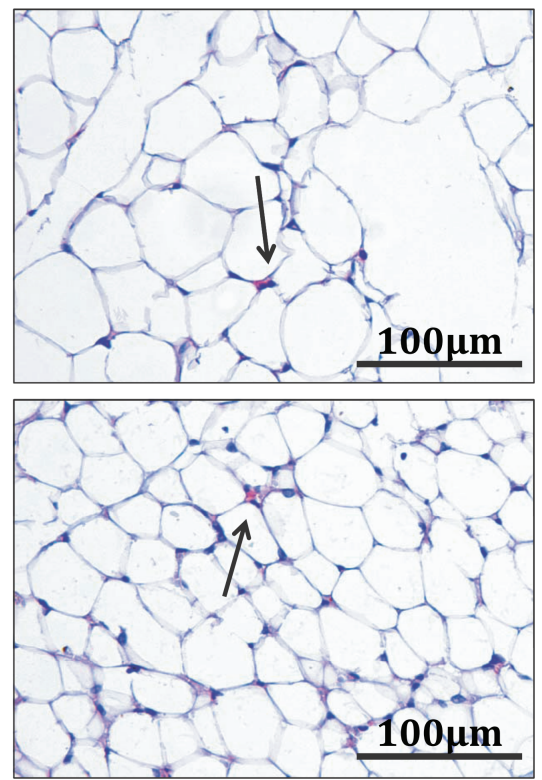

Mice were sacrificed after 21 days of normoxic $(n=6)$ or hypoxic $(n=8)$ conditions and VAT and SCAT were collected. A) Decreased mRNA levels of the macrophage markers Emr1 (encoding F4/80), and Ccl2 (encoding monocyte chemotactic protein-1, MCP-1) were observed in VAT and SCAT after chronic hypoxia. mRNA expression was corrected for a stable GeNorm factor and presented relative to the levels in VAT of normoxic mice. B) Adipose tissue macrophage density was assessed by quantification of immunohistochemically stained macrophages. A significant decrease was observed in AT of mice exposed to chronic hypoxia $C$ ) The representative pictures illustrate decreased AT macrophage density and adipocyte size after exposure to chronic hypoxia (at 200× magnification). ${ }^{*}<<.05$.

In addition, gene expression of Tnf, Il10 and Lep was lower in VAT of mice exposed to chronic hypoxia, whereas expression of Adipoq and Serpine2 was increased (Figure 5A). SCAT of mice exposed to chronic hypoxia was further characterized by lower expression of Il10 and Lep, and an increased Serpine2 
expression (Figure 4B). The decrease in Lep and the increase in Adipoq expression were more pronounced in VAT than in SCAT. Additionally, the decrease in Il10 expression was greater in SCAT compared to VAT. The lower expression of $I l 1 b$ in mice exposed to chronic hypoxia did not reach statistical significance, and no changes were observed in Il6 expression.

Chronic hypoxia increases expression of genes involved in oxidative and lipid metabolism in adipose tissue

We found significantly higher expression of regulators and markers of oxidative metabolism in the AT of mice exposed to chronic hypoxia (Figure 5B). VAT of mice exposed to chronic hypoxia was characterized by increased Ppargc1a, Ppargc1b, Tfam, Adrb3, Cyc1, Ucp1 and Cidea expression. Congruently, SCAT of mice exposed to chronic hypoxia was characterized by increased Ppargc1b, Adrb3, Cyc1 and Ucp1 expression. The expression of the adipogenesis marker Pparg and of the lipogenesis marker Srebp1c were unchanged, whereas expression of the lipolysis markers Lipe and Pnpla2 was increased in both VAT and SCAT of mice exposed to chronic hypoxia (Figure 5C). Furthermore, the expression of Pck1, encoding phosphoenolpyruvate carboxykinase (PEPCK), was significantly increased in both VAT and SCAT of these mice (Figure 5C). None of the chronic hypoxia-induced changes in metabolic gene expression were different between VAT and SCAT.

The alterations in metabolic gene expression after chronic hypoxia, in particular the markedly increased Ucp1 expression, suggest 'browning' of these white adipose tissue pads. Interestingly, we found that the adipose tissue pads were indeed characterized by a brown appearance (Figure 6).

\section{Discussion}

In mice exposed to chronic hypoxia, we found consistent evidence of decreased AT inflammation and alterations in metabolic AT gene expression, suggesting increased oxidative metabolism and enhanced lipolysis. In view of the proinflammatory and oxidative-to-glycolytic shifts that have been documented after exposing adipocytes to acute and severe hypoxia in vitro, and of studies in obese mice suggesting a link between AT hypoxia and local inflammation, our findings may be unexpected. However, the present findings are in line with previous reports, showing that abdominal subcutaneous AT $\mathrm{PaO}_{2}$ was significantly increased rather than decreased in obese insulin resistant individuals, and was positively associated with AT gene expression of several pro-inflammatory markers [5]. In that study, the lower $\mathrm{AT}^{\mathrm{PaO}_{2}}$ in obesity seemed to be due to decreased in vivo abdominal subcutaneous AT oxygen consumption, suggesting a lower metabolic rate of AT in obese subjects. Furthermore, abdominal subcutaneous AT $\mathrm{PaO}_{2}$ was inversely associated with AT expression of 
Figure 5. Significant alterations in adipose tissue gene expression of adipocytokines and of key markers of oxidative and lipid metabolism after chronic hypoxia.

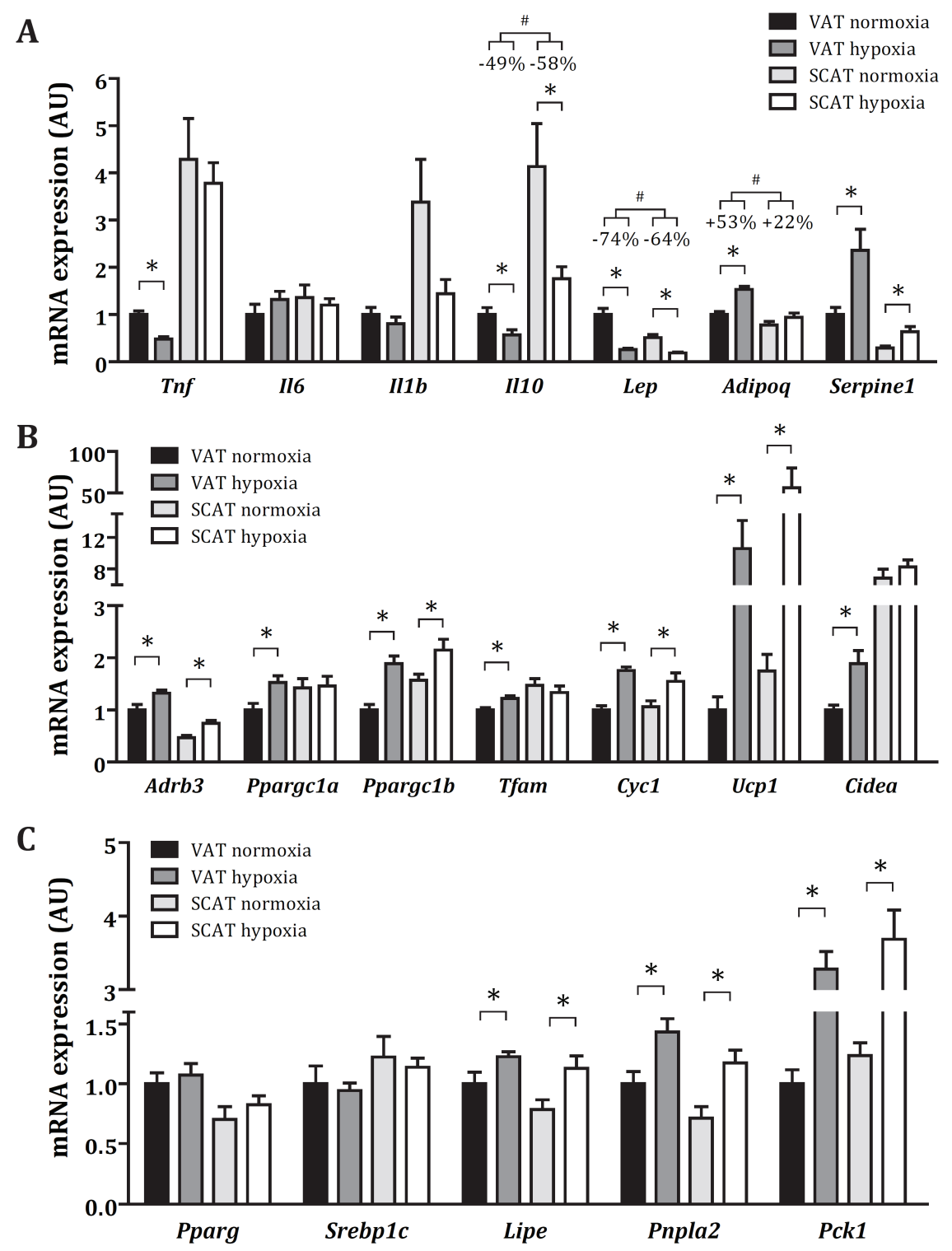

Mice were sacrificed after 21 days of normoxic $(n=6)$ or hypoxic $(n=8)$ conditions and VAT and SCAT were collected. A) mRNA levels of specific cytokines and adipokines. B) $m R N A$ levels of regulators and markers of oxidative metabolism in adipose tissue of mice exposed to chronic hypoxia. C) mRNA levels of lipolysis-related markers. mRNA expression was corrected for a stable GeNorm factor and presented relative to the levels in VAT of normoxic mice. ${ }^{*}<<.05$ for within-fat pad comparisons, ${ }^{\#}<<.05$ for between-fat pad comparisons. 
Figure 6. Brown appearance of visceral and subcutaneous adipose tissue after chronic hypoxia.
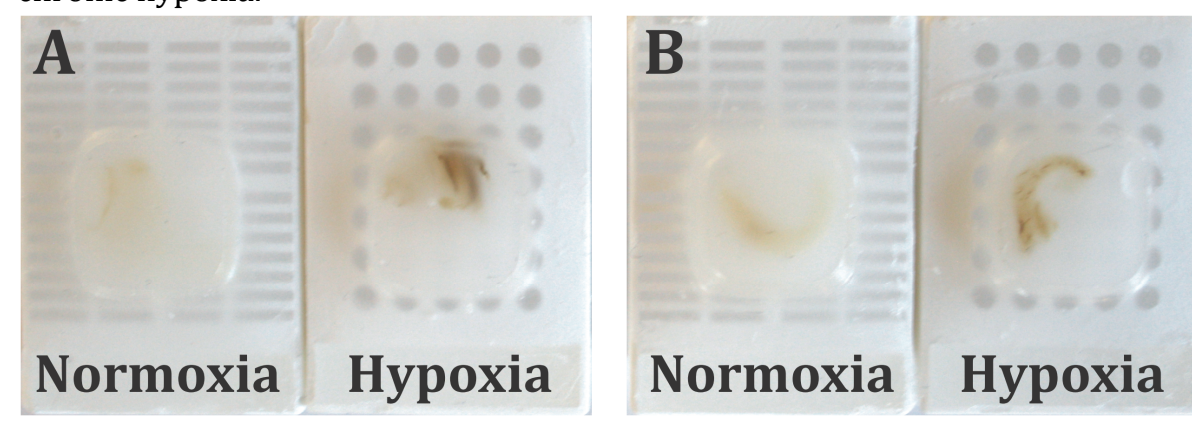

Pictures show representative adipose tissue pads of mice exposed to 21 days of normoxia or hypoxia. Pictures were taken once the tissues were embedded in paraffin. Note the brown appearance of the adipose tissue pads of mice exposed to chronic hypoxia. A) Visceral adipose tissue. B) Subcutaneous adipose tissue.

PPARGC1A and VEGFA [5]. The present data suggest that these associations may also hold in a model of chronic hypoxia. Congruently, it has recently been reported that primary human SCAT-derived adipocytes from overweight individuals displayed reduced expression of nuclear factor- $\kappa \mathrm{B}$ related genes (including CCL2), and showed a blunted response to TNF- $\alpha$ stimulation in terms of CCL2 expression and protein secretion when exposed to hypoxia [20]. Our data underline the complexity of the effects of hypoxia on AT function and suggest important differences between acute and chronic effects. To the best of our knowledge, no previous study has investigated AT function after exposure to chronic hypoxia, precluding direct comparisons.

The gross phenotypical changes in mice exposed to chronic hypoxia should not be disregarded when interpreting AT inflammatory and metabolic alterations. Chronic hypoxia markedly reduced fat mass and, congruently, decreased adipocyte size. This may have contributed to decreased AT inflammation. Indeed, adipocyte size has been recognized as an important determinant of adipokine expression and secretion, with large adipocytes being more pro-inflammatory than small adipocytes [36]. During the course of hypertrophy, adipocytes produce CCL2, and fatty acids released from hypertrophied adipocytes can bind Toll-like receptor 4 complex, thereby activating an inflammatory response in AT macrophages [37]. Conversely, our data on smaller adipocytes, decreased AT Ccl2 and Emr1 expression and decreased AT macrophage density suggest that these mechanisms of AT macrophage infiltration and activation are significantly attenuated after chronic hypoxia.

Low-grade systemic inflammation, associated with elevated IL-6, has been suggested to play a pivotal role in both obesity and COPD, and AT has been considered as an important contributor in both diseases [38, 39]. It has 
previously been shown that sustained hypoxia results in increased levels of circulating IL-6 [40, 41], which is confirmed by the current data. Also, chronic hypoxia almost doubled the concentrations of circulating PAI-1, which is a main inhibitor of fibrinolysis. This is in line with a previous study [42], and with the well-known association between systemic inflammation and a pro-thrombotic state [43]. The changes in circulating PAI-1 and leptin concentrations after chronic hypoxia were paralleled by changes in AT gene expression of these adipokines. However, AT IL-6 gene expression was unchanged and other proinflammatory markers were even decreased. This suggests that chronic hypoxiaenhanced circulating IL-6 levels and likely chronic hypoxia-induced low-grade systemic inflammation in general, are not accounted for by the AT.

In our model, exposure to hypoxia initially induced significant weight loss and decreased food intake, but after ten days food intake completely normalized whereas body weight remained stably low. These data suggest that a new homeostatic equilibrium was established which is characterized by a hypermetabolic state. Interestingly, this was accompanied by major changes in AT metabolic gene expression that collectively suggest increased mitochondrial biogenesis, mitochondrial function and lipolysis after chronic hypoxia. Given this specific pattern of metabolic gene expression, it is tempting to speculate that AT remodeling occurred via chronic stimulation of adipocytic $\beta_{3}$-adrenergic receptors $\left(\beta_{3}-\mathrm{AR}\right)$. Indeed, nor-adrenergic remodeling of white AT is characterized by an elevation of the metabolic rate, an expansion of mitochondrial mass and upregulation of fatty acid oxidation genes, and has even been shown to induce uncoupling protein-1 (UCP-1), which is typically a brown AT marker [44, 45]. Hormone sensitive lipase-mediated lipolysis has, notably, been recognized as an important component of AT remodeling following $\beta_{3}-\mathrm{AR}$ activation [45]. Additionally, PEPCK (encoded by Pck1) is a key mediator of glyceroneogenesis, which involves re-esterification of fatty acids to triacylglycerol serving adipocytic retention rather than secretion of fatty acids [46]. In brown AT, it has been suggested that glyceroneogenesis regulates the delivery of FA to the mitochondria, allowing for UCP-1 activation [46]. Moreover, Pck1 transcription is induced by nor-adrenergic stimulation in brown AT [47] and in white AT pro-inflammatory cytokines inhibit Pck1 expression [48]. $\beta_{3^{-}}$ adrenergic remodeling is induced by chronic cold exposure [44], therefore, a limitation of the present study is that we did not assess body temperature nor apply a thermoneutral environment. For these reasons, we cannot fully exclude that part of our findings can be explained by relative cold exposure in mice exposed to chronic hypoxia. As metabolic remodeling of white AT is receiving a great deal of attention in the combat against obesity, our finding of this phenomenon coinciding with decreased AT inflammation may be relevant to the obesity field. The lower fat mass and the markedly reduced adipocyte size point towards increased lipolysis after chronic hypoxia, which is further supported by the increased gene expression of the key lipolytic enzymes HSL and ATGL, and 
the unchanged gene expression of the adipogenic/lipogenic markers PPAR- $\gamma$ and SREBP-1c. A limitation of this study, however, is that we did not assess systemic markers of lipolysis due to limited availability of material.

In conclusion, chronic hypoxia is associated with decreased rather than increased AT inflammation, and markedly decreased fat mass and adipocyte size. Furthermore, our data indicate that chronic hypoxia is accompanied by alterations in AT metabolic gene expression, pointing towards an enhanced AT metabolic rate. 


\section{HYPOXIA, ADIPOSE TISSUE INFLAMMATION AND METABOLISM}

\section{References}

1. Buist AS, McBurnie MA, Vollmer WM, Gillespie S, Burney P, Mannino DM, Menezes AM, Sullivan SD, Lee TA, Weiss KB, et al. International variation in the prevalence of COPD (the BOLD Study): a population-based prevalence study. Lancet. 2007;370(9589):741-50.

2. Popkin BM. Recent dynamics suggest selected countries catching up to US obesity. Am J Clin Nutr. 2010;91(1):284S-8S.

3. Franssen FM, O'Donnell DE, Goossens GH, Blaak EE, Schols AM. Obesity and the lung: 5. Obesity and COPD. Thorax. 2008;63(12):1110-7.

4. Vozoris N, O'Donnell DE. Prevalence, risk factors, activity limitation and health care utilization of an obese, population-based sample with chronic obstructive pulmonary disease. Can Respir J. 2012;19(3):e18-24.

5. Goossens GH, Bizzarri A, Venteclef N, Essers Y, Cleutjens JP, Konings E, Jocken JW, Cajlakovic M, Ribitsch V, Clement $\mathrm{K}$, et al. Increased adipose tissue oxygen tension in obese compared with lean men is accompanied by insulin resistance, impaired adipose tissue capillarization, and inflammation. Circulation.2011;124(1):67-76.

6. Goossens GH, Blaak EE. Adipose tissue oxygen tension: implications for chronic metabolic and inflammatory diseases. Curr Opin Clin Nutr Metab Care. 2012;15(6):539-46.

7. Pasarica M, Sereda OR, Redman LM, Albarado DC, Hymel DT, Roan LE, Rood JC, Burk DH, Smith SR. Reduced adipose tissue oxygenation in human obesity: evidence for rarefaction, macrophage chemotaxis, and inflammation without an angiogenic response. Diabetes. 2009;58(3):718-25.

8. Trayhurn P. Hypoxia and adipose tissue function and dysfunction in obesity. Physiol Rev. 2013;93(1):1-21.

9. Raguso CA, Luthy C. Nutritional status in chronic obstructive pulmonary disease: role of hypoxia. Nutrition. 2011;27(2):138-43.

10. Schols AM. Pulmonary cachexia. Int J Cardiol. 2002;85(1):101-10.

11. Wagner PD. Possible mechanisms underlying the development of cachexia in COPD. Eur Respir J. 2008;31(3):492-501.

12. Goossens GH. The role of adipose tissue dysfunction in the pathogenesis of obesity-related insulin resistance. Physiol Behav. 2008;94(2):206-18.

13. Trayhurn P, Wood IS. Adipokines: inflammation and the pleiotropic role of white adipose tissue. $B r J$ Nutr. 2004;92(3):347-55.

14. Hosogai N, Fukuhara A, Oshima K, Miyata Y, Tanaka S, Segawa K, Furukawa S, Tochino Y, Komuro R, Matsuda $\mathrm{M}$, et al. Adipose tissue hypoxia in obesity and its impact on adipocytokine dysregulation. Diabetes. 2007;56(4):901-11.

15. Rausch ME, Weisberg S, Vardhana P, Tortoriello DV. Obesity in C57BL/6J mice is characterized by adipose tissue hypoxia and cytotoxic T-cell infiltration. Int J Obes (Lond). 2008;32(3):451-63.

16. Ye J, Gao Z, Yin J, He Q. Hypoxia is a potential risk factor for chronic inflammation and adiponectin reduction in adipose tissue of ob/ob and dietary obese mice. Am J Physiol Endocrinol Metab. 2007;293(4):E1118-28.

17. Mazzatti D, Lim FL, O'Hara A, Wood IS, Trayhurn P. A microarray analysis of the hypoxia-induced modulation of gene expression in human adipocytes. Arch Physiol Biochem. 2012;118(3):112-20.

18. Wree A, Mayer A, Westphal S, Beilfuss A, Canbay A, Schick RR, Gerken G, Vaupel P. Adipokine expression in brown and white adipocytes in response to hypoxia. J Endocrinol Invest. 2012;35(5):522-7.

19. Yu J, Shi L, Wang H, Bilan PJ, Yao Z, Samaan MC, He Q, Klip A, Niu W. Conditioned medium from hypoxiatreated adipocytes renders muscle cells insulin resistant. Eur J Cell Biol. 2011;90(12):1000-15.

20. Famulla S, Horrighs A, Cramer A, Sell H, Eckel J. Hypoxia reduces the response of human adipocytes towards TNFalpha resulting in reduced NF-kappaB signaling and MCP-1 secretion. IntJObes (Lond).2012;36(7):986-92.

21. DiGirolamo M, Newby FD, Lovejoy J. Lactate production in adipose tissue: a regulated function with extraadipose implications. FASEB J. 1992;6(7):2405-12.

22. Perez de Heredia F, Wood IS, Trayhurn P. Hypoxia stimulates lactate release and modulates monocarboxylate transporter (MCT1, MCT2, and MCT4) expression in human adipocytes. Pflugers Arch. 2010;459(3):509-18.

23. Yin J, Gao Z, He Q, Zhou D, Guo Z, Ye J. Role of hypoxia in obesity-induced disorders of glucose and lipid metabolism in adipose tissue. Am J Physiol Endocrinol Metab. 2009;296(2):E333-42.

24. Quintero P, Gonzalez-Muniesa P, Garcia-Diaz DF, Martinez JA. Effects of hyperoxia exposure on metabolic markers and gene expression in 3T3-L1 adipocytes. J Physiol Biochem. 2012;68(4):663-9.

25. Tkacova R, Ukropec J, Skyba P, Ukropcova B, Pobeha P, Kurdiova T, Joppa P, Klimes I, Tkac I, Gasperikova D. Increased adipose tissue expression of proinflammatory CD40, MKK4 and JNK in patients with very severe chronic obstructive pulmonary disease. Respiration. 2011;81(5):386-93.

26. Tkacova R, Ukropec J, Skyba P, Ukropcova B, Pobeha P, Kurdiova T, Joppa P, Klimes I, Tkac I, Gasperikova D. Effects of Hypoxia on Adipose Tissue Expression of NFkappaB, IkappaBalpha, IKKgamma and IKAP in Patients with Chronic Obstructive Pulmonary Disease. Cell Biochem Biophys. 2012.

27. Morris DL, Singer K, Lumeng CN. Adipose tissue macrophages: phenotypic plasticity and diversity in lean and obese states. Curr Opin Clin Nutr Metab Care. 2011;14(4):341-6. 


\section{CHAPTER 6}

28. Sabo-Attwood T, Ramos-Nino M, Bond J, Butnor KJ, Heintz N, Gruber AD, Steele C, Taatjes DJ, Vacek P, Mossman BT. Gene expression profiles reveal increased mClca3 (Gob5) expression and mucin production in a murine model of asbestos-induced fibrogenesis. Am J Pathol. 2005;167(5):1243-56.

29. Lubin JH, Colt JS, Camann D, Davis S, Cerhan JR, Severson RK, Bernstein L, Hartge P. Epidemiologic evaluation of measurement data in the presence of detection limits. Environ Health Perspect. 2004;112(17):1691-6.

30. Wong HL, Pfeiffer RM, Fears TR, Vermeulen R, Ji S, Rabkin CS. Reproducibility and correlations of multiplex cytokine levels in asymptomatic persons. Cancer Epidemiol Biomarkers Prev. 2008;17(12):3450-6.

31. Helsel DR. Fabricating data: how substituting values for nondetects can ruin results, and what can be done about it. Chemosphere. 2006;65(11):2434-9.

32. Vandesompele J, De Preter K, Pattyn F, Poppe B, Van Roy N, De Paepe A, Speleman F. Accurate normalization of real-time quantitative RT-PCR data by geometric averaging of multiple internal control genes. Genome Biol. 2002;3(7):RESEARCH0034.

33. Poggi M, Engel D, Christ A, Beckers L, Wijnands E, Boon L, Driessen A, Cleutjens J, Weber C, Gerdes N, et al. CD40L deficiency ameliorates adipose tissue inflammation and metabolic manifestations of obesity in mice. Arterioscler Thromb Vasc Biol. 2011;31(10):2251-60.

34. Obach M, Navarro-Sabate A, Caro J, Kong X, Duran J, Gomez M, Perales JC, Ventura F, Rosa JL, Bartrons R. 6Phosphofructo-2-kinase (pfkfb3) gene promoter contains hypoxia-inducible factor-1 binding sites necessary for transactivation in response to hypoxia. J Biol Chem. 2004;279(51):53562-70.

35. Trayhurn P, Wang B, Wood IS. Hypoxia in adipose tissue: a basis for the dysregulation of tissue function in obesity? BrJ Nutr. 2008;100(2):227-35.

36. Skurk T, Alberti-Huber C, Herder C, Hauner H. Relationship between adipocyte size and adipokine expression and secretion. J Clin Endocrinol Metab. 2007;92(3):1023-33.

37. Itoh M, Suganami T, Hachiya R, Ogawa Y. Adipose tissue remodeling as homeostatic inflammation. Int J Inflam. 2011;2011:720926.

38. Eder K, Baffy N, Falus A, Fulop AK. The major inflammatory mediator interleukin- 6 and obesity. Inflamm Res. 2009;58(11):727-36

39. van den Borst B, Gosker HR, Koster A, Yu B, Kritchevsky SB, Liu Y, Meibohm B, Rice TB, Shlipak M, Yende S, et $a l$. The influence of abdominal visceral fat on inflammatory pathways and mortality risk in obstructive lung disease. Am J Clin Nutr. 2012;96(3):516-26.

40. Kozak W, Wrotek S, Walentynowicz K. Hypoxia-induced sickness behaviour. J Physiol Pharmacol. 2006;57 Suppl 8:35-50.

41. Raja KB, G OL-D, Peters TJ, McKie AT, Simpson RJ. Role of interleukin-6 in hypoxic regulation of intestinal iron absorption. BrJ Haematol. 2005;131(5):656-62.

42. Pinsky DJ, Liao H, Lawson CA, Yan SF, Chen J, Carmeliet P, Loskutoff DJ, Stern DM. Coordinated induction of plasminogen activator inhibitor-1 (PAI-1) and inhibition of plasminogen activator gene expression by hypoxia promotes pulmonary vascular fibrin deposition. J Clin Invest. 1998;102(5):919-28.

43. Esmon CT. The interactions between inflammation and coagulation. BrJ Haematol. 2005;131(4):417-30.

44. Lowell BB, Spiegelman BM. Towards a molecular understanding of adaptive thermogenesis. Nature. 2000;404(6778):652-60.

45. Mottillo EP, Shen XJ, Granneman JG. Role of hormone-sensitive lipase in beta-adrenergic remodeling of white adipose tissue. Am J Physiol Endocrinol Metab. 2007;293(5):E1188-97.

46. Hanson RW, Reshef L. Glyceroneogenesis revisited. Biochimie. 2003;85(12):1199-205.

47. Hahn P, Kirby LT. The effects of catecholamines, glucagon, and diet on enzyme activities in brown fat and liver of the rat. Can J Biochem. 1974;52(9):739-43.

48. Feingold KR, Moser A, Shigenaga JK, Grunfeld C. Inflammation inhibits the expression of phosphoenolpyruvate carboxykinase in liver and adipose tissue. Innate Immun. 2012;18(2):231-40. 



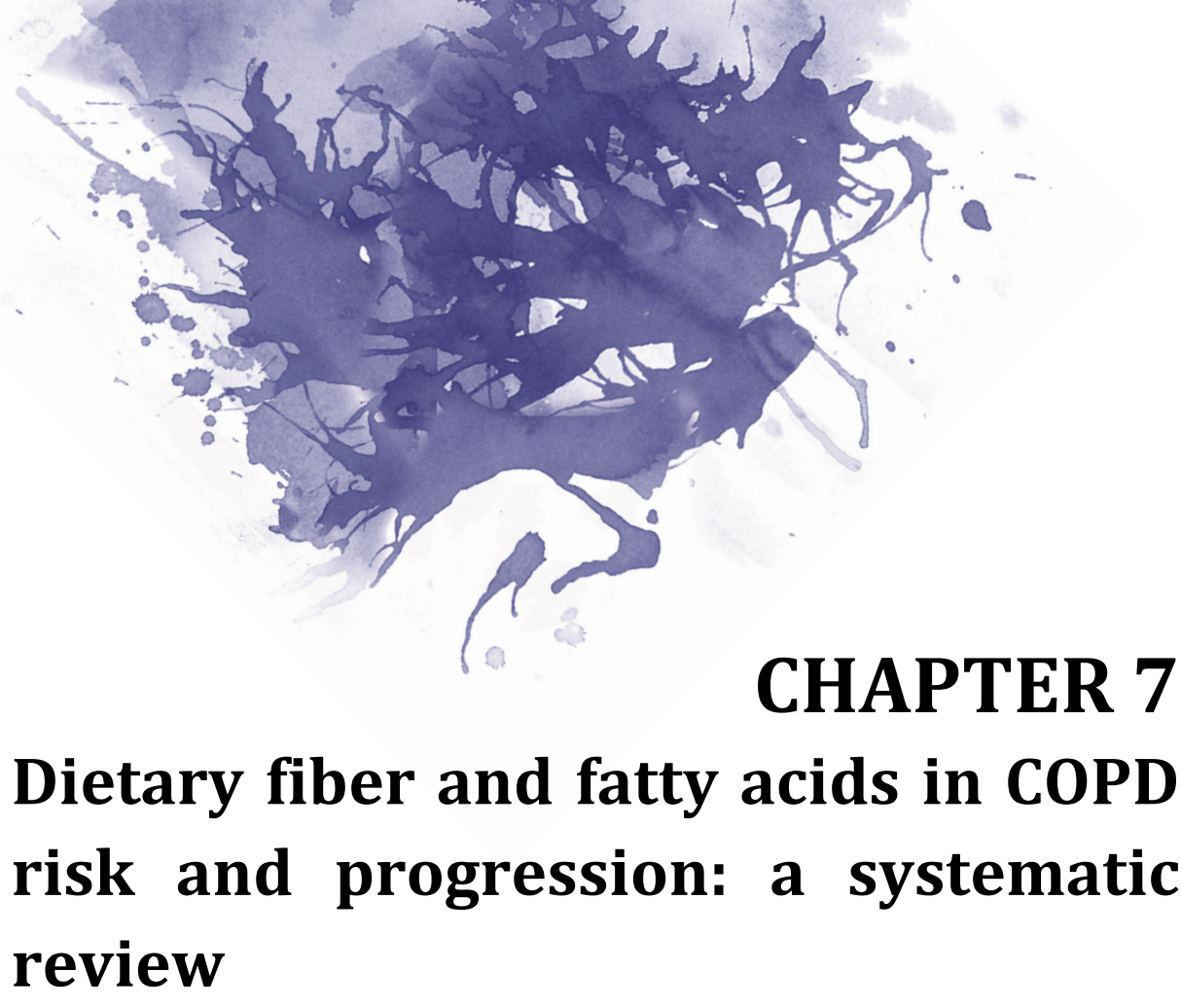

Eric L.A. Fonseca Wald, Bram van den Borst, Harry R. Gosker, Annemie M.W.J. Schols

Submitted 


\section{Abstract}

Background: Non-smoking lifestyle factors including dietary components have attracted increasing attention in the risk for and course of chronic obstructive pulmonary disease (COPD). Dietary fiber and fatty acids have been hypothesized to play an immunomodulating role in chronic inflammatory diseases, including COPD.

Objective: To review the current evidence on the potential roles of dietary fiber or fatty acids in COPD risk and progression.

Methods: We systematically searched Pubmed, EMBASE, Cochrane Collaboration Database and conference databases for original studies in adults addressing the association between fiber or fatty acid intake and COPD in terms of risk, lung function and respiratory symptoms.

Results: Nine articles were included of which four reported on dietary fiber and five on fatty acids. Data of studies could not be pooled because of methodological diversity. Greater intake of dietary fiber has been consistently associated with reduced COPD risk, better lung function, and reduced respiratory symptoms. Results on the associations between fatty acids and COPD are inconsistent.

Conclusions: Dietary quality, particularly in terms of dietary fiber amount, deserves further attention in COPD prevention and management programs. 


\section{Introduction}

An estimated 64 million people suffer from chronic obstructive pulmonary disease (COPD) worldwide, a disease that is associated with high morbidity and mortality [1]. COPD has been defined as a preventable and largely lifestyleinduced disease characterized by an abnormal pulmonary inflammatory response resulting in a progressive, partially irreversible airflow limitation [2]. In addition, COPD has been shown to have a profound systemic component characterized by low-grade systemic inflammation and co-morbidities [2].

The disease state of COPD is likely the product of genetic and environmental factors [3]. Although exposure to cigarette smoke is considered the principal environmental risk factor, an estimated $25-45 \%$ of COPD patients have never smoked [4], only $\sim 20 \%$ of smokers eventually develop COPD [5], and only 10\% of the variability in forced expiratory volume in $1 \mathrm{~s}\left(\mathrm{FEV}_{1}\right)$ is explained by smoking in the general population [6]. It has therefore been suggested that nonsmoking environmental factors such as diet and physical activity should also be considered. For a comprehensive overview on the effects of physical inactivity on COPD risk we refer the reader to a recent review by Hopkinson et al. [7]. The present systematic review was undertaken to summarize the current knowledge on the effects of specific dietary components, more specifically dietary fiber and fatty acids, on COPD risk and progression.

Nutritional support in COPD management currently has a primary focus on malnourished patients. In recent years, however, nutritional research in COPD has also explored associations between dietary patterns and specific dietary components with COPD risk and progression. It was shown that a diet rich in fruit, vegetables, whole-meal cereals and fish reduces the risk of COPD whereas a "Western diet" rich in refined grains, cured and red meats, desserts and French fries has been shown to increase COPD risk [8-10]. However, knowledge on the influence of specific dietary components may ultimately provide the best possible way to optimize dietary recommendations in COPD. Dietary fiber and fatty acids have been shown to influence the immune system in various ways and could be hypothesized to play a role in chronic inflammatory diseases including COPD. Greater intake of dietary fiber has been associated with improved gut immunity and reduced systemic inflammation [11-14]. Polyunsaturated fatty acids (PUFAs) have been shown to possess pro- and anti-inflammatory properties through direct influences on membrane functioning and through binding with peroxisome proliferator-activated receptors (PPARs), and indirectly via their metabolization into eicosanoids [15].

The present systematic review summarizes the current evidence on the potential roles of dietary fiber or specific fatty acids in COPD risk and progression. 


\section{Methods}

\section{Data sources and search strategy}

This systematic review was performed according to MOOSE (Meta-analysis of Observational Studies in Epidemiology) guidelines [16]. Relevant articles were searched in Pubmed (through August 2012), EMBASE (1989 through August 2012), Cochrane Collaboration Database (through August 2012), and in conference databases of the European Respiratory Society (2006-2011), American Thoracic Society (2008-2012), European Society for Clinical Nutrition and Metabolism (2003-2012), American Society for Parenteral and Enteral Nutrition (2009-2011) and Experimental Biology (2010-2012). Databases were either systematically searched by combining free terms and subject headings (Mesh or Emtree terms for Pubmed and EMBASE, respectively) when available, or were hand searched. The search strategy consisted of terms on dietary fiber and specific fatty acids in combination with relevant COPD-related terms and lung function (see Appendix for terms used and search strategies per edatabase). In Pubmed and EMBASE the limits 'humans' and 'adults' were imposed. Additionally, references of retrieved articles were hand searched to find more articles.

\section{$\underline{\text { Study selection }}$}

Articles identified by the search were first screened by title. Subsequently, the corresponding abstracts of potentially relevant hits were independently screened by two researchers (ELAFW and BB) based on selection criteria. The second researcher was blinded for journal, authors, title, publication date and publication language (all abstracts were in English). In case of disagreement, consensus was reached on the selection of studies for full-text assessment. To be included, studies had to meet the following criteria: studies needed to be original studies in adults addressing the association between dietary fiber or fatty acids with predefined outcome measures (pulmonary function, pulmonary symptoms and/or COPD risk/ incidence/ prevalence). Studies that assessed plasma biomarkers of specific fatty acids as surrogate marker of dietary intake were excluded. In case of uncertainty for inclusion of full-text articles or conference abstracts, consensus was reached via a second reviewer. Native speakers were consulted for foreign language articles. 


\section{Results}

\section{$\underline{\text { Search results }}$}

A flowchart of study selection is presented in Figure 1. Briefly, the search in electronic databases yielded 5016 hits from Pubmed, 5088 from EMBASE and 218 from the Cochrane Collaboration Database, from which in total 220 possibly eligible articles were found. Additionally, 16 articles were identified in reference lists. In total, 236 abstracts were judged on the need to assess the full-text. Subsequently, 88 full-text articles and 41 conference abstracts underwent thorough assessment based on the predefined criteria. Finally, nine articles were included. Of these, four reported data on associations between fiber intake and COPD, and five investigated associations between fatty acid intake and COPD. At first, the objective was to perform a meta-analysis. However, the studies proved insufficiently homogeneous to allow pooling of results or tabulating their respective data. Hence, we provide a narrative synthesis of the respective studies.

All the studies used a food frequency questionnaire or validated analogues to assess nutrient intake. In addition, all the studies adjusted extensively for possible confounding by known risk factors, including smoking.

Figure 1. Flow chart of article selection.

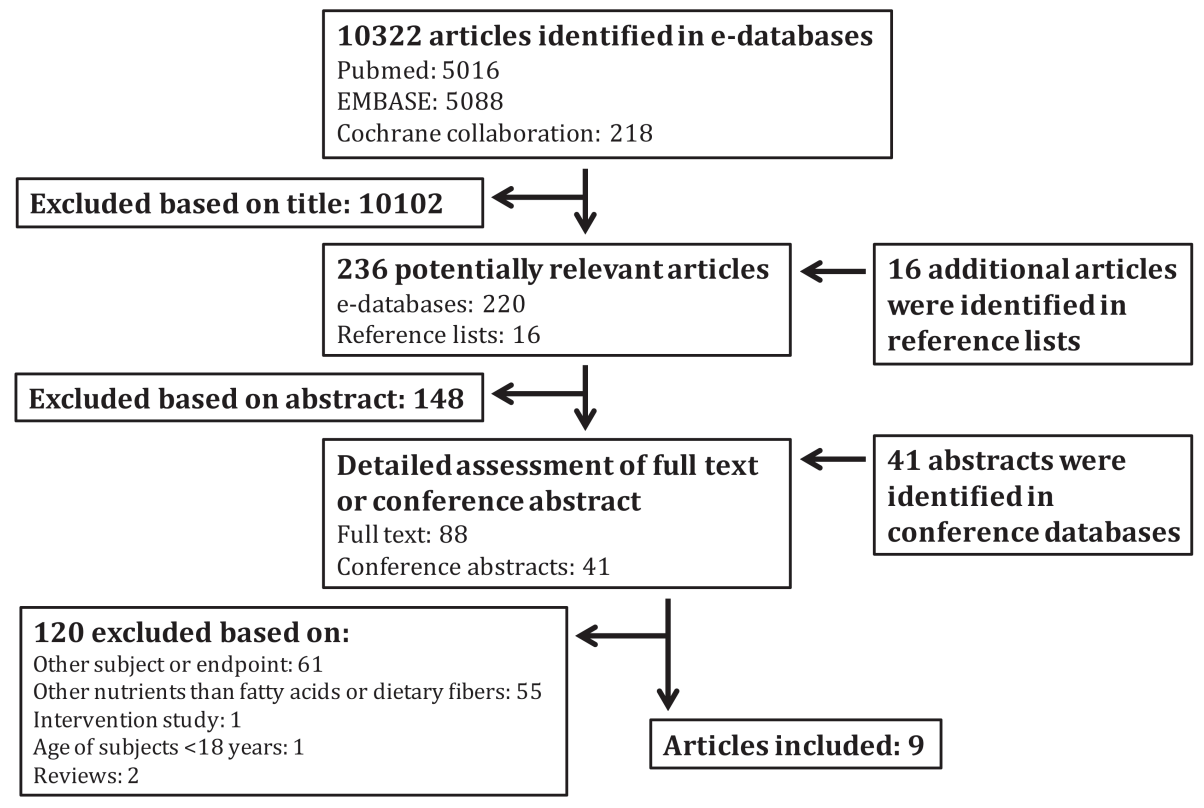




\section{$\underline{\text { Associations between dietary fiber and COPD }}$}

In the large population-based Atherosclerosis Risk in Communities (ARIC) Study comprising 11.897 US men and women aged 44-66y, higher total dietary fiber intake was cross-sectionally associated with better lung function (FEV $1, F V$ and $\mathrm{FEV}_{1}$ /FVC ratio) [17]. Notably, people in the highest quintile of total dietary fiber intake (median $25.0 \mathrm{~g}$ /day) had an adjusted $60 \mathrm{ml}$ higher $\mathrm{FEV}_{1}$ compared with people in the lowest quintile (median $10.2 \mathrm{~g}$ /day). In addition, higher total dietary fiber intake was associated with lower odds ratios for COPD (OR 0.85, 95\% CI 0.68-1.05). COPD was defined as pre-bronchodilator $\mathrm{FEV}_{1} / \mathrm{FVC}<0.7$ and $\mathrm{FEV}_{1}<80 \%$ of predicted and/or self-reported persisted cough and production of phlegm on most days for at least three consecutive months of the year for two or more years. Similar data were obtained when investigated for fiber from cereals and fiber from fruit but not for fiber from vegetables.

Another study by Hirayama et al. [18] compared $n=278$ Japanese COPD patients (mean $\mathrm{FEV}_{1} 57 \%$ of predicted) and $\mathrm{n}=340$ community-based non-COPD controls and found that the mean vegetable and fruit intakes of COPD patients were significantly lower. The authors subsequently applied logistic regression analyses to estimate the odds of having COPD across quartiles of nutrient intakes. They found that people who consumed $\geq 16.1 \mathrm{~g}$ total dietary fiber per day had lower odds of having COPD compared to those who consumed $<8.8 \mathrm{~g}$ total dietary fiber per day (OR $0.49,95 \%$ CI $0.26-0.94$ ). Upon stratification into soluble and insoluble fiber intake, the authors found a similar association for insoluble but not soluble fiber.

Although the above referenced data from the ARIC study and the Japanese study may suggest a role for dietary fiber in COPD etiology, their cross-sectional natures preclude from drawing any causal inferences. Two other studies, however, applied a prospective design and showed remarkably consistent results. First, in a 5-year prospective population-based cohort of 63.257 middleaged men and women residing in China and Singapore [19], higher intake of nonstarch polysaccharides was negatively associated with the incidence of "COPD symptoms" (defined as cough and phlegm, both shorter and longer than 3 months). Interestingly, whereas fruit and vitamin $\mathrm{C}$ intakes were also associated with incident COPD symptoms, these associations disappeared after further adjustment for dietary fiber intake. This suggests that dietary fiber intake may be at least partly responsible for these associations. It should be taken into account that no pulmonary function data were available in this study, and that the respiratory symptoms designated as "COPD symptoms" may have reflected respiratory conditions other than COPD. Another 16-year prospective study by Varraso et al. [20] in 111.580 US men and women from the Nurses' Health Study and Health Professionals Follow-up Study identified incident COPD cases by means of a thorough questionnaire and required report of a diagnostic test at diagnosis. Furthermore, the epidemiologic COPD definition was validated in a 
random sample and showed confirmation of diagnosis in up to 88\%. It was found that compared to people in the lowest quintile of total dietary fiber intake (median $11.2 \mathrm{~g} /$ day) those in the highest quintile (median $28.4 \mathrm{~g} /$ day) had a lower adjusted relative risk of newly diagnosed COPD (RR 0.67, 95\% CI 0.500.90). Upon stratification on dietary fiber type, only cereal (primarily insoluble) fiber intake was independently associated with newly diagnosed COPD.

\section{$\underline{\text { Associations between fatty acids and COPD }}$}

Shahar et al. [21] investigated the cross-sectional associations between n-3 fatty acid intake (eicosapentaenoic acid [EPA] and docosahexaenoic acid [DHA]) and lung function and COPD status in subjects participating in the population-based ARIC Study. It was found that higher fish consumption but also specifically higher total n-3 fatty acid intake was strongly associated with lower odds for COPD and lower lung function (dose-dependently). No significant findings were obtained in analyses restricted to never-smokers in this study. N-6 fatty acid intake was not reported in this study.

In the cross-sectional population-based MORGEN-EPIC study [22], data on intake of specific fatty acids and lung function were available of 13.820 Dutch men and women aged 20-59y. The prevalence of COPD (GOLD 2 or higher, no post-bronchodilator data) was $4 \%$. Of the n-3 fatty acids, only DHA was significantly associated with $\mathrm{FEV}_{1}$, but the direction of this association was inverse. Also, higher intake of n- 6 fatty acids were generally associated with lower $\mathrm{FEV}_{1}$ and greater ORs for COPD. Moreover, it was found that smoking status significantly interacted with the associations between $n-6$ fatty acids and $\mathrm{FEV}_{1}$; the inverse associations were stronger in smokers compared to nonsmokers. In the entire population, $\alpha$-linolenic acid, EPA, docosapentaenoic acid and DHA (all n-3) intake were all associated with an increased risk of wheeze, and EPA (n-3), eicosadienoic acid (n-6) and eicosatrienoic acid (n-6) intake were positively associated with respiratory symptoms (chronic cough, chronic phlegm and/or breathlessness). Finally, COPD prevalence was negatively associated with docosapentainoic acid (n-3) and docosapentaenoic acid (n-6), and positively with eicosadienoic acid (n-6), eicosatrienoic acid (n-6), arachidonic acid (n-6) and docosatetraenoic acid (n-6) intake.

In the much smaller population-based Hunter Community Study [23], comprising $n=195$ Australian men and women aged 55-85y (including $n=45$ subjects with $\mathrm{FEV}_{1}<80 \%$ of predicted), no cross-sectional associations were found between dietary intake of saturated fatty acids, monounsaturated fatty acids, n-3 polyunsaturated fatty acids (PUFA) and n-6-PUFAs with FEV $_{1}$, FVC or $\mathrm{FEV}_{1} / \mathrm{FVC}$.

In the same population in which Hirayama et al. reported data on associations between dietary fiber and COPD [18], the authors also investigated associations for specific fatty acids which were published in a separate paper 
[24]. Compared to controls, COPD patients consumed significantly less PUFAs, n6 fatty acids and n-3 fatty acids but similar quantities of saturated fatty acids and mono-unsaturated fatty acids. Significant $P$ values for trends were reported for COPD ORs and for breathlessness across quartiles of PUFA and n- 6 fatty acid intakes, but not of n-3 fatty acids or (n-3):(n-6) ratio. In contrast with the other papers referenced above, this study excluded fatty acids from cooking oils, margarine, butter, mayonnaise and salad dressings, and may therefore have underestimated actual intake levels.

Finally, another cross-sectional study among 20.322 people aged $>30 y$ from the population-based Second National Health and Nutrition Examination Survey (NHANES II) did not find any significant association between oleic acid (n-9) or linoleic acid (n-6) intake with wheezing [25].

\section{Discussion}

There is growing attention for the influences of an overall poor lifestyle in the risk for and course of COPD, which goes beyond smoking. This review was undertaken to summarize the current data on the relations between dietary fiber or fatty acids and COPD risk and progression. At present, the available data suggest a particular important role for dietary fiber in COPD. Indeed, greater intake of dietary fiber has been associated with better lung function in the general population, lower odds of COPD, and lower risk of incident respiratory symptoms and COPD. On the contrary, the studies examining associations of fatty acids are limited by their cross-sectional natures and we must interpret their data as being inconsistent. Concerning both the included studies on dietary fiber and fatty acids, most of them retrospectively analyzed data of pre-existing epidemiological cohorts. Consequently, the methodological differences precluded performing a meta-analysis.

Studies have consistently shown that COPD patients consume less dietary fiber, vegetables and fruit compared with control subjects $[18,26]$. According to the European Food Safety Authority (EFSA) the current recommendation for dietary fiber intake is $25 \mathrm{~g} /$ day, and the actual intake averages between 15-30 g/day across European countries [27]. Of the studies we reviewed, only those in the highest quartiles (or quintiles) of two studies met this recommendation. The EFSA also states that dietary fiber intake of $>25 \mathrm{~g} /$ day may be even more beneficial as it has been consistently shown to reduce the risk of type 2 diabetes, cardiovascular disease and colorectal cancer [27]. There is currently no data available whether such amounts of dietary fiber intake are also beneficial in terms of reduced COPD risk, but it may improve systemic manifestations of the disease. In a recent 3-year prospective study in 120 COPD patients, participants were randomized to follow a fruit and vegetable rich diet or their regular diet. The former group succeeded to increase fruit and vegetable intake and, interestingly, this was associated with a slight improvement in $\mathrm{FEV}_{1}$ over 3 years 
(by approximately 5\% of predicted), whereas the control group was characterized by a decline in $\mathrm{FEV}_{1}$ (by approximately $9 \%$ of predicted, betweengroup difference $P=.03$ ) [28]. That study was performed against the background of a potential benefit of increased dietary antioxidants; however, the results may also have been partly accounted for by the simultaneous increase in dietary fiber intake. The feasibility of increasing fruit and vegetable intake in COPD patients was confirmed in a recent exploratory study [29].

The ARIC study reported a $60 \mathrm{ml}$ difference in $\mathrm{FEV}_{1}$ between persons in the lowest $v s$ highest quintiles of fiber intake, in favor of the latter [17]. This is a clinically substantial difference since normal $\mathrm{FEV}_{1}$ decline in adults is approximately $30 \mathrm{ml} / \mathrm{y}$ [30], and the $\mathrm{FEV}_{1}$ difference between never smokers and current smokers is generally around $200 \mathrm{ml}$ [31]. Dietary fiber may therefore be an important modifiable factor to prevent or delay significant lung function decline.

Current evidence is not conclusive about which food items containing dietary fiber are more inversely associated with COPD. Two studies found significant associations for fruit and cereal fiber but not for vegetable fiber [17, 20]. However, it is not clear whether this is accountable to soluble or insoluble fiber. Generally, cereals contain mainly water-insoluble fiber, but are also a relatively good source of water-soluble fiber (about 25\% [11]); fruits contain mainly water-soluble fiber and vegetables water-insoluble fiber [32]. On the contrary, only insoluble fiber was associated with lower COPD ORs in the Japanese study [18], but the poor range of soluble fiber intake in that study $(\geq 3.4 \mathrm{~g} /$ day $v s \leq 1.6$ $\mathrm{g} /$ day) is a limitation in this respect.

n- 6 fatty acids are thought to be more pro-inflammatory than their n-3 counterparts [15], and it is hypothesized that greater n-3 fatty acid intake and/or lower n-6:n-3 fatty acid ratios are associated with beneficial outcomes related to COPD. In a cross-sectional analysis of 250 COPD patients, higher intake of $\alpha$ linolenic acid (n-3) was associated with lower circulating tumor necrosis factor$\alpha$ concentrations and higher intake of arachidonic acid (n-6) was related to higher interleukin-6 and C-reactive protein concentrations [33]. However, whereas specific dietary fatty acids may be associated with systemic inflammation in COPD patients, the reviewed articles have produced inconclusive data with respect to outcome measures related to COPD. In most studies n-3 fatty acid intake does not seem to be associated with COPD. However, one cross-sectional study did show a significant association between n-3 fatty acid intake and lung function and COPD risk [21]. The median intake of the highest quartile of EPA and DHA in this study was considerably higher compared to that in the other studies. Nonetheless, in all studies, n-3 fatty acid intake was far below the current recommendations of $1.6 \mathrm{~g} /$ day for men and $1.1 \mathrm{~g} /$ day for woman [34]. Protective effects may only become apparent with higher intake levels, which may explain the lack of significant results. Furthermore, it has been suggested that a n-6:n-3 fatty acid ratio between 1:1 to 4:1 may be most 
beneficial whereas current ratios are approximately 16:1 in Western diets [35]. Unfortunately, this hypothesis has not been investigated appropriately with respect to COPD outcomes. Two studies indicated that smoking status is important to consider when interpreting associations between fatty acid intake and COPD related outcomes, as the negative associations with n- 6 fatty acids were stronger in smokers than in non-smokers [22], and positive associations with EPA+DHA were found in ever-smokers [21]. These data may suggest that lower n-6:n-3 ratios may be beneficial particularly in smokers, however, this hypothesis has not been addressed in the current literature.

In conclusion, current data indicate that changes in dietary composition, in particular with respect to dietary fiber amount, may have beneficial effects in terms of COPD risk and progression. Therefore it is worthwhile to further study the underlying mechanisms in order to optimize specific nutritional recommendations in COPD. 


\section{CHAPTER 7}

\section{References}

1. World Health Organization. The global burden of disease: 2004 update. 2008; Available from http://www.who.int/healthinfo/global_burden_disease/GBD_report_2004update_full.pdf.

2. Global Initiative for Chronic Obstructive Lung Disease. Global strategy for the diagnosis, management, and prevention of chronic obstructive pulmonary disease. Revised 2011. Available from http://www.goldcopd.org/uploads/users/files/GOLD_Report_2011_Feb21.pdf.

3. Wan ES, Silverman EK. Genetics of COPD and emphysema. Chest. 2009;136(3):859-66.

4. Salvi SS, Barnes PJ. Chronic obstructive pulmonary disease in non-smokers. Lancet. 2009;374(9691):733-43.

5. Madison JM, Irwin RS. Chronic obstructive pulmonary disease. Lancet. 1998;352(9126):467-73.

6. Peat JK, Woolcock AJ, Cullen K. Decline of lung function and development of chronic airflow limitation: a longitudinal study of non-smokers and smokers in Busselton, Western Australia. Thorax. 1990;45(1):32-7.

7. Hopkinson NS, Polkey MI. Does physical inactivity cause chronic obstructive pulmonary disease? Clin Sci (Lond). 2010;118(9):565-72.

8. Shaheen SO, Jameson KA, Syddall HE, Aihie Sayer A, Dennison EM, Cooper C, Robinson SM. The relationship of dietary patterns with adult lung function and COPD. Eur Respir J. [Research Support, Non-U.S. Gov't]. 2010;36(2):277-84.

9. Varraso R, Fung TT, Barr RG, Hu FB, Willett W, Camargo CA, Jr. Prospective study of dietary patterns and chronic obstructive pulmonary disease among US women. Am J Clin Nutr. 2007;86(2):488-95.

10. Varraso R, Fung TT, Hu FB, Willett W, Camargo CA. Prospective study of dietary patterns and chronic obstructive pulmonary disease among US men. Thorax. 2007;62(9):786-91.

11. Galisteo M, Duarte J, Zarzuelo A. Effects of dietary fibers on disturbances clustered in the metabolic syndrome. J Nutr Biochem. 2008;19(2):71-84.

12. Ghanim H, Abuaysheh S, Sia CL, Korzeniewski K, Chaudhuri A, Fernandez-Real JM, Dandona P. Increase in plasma endotoxin concentrations and the expression of Toll-like receptors and suppressor of cytokine signaling-3 in mononuclear cells after a high-fat, high-carbohydrate meal: implications for insulin resistance. Diabetes Care. 2009;32(12):2281-7.

13. Kaczmarczyk MM, Miller MJ, Freund GG. The health benefits of dietary fiber: Beyond the usual suspects of type 2 diabetes mellitus, cardiovascular disease and colon cancer. Metabolism: clinical and experimental. 2012;61(8):1058-66.

14. Vinolo MA, Rodrigues HG, Nachbar RT, Curi R. Regulation of inflammation by short chain fatty acids. Nutrients. [Research Support, Non-U.S. Gov't Review]. 2011;3(10):858-76.

15. Wall R, Ross RP, Fitzgerald GF, Stanton C. Fatty acids from fish: the anti-inflammatory potential of long-chain omega-3 fatty acids. Nutr Rev. 2010;68(5):280-9.

16. Stroup DF, Berlin JA, Morton SC, Olkin I, Williamson GD, Rennie D, Moher D, Becker BJ, Sipe TA, Thacker SB. Meta-analysis of observational studies in epidemiology: a proposal for reporting. Meta-analysis of Observational Studies in Epidemiology (MOOSE) group. JAMA. 2000;283(15):2008-12.

17. Kan H, Stevens J, Heiss G, Rose KM, London SJ. Dietary fiber, lung function, and chronic obstructive pulmonary disease in the atherosclerosis risk in communities study. Am J Epidemiol. 2008;167(5):570-8.

18. Hirayama F, Lee AH, Binns CW, Zhao Y, Hiramatsu T, Tanikawa Y, Nishimura K, Taniguchi H. Do vegetables and fruits reduce the risk of chronic obstructive pulmonary disease? A case-control study in Japan. Prev Med. 2009;49(2-3):184-9.

19. Butler LM, Koh WP, Lee HP, Yu MC, London SJ. Dietary fiber and reduced cough with phlegm: a cohort study in Singapore. Am J Respir Crit Care Med. 2004;170(3):279-87.

20. Varraso R, Willett WC, Camargo CA, Jr. Prospective study of dietary fiber and risk of chronic obstructive pulmonary disease among US women and men. Am J Epidemiol. 2010;171(7):776-84.

21. Shahar E, Folsom AR, Melnick SL, Tockman MS, Comstock GW, Gennaro V, Higgins MW, Sorlie PD, Ko WJ, Szklo M. Dietary n-3 polyunsaturated fatty acids and smoking-related chronic obstructive pulmonary disease. Atherosclerosis Risk in Communities Study Investigators. N Engl J Med. 1994;331(4):228-33.

22. McKeever TM, Lewis SA, Cassano PA, Ocke M, Burney P, Britton J, Smit HA. The relation between dietary intake of individual fatty acids, $\mathrm{FEV}_{1}$ and respiratory disease in Dutch adults. Thorax. 2008;63(3):208-14.

23. Wood LG, Attia J, McElduff P, McEvoy M, Gibson PG. Assessment of dietary fat intake and innate immune activation as risk factors for impaired lung function. Eur J Clin Nutr. 2010;64(8):818-25.

24. Hirayama F, Lee AH, Binns CW, Hiramatsu N, Mori M, Nishimura K. Dietary intake of isoflavones and polyunsaturated fatty acids associated with lung function, breathlessness and the prevalence of chronic obstructive pulmonary disease: Possible protective effect of traditional Japanese diet. Mol Nutr Food Res. 2010;54(7):909-17.

25. Schwartz J, Weiss ST. Dietary factors and their relation to respiratory symptoms. The Second National Health and Nutrition Examination Survey. Am J Epidemiol. 1990;132(1):67-76.

26. van den Borst B, Gosker HR, Koster A, Yu B, Kritchevsky SB, Liu Y, Meibohm B, Rice TB, Shlipak M, Yende S, et $a l$. The influence of abdominal visceral fat on inflammatory pathways and mortality risk in obstructive lung disease. Am J Clin Nutr. 2012;96(3):516-26.

27. EFSA. Panel on Dietetic Products, Nutrition \& Allergies. Scientific Opinion on Dietary Reference Values for carbohydrates and dietary fibre. EFSA J. 2010;8:1462-539.

28. Keranis E, Makris D, Rodopoulou P, Martinou H, Papamakarios G, Daniil Z, Zintzaras E, Gourgoulianis KI. Impact of dietary shift to higher-antioxidant foods in COPD: a randomised trial. Eur Respir J. 2010;36(4):774-80. 


\section{DIETARY FIBER AND FATTY ACIDS IN COPD}

29. Baldrick FR, Elborn JS, Woodside JV, Treacy K, Bradley JM, Patterson CC, Schock BC, Ennis M, Young IS, McKinley MC. Effect of fruit and vegetable intake on oxidative stress and inflammation in COPD: a randomised controlled trial. The European respiratory journal : official journal of the European Society for Clinical Respiratory Physiology. [Research Support, Non-U.S. Gov't]. 2012;39(6):1377-84.

30. Lee PN, Fry JS. Systematic review of the evidence relating FEV $_{1}$ decline to giving up smoking. BMC Med. 2010;8:84.

31. Omori H, Nonami Y, Morimoto Y. Effect of smoking on FEV decline in a cross-sectional and longitudinal study of a large cohort of Japanese males. Respirology. 2005;10(4):464-9.

32. Theuwissen E, Mensink RP. Water-soluble dietary fibers and cardiovascular disease. Physiol Behav. 2008;94(2):285-92.

33. de Batlle J, Sauleda J, Balcells E, Gomez FP, Mendez M, Rodriguez E, Barreiro E, Ferrer JJ, Romieu I, Gea J, et al. Association between Omega3 and Omega6 fatty acid intakes and serum inflammatory markers in COPD. The Journal of nutritional biochemistry. [Research Support, Non-U.S. Gov't]. 2012;23(7):817-21.

34. Food and Nutrition Board IoM. Dietary reference intakes for carbohydrate, fiber, fat, fatty acids, cholesterol, protein, and amino acid. Washington, DC: National Academies Press. 2005.

35. Simopoulos AP. The importance of the omega-6/omega-3 fatty acid ratio in cardiovascular disease and other chronic diseases. Exp Biol Med (Maywood). 2008;233(6):674-88. 


\title{
Appendix: search terms used in online databases
}

\author{
Search in Pubmed on August 4, 2012 yielding 5016 hits:
}

("dietary fiber"[All Fields] OR "soluble fiber"[All Fields] OR "insoluble fiber"[All Fields] OR fibre[All Fields] OR "non starch polysaccharides"[All Fields] OR ("glucans"[MeSH Terms] OR "glucans"[All Fields]) OR ("inulin"[MeSH Terms] OR "inulin"[All Fields]) OR ("dextrins"[MeSH Terms] OR "dextrins"[All Fields]) OR ("lignin"[MeSH Terms] OR "lignin"[All Fields]) OR ("waxes"[MeSH Terms] OR "waxes"[All Fields]) OR ("chitin"[MeSH Terms] OR "chitin"[All Fields]) OR ("pectins"[MeSH Terms] OR "pectins"[All Fields]) OR ("oligosaccharides"[MeSH Terms] OR "oligosaccharides"[All Fields]) OR ("gingiva"[MeSH Terms] OR "gingiva"[All Fields] OR "gums"[All Fields]) OR "resistant starches"[All Fields] OR ("dietary fiber"[MeSH Terms] OR ("dietary"[All Fields] AND "fiber"[All Fields]) OR "dietary fiber"[All Fields] OR "roughage"[All Fields]) OR ("dietary fiber"[MeSH Terms] OR ("dietary"[All Fields] AND "fiber"[All Fields]) OR "dietary fiber"[All Fields] OR "roughages"[All Fields]) OR arabinoxylans[All Fields] OR ("cellulose"[MeSH Terms] OR "cellulose"[All Fields]) OR "fatty acids"[All Fields] OR "SFA"[All Fields] OR "saturated fatty acids"[All Fields] OR "MUFA"[All Fields] OR "monounsaturated fatty acids"[All Fields] OR "PUFA"[All Fields] OR "polyunsaturated fatty acids"[All Fields] OR "n-3 fatty"[All Fields] OR omega-3[All Fields] OR omega-6[All Fields] OR "EPA"[All Fields] OR "eicosapentaenoic acid"[All Fields] OR "DHA"[All Fields] OR "docosahexaenoic acid"[All Fields] OR "ALA"[All Fields] OR "alpha-linolenic acid"[All Fields] OR "n-6 fatty"[All Fields] OR "linoleic acid"[All Fields] OR "arachidonic acid"[All Fields] OR "gamma-linolenic acid"[All Fields] OR "trans fatty acids"[All Fields] OR "Hexadecatrienoic acid"[All Fields] OR "Stearidonic acid"[All Fields] OR "Eicosatrienoic acid"[All Fields] OR "Eicosatetraenoic acid"[All Fields] OR "Clupanodonic acid"[All Fields] OR "Tetracosapentaenoic acid"[All Fields] OR "Tetracosahexaenoic acid"[All Fields] OR "Eicosadienoic acid"[All Fields] OR "Dihomo gamma linolenic acid"[All Fields] OR (Docosadienoic[All Fields] AND ("acids"[MeSH Terms] OR "acids"[All Fields] OR "acid"[All Fields])] OR "Adrenic acid"[All Fields] OR "Docosapentaenoic acid"[All Fields] OR "Calendic acid"[All Fields] OR "Myristoleic acid"[All Fields] OR "Palmitoleic acid"[All Fields] OR (Sapienic[All Fields] AND ("acids"[MeSH Terms] OR "acids"[All Fields] OR "acid"[All Fields])) OR "Oleic acid"[All Fields] OR "erucic acid"[All Fields] OR "lauric acid"[All Fields] OR "myristic acid"[All Fields] OR "palmitic acid"[All Fields] OR "stearic acid"[All Fields] OR "arachidic acid"[All Fields] OR "behenic acid"[All Fields] OR "lignoceric acid"[All Fields] OR "cerotic acid"[All Fields] OR "lard"[All Fields] OR "butter"[All Fields] OR "coconut oil"[All Fields] OR "palm oil"[All Fields] OR "cottonseed oil"[All Fields] OR "wheat germ oil"[All Fields] OR "soya oil"[All Fields] OR "olive oil"[All Fields] OR "corn oil"[All Fields] OR "sunflower oil"[All Fields] OR "hemp oil"[All Fields] OR "canola oil"[All Fields] OR "short chain fatty acids"[All Fields] OR "medium chain fatty acids"[All Fields] OR "long chain fatty acids"[All Fields] OR "rapeseed oil"[All Fields] OR "Dietary Fiber"[Mesh] OR "Polysaccharides"[Mesh] OR "Dietary fats"[Mesh] OR "Fatty acids"[Mesh] OR "Fish Oils"[Mesh] OR ("fruit"[MeSH Terms] OR "fruit"[All Fields] OR "fruits"[All Fields]) OR ("fishes"[MeSH Terms] OR "fishes"[All Fields] OR "fish"[All Fields]) OR ("vegetables"[MeSH Terms] OR "vegetables"[All Fields]) OR ("meat"[MeSH Terms] OR "meat"[All Fields]) OR fowl[All Fields] OR ("cereals"[MeSH Terms] OR "cereals"[All Fields] OR "grain"[All Fields]) OR ("eggs"[MeSH Terms] OR "eggs"[All Fields]) OR ("nuts"[MeSH Terms] OR "nuts"[All Fields])) AND ("lung function"[All Fields] OR "pulmonary function"[All Fields] OR "respiratory function"[All Fields] OR "respiratory symptoms"[All Fields] OR "pulmonary symptoms"[All Fields] OR ("dyspnea"[MeSH Terms] OR "dyspnea"[All Fields] OR "breathlessness"[All Fields]) OR ("cough"[MeSH Terms] OR "cough"[All Fields]) OR phlegm[All Fields] OR ("dyspnoea"[All Fields] OR "dyspnea"[MeSH Terms] OR "dyspnea"[All Fields]) OR ("dyspnoea"[All Fields] OR "dyspnea"[MeSH Terms] OR "dyspnea"[All Fields]) OR ("sputum"[MeSH Terms] OR "sputum"[All Fields]) OR FEV[All Fields] OR FEV1[All Fields] OR "forced expiratory volume"[All Fields] OR "forced vital capacity"[All Fields] OR FVC[All Fields] OR ("pulmonary disease, chronic obstructive"[MeSH Terms] OR ("pulmonary"[All Fields] AND "disease"[All Fields] AND "chronic"[All Fields] AND "obstructive"[All Fields]) OR "chronic obstructive pulmonary disease"[All Fields] OR "copd"[All Fields]) OR "chronic obstructive pulmonary disease"[All Fields] OR ("bronchitis, chronic"[MeSH Terms] OR ("bronchitis"[All Fields] AND "chronic"[All Fields]) OR "chronic bronchitis"[All Fields] OR ("chronic"[All Fields] AND "bronchitis"[All Fields])) OR ("pulmonary emphysema"[MeSH Terms] OR ("pulmonary"[All Fields] AND "emphysema"[All Fields]) OR "pulmonary emphysema"[All Fields] OR "emphysema"[All Fields] OR "emphysema"[MeSH Terms]) OR "Respiratory function tests"[Mesh] OR "pulmonary disease, chronic obstructive"[Mesh]) AND ("humans"[MeSH Terms] AND "adult"[MeSH Terms]) 


\section{DIETARY FIBER AND FATTY ACIDS IN COPD}

\section{Search in EMBASE on August 4, 2012 yielding 5088 hits:}

1. exp dietary fiber/

2. fructose oligosaccharide/ or dextrin/ or guar gum/ or pectin/

3. exp high fiber diet/

4. exp fiber/

5. *fiber/

6. cereal/ or polysaccharide/ or pectin/

7. exp glucan/

8. exp INULIN/

9. $\exp$ DEXTRIN/

10. exp LIGNIN/

11. exp CHITIN/

12. exp oligosaccharide/

13. exp ARABINOXYLAN/

14. exp CELLULOSE/

15. exp fatty acid/

16. exp saturated fatty acid/

17. exp unsaturated fatty acid/

18. exp fish oil/ or exp omega 3 fatty acid/ or exp docosahexaenoic acid/ or exp icosapentaenoic acid/ or exp fat intake/

19. exp omega 6 fatty acid/

20. eicosapentaenoic acid.mp. or exp icosapentaenoic acid/

21. PUFA.mp.

22. SFA.mp.

23. MUFA.mp.

24. EPA.mp.

25. DHA.mp.

26. alpha-linolenic acid.mp. or exp linolenic acid/

27. exp linolenic acid/

28. n-3 fatty.mp.

29. n-6 fatty.mp.

30. exp arachidonic acid/

31. exp gamma linolenic acid/

32. exp trans fatty acid/

33. exp palmitoleic acid/ or exp hexadecatrienoic acid/

34. exp stearidonic acid/

35. eicosatrienoic acid.mp. or exp icosatrienoic acid/

36. eicosatetraenoic acid.mp. or exp icosatetraenoic acid/

37. clupanodonic acid.mp.

38. tetracosapentaenoic acid.mp.

39. eicosadienoic acid.mp.

40. exp dihomo gamma linolenic acid/

41. docosadienoic acid.mp.

42. exp adrenic acid/

43. exp docosapentaenoic acid/

44. exp conjugated linolenic acid/ or exp calendic acid/ or exp conjugated linoleic acid/

45. exp volatile fatty acid/ or exp myristoleic acid/

46. exp lauric acid/ or exp sapienic acid/

47. exp oleic acid/

48. exp erucic acid/

49. exp lauric acid/

50. exp myristic acid/

51. exp palmitic acid/

52. exp stearic acid/

53. exp arachidic acid/

54. exp behenic acid/

55. exp lignoceric acid/

56. cerotic acid.mp. or exp oleanolic acid/ or exp hexacosanoic acid/ 


\section{CHAPTER 7}

57. exp very long chain fatty acid/ or exp long chain fatty acid/ or exp short chain fatty acid/ or exp acetic acid/ or exp butyric acid/

58. exp 3 hydroxybutyric acid/ or exp medium chain fatty acid/

59. exp BUTTER/

60. exp coconut oil/

61. exp palm oil/

62. exp cotton seed oil/

63. exp wheat germ oil/ or exp vegetable oil/

64. soya oil.mp. or exp soybean oil/

65. exp olive oil/

66. exp corn oil/

67. exp sunflower oil/

68. hemp oil.mp.

69. exp rapeseed oil/ or exp canola oil/

70. exp FRUIT/

71. exp VEGETABLE/

72. $\exp$ MEAT/

73. exp FISH/

74. exp CHICKEN MEAT/

75. exp egg/

76. exp nut/

77. 1 or 2 or 3 or 4 or 5 or 6 or 7 or 8 or 9 or 10 or 11 or 12 or 13 or 14 or 15 or 16 or 17 or 18 or 19 or 20 or 21 or 22 or 23 or 24 or 25 or 26 or 27 or 28 or 29 or 30 or 31 or 32 or 33 or 34 or 35 or 36 or 37 or 38 or 39 or 40 or 41 or 42 or 43 or 44 or 45 or 46 or 47 or 48 or 49 or 50 or 51 or 52 or 53 or 54 or 55 or 56 or 57 or 58 or 59 or 60 or 61 or 62 or 63 or 64 or 65 or 66 or 67 or 68 or 69 or 70 or 71 or 72 or 73 or 74 or 75 or 76

78. exp lung function/

79. pulmonary function.mp.

80. exp respiratory function/

81. ventilatory function.mp.

82. exp chronic bronchitis/ or exp wheezing/ or respiratory symptoms.mp. or exp coughing/

83. pulmonary symptoms.mp.

84. breathlessness.mp. or exp dyspnea/

85. exp coughing/ or exp sputum/ or phlegm.mp.

86. dyspnoea.mp.

87. FEV.mp. or exp forced expiratory volume/

88. exp vital capacity/ or exp chronic obstructive lung disease/ or exp airway obstruction/ or exp lung function test/ or FEV1.mp.

89. FVC.mp.

90. exp forced vital capacity/

91. COPD.mp.

92. exp LUNG EMPHYSEMA/ or exp EMPHYSEMA/

93. 78 or 79 or 80 or 81 or 82 or 83 or 84 or 85 or 86 or 87 or 88 or 89 or 90 or 91 or 92

94.77 and 93

95. limit 94 to (human and (adult $<18$ to 64 years $>$ or aged $<65+$ years $>$ ))

\section{Search in Cochrane Collaboration Database on August 4, 2012 yielding 218 hits:}

(dietary fiber OR soluble fiber OR insoluble fiber OR fibre OR non starch polysaccharides OR glucans OR inulin OR dextrins OR lignin OR waxes OR chitin OR pectins OR oligosaccharides OR gums OR resistant starches OR roughage OR roughages OR arabinoxylans OR cellulose OR fatty acids OR SFA OR saturated fatty acids OR MUFA OR monounsaturated fatty acids OR PUFA OR polyunsaturated fatty acids OR n-3 fatty OR omega-3 OR omega-6 OR EPA OR eicosapentaenoic acid OR DHA OR docosahexaenoic acid OR ALA OR alpha-linolenic acid OR n-6 fatty OR linoleic acid OR arachidonic acid OR gamma-linolenic acid OR trans fatty acids OR Hexadecatrienoic acid OR Stearidonic acid OR Eicosatrienoic acid OR Eicosatetraenoic acid OR Clupanodonic acid OR Tetracosapentaenoic acid OR Tetracosahexaenoic acid OR Eicosadienoic acid OR Dihomo gamma linolenic acid OR Docosadienoic acid OR Adrenic acid OR Docosapentaenoic acid OR Calendic acid OR Myristoleic acid OR Palmitoleic 


\section{DIETARY FIBER AND FATTY ACIDS IN COPD}

acid OR Sapienic acid OR Oleic acid OR erucic acid OR lauric acid OR myristic acid OR palmitic acid OR stearic acid OR arachidic acid OR behenic acid OR lignoceric acid OR cerotic acid OR lard OR butter OR coconut oil OR palm oil OR cottonseed oil OR wheat germ oil OR soya oil OR olive oil OR corn oil OR sunflower oil OR hemp oil OR canola oil OR short chain fatty acids OR medium chain fatty acids OR long chain fatty acids OR rapeseed oil OR fruits OR vegetables OR meat OR fowl OR grain OR eggs OR nuts OR fish OR ("Dietary Fiber"[Mesh]) OR ("Polysaccharides"[Mesh]) OR ("Dietary fats"[Mesh]) OR ("Fatty acids"[Mesh]) OR ("Fish Oils"[Mesh])) AND (lung function OR pulmonary function OR respiratory function OR respiratory symptoms OR pulmonary symptoms OR breathlessness $\mathrm{OR}$ cough OR phlegm OR dyspnea OR dyspnoea OR sputum OR FEV OR FEV1 OR forced expiratory volume OR forced vital capacity OR FVC OR COPD OR chronic obstructive pulmonary disease OR chronic bronchitis OR emphysema OR ("Respiratory function tests"[Mesh]) OR ("Lung diseases, obstructive"[Mesh]) OR ("pulmonary disease, chronic obstructive"[Mesh])) 


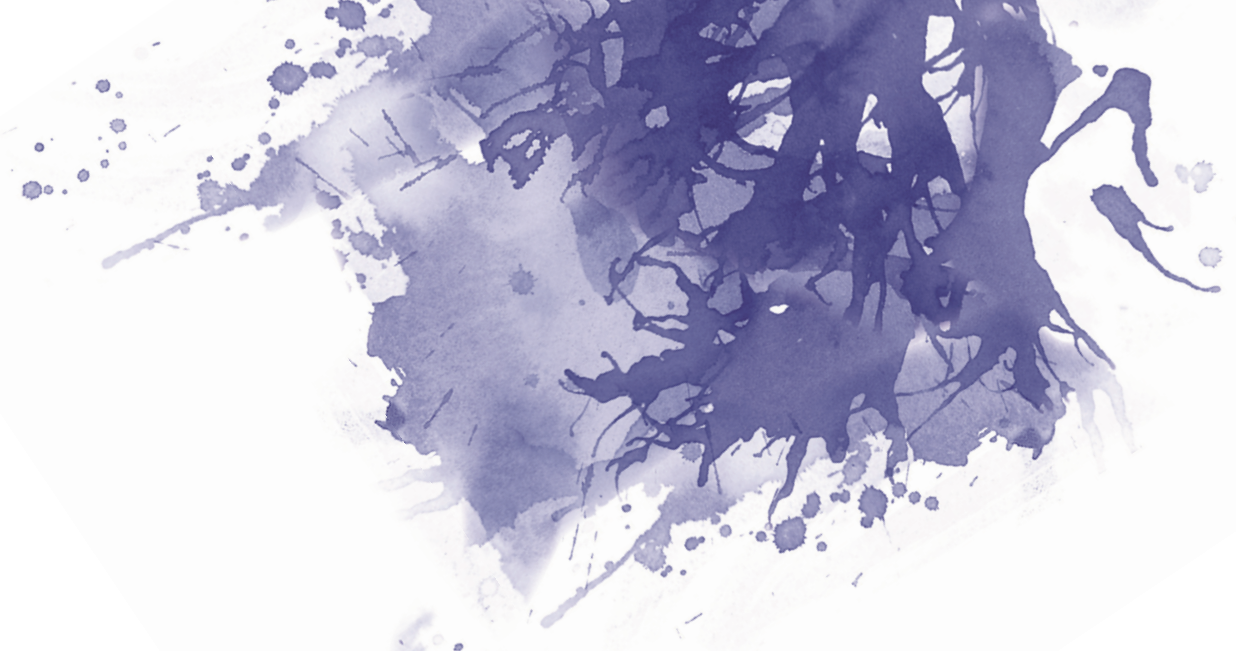

\section{CHAPTER 8}

\section{Discussion \\ Central fat and peripheral muscle: partners in crime in COPD}

Bram van den Borst, Harry R. Gosker, Annemie M.W.J. Schols

American Journal of Respiratory and Critical Care Medicine 2013;187(1):8-13 


\section{Introduction}

According to the World Health Organisation, by the year 2020, chronic obstructive pulmonary disease (COPD) is expected to be the third-leading cause of death, and it is the only major chronic disease with an increasing mortality rate. Successful efforts to reduce this mortality will require a better understanding of the relationship between risk factors and the severity of the underlying lung disease. In patients with advanced disease, respiratory failure is the most common cause of death and weight loss and low muscle mass and strength are important determinants of mortality [1]. In these patients, the risk of death is remarkably lower in obese patients. In contrast, in patients with mildto-moderate disease, the primary cause of death is ischemic cardiovascular disease, for which overweight and obesity are important risk factors [2]. The ongoing worldwide obesity epidemic necessitates an enhanced understanding of the interactions between cigarette smoke exposure, cardiovascular disease, skeletal muscle dysfunction and adiposity in patients with COPD. In this essay, we will discuss some of the mechanisms linking metabolism and adiposity with clinical outcomes in patients with COPD and offer tailored lifestyle interventions that may reduce morbidity and mortality in these patients.

\section{Drivers of cardiovascular and metabolic risk in COPD}

\section{Loss of peripheral skeletal muscle oxidative phenotype}

Muscle atrophy is highly prevalent in COPD irrespective of disease severity $[3,4]$. In moderate-to-severe COPD, this atrophy is associated with a reduction in the activity of oxidative enzymes, a decrease in mitochondrial density, impaired mitochondrial function, and a fiber type I-to-II shift [5]. This loss of skeletal muscle "oxidative phenotype" has been associated with muscle fatigue [6] and decreased mechanical efficiency [7], and has recently also been demonstrated in patients with mild-to-moderate COPD in the absence of muscle atrophy [8].

In diabetes, it has been proposed that skeletal muscle mitochondrial dysfunction may underlie peripheral insulin resistance via complex mechanisms including oxidative stress, intramuscular lipid accumulation, and inflammation $[9,10]$. However, recent tests of this hypothesis in human subjects have suggested that the mitochondrial defect observed in the skeletal muscles of patients with diabetes might be secondary to the insulin-resistant state instead of being a causal factor (reviewed in [11]). This notion is supported by striking parallels in skeletal muscle oxidative phenotype between underweight/normal weight non-diabetic COPD patients and overweight/obese diabetes patients. For example, decreased mitochondrial respiration has also been reported in patients with type 2 diabetes [12,13], and the magnitude of reduced skeletal muscle PGC$1 \alpha$ gene (the master regulator of mitochondrial biogenesis) expression is 
comparable between non-obese COPD patients $[8,14]$ and obese subjects with type 2 diabetes [15]. Also, several studies have shown evidence for a decreased type I fiber proportion in overweight/obese type 2 diabetes patients compared to BMI-matched controls $[16,17]$. The decreased oxidative capacity of the skeletal muscle has been suggested to play a major role in 'metabolic inflexibility' [18], which is defined by a reduced capacity to increase fat oxidation in response to increased fatty acid availability and an impaired switch from fat to glucose as the primary fuel source after a meal. Metabolic inflexibility may lead to the accumulation of intramyocellular lipids which has been associated with insulin resistance through mechanisms possibly involving the lipid intermediates ceramides and diacylglycerol that interfere with insulin signaling pathways [19]. In case of high caloric intake and lack of physical exercise, a positive energy balance may then further enhance ectopic fat deposition.

Investigators have employed homeostatic modeling of insulin resistance (HOMA index) to show that insulin sensitivity is lower in non-obese and nondiabetic COPD patients compared with BMI-matched healthy controls [20-22]. The HOMA index, however, primarily reflects hepatic insulin sensitivity, while skeletal muscle insulin sensitivity can be most accurately assessed with the euglycaemic insulin clamp technique. Therefore, clamp studies are indicated in order to proof or dispute that a decreased skeletal muscle oxidative phenotype is associated with insulin resistance at the level of skeletal muscle in COPD as it is in diabetes.

\section{Visceral obesity}

Several groups of investigators have suggested that low-grade systemic inflammation characteristic of a number of diseases including COPD is associated with an increased risk for the development of atherosclerosis and ischemic cardiovascular events [23]. There is increasing evidence that adipose tissue is a significant contributor to the systemic inflammatory load in COPD. For example, a persistent systemic inflammation phenotype was recently described in patients with COPD and was associated with body mass index (BMI) but not with fat-free mass index, suggesting an inflammatory role for adipose tissue [24]. Moreover, in a subgroup of COPD patients, low-grade systemic inflammation has been positively related to total abdominal fat mass [25]. Thus, adipose tissue dysfunction, including enhanced adipose tissue inflammation, may contribute to low-grade systemic inflammation in COPD patients with absolute or relative fat abundance.

Abdominal visceral fat appears to be more strongly associated than subcutaneous fat with risk factors for cardiovascular and metabolic disorders, including hypertension and insulin resistance [26, 27], and is receiving increasing attention in COPD. Indeed, two recent studies have reported excessive visceral fat mass in non-obese mild-to-moderate COPD patients as detected by 


\section{DISCUSSION}

CT scanning [28, 29]. Moreover, excessive visceral fat mass was positively associated with circulating interleukin (IL)-6 levels, which were strongly associated with all-cause and CVD mortality [28]. Importantly, excessive visceral fat mass in these COPD patients existed in the absence of obesity or increased abdominal circumference compared with the control persons in these studies, suggesting enhanced fat accumulation specifically in the visceral compartment. It is unclear whether the pulmonary impairment per se or an overall poor lifestyle, or both, predispose to excessive visceral fat accumulation. A similar selective increase in visceral fat mass has been observed in other chronic diseases characterized by tissue inflammation including rheumatoid arthritis, Crohn's disease, and psoriasis. These intriguing findings suggest a link between inflammation, visceral fat and cardiovascular risk. Careful mechanistic studies will be required to determine whether an increase in visceral fat plays a causal role in this chain.

The inflammatory capacity of visceral fat is considerably greater than that of subcutaneous fat, and it has been suggested that visceral fat is an important source of IL- 6 and IL-1 $\beta$ [30]. In addition, there is evidence that an increase in visceral relative to subcutaneous fat is associated with hypertriglyceridaemia and a decreased rate of glucose utilization in obese humans [31]. Differential expression of the fat mass and obesity associated (FTO) gene has been associated with the differential deposition of fat in the visceral or subcutaneous stores, adipose tissue inflammation and differences in the expression of inflammatory and insulin resistance-related genes in the visceral compared with the subcutaneous fat in otherwise healthy overweight/obese subjects [32]. Consistent with the hypothesis that this gene may contribute to obesity-related inflammation in patients with COPD, single nucleotide polymorphisms in FTO gene were reported to be positively associated with BMI in patients with COPD [33].

Increased visceral fat mass has been associated with increased portal drainage of free fatty acids and adipokines to the liver, which may induce hepatic insulin resistance, inflammation and oxidative stress ('portal hypothesis' [34]). Furthermore, visceral adiposity has been associated with fat deposition in other undesirable sites such as the liver, the heart, and the skeletal muscle [35]. To date, there is no data available if ectopic fat deposition plays a role in the risk of cardiovascular and metabolic disease in COPD, but it may be involved in those with increased visceral fat mass.

There is increasing evidence that components of the metabolic syndrome are more prevalent in overweight patients with mild-to-moderate COPD compared with BMI-matched controls. A study reported that in overweight COPD patients $47 \%$ had the metabolic syndrome compared to $21 \%$ in BMI-matched healthy subjects [36]. In another study of 170 German patients with COPD, 53\% of GOLD II patients met the criteria for metabolic syndrome and as much as $83 \%$ fulfilled the criteria for abdominal obesity [37]. Congruently, a large population study showed that those with airflow obstruction had greater odds of having the 
metabolic syndrome when adjusted for BMI, and when its components were further analyzed only abdominal obesity was significantly related to airflow obstruction [38].

\section{Lifestyle intervention to reduce the risk of cardiovascular and metabolic disease in patients with COPD}

\section{$\underline{\text { Smoking cessation }}$}

It is well-known that smoking is an independent risk factor for both COPD and cardiovascular disease. Less recognized is that smokers have more central adiposity [39] and exposure to smoking is associated with poor skeletal muscle function [40]. Very recent data showed that smokers are characterized by decreased skeletal muscle insulin sensitivity, which was partially reversible upon smoking cessation. Experimental evidence suggests involvement of skeletal muscle mammalian target of rapamycin (mTOR) in this process, a crucial regulator of cellular protein synthesis [41]. BMI, as well as whole-body muscle and fat masses, are comparably reduced in older mild-to-moderate COPD patients and age-matched non-COPD smokers compared with non-smokers, suggesting a common insult earlier in life related to smoking [4]. Furthermore, the peripheral skeletal muscle of non-COPD smokers shows a loss of oxidative phenotype compared to non-smoking healthy controls [42]. Smoking induces low-grade systemic inflammation, independently of COPD [43], and the persistent systemic inflammation observed in patients with COPD was predicted by current smoking status [24]. Notably, chronic exposure of mice to cigarette smoke also induces systemic inflammation and decreased skeletal muscle oxidative capacity [44]. Smoking cessation is associated with fat mass gain, particularly in the visceral compartment [45], stressing the need for broad lifestyle interventions beyond smoking cessation.

\section{Physical activity and aerobic exercise training}

The Centers for Disease Control and Prevention and the American College of Sports Medicine recommend that a person should engage in $\geq 30$ minutes of moderate-to-vigorous physical activity each day, preferably in bouts of $\geq 10$ minutes [46]. The majority of patients with COPD have a sedentary lifestyle [5] and physical inactivity contributes to the risk and mortality associated with cardiovascular and metabolic disease. Patients with COPD, irrespective of disease severity, have fewer, shorter and less intense periods of intense physical activity, and spend more time sedentary compared with healthy subjects [8]. It has been argued that the reduced level of physical activity level is causally implicated in the development of COPD, as studies have consistently reported 


\section{DISCUSSION}

attenuated $\mathrm{FEV}_{1}$ decline in physically active persons (smokers and non-smokers) [47].

Bed-rest studies in healthy, lean subjects have shown that physical inactivity induces a wide array of metabolic abnormalities including skeletal muscle insulin resistance, impaired skeletal muscle lipid trafficking, a shift in fuel metabolism in favor of carbohydrate oxidation and in detriment of lipid oxidation, an increase in intramyocellular lipid content, muscle atrophy and muscle fiber type I-to-II shift, and increased plasma non-esterified fatty acid levels [48]. As many of these metabolic abnormalities have also been found in COPD, the adverse effects of physical inactivity are likely to be substantial.

The benefits of aerobic exercise training on cardiometabolic health have been well-described in overweight or obese adults with and without type 2 diabetes, but have been incompletely studied in patients with COPD. In healthy overweight or obese adults, aerobic exercise training improves insulin sensitivity and induces mitochondrial biogenesis in the skeletal muscle $[49,50]$, and induces the loss of visceral fat mass [51]. These effects were observed even in patients whose body mass or waist circumference did not change.

Classically, it was assumed that aerobic exercise training intensity in COPD could not reach the levels required to induce physiological effects due to ventilatory limitation. Two important papers disputed this assumption by showing improved lactate-to-work ratios and increased activity of key mitochondrial enzymes in muscle biopsies after aerobic exercise training [52, 53] and these findings have been subsequently confirmed.

Arterial stiffness is an independent cardiovascular risk factor, which is also improved by aerobic exercise training in healthy subjects [54]. Increased arterial stiffness has been reported in patients with COPD, particularly those with advanced disease [55]. Interestingly, Vivodtzev et al. reported that a relatively short aerobic exercise training program improved arterial stiffness and quadriceps muscle endurance in a cohort of patients with COPD [56]. Gale et al. [57] showed that standard multidisciplinary pulmonary rehabilitation including aerobic exercise training reduced arterial stiffness without changing BMI in mildly overweight COPD patients.

\section{Diet and nutritional modulation}

While weight gain and improved nutrition are recommended for underweight patients with COPD [58], there is no systematic study demonstrating efficacy of improved nutrition or weight reduction strategies in overweight or obese patients with COPD. It seems likely that the obesity paradox has limited enthusiasm for this approach. However, data from weight loss interventions in patients at risk for diabetes suggest that even modest reductions in weight can reduce the risk of cardiovascular and metabolic diseases, perhaps through improvements in body fat distribution. For example, an $\sim 2-5 \%$ loss of body mass 
was reported to be associated with a sustained and preferential loss of visceral relative to subcutaneous fat in otherwise healthy overweight or obese persons, however, weight loss $>5 \%$ was associated with the loss of fat in both compartments [59].

Dietary factors have recently also been put forward as contributing environmental factors in COPD etiology and pathology. A diet rich in fruit, vegetables, whole-meal cereals and fish is associated with a reduced COPD risk, whereas a "western diet" rich in refined grains, cured and red meats, desserts and French fries is associated with increased COPD risk, independent of smoking $[60,61]$. Further study is required to identify the specific dietary components with COPD risk as these strategies might be used to prevent the development or slow the progression of COPD while simultaneously reducing cardiovascular risk. The available literature suggests a particular important role for dietary fiber. There is convincing evidence of lower fiber intake in COPD patients [28] and that increased dietary fiber intake is inversely associated with respiratory mortality [62]. Dietary fiber has been shown to alter gut immunity and reduce systemic inflammation, which may be mediated by alterations in the gut microbiome or other mechanisms. Poly-unsaturated fatty acids (PUFAs) warrant further investigation in targeted nutritional modulation as PUFAs (in particular n-3 fatty acids) are known agonists of peroxisome proliferator-activated receptors (PPARs), which are implicated in skeletal muscle oxidative gene expression. PUFA supplementation was also shown to enhance training effects on exercise capacity in a randomized controlled trial that included patients with moderateto-severe COPD [63]. PPARs as potential targets for nutritional as well as pharmacological modulation in COPD have been discussed in detail elsewhere [64].

Another promising example of nutritional modulation to improve the cardiovascular and metabolic disease risk profile in COPD is resveratrol, a natural polyphenolic compound in nuts and grapes that is widely available as a nutritional supplement. Resveratrol supplementation $(150 \mathrm{mg} /$ day $)$ has emerged as a calorie restriction mimetic with beneficial cardiovascular, antiaging and anti-diabetogenic properties in otherwise healthy overweight or obese men [65]. Interestingly, pharmacological inhibition of phosphodiesterase-4 reproduced all of the metabolic benefits of resveratrol in experimental studies, likely through the same potential mechanisms. These include elevation of intracellular cAMP levels, thereby increasing $\mathrm{NAD}(+)$ and the activity of SirT1, which in concert provide a drive for increasing oxidative metabolism [66].

\section{Concluding remarks}

Adverse metabolic health, in terms of loss of peripheral skeletal muscle oxidative phenotype and excessive visceral fat accumulation is associated with increased morbidity and mortality in patients with COPD. This increased risk is evident at 


\section{DISCUSSION}

all stages of the disease and is not necessarily restricted to obese patients. Ruderman et al. described this phenotype as a "metabolically obese, but normal weight person" [67]. Physical inactivity, poor dietary quality, and smoking contribute to these metabolic abnormalities, and in concert further increase the risk of cardiovascular morbidity and mortality (Figure 1).

Because loss of muscle oxidative phenotype and excessive visceral fat accumulation can exist without changes in muscle mass and abdominal circumference, there is a need for new diagnostic tools and biomarkers to reveal these hidden phenomena. Quadriceps muscle endurance tests or the lactate response upon exercise may provide good indicators of skeletal muscle oxidative phenotype, and abdominal bioelectrical impedance, ultrasound and plasma levels of the pro-thrombotic adipokine plasminogen activator inhibitor-1 have shown good correlations with CT-acquired visceral fat mass but require validation in COPD.

The most important question that needs to be answered in future studies is whether the adverse metabolic profile in COPD patients is caused by the disease itself or by an overall poor lifestyle, and whether the two act synergistically. Studies in patients with COPD and control subjects without COPD matched for overall lifestyle may help in disentangling COPD-specific versus lifestylemediated influences. Other important questions remain: Is the loss of peripheral skeletal muscle oxidative phenotype in COPD an accelerator of or causally implicated in insulin resistance? Is there a physiological link between the loss of peripheral skeletal muscle oxidative phenotype and visceral fat accumulation? Is the inflammatory status of visceral versus subcutaneous fat enhanced in COPD, and does this relate to an adverse cardiovascular or metabolic profile? What is the role of ectopic fat deposition in the adverse cardiovascular and metabolic profile in COPD? Finally, a possible link between adipose hormones and pulmonary inflammation may shed new lights on the importance of adipose tissue in COPD progression in the current obesogenic society.

It is projected that increased knowledge of the metabolic changes in patients with COPD will allow investigators to test interventions aimed at reducing the risk of cardiovascular and metabolic diseases and their associated morbidity and mortality. Available data suggest that the early implementation of tailored lifestyle interventions in patients with COPD who are not yet physically impaired are likely to be beneficial. These lifestyle factors extend beyond recommendations for smoking cessation, instead an integrated systems approach addressing smoking, physical inactivity, and poor diet may be most beneficial in slowing the progression of the disease. 
Figure 1. Conceptual representation of the drivers of cardiovascular and metabolic risk in COPD.

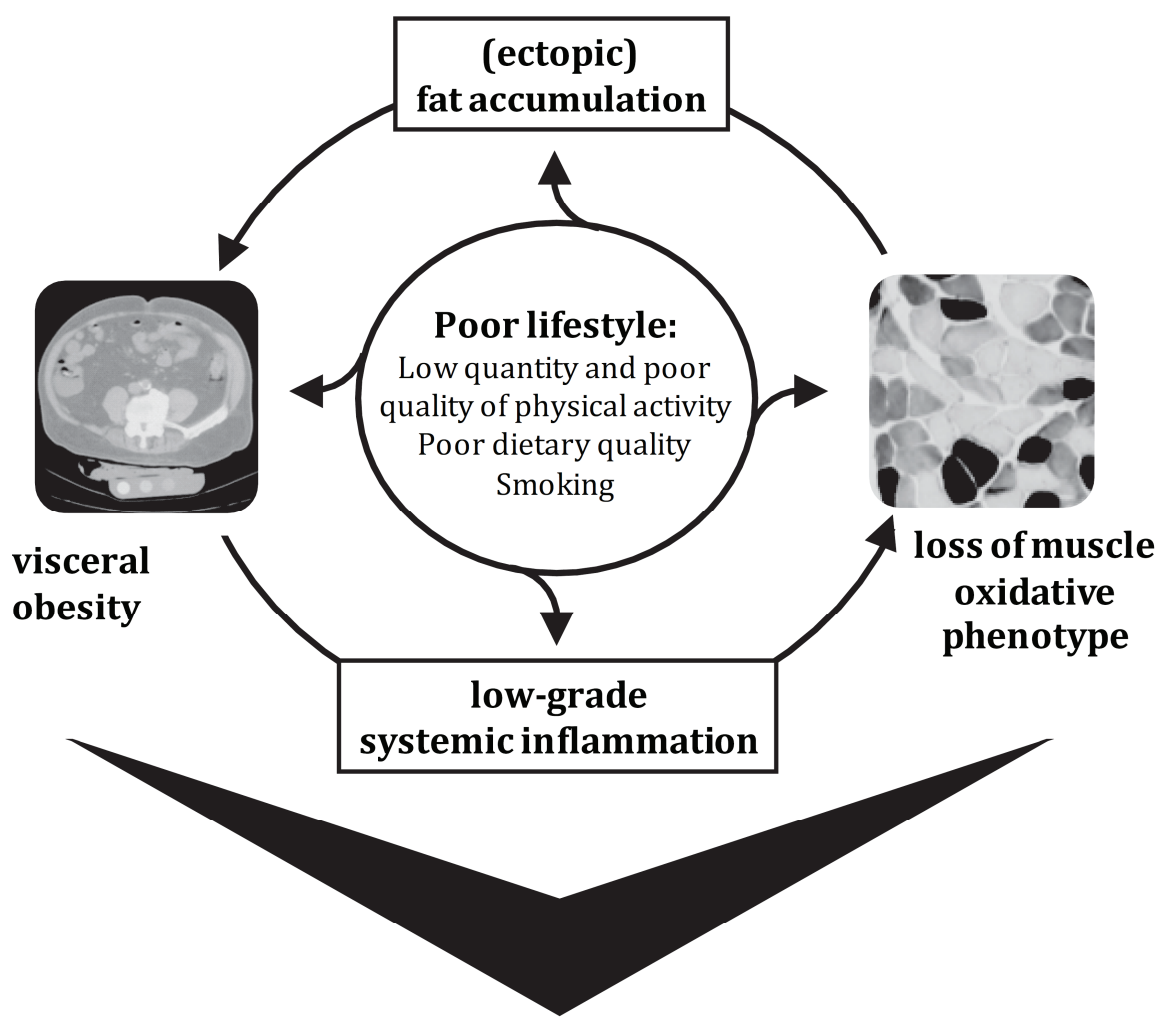

\section{Cardiometabolic risk}

Hypertension

Dyslipidemia

Insulin resistance

Microvascular damage

Arterial stiffness

Cardiovascular mortality 


\section{DISCUSSION}

\section{References}

1. Swallow EB, Reyes D, Hopkinson NS, Man WD, Porcher R, Cetti EJ, Moore AJ, Moxham J, Polkey MI. Quadriceps strength predicts mortality in patients with moderate to severe chronic obstructive pulmonary disease. Thorax. 2007;62(2):115-20.

2. McGarvey LP, John M, Anderson JA, Zvarich M, Wise RA. Ascertainment of cause-specific mortality in COPD: operations of the TORCH Clinical Endpoint Committee. Thorax. 2007;62(5):411-5.

3. Shrikrishna D, Patel M, Tanner RJ, Seymour JM, Connolly BA, Puthucheary ZA, Walsh SL, Bloch SA, Sidhu PS, Hart N, et al. Quadriceps wasting and physical inactivity in patients with COPD. Eur Respir J. 2012 Feb 23 [Epub ahead of print].

4. van den Borst B, Koster A, Yu B, Gosker HR, Meibohm B, Bauer DC, Kritchevsky SB, Liu Y, Newman AB, Harris $\mathrm{TB}$, et al. Is age-related decline in lean mass and physical function accelerated by obstructive lung disease or smoking? Thorax. 2011;66(11):961-9.

5. Rabinovich RA, Vilaro J. Structural and functional changes of peripheral muscles in chronic obstructive pulmonary disease patients. Curr Opin Pulm Med. 2010;16(2):123-33.

6. Allaire J, Maltais F, Doyon JF, Noel M, LeBlanc P, Carrier G, Simard C, Jobin J. Peripheral muscle endurance and the oxidative profile of the quadriceps in patients with COPD. Thorax. 2004;59(8):673-8.

7. Layec G, Haseler LJ, Richardson RS. The effect of higher ATP cost of contraction on the metabolic response to graded exercise in patients with chronic obstructive pulmonary disease. J Appl Physiol. 2012;112(6):1041-8.

8. van den Borst B, Slot IGM, Hellwig VACV, Vosse BAH, Kelders MCJM, Barreiro E, Schols AMWJ, Gosker HR. Loss of quadriceps muscle oxidative phenotype and decreased endurance in patients with mild-to-moderate COPD. Journal of Applied Physiology. 2012 Jul 19 [Epub ahead of print].

9. Schrauwen P, Schrauwen-Hinderling V, Hoeks J, Hesselink MK. Mitochondrial dysfunction and lipotoxicity. Biochim Biophys Acta. 2010;1801(3):266-71.

10. Wang $\mathrm{CH}$, Wang CC, Wei YH. Mitochondrial dysfunction in insulin insensitivity: implication of mitochondrial role in type 2 diabetes. Ann N Y Acad Sci. 2010;1201:157-65.

11. Hoeks J, Schrauwen P. Muscle mitochondria and insulin resistance: a human perspective. Trends Endocrinol Metab. 2012;23(9):444-50.

12. Mogensen M, Sahlin K, Fernstrom M, Glintborg D, Vind BF, Beck-Nielsen H, Hojlund K. Mitochondrial respiration is decreased in skeletal muscle of patients with type 2 diabetes. Diabetes. 2007;56(6):1592-9.

13. Rabol R, Larsen S, Hojberg PM, Almdal T, Boushel R, Haugaard SB, Andersen JL, Madsbad S, Dela F. Regional anatomic differences in skeletal muscle mitochondrial respiration in type 2 diabetes and obesity. J Clin Endocrinol Metab. 2010;95(2):857-63.

14. Remels AH, Schrauwen P, Broekhuizen R, Willems J, Kersten S, Gosker HR, Schols AM. Peroxisome proliferator-activated receptor expression is reduced in skeletal muscle in COPD. Eur Respir J. 2007;30(2):245-52.

15. Mensink M, Hesselink MK, Russell AP, Schaart G, Sels JP, Schrauwen P. Improved skeletal muscle oxidative enzyme activity and restoration of PGC-1 alpha and PPAR beta/delta gene expression upon rosiglitazone treatment in obese patients with type 2 diabetes mellitus. Int J Obes (Lond). 2007;31(8):1302-10.

16. Segerstrom AB, Elgzyri T, Eriksson KF, Groop L, Thorsson O, Wollmer P. Exercise capacity in relation to body fat distribution and muscle fibre distribution in elderly male subjects with impaired glucose tolerance, type 2 diabetes and matched controls. Diabetes Res Clin Pract. 2011;94(1):57-63.

17. Marin P, Andersson B, Krotkiewski M, Bjorntorp P. Muscle fiber composition and capillary density in women and men with NIDDM. Diabetes Care. 1994;17(5):382-6.

18. Kelley DE, Mandarino LJ. Fuel selection in human skeletal muscle in insulin resistance: a reexamination. Diabetes. 2000;49(5):677-83.

19. Coen PM, Goodpaster BH. Role of intramyocellular lipids in human health. Trends Endocrinol Metab. 2012;23(8):391-8.

20. van den Borst B, Gosker HR, Wesseling G, de Jager W, Hellwig VA, Snepvangers FJ, Schols AM. Low-grade adipose tissue inflammation in patients with mild-to-moderate chronic obstructive pulmonary disease. Am J Clin Nutr. 2011;94(6):1504-12.

21. Bolton CE, Evans M, Ionescu AA, Edwards SM, Morris RH, Dunseath G, Luzio SD, Owens DR, Shale DJ. Insulin resistance and inflammation - A further systemic complication of COPD. COPD. 2007;4(2):121-6.

22. Franssen FM, Sauerwein HP, Ackermans MT, Rutten EP, Wouters EF, Schols AM. Increased postabsorptive and exercise-induced whole-body glucose production in patients with chronic obstructive pulmonary disease. Metabolism. 2011;60(7):957-64.

23. Sin DD, Man SF. Why are patients with chronic obstructive pulmonary disease at increased risk of cardiovascular diseases? The potential role of systemic inflammation in chronic obstructive pulmonary disease. Circulation. 2003;107(11):1514-9.

24. Agusti A, Edwards LD, Rennard SI, Macnee W, Tal-Singer R, Miller BE, Vestbo J, Lomas DA, Calverley PM, Wouters E, et al. Persistent Systemic Inflammation is Associated with Poor Clinical Outcomes in COPD: A Novel Phenotype. PLoS One. 2012;7(5):e37483.

25. Rutten EP, Breyer MK, Spruit MA, Hofstra T, van Melick PP, Schols AM, Wouters EF. Abdominal fat mass contributes to the systemic inflammation in chronic obstructive pulmonary disease. Clin Nutr. 2010;29(6):756-60.

26. Kishida K, Funahashi T, Matsuzawa Y, Shimomura I. Visceral adiposity as a target for the management of the metabolic syndrome. Ann Med. 2012;44(3):233-41. 
27. Perrini S, Leonardini A, Laviola L, Giorgino F. Biological specificity of visceral adipose tissue and therapeutic intervention. Arch Physiol Biochem. 2008;114(4):277-86.

28. van den Borst B, Gosker HR, Koster A, Yu B, Kritchevsky SB, Liu Y, Meibohm B, Rice TB, Shlipak M, Yende S, et $a l$. The influence of abdominal visceral fat on inflammatory pathways and mortality risk in obstructive lung disease. Am J Clin Nutr. 2012;96(3):516-26.

29. Furutate R, Ishii T, Wakabayashi R, Motegi T, Yamada K, Gemma A, Kida K. Excessive visceral fat accumulation in advanced chronic obstructive pulmonary disease. Int J Chron Obstruct Pulmon Dis. 2011;6:423-30.

30. Zafon C. Fat and aging: a tale of two tissues. Curr Aging Sci. 2009;2(2):83-94.

31. Klimcakova E, Roussel B, Kovacova Z, Kovacikova M, Siklova-Vitkova M, Combes M, Hejnova J, Decaunes P, Maoret JJ, Vedral T, et al. Macrophage gene expression is related to obesity and the metabolic syndrome in human subcutaneous fat as well as in visceral fat. Diabetologia. 2011;54(4):876-87.

32. Samaras K, Botelho NK, Chisholm DJ, Lord RV. Subcutaneous and visceral adipose tissue FTO gene expression and adiposity, insulin action, glucose metabolism, and inflammatory adipokines in type 2 diabetes mellitus and in health. Obes Surg. 2010;20(1):108-13.

33. Wan ES, Cho MH, Boutaoui N, Klanderman BJ, Sylvia JS, Ziniti JP, Won S, Lange C, Pillai SG, Anderson WH, et al. Genome-wide association analysis of body mass in chronic obstructive pulmonary disease. Am J Respir Cell Mol Biol. 2011;45(2):304-10.

34. Bjorntorp P. "Portal" adipose tissue as a generator of risk factors for cardiovascular disease and diabetes. Arteriosclerosis. 1990;10(4):493-6.

35. Despres JP, Lemieux I. Abdominal obesity and metabolic syndrome. Nature. 2006;444(7121):881-7.

36. Marquis K, Maltais F, Duguay V, Bezeau AM, LeBlanc P, Jobin J, Poirier P. The metabolic syndrome in patients with chronic obstructive pulmonary disease. J Cardiopulm Rehabil. 2005;25(4):226-32; discussion 33-4.

37. Watz H, Waschki B, Kirsten A, Muller KC, Kretschmar G, Meyer T, Holz O, Magnussen H. The metabolic syndrome in patients with chronic bronchitis and COPD: frequency and associated consequences for systemic inflammation and physical inactivity. Chest. 2009;136(4):1039-46.

38. Lam KB, Jordan RE, Jiang CQ, Thomas GN, Miller MR, Zhang WS, Lam TH, Cheng KK, Adab P. Airflow obstruction and metabolic syndrome: the Guangzhou Biobank Cohort Study. Eur RespirJ. 2010;35(2):317-23.

39. Canoy D, Wareham N, Luben R, Welch A, Bingham S, Day N, Khaw KT. Cigarette smoking and fat distribution in 21,828 British men and women: a population-based study. Obes Res. 2005;13(8):1466-75.

40. Strand BH, Mishra G, Kuh D, Guralnik JM, Patel KV. Smoking history and physical performance in midlife: results from the British 1946 birth cohort. J Gerontol A Biol Sci Med Sci. 2011;66(1):142-9.

41. Bergman BC, Perreault L, Hunerdosse D, Kerege A, Playdon M, Samek AM, Eckel RH. Novel and Reversible Mechanisms of Smoking-Induced Insulin Resistance in Humans. Diabetes. 2012;61(12):3156-66.

42. Montes de Oca M, Loeb E, Torres SH, De Sanctis J, Hernandez N, Talamo C. Peripheral muscle alterations in non-COPD smokers. Chest. 2008;133(1):13-8.

43. Yanbaeva DG, Dentener MA, Creutzberg EC, Wesseling G, Wouters EF. Systemic effects of smoking. Chest. 2007;131(5):1557-66.

44. Gosker HR, Langen RC, Bracke KR, Joos GF, Brusselle GG, Steele C, Ward KA, Wouters EF, Schols AM. Extrapulmonary manifestations of chronic obstructive pulmonary disease in a mouse model of chronic cigarette smoke exposure. Am J Respir Cell Mol Biol. 2009;40(6):710-6.

45. Matsushita Y, Nakagawa T, Yamamoto S, Takahashi Y, Noda M, Mizoue T. Associations of smoking cessation with visceral fat area and prevalence of metabolic syndrome in men: the Hitachi health study. Obesity (Silver Spring). 2011;19(3):647-51.

46. Pate RR, Pratt M, Blair SN, Haskell WL, Macera CA, Bouchard C, Buchner D, Ettinger W, Heath GW, King AC, et al. Physical activity and public health. A recommendation from the Centers for Disease Control and Prevention and the American College of Sports Medicine. JAMA. 1995;273(5):402-7.

47. Hopkinson NS, Polkey MI. Does physical inactivity cause chronic obstructive pulmonary disease? Clin Sci (Lond). 2010;118(9):565-72.

48. Bergouignan A, Rudwill F, Simon C, Blanc S. Physical inactivity as the culprit of metabolic inflexibility: evidence from bed-rest studies. J Appl Physiol. 2011;111(4):1201-10.

49. Olesen J, Kiilerich K, Pilegaard H. PGC-1alpha-mediated adaptations in skeletal muscle. Pflugers Arch. 2010;460(1):153-62.

50. Bruce CR, Hawley JA. Improvements in insulin resistance with aerobic exercise training: a lipocentric approach. Med Sci Sports Exerc. 2004;36(7):1196-201.

51. Ismail I, Keating SE, Baker MK, Johnson NA. A systematic review and meta-analysis of the effect of aerobic vs. resistance exercise training on visceral fat. Obes Rev. 2012;13(1):68-91.

52. Casaburi R, Patessio A, Ioli F, Zanaboni S, Donner CF, Wasserman K. Reductions in exercise lactic acidosis and ventilation as a result of exercise training in patients with obstructive lung disease. Am Rev Respir Dis. 1991;143(1):9-18

53. Maltais F, LeBlanc P, Simard C, Jobin J, Berube C, Bruneau J, Carrier L, Belleau R. Skeletal muscle adaptation to endurance training in patients with chronic obstructive pulmonary disease. Am J Respir Crit Care Med. 1996;154(2 Pt 1):442-7.

54. Mattace-Raso FU, van der Cammen TJ, Hofman A, van Popele NM, Bos ML, Schalekamp MA, Asmar R, Reneman RS, Hoeks AP, Breteler MM, et al. Arterial stiffness and risk of coronary heart disease and stroke: the Rotterdam Study. Circulation. 2006;113(5):657-63. 


\section{DISCUSSION}

55. McAllister DA, Maclay JD, Mills NL, Mair G, Miller J, Anderson D, Newby DE, Murchison JT, Macnee W. Arterial stiffness is independently associated with emphysema severity in patients with chronic obstructive pulmonary disease. Am J Respir Crit Care Med. 2007;176(12):1208-14.

56. Vivodtzev I, Minet C, Wuyam B, Borel JC, Vottero G, Monneret D, Baguet JP, Levy P, Pepin JL. Significant improvement in arterial stiffness after endurance training in patients with COPD. Chest. 2010;137(3):585-92.

57. Gale NS, Duckers JM, Enright S, Cockcroft JR, Shale DJ, Bolton CE. Does pulmonary rehabilitation address cardiovascular risk factors in patients with COPD? BMC Pulm Med. 2011;11:20

58. Schols AM, Slangen J, Volovics L, Wouters EF. Weight loss is a reversible factor in the prognosis of chronic obstructive pulmonary disease. Am J Respir Crit Care Med. 1998;157(6 Pt 1):1791-7.

59. Chaston TB, Dixon JB. Factors associated with percent change in visceral versus subcutaneous abdominal fat during weight loss: findings from a systematic review. Int J Obes (Lond). 2008;32(4):619-28.

60. Varraso R, Fung TT, Hu FB, Willett W, Camargo CA. Prospective study of dietary patterns and chronic obstructive pulmonary disease among US men. Thorax. 2007;62(9):786-91.

61. Shaheen SO, Jameson KA, Syddall HE, Sayer AA, Dennison EM, Cooper C, Robinson SM. The relation of dietary patterns with adult lung function and COPD. Eur Respir J. 2010;36(2):277-84.

62. Chuang SC, Norat T, Murphy N, Olsen A, Tjonneland A, Overvad K, Boutron-Ruault MC, Perquier F, Dartois L, Kaaks R, et al. Fiber intake and total and cause-specific mortality in the European Prospective Investigation into Cancer and Nutrition cohort. Am J Clin Nutr. 2012;96(1):164-74.

63. Broekhuizen R, Wouters EF, Creutzberg EC, Weling-Scheepers CA, Schols AM. Polyunsaturated fatty acids improve exercise capacity in chronic obstructive pulmonary disease. Thorax. 2005;60(5):376-82.

64. Remels AH, Gosker HR, Schrauwen P, Langen RC, Schols AM. Peroxisome proliferator-activated receptors: a therapeutic target in COPD? Eur Respir J. 2008;31(3):502-8.

65. Timmers S, Konings E, Bilet L, Houtkooper RH, van de Weijer T, Goossens GH, Hoeks J, van der Krieken S, Ryu D, Kersten S, et al. Calorie restriction-like effects of 30 days of resveratrol supplementation on energy metabolism and metabolic profile in obese humans. Cell Metab. 2011;14(5):612-22.

66. Park SJ, Ahmad F, Philp A, Baar K, Williams T, Luo H, Ke H, Rehmann H, Taussig R, Brown AL, et al. Resveratrol ameliorates aging-related metabolic phenotypes by inhibiting cAMP phosphodiesterases. Cell. 2012;148(3):421-33.

67. Ruderman NB, Schneider SH, Berchtold P. The "metabolically-obese," normal-weight individual. Am J Clin Nutr. 1981;34(8):1617-21. 


\section{Summary}

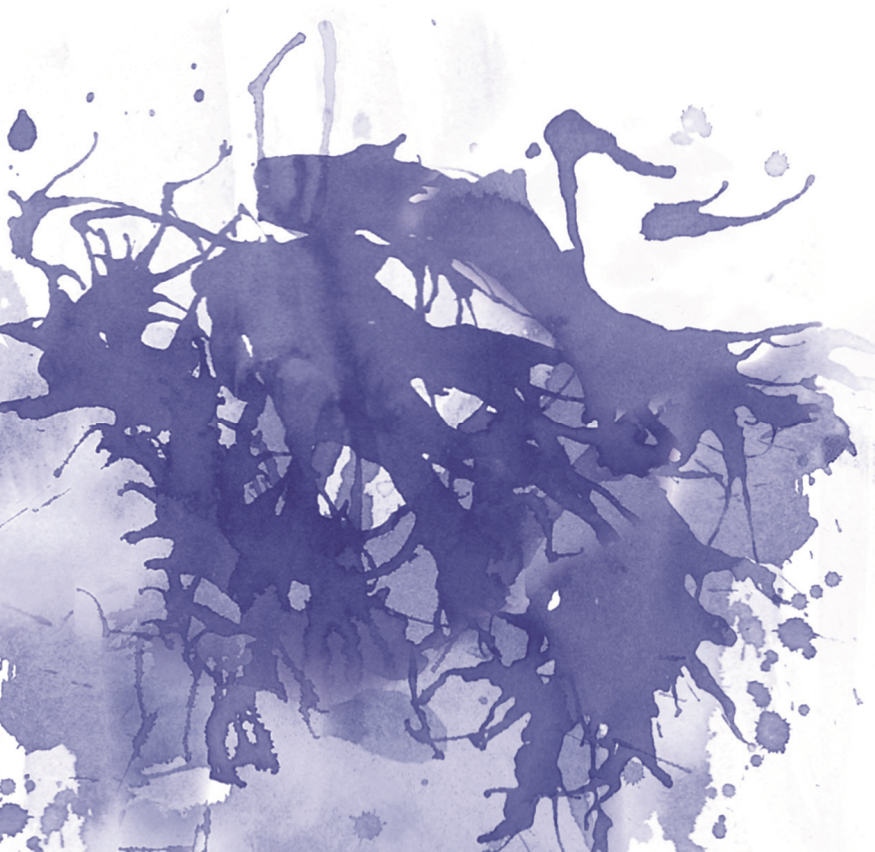


Chronic obstructive pulmonary disease (COPD) affects 64 million people worldwide and is projected to be the third leading cause of death by the year 2020. Patients with advanced COPD primarily die from respiratory failure, whereas those with mild-to-moderate COPD most often die from cardiovascular events. Morbidity and mortality risk in COPD are likely determined by a combination of disease-specific factors and an aging and obesogenic society in general. This thesis has a focus on patients with mild-to-moderate COPD and investigates whether they are characterized by an increased metabolic risk and to what extent aging and an unhealthy lifestyle are involved.

\section{Peripheral muscle in mild-to-moderate COPD: smoked and tired}

The loss of muscle mass during the aging process is a physiological phenomenon (termed 'sarcopenia') and has been associated with deterioration in physical functioning. Many patients with COPD experience muscle weakness that hampers their daily life activities and the question arises whether this can be attributed to their disease or simply be explained by sarcopenia. In Chapter 2 it is shown that the rate with which the sarcopenic process takes place in patients with COPD is comparable to that of age-matched subjects without COPD. However, patients with COPD enter old-age with much lower absolute muscle mass than subjects without COPD. Thus, either the deterioration of muscle mass in patients with COPD had initiated earlier in life, or they had been lean all along. The Chapter also shows that smokers without COPD are just as lean as the patients with COPD when entering old-age. Being the major cause of COPD, exposure to cigarette smoke thus also seems to affect muscle mass, apparently earlier in life.

The mechanisms leading to muscle dysfunction have been particularly well studied in patients with severe COPD, but not in patients with milder degrees of airflow limitation. Chapter 3 provides evidence for reduced quadriceps muscle endurance in patients with mild-to-moderate COPD who had normal muscle mass. Muscle fatigue was associated with a clear loss of oxidative phenotype of the quadriceps muscle that was characterized by a loss of oxidative type I muscle fibers and decreased peroxisome-proliferator activated receptor- $\gamma$ co-activator $1 \alpha$ gene expression (being the major regulator of oxidative metabolism). Thus, a loss of peripheral muscle oxidative phenotype can exist already in the absence of muscle wasting, and already in patients with less-advanced COPD.

\section{Adipose tissue inflammation in COPD: core business}

Over the past decade, emerging research has shown that adipose tissue is not just an energy storage compartment but actively secretes proteins with 
inflammatory properties, commonly known as adipokines. It has been suggested that a dysregulation of adipokine secretion may play a role in systemic as well as pulmonary inflammation in COPD. Chapter 4 presents the first comparison of adipose tissue inflammatory status between mild-to-moderate COPD patients and matched healthy subjects. Neither adipose tissue adipokine gene expression, nor adipose tissue macrophage infiltration, nor plasma concentrations of adipokines were different between the COPD patients and the healthy subjects. Adiposity was positively associated with adipose tissue inflammation in both the COPD patients and the healthy subjects. As part of metabolic risk assessment, the COPD patients did have lower insulin sensitivity compared with the healthy controls. These data suggest that abdominal subcutaneous adipose tissue inflammatory status is generally not affected in mild-to-moderate COPD.

Chapter 5 shows that COPD patients with mild airflow obstruction are characterized by increased intra-abdominal fat mass which is not necessarily associated with obesity or increased abdominal circumference. Plasma concentrations of interleukin (IL)- 6 were also increased in these patients and were positively associated with intra-abdominal fat mass. Also, plasma IL-6 concentration predicted excess 9-year mortality of the COPD patients. The results suggest that interventions aimed at lowering intra-abdominal fat mass may be beneficial in COPD patients in terms of lowering systemic inflammation and related mortality.

Experimental studies have suggested that local tissue hypoxia in obesity induces adipose tissue inflammation. If hypoxia is indeed one of the mechanisms involved, this may be of importance for COPD as it often associated with hypoxia. In Chapter 6 it was explored whether mice exposed to chronic hypoxia are characterized by adipose tissue inflammation. Interestingly, decreased rather than increased inflammation was found in both subcutaneous and visceral adipose tissue. In conjunction, marked alterations of metabolic gene expression were shown consistent with upregulation of oxidative metabolism. This study argues against chronic hypoxia being associated with adipose tissue inflammation, and simultaneously suggests a significant metabolic shift towards increased fat oxidative metabolism during chronic hypoxia. Future studies are warranted to investigate the effects of hypoxia on adipose tissue inflammation and metabolism in humans.

\section{Unhealthy lifestyle of COPD patients: behind the smoke screen}

In Chapter 2, it is shown that smoking is associated with decreased muscle, fat and bone masses independently of lung function. Thereby, smoking alone poses individuals at risk for accelerated physical deterioration. Smoking cessation is one of the hallmarks in COPD treatment, but it may not be sufficient in terms of lifestyle management in COPD. It is increasingly becoming clear that COPD patients engage in an overall poor lifestyle that is also characterized by physical 
inactivity and an unhealthy diet. Importantly, this concerns not only those with severe COPD but also those with milder degrees of airflow obstruction. Chapter 3 demonstrates a $40 \%$ decreased daily physical activity in mild-to-moderate COPD patients which is further characterized by fewer, shorter, and less intensive bouts of moderate-to-vigorous exercise compared with those of healthy subjects. Nearly $70 \%$ of their time during the day, COPD patients spend sedentary. Furthermore, Chapter 5 shows that only 8\% of COPD patients perform high-intensity physical activities for more than 90 minutes per week. Physical inactivity can lead to muscular deconditioning, adverse body fat distribution and low-grade systemic inflammation, and may thereby contribute to disease burden and progression of COPD.

The studied COPD patients in Chapter $\mathbf{5}$ had a poor dietary quality characterized by increased fat consumption, and decreased consumption of fruit, vegetables, and dietary fiber. A systematic review of the literature (Chapter 7) further revealed that a greater intake of dietary fiber has been consistently associated with better lung function in the general population, lower odds of COPD, and lower risk of incident respiratory symptoms and COPD. Importantly, these associations were independent of smoking. The mechanisms by which dietary fiber leads to these beneficial effects require further study.

\section{Early metabolic risk in COPD}

Chapter 8 puts into perspective the work described in this thesis and discusses future directions. Early loss of peripheral muscle oxidative phenotype and adverse body fat distribution put the patient with COPD at risk for metabolic and cardiovascular diseases- already in those with mild pulmonary deficits. Future research should elucidate whether this early metabolic risk is caused by COPD itself or by an unhealthy lifestyle, and whether the two act synergistically.

An improved understanding of the mechanisms of increased early metabolic risk in patients with COPD is projected to result in new therapeutic directions to reduce disease burden and mortality. 


\section{SAMENVAT TING}

Wereldwijd lijden 64 miljoen mensen aan de chronische longziekte COPD, en de verwachting is dat COPD in het jaar 2020 doodsoorzaak nummer drie zal zijn. COPD is een verzamelnaam voor emfyseem en chronische bronchitis. Patiënten met vergevorderd COPD overlijden hoofdzakelijk aan de gevolgen van het primaire longlijden terwijl patiënten met mild-tot-matig COPD juist vaker overlijden aan de gevolgen van hart- en vaatziekten. De verhoogde ziektelast en sterfte bij COPD patiënten wordt waarschijnlijk bepaald door zowel ziektespecifieke factoren als door algemene trends in de bevolking zoals vergrijzing en vervetting. Dit proefschrift richt zich op patiënten met mild-tot-matig COPD en onderzoekt of er bij hen sprake is van een verhoogd metabool risico. Tevens wordt onderzocht of veroudering en een ongezonde leefstijl hierin een rol spelen.

\section{Beenspieren al vroeg opgerookt en uitgeblust}

Verlies van spiermassa tijdens veroudering (genaamd 'sarcopenie') is normaal en gaat gepaard met een achteruitgang van het lichamelijk functioneren. Veel patiënten met COPD ervaren spierzwakte waardoor ze beperkt zijn in het uitvoeren van dagelijkse activiteiten. De vraag rijst of deze spierzwakte veroorzaakt wordt door de COPD of dat het 'simpelweg' te verklaren is door sarcopenie. Hoofdstuk 2 toont aan dat de snelheid van het sarcopenieproces

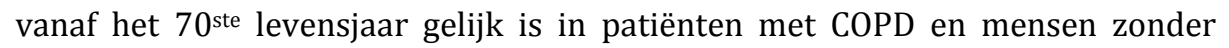
COPD. Echter, voor die tijd hebben ze reeds veel minder spiermassa dan gezonde ouderen. Dus het verlies van spiermassa begint aanzienlijk vroeger in het leven van deze patiënten, ofwel ze hadden altíjd al minder spiermassa. Het hoofdstuk laat tevens zien dat ouderen die roken maar geen COPD hebben, even mager zijn als hun leeftijdsgenoten mét COPD. Als primaire risicofactor voor COPD heeft roken dus niet alleen een negatief effect op de longen maar ook op spiermassa.

De mechanismen die leiden tot spierdisfunctie zijn goed bestudeerd in patiënten met ernstig COPD, maar niet in patiënten met mildere vormen van COPD. Hoofdstuk 3 toont bewijs voor een verminderd uithoudingsvermogen van de bovenbeenspier in patiënten met mild-tot-matig COPD die nog een normale spiermassa hebben. Het uithoudingsvermogen van de bovenbeenspier was gerelateerd aan nadelige veranderingen in de stofwisseling van diezelfde spier. Deze werden onder andere gekarakteriseerd door een verlies van het aantal zuurstofafhankelijke spiervezels en een verlaagde genexpressie van peroxisome proliferator-activated receptor- $\gamma$ co-activator $1 \alpha$ (een belangrijke regulator van zuurstofafhankelijke stofwisseling). Dus, reeds in mildere vormen van COPD bestaan er nadelige veranderingen van de stofwisseling van de bovenbeenspieren en een verminderd uithoudingsvermogen van die spieren. 


\section{Vet als ontstekingsbron}

In de afgelopen 10 jaar heeft wetenschappelijk onderzoek aangetoond dat vetweefsel niet enkel een opslagplaats is voor energie, maar tegelijkertijd eiwitten uitscheidt met ontstekingsactiviteit (genaamd 'adipokines'). Er wordt gesuggereerd dat een disregulatie van adipokine-uitscheiding een rol speelt in ontstekingsactiviteit bij COPD. Hoofdstuk 4 presenteert een vergelijking van de mate van vetweefselontsteking tussen patiënten met mild-tot-matig COPD en gezonde mensen. In biopten van onderhuids buikvet bleek dat noch genexpressie van adipokines, noch het aantal ontstekingscellen (macrofagen) verschillend waren tussen patiënten met de mild-tot-matig COPD en de gezonde mensen. Evenmin waren er verschillen in bloedconcentraties van adipokines tussen de patiënten en de gezonde mensen. Een hogere vetmassa hing wel samen met meer vetweefselontsteking in zowel de COPD patiënten als in de gezonde mensen. Deze resultaten suggereren dat ontsteking van het onderhuidse buikvet over het algemeen niet afwijkend is in patiënten met mild-tot-matig COPD. Als onderdeel van de metabole-risicobepaling bleek dat de patiënten met COPD wel een verminderde insuline gevoeligheid hadden in vergelijking met de gezonde mensen. Dit staat dus mogelijk los van de ontstekingsactiviteit in onderhuids buikvet.

Hoofdstuk 5 laat zien dat patiënten met mild COPD een verhoogde hoeveelheid vetweefsel ín hun buik hebben, onafhankelijk van obesitas of een toegenomen buikomvang. Bloedconcentratie van het ontstekingseiwit interleukine (IL)- 6 was eveneens verhoogd en was positief geassocieerd met de hoeveelheid vetweefsel in de buik. Bovendien was de IL-6 concentratie voorspellend voor de hogere sterfte van de COPD patiënten. Deze resultaten suggereren dat interventies gericht op het verminderen van vetmassa ín de buik een gunstig effect in COPD kunnen hebben door verlaging van systemische ontsteking en geassocieerde mortaliteit.

Experimentele studies suggereren dat een laag zuurstofgehalte (hypoxie) een lokale ontstekingsreactie uitlokt in vetweefsel van obese muizen. Als hypoxie inderdaad een van de mechanismen is die vetweefselontsteking kan veroorzaken, kan dit relevant zijn voor patiënten met COPD aangezien zij vaak hypoxie hebben door hun longfalen. In hoofdstuk 6 is geëxploreerd of muizen die blootgesteld worden aan chronische hypoxie gekarakteriseerd worden door vetweefselontsteking. Er werd echter een verlaagde en niet een verhoogde vetweefselontsteking gevonden in zowel onderhuids vet alsook buikvet van deze muizen. Tevens was er in het vetweefsel een verhoogde expressie van genen die belangrijk zijn voor de zuurstofwisseling. Deze studie pleit ertegen dat chronische hypoxie gepaard gaat met vetweefselontsteking, en suggereert een belangrijke verschuiving naar meer vetverbranding tijdens chronische hypoxie. Toekomstige studies zijn nodig om te onderzoeken of deze resultaten ook bevestigd worden bij COPD patiënten met hypoxie. 


\section{Ongezonde leefstijl in COPD: achter het rookgordijn}

In hoofdstuk 2 blijkt dat roken geassocieerd is met verminderde spier-, vet- en botmassa, onafhankelijk van de longfunctie. Daarmee verhoogt roken het risico voor een versnelde achteruitgang van fysiek functioneren. Stoppen met roken is een van de hoekstenen in de behandeling van COPD, maar het is mogelijk niet genoeg in het kader van leefstijl optimalisatie. Het wordt in toenemende mate bekend dat patiënten met COPD een algeheel ongezonde leefstijl hebben die naast roken ook gekenmerkt wordt door verminderde lichamelijke activiteit en een ongezond voedingspatroon. Het is belangrijk te benadrukken dat dit niet enkel patiënten met ernstig COPD betreft, maar ook al patiënten met mild-totmatig COPD. Hoofdstuk 3 toont een afname van dagelijkse fysieke activiteit van $40 \%$ in patiënten met mild-tot-matig COPD in vergelijking met gezonde mensen. Bovendien hadden deze patiënten slechts weinig aaneengesloten perioden van lichamelijke activiteit van een hoog genoeg niveau dat gezondheidswinst oplevert zoals wandelen of sporten. Sterker nog: bijna $70 \%$ van de dag spendeerden de patiënten zittend. Hoofdstuk 5 laat bovendien zien dat slechts 8\% van de patiënten met mild COPD meer dan 90 minuten per week hoogintense fysieke activiteit beoefenen, tegenover 18\% van mensen zonder COPD. Lichamelijke inactiviteit leidt tot een deconditionering van spieren, een ongunstige verdeling van lichaamsvet en systemische ontsteking, en kan via die wegen bijdragen aan ziektelast en progressie in COPD.

In vergelijking met mensen zonder COPD, hadden de COPD patiënten bestudeerd in Hoofdstuk $\mathbf{5}$ een slechte voedingskwaliteit welke werd gekarakteriseerd door een hoge vetconsumptie, en verminderde consumptie van fruit, groenten en vezels. Een systematisch overzicht van de literatuur (Hoofdstuk 7) laat zien dat juist een hogere inname van vezels gerelateerd is aan betere longfunctie in de algemene populatie, en een lagere kans op het ontwikkelen van symptomen van de luchtwegen en het ontstaan van COPD. Deze associaties staan los van de invloeden van roken. De mechanismen hoe voedingsvezels tot deze gunstige effecten kunnen leiden, dienen verder onderzocht te worden.

\section{Vroeg metabool risico in COPD}

Hoofdstuk 8 zet de resultaten van dit proefschrift in perspectief en bediscussieert toekomstige onderzoeksrichtingen. Nadelige verandering in de stofwisseling van de beenspieren en een ongunstige verdeling van lichaamsvet verhogen het risico op metabole en hart- en vaatcomplicaties in patiënten met COPD- reeds in de vroege fase van hun ziekte. Toekomstig onderzoek zal uitwijzen of dit vroeg metabool risico veroorzaakt wordt door COPD zelf, of dat een algeheel ongezonde leefstijl hieraan ten grondslag ligt, en of COPD en een ongezonde leefstijl elkaar versterken. 
Meer kennis over de mechanismen van verhoogd vroeg metabool risico in patiënten met COPD zal leiden tot nieuwe therapeutische opties om de ziektelast en sterfte van COPD te verminderen. 



\section{DAN K WOORD}

Het uitvoeren van promotieonderzoek is allesbehalve een onemanshow. Op deze plaats wil ik iedereen bedanken die heeft bijgedragen aan de totstandkoming van dit proefschrift.

Allereerst ben ik alle patiënten en gezonde vrijwilligers zeer dankbaar voor hun participatie in ons onderzoek.

Dan mijn promotor, prof. Annemie Schols. Het is al door zo velen gezegd, en ik kan me daar alleen maar bij aansluiten; jouw wetenschappelijk enthousiasme is benijdenswaardig en enorm inspirerend. Je gaf me de mogelijkheid om in Amerika onderzoek te doen, waarvoor ik je zeer dankbaar ben. Mede door de enorm hoge snelheid waarmee je mijn e-mails beantwoordde, heeft mijn onderzoek in een constante stroomversnelling gestaan. Soms leek het wel of je met Harry Gosker, mijn co-promotor, een wedstrijdje deed wie het snelst reageerde. Harry, ontzettend bedankt voor al je inhoudelijke en praktische support. Ik kon altijd bij je binnenlopen en geen wetenschappelijke uitdaging is je te gek. Annemie en Harry, ik wil jullie hartelijk bedanken voor de leerzame en fijne jaren. Dat we op een zaterdag tot diep in de nacht brainstormden over de stellingen was tekenend voor jullie toewijding en betrokkenheid. Ik ben zeer verheugd dat we een subsidie van het Longfonds hebben binnengehaald zodat we onze samenwerking kunnen vervolgen.

Ik wil de leden van de beoordelingscommissie bedanken voor hun kritische beoordeling en goedkeuring van dit proefschrift.

Prof. Emiel Wouters, u introduceerde mij in dit onderzoeksproject waarvoor ik u dankbaar ben.

Top Institute Pharma en alle partners binnen ons project (Maastricht UMC+, UMC Utrecht, UMC Groningen, AstraZeneca, GlaxoSmithKline, Takeda, en Danone) ben ik dankbaar voor de vruchtbare samenwerking en leerzame bijeenkomsten.

Valéry Hellwig, roomie, wat moest ik zonder jou? Waar ligt die map? Wat moet ik met dit formulier? Jouw logistieke en praktische bijdragen aan de klinische studie zijn zeer waardevol geweest. We begonnen vrijwel tegelijkertijd op dit project en hebben elkaar de weg gewezen in onderzoeksland. Het lag voor de hand dat jij paranimf werd, dankjewel voor alles!

Paul Popelier, een vanzelfsprekendheid dat jij paranimf werd. Bedankt voor je hulp met Prezi. 
Aging and for introducing me to the Health ABC Study. Annemarie Koster, bedankt voor de fijne tijd, voor je intensieve begeleiding en voor je hulp bij alle bureaucratie rondom het verwezenlijken van een tijdelijke baan in Amerika.

Thanks to all the Health ABC Study co-authors for your valuable input.

Ramon Langen, bedankt voor die keer dat je mijn samples uit de kapotte vriezer hebt gered! Tevens bedankt voor de vele brainstormsessies. En laten we de volgende keer maar passen voor die Catalaanse stierenballen.

Bettine Vosse, bedankt voor het opstarten van de klinische studie. Zowel in de aanvraag voor de medisch ethische commissie als in de praktische voorbereidingen heb jij veel werk verricht.

Chiel de Theije, jij voerde de muisstudies uit voor je eigen proefschrift. Regelmatig heb ik naast je gezeten om de weefsels te verzamelen. Het lag voor de hand om een samenwerking aan te gaan om het vetweefsel van deze muizen onder de loep te nemen, wat een mooi hoofdstuk heeft opgeleverd. Bedankt.

Ilse Slot, bedankt voor je inspanningen die kwalitatief hoogstaande laboratorium analyses opleverden.

Frank Snepvangers en Marco Kelders, bedankt voor jullie expertise en het verlenen van assistentie bij de verschillende laboratorium analyses.

Mijn dank gaat uit naar de longartsen van het Maastricht UMC+, in het bijzonder prof. Geertjan Wesseling, voor de rekrutering van COPD patiënten voor de klinische studie.

Gijs Goossens, bedankt voor je inzichten die richting gaven aan de muisstudie.

Juanita Vernooy, bij jou deed ik een vrijwillige stage en mijn afstudeerstage in het lab van de Longziekten en raakte ik besmet met het onderzoeksvirus. Bedankt dat je een 'goed woordje' voor me deed.

Frits Franssen, bedankt voor het advies om eerst promotie onderzoek te doen vóór de klinische opleiding. Ik zou dit op mijn beurt ook iedereen willen aanraden.

Agnes Boots, bedankt voor je inspanningen met de Luminex analyses en je immer snelle reacties. 


\section{DAN K WOORD}

Een aantal publicaties is uiteindelijk niet in mijn proefschrift terechtgekomen. Desalniettemin wil ik prof. Maurice Zeegers, Nicole Souren en de overige coauteurs bedanken voor hun betrokkenheid hierbij.

Bedankt aan alle collega's van de afdeling Longziekten voor de prettige jaren.

Beste Tijs, lieve broer, bedankt voor alle tijd en energie die je stak in het ontwerpen van de cover van mijn proefschrift. Het is prachtig geworden!

Lieve Berty en Martin, bedankt voor jullie support en interesse in de afgelopen jaren.

Tot slot, lieve Sharon, het is een hele tocht geweest maar nu is het promotieonderzoek dan écht klaar. Ik wil je enorm bedanken voor alle steun in deze jaren en voor de vrijheid die je me gunde om een tijdje in Amerika te wonen. Hopelijk breekt er nu een rustigere periode aan met onze mooie zoon Nathan. 

Bram van den Borst (18 juli 1983) behaalde in 2001 zijn VWO diploma aan het Van Maerlant Lyceum in Eindhoven. In 2002 kon hij starten met de opleiding Geneeskunde aan de Universiteit Maastricht. Tijdens zijn opleiding deed hij stages aan de Universiteit van Linköping in Zweden en de Royal Victoria Infirmary, Newcastle in Engeland. Zijn afstudeerjaar stond geheel in het teken van longziekten, en in 2008 behaalde hij zijn artsendiploma. Van 2008 tot 2012 werkte hij als promovendus binnen de onderzoeksschool NUTRIM bij de vakgroep Longziekten van het Maastricht University Medical Center+ onder supervisie van prof. dr. ir. Annemie Schols en dr. Harry Gosker. Een deel van het onderzoek dat hij in die periode uitvoerde staat beschreven in dit proefschrift. Twee hoofdstukken komen voort uit onderzoek dat hij deed aan het National Institute on Aging in Bethesda, USA. Sinds juli 2012 volgt hij de specialistenopleiding tot longarts in het Orbis Medisch Centrum in Sittard-Geleen en het Maastricht University Medical Center+. Voortvloeiend uit dit proefschrift, en financieel gesteund door het Longfonds, zal in 2013 een vervolgonderzoek van start gaan met als titel "Vermindering van het verhoogde metabole en cardiovasculaire risico bij COPD patiënten met overgewicht." 



\section{List of publications}

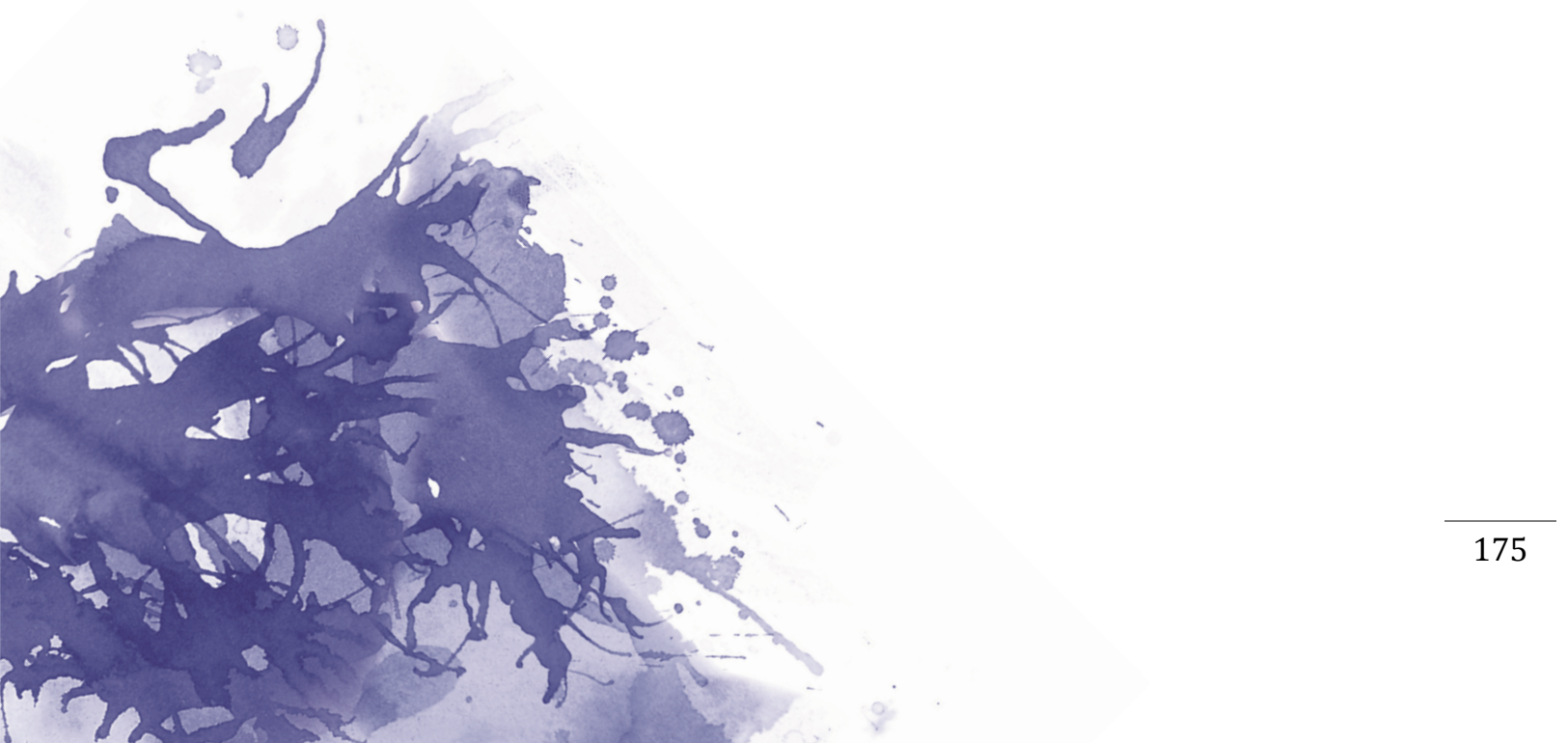




\section{Original research articles and reviews}

Bram van den Borst, Annemie MWJ Schols, Chiel de Theije, S Eleonore Koehler, Agnes W Boots, Gijs H Goossens, Harry R Gosker. Characterization of the inflammatory and metabolic profile of adipose tissue in a mouse model of chronic hypoxia. Journal of Applied Physiology 2013 Mar 28 [Epub ahead of print], doi: jap.00460.2012

Bram van den Borst, Harry R Gosker, Annemie MWJ Schols. Central fat and peripheral muscle: partners in crime in chronic obstructive pulmonary disease. American Journal of Respiratory and Critical Care Medicine 2013;187(1):8-13

Bram van den Borst, Ilse GM Slot, Valéry ACV Hellwig, Bettine AH Vosse, Marco CJM Kelders, Esther Barreiro, Annemie MWJ Schols, Harry R Gosker. Loss of quadriceps muscle oxidative phenotype and decreased endurance in patients with mild-to-moderate COPD. Journal of Applied Physiology 2012 Jul 19 [Epub ahead of print], doi: jap.00508.2012

Bram van den Borst, Harry R Gosker, Annemarie Koster, Binbing Yu, Stephen B Kritchevsky, Yongmei Liu, Bernd Meibohm, Thomas B Rice, Michael Shlipak, Sachin Yende, Tamara B Harris, Annemie MWJ Schols. The influence of abdominal visceral fat on inflammatory pathways and mortality risk in obstructive lung disease. American Journal of Clinical Nutrition 2012;96(3):516-26

Bram van den Borst, Harry R Gosker, Geertjan Wesseling, Wilco de Jager, Valéry ACV Hellwig, Frank J Snepvangers, Annemie MWJ Schols. Low-grade adipose tissue inflammation in patients with mild-to-moderate chronic obstructive pulmonary disease. American Journal of Clinical Nutrition 2011;94(6):1504-12

Bram van den Borst, Nicole YP Souren, Ruth JF Loos, Aimée DC Paulussen, Catherine Derom, Annemie MWJ Schols, Maurice P Zeegers. Genetics of maximally attained lung function: a role for leptin? Respiratory Medicine 2012;106(2):235-42

Bram van den Borst, Annemarie Koster, Binbing Yu, Harry R Gosker, Bernd Meibohm, Douglas C Bauer, Stephen B Kritchevsky, Yongmei Liu, Anne B Newman, Tamara B Harris, Annemie MWJ Schols. Is age-related decline in lean mass and physical function accelerated by obstructive lung disease or smoking? Thorax 2011;66(11):961-9

Bram van den Borst, Harry R Gosker, Maurice P Zeegers, Annemie MWJ Schols. Pulmonary function in diabetes: a metaanalysis. Chest 2010;138(2):393-406 
Eric LA Fonseca Wald, Bram van den Borst, Harry R Gosker, Annemie MWJ Schols. Dietary fiber and fatty acids in COPD risk and progression: a systematic review. [submitted]

Bram van den Borst, Ilse GM Slot, Valéry ACV Hellwig, Esther Barreiro, Annemie MWJ Schols, Harry R Gosker. Normal muscle oxidative metabolic gene response to $\mathrm{O}_{2}$-desaturating exercise in COPD. [submitted]

\section{Case report}

Bram van den Borst, Michiel de Vries, Wiel de Lange. A man with a tumor on his back [in Dutch]. Tijdschrift voor Geneeskunde 2008;64(18):932-4

\section{Peer-reviewed letters to the editor}

Bram van den Borst, Geertjan Wesseling. Acute exacerbations in COPD: it's the weekend but it can't wait until Monday. European Respiratory Journal 2012;39(6):1547

Bram van den Borst, Annemie MWJ Schols. Low bone mineral density in emphysema: epiphenomenon of a wasting phenotype? American Journal of Respiratory and Critical Care Medicine 2011;184(9):1087-8

Bram van den Borst, Nicole YP Souren, Marij Gielen, Ruth JF Loos, Aimée DC Paulussen, Catherine Derom, Annemie MWJ Schols, Maurice P Zeegers. Association between the IL6 -174G/C SNP and maximally attained lung function. Thorax 2011;66(2):179

\section{Book chapter}

Bram van den Borst, Annemie MWJ Schols. Chronic Obstructive Pulmonary Disease. Co-Morbidities and Systemic Consequences. $1^{\text {st }}$ ed. New York (NY): Humana Press; 2012. Chapter 11, Body composition abnormalities in COPD; Pp. $171-92$ 
